





$$
D-9
$$



<smiles>[CH][TlH]</smiles> 


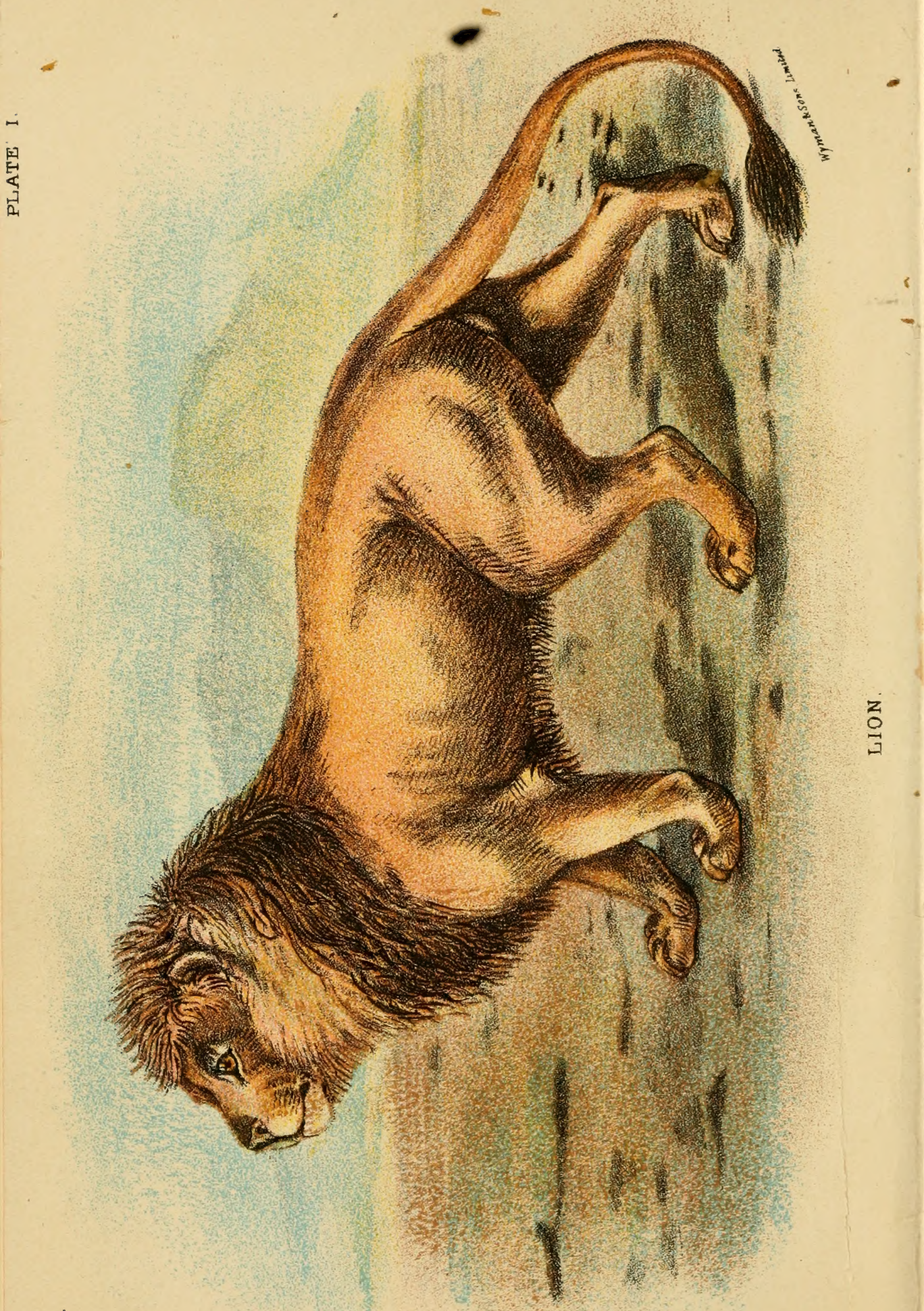


LLOYD'S NATURAL HISTORY. Edited by R. Bowdler Sharpe, LL.D., F.L.S., \&c.

QL

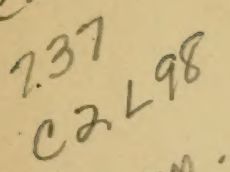
MAMM.
A HAND-BOOK
TO THE
CARNIVORA./
PART I.

\section{CATS, CIVETS, AND MUNGOOSES.}

BY

RICHARD LYDEKKER, B.A., F.R.S.,

Vice-Fresident of the Geological Society, etc., etc., etc.

\section{LIBRARIES}

c

228275

MEARNS

COLLECTION

LONDON :

EDWARD LLOYD, LIMITED,

I2, SALISBURY SQUARE, FLEET STREET.

1896. 
PRINTED BY

WYMAN AND SONS, LIMITED.

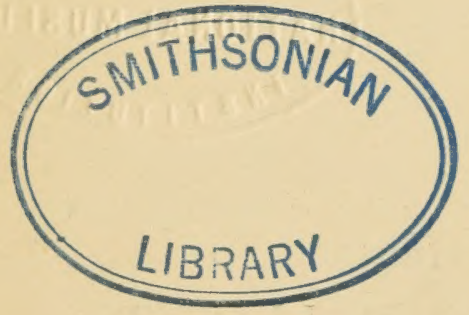




\section{PREFACE.}

THE present volume deals with the members of the Carnivora, with which most people are familiar, viz., the Cats, and I am again indebted to $\mathrm{Mr}$. Lydekker for a most useful summary of our present knowledge of these animals, and also for his very interesting conclusion to the work, wherein he deals with the extinct members of the Order.

To one trained like myself, by long years of work in the field of ornithological synonymy and literature, the nomenclature; employed for some of the Mammalia appears somewhat strange; but I am glad to say that I have induced the author to latinise the generic term "Linsang" into Linsanga.

The duplication of the generic and specific names, for the necessity of which I always strongly insist, whenever Linnean specific names have been misappropriated for generic titles by subsequent writers, appears to be necessary in only three instances in the present volume. Mr. Lydekker, as is well known, does not hold with the practice, but, in my opinion, the name of the Common Genet should be Genetta genetta (L.), that of the Meerkat, Suricata suricatta (Erxl.), and that of Daubenton's Civet, Fossa fossa (Schreb.).

R. BOWDLER SHARPE. 


\section{AUTHOR'S PREFACE.}

Among the great Order of Carnivorous Mammals the Cats will always claim the largest share of general interest, not only on account of their including some of the largest and most powerful of all beasts of prey, but likewise from the beauty of their form, the elegance of their coloration, and the gracefulness and activity of their movements. Accordingly, in the present volume of the "Naturalist's Library," this group of the Order has been treated in comparatively full detail, and a large number of the species illustrated by plates, whereas in the lessknown group of Civets, Mungooses, \&c., the amount of space devoted to each genus and species is naturally less, and the illustrations are much less numerous.

In both groups every existing species hitherto described is mentioned, together with its most important synonymy; but in several instances the question of the right of a particular form to be regarded as a species, or merely as a variety, is left more or less open. In the compilation of the volume especial assistance has been derived from Mr. W. T. Blanford's "Mammals of British India," from Professor St. George Mivart's work on "The Cat," and his papers on the Cats and Civets in the "Proceedings of the Zoological Society," and also from various memoirs by Mr. Oldfield Thomas, published in the same serial.

RICHARD LYDEKKER. 


\section{SYSTEMATIC INDEX.}

ORDER CARNIVORA $\quad \ldots \quad$ I FAMILY FELID $A$... I

I. FELIS, L. $\ldots . \quad \ldots \quad \ldots \quad 26$

I. leo, L. $\quad \ldots \quad \ldots \quad 27$

2. tigris, L. $\ldots . \quad \ldots \quad 48$

3. pardus, L. ... ... 7 I

4. uncia, Schreb. $\quad \ldots \quad 92$

5. onca, L. ... ... 95

6. concolor, L. ... IOI

7. nebulosa, Griff. ... II 3

8. marmorata, Martin II

9. scripta, Milne-Edw. II 9

- Io. tristis, Milne-Edw. I20

- I I. temmincki, V. and H. 120

I2. planiceps, V. and H. I2 I

I3. badia, Gray _... I22

I4. viverrina, Benn. ... I 23

I 5. bengalensis, Kerr ... I 26

- I6. euptilura, Elliot ... I32

I7. rubiginosa, I. Geofir. I33

IS. serval, Erxl.

... 135

19. togoënsis, Matschie 137

20. chrysothrix, Temm. I 37

21. celidogaster, Temm. ${ }_{13} 8$

22. pardalis, L.... ... I 39

23. tigrina, Schreb. ... 144

24. guigna, Molina ... I49

25. pardinoides, Gray ... I 50

26. jaguarondi, Fischer I5 I
FELIS-(continued).

27. braccata, Cope ... 152

28. eyra, Fischer ... 153

29. caffra, Desm. ... I 55

30. domestica, Gm. ... 156

3I. catus, L. ... ... I70

- 32. manul, Pall. ... I74

33. pajeros, Desm. ... I75

34. colocolo, H. Smith I77

35. ornata, Gray _.. I79

36. shawiana, Blanf. ... I82

- 37. chaus, Güldenst. ... I 82

-38. pallida, Büchn. ... I 86

239. caudata, Gray ... I 87

40. caracal, Güldenst.... I $\delta 8$

4I. lynx, L. ... ... I9I

42. canadensis, Desm. ... I95

43. rufa, Gülddenst. $\quad \ldots \quad 197$

44. baileyi, Merriam ... 200

45. pardina, Temm. ...200

II. Cynelurus, Wagl. ... 201

I. jubatus (Erxl.) ‥202

FAMILY II., VIVERRID 206

1. Cryptoprocta, Benn. ...208

I. ferox, Benn. ...208

II. VIVERRA, L. ... ... 2 IO

I. civetta, Schreb. ...2 2 I

2. zibetha, L. ... ...2 2 I I

3. civettina, Blyth $\ldots 213$ 
VIVERRA-(continued).

4. megaspila, Blyth ... 2I3

5. tangalunga, Gray $\ldots 214$

6. malaccensis, Gm. ... 214

III. Fossa, Gray $\quad \ldots \quad \ldots 216$

I. daubentoni, Gray ... 216

IV. Genetta, Cuv, ... ... 217

I, vulgaris, Less. $\quad . .218$

2. felina (Thunb.) ...219

3. senegalensis (Fischer) 219

4. tigrina (Schreb.) ... 219

5. pardina, Geoffr. ... 220

6. rubiginosa, Pucher. $22 \mathrm{I}$

V. Linsanga, S. Müll. _.. 22 I

I. gracilis (Desm.) ... 222

2. maculosa (Blanf.) ... 223

3. pardicolor (Hodgs.) 224

VI. Poinana, Gray .. $\quad \ldots 225$

I. pöensis (Waterh.) ... 225

VII. Hemigale, Jourd. ..226

I. hardwickii (Gray) ... 227

2. hosii, Thomas $\quad . .228$

VIII. NANDinia, Gray $\quad \ldots 228$

I. binotata (Reinw.) ... 229

2. gerrardi, Thomas ... 229

IX. Arctogale, Gray $\ldots 230$

I. leucotis (IIorsf.) .. 230

2. trivirgata (Gray) ... 23I

X. Paradoxurus, F. Cuv.... 23I

I. hermaphroditus

(Schreb.) ... ...2233

2. philippinensis, Jourd. 235

3. macrodus, Gray $\quad \ldots 236$

4. jerdoni, Blanf. ... 236

5. aureus, F. Cuv. ... 236

6. grayi Benn. …237

7. larvatus (Temm.) ... 238
Paradoxurus-(contimued).

8. leucomystax, Gray ... 238

9. musschenbroecki, Schl. ... ... 239

Io. laniger, Hodgs. $\quad$... 240

XI. Arctictis, Temm. ... 240

I. binturong (Raffl.) ... 24I

XII. Cynogale, Gray $\quad \ldots 242$

I. bennetti, Gray $\quad \ldots 242$

XIII. Herpestes, Lacép. ... 244

I. ichneumon (L.) …246

2. caffer (Gm.) ‥ 247

3. angolensis, Bocage... 249

4. gracilis, Riipp. ...2 250

5. sanguineus, Rüpp.... 25I

6. neumanni, Matschie 252

7. galera (Erxl.) ‥ 253

8. pulverulentus, IVagn. 254

9. punctatissimus,

Temm. ... ... 254

Io. auropunctatu

$$
\text { (Hodgs.) ... ... } 255
$$

II. mungo (Gm.) ‥ 257

I2. smithi, Gray $\ldots 258$

I3. fuscus, Waterh. ... 259

I4. fulvescens, Blyth ... 260

15. javanicus (Geoffr.) ... 260

16. brachyurus, Gray ... 26I

I7. vitticollis, Benn. ...2 26I

I8. semitorquatus, Gray 262

19. urva (Hodgs.) ... 263

20. albicauda, Cuv. ...264

21. grandis, Thomas ... 266

XIV. Helogale, Gray ‥ 266

I. parvula (Sundev.) ... 267

XV. Bdeogale, Peters $\quad$... 268

I. crassicauda, Peters... 268 


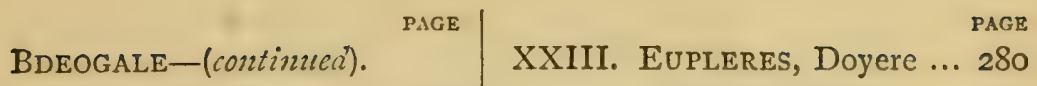

2. fusca, Peters ‥ 268

I. goucoti, Doyere ...28 28

3. nigripes, Pucher. ... 269

XVI. Cynictis, Ogilby $\quad$... 269

I. penicillata (Cuv.) ... 270

XVIII. Rhynchogale,

Thomas $\ldots \quad \ldots 27 \mathrm{I}$

I. melleri (Gray) …27I

XVIII. Crossarchus, F. Cuv. 272

I. obscurus, F. Cuv. ... 273

2. gambianus (Ogilby) 273

3. zebra (Riipp.) ‥ 274

4. fasciatus (Desm.) ... 275

5. dybowskii, Pous. ... 275

XIX. Suricata, Desm. ... 276

I. tetradactyla (Schreb.) 276

XX. Galidictis, Geoffr. ... 277
I. striata (Cuv.)
... 278
2. vittata, Gray
... 279

XXI. Galidia, Geoffr. $\quad$... 279

I. elegans, Geoffr. $\quad \ldots 279$

XXII. Hemigalidia, Mivart 280 I. unicolor (Geoffr.) ‥ $2 \mathrm{SO}$

2. olivacea (Geoffr.) ... 2So EXTINCT CARNIVORA ... 282 FAMILY FELID $A$... I $\quad 282$

I. FELIS, L. $\ldots \quad 26,282$

II. Cynælelurus, Wagl. 20I, 282

III. MACHÆRODUS, Kaup. 283 IV. Eusmilus, Gerv. ‥ 285

V. Alunictis, Trouess.... 285

VI. Dinictis, Leidy …286 VII. Nimravus, Cope ...287 VIII. Pogonodon, Cope ... 288 IX. Arcilelunus, Cope ... 288

X. IIoplophoneus, Cope 288

XI. Pseudalurus, Gerv. 289 XII. Proelurus, Filhol ... 290 FAMILY VIVERRID E ... 291

I. ViverRA, L. ... 2IO, 29I

II. Amphictis, Pomel ... 29I III. Herpestes, Lacép. 244, 292 IV. Progenetta, Depéret 292

V. ICTITHERIUM, Wagn. 293 VI. PALAORRIONODON,

Filhol $\quad$.. ... 293

VII. Stenoplesictis, Filhol 295 


\section{LIST OF PLATES.}

I.--Lion ... $\quad . . \quad \ldots \quad \ldots$ Felis leo o $\quad$... Frontispiece

II.-Lioness $\quad \ldots \quad \ldots \quad \ldots$ Felis leo $q \quad \ldots$ facing $p .27$

II.-Lion-Tiger ... ... ... Felis leo (hybrid) " 45

IV.-Tiger $\quad \ldots \quad \ldots \quad \ldots \quad$ Felis tigris $\quad \ldots \quad \quad, \quad 49$

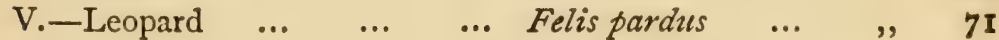

VI.-Ounce $\quad \ldots \quad \ldots \quad$... Felis uncia. ... $\quad$,

VII.-Jaguar $\quad \ldots \quad \ldots \quad \ldots$ Felis onca $\quad \ldots \quad$,, 95

VIII._Puma $\quad \ldots \quad \ldots \quad \ldots$ Felis concolor $\quad . . \quad \quad, \quad$ I03

IX._Clouded Leopard ... $\quad$... Felis nebulosa ... $\quad$,, II5

X. - Marbled Cat $\quad . . \quad$... Felis marmorata $\quad$ ", II9

XI._Fishing Cat... $\quad \ldots \quad$... Felis viverrina ... $\quad, \quad$, 125

XII._Leopard-Cat $\quad . . \quad \ldots$ Felis bengalensis... , , 127

XIII.-Leopard-Cat (variety) _.. Felis bengalensis ... , , - I3I

XIV.-Serval $\quad \ldots \quad \ldots \quad \ldots \quad \ldots$ Felis serval $\quad \ldots \quad$,, 135

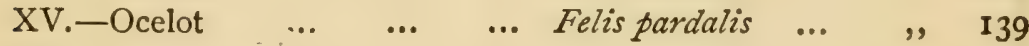

XVI.—Ocelot (variety) $\quad$... Felis pardalis ... $\quad$, I43 $_{4}$

$\begin{array}{llllllll}\text { XVII.-Tiger-Cat } & \ldots & \ldots & \ldots & \text { Felis tigrina } & \ldots & , & \mathbf{1} 45\end{array}$

XVIII._Eyra ... $\quad \ldots \quad$.. $\quad \ldots$ Felis eyra $\quad \ldots \quad$, 153

XIX.-Caffre Cat ... $\quad \ldots \quad$... Felis caffra $\quad$... $\quad$, 155

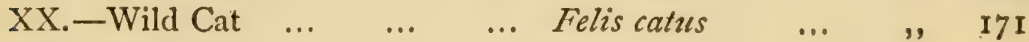

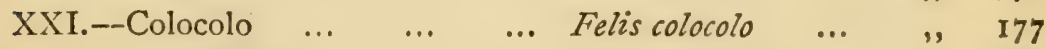

XXII.-Desert Cat ... $\quad \ldots \quad$... Felis ornata $\quad . . . \quad,, \quad$ I8I

$\begin{array}{llllllll}\text { XXIII.-Caracal } & \ldots & \ldots & \ldots & \text { Felis caracal } & \ldots & , & 189\end{array}$

$\begin{array}{llllllll}\text { XXIV.-Lynx } & \ldots & \ldots & \ldots & \text { Felis lynx } & \ldots & \text {, } & 193\end{array}$

XXV.-Hunting-Leopard ... ... Cynalurus jubatus $\quad$ " 202

$\begin{array}{lllllll}\text { XXVI.-Fossa } & \ldots & \ldots & \ldots & \text { Cryptoprocta ferox } & \text {, } & 209\end{array}$

XXVII.-African Civet $\quad \ldots \quad \ldots \quad$ Viverra civetta ... , , 2 II

XXVIII.-Blotched Genet $\quad \ldots \quad$... Genetta tigrina ... , , 2 I9

XXIX.-Hardwicke's Hemigale ... Hemigale hardwickii , 227

XXX.-Common Palm-Civet $\quad$... Paradoxumus herma-

XXXI.-Egyptian Mungoose _.. Herpestes ichneunnon ", 247

XXXII.-Broad-Danded Cusimanse ... Crossarchus fasciatus „ 275 


\section{CARNIVORES.}

\section{ORDER CARNIVORA.}

\section{PART I. \\ I. THE CATS. FAMILY FELID E.}

If a naturalist were asked to select two groups of Mammals severally representing the most highly developed and beautiful type of the carnivorous and herbivorous modifications, he would certainly make choice of the Cat tribe for the one, while for the other he would most probably select the Antelopes and Gazelles. Both of these groups do, indeed, seem to present the highest modification and specialisation which the particular type of structure by which they are characterised is susceptible of attaining ; and it is curious to notice the kind of parallelism in development which may be traced between the two groups. In both groups, for instance, the limbs have been more or less elongated, these animals walking only on their toes, instead of on the whole sole of the foot. Whereas, however, in the Antelopes the elongation of the limbs has been excessive, and mainly concentrated on the segment immediately above the fore- and hind-foot-that is to say, the metacarpus and metatarsus-while the toes have been reduced to a single functional pair on each foot, in the Cats the bones of the 
lower portions of the limbs have not undergone such excessive elongation, while the fore-feet retain the original typical number of five toes, and in the hind pair the number of digits is only reduced by one. Then, again, whereas in the Antelopes the movements of the fore-limb have become restricted to a backwards-and-forwards direction, while its extremities (like those of the hind-limb) are encased in solid horny hoofs, in the Cats the same limb is capable of a free rotatory motion, and its toes are armed with sharp and powerful claws. These divergencies of structure are, of course, to be accounted for by the respective exigencies of the mode of life of the members of the two groups; the Antelopes having merely had to attain a speed sufficient to enable them to escape the attacks of their enemies, while the Cats had not only to equal or surpass this speed, but to have the power of striking down their prey and holding it when struck.

Another parallelism between the two groups may be detected in their dentition, which in each case has been specially modified for the exigencies of a particular mode of existence, and has thus departed very widely from the generalised type prevalent in many of the older Mammals, and which is partially retained in the common Pig. In the Antelopes the object of the modification has been to produce a type of dentition best suited for the cropping and mastication of grasses. Consequently, while the teeth of the cheek-series, that is to say, the pre-molars and molars, have been retained in their full number, though their crowns have been lengthened, and likewise complicated by infoldings and flutings of their summits and sides, so as to form the best possible masticating apparatus, the tusks, or canines, have disappeared, either totally or as such, while the lower incisor teeth have assumed spatulate crowns admirably adapted for plucking off the tufts of grass seized in the tongue, by biting against the hard, callous pad in the front of the 
upper jaw, from which the whole of the teeth have disappeared. On the other hand, in the Cats the object has been to produce a type of dentition adapted for seizing and holding a living prey, and afterwards devouring it by tearing and clitting off the flesh and sinews from the bones, without attempting to crack the bones themselves. Consequently, we find that the three pairs of incisor teeth in each jaw, characteristic of the older types of Mammals, have been retained, and have assumed a pincer-like form; while the tusks, or canines, have been greatly developed, and project far in advance of the level of the crowns of the other teeth. On the other hand, the pre-molar and molar teeth, constituting the cheek-series, have been greatly reduced in numbers, their whole strength being, indeed, concentrated on a single pair in each jaw-the carnassial, or sectorial teeth-which bite against one another with a scissorlike action.

Assuming it to be a fact that all Mammals have been derived from a common ancestral stock, presenting none of the specialised features respectively characteristic of the Antelopes and the Cats, these two groups present us the extreme modification of which the original stock was susceptible in two opposite directions, according to the exigencies of a particular mode of life. Before passing on to the consideration of the distinctive structural features of the group before us, it may be mentioned that the Cats and Antelopes are alike characterised by the prevalence of tawny and rufous hues in their general coloration. Moreover, in both groups the ornamentation of the pelage takes the form of either spots or stripes; although among the Cats many species have a kind of clouded marking, somewhat intermediate between the other two types of coloration. Whereas, however, among the Cats, dark transverse stripes are of common occurrence, among the Antelopes this kind of ornamentation is met with only in the Zebra-Antelope and the 
Gnus of Africa. On the other hand, white transverse stripes on a tawny or chestnut ground are common among Antelopes, whereas they are quite unknown in the Cats. And whereas in the latter group dark spots on a light ground are prevalent, in the former just the reverse of this arrangement holds gocd. That there is some sufficient reason for this prevalence of one type of coloration in one group of animals, and its replacement by another in a second, may be taken for granted, although at present naturalists have not succeeded in unravelling the mystery in which the subject is enveloped.

The Cats, under which title are included Lions, Tigers, Leo. pards, Pumas, Tiger-Cats, Domestic Cats, and Lynxes, form a well-marked family group of the Terrestrial Carnivora, readily distinguished from most of their allies, with the exception of the Fossa (Cryptoprocta) of Madagascar, by which they appear closely connected with the Civets (Viverride). In this work we must take it for granted that the reader is more or less intimately acquainted with the distinctive structural features of the Carnivora-a group which, in addition to the more typical terrestrial forms, is likewise taken to include the aquatic Seals and Walruses. It may be mentioned here, however, that the Terrestrial Carnivora, among which the Otters and Sea-Otters are included, are specially characterised by the special development of a pair of teeth in each jaw to bite against one another with a more or less marked "scissor"-like action; although the peculiar features of these teeth are less conspicuously marked in the Bears and Racoons than in the majority of the other members of the group. Not the least remarkable feature connected with these teeth, which, as already mentioned, are termed carnassials or sectorials, is the circumstance that the upper pair do not correspond serially with those of the lower jaw. 'That is to say, that while in the upper jaw this pair of teeth belong to the pre-molar series, or those preceded by milk- or baby-teeth, 
in the lower jaw they are true molars, or have no such deciduous predecessors. In the Cats these teeth attain the largest and most specialised development in the entire carnivorous Order.

The whole of the Cats are graceful and elegantly made animals, showing a marked general similarity in structure and appearance, although one species-the Hunting-Leopard-differs so markedly from all the other living representatives of the family, as to necessitate its reference to a genus (Cyncelurus) apart from the rest. All are remarkable for their strength and agility, but while some are arboreal in their habits, others are terrestrial. Many, moreover, are more or less exclusively nocturnal animals, and all have the power of preventing during the daytime the entrance of too much light into their large and full eyes-so admirably adapted to receive every gleam of light during their nocturnal wanderings - by diminishing the size of the pupil by the contraction of the retina, or coloured portion of the eye, as will be fully explained in the sequel. Having highly developed senses and mental powers, the Cats are ill-adapted to become the servants or companions of man, even the domestic breeds only associating with him to a great extent as a matter of convenience to themselves, and never sympathising and confiding in him after the manner of a Dog. Indeed, unlike the latter, it requires but little inducement to make even the most affectionate of Domestic Cats revert to the wild life of her ancestors, and whenever such an animal does escape to the woods it has little difficulty in accustoming itself to the new conditions, whereas, under similar circumstances, most Dogs would soon die of starvation. As a matter of fact, the whole of the Cat tribe are of but little importance to mankind, with the exception of the domesticated races, their only use being as a source of handsome and valuable furs.

Subsisting almost, or quite exclusively, upon flesh, and preferring a living prey to one which has been killed for them by 
other animals, or which has succumbed to a natural death, the Cats creep upon their victims with a characteristic stealth and patience, and seldom pursue the chase if their first deadly spring has missed its mark. They never hunt in packs, although Lions have been observed to combine with one another to drive their prey in the direction where others are awaiting it, and generally pursue their victims singly, except in the earlier stages of their existence, when they often go in couples. A peculiar and, at the same time, most unpleasing trait of most or all the members of the Family, is their habit of playing with and torturing their victims before finally despatching them, as if to prolong the pleasure and excitement of the chase.

Regarding their method of hunting and capturing their prey, Jardine writes that "morning and evening are the times when it is chiefly sought, and it is either crept upon by stealth or lain in wait for. Near to the passes in the thick forests, the edges of the jungle, the banks of the springs and rivers, where the beasts daily seek for water, are situations favourable for the exercise of their perfidious ambuscade; when the prey approaches, the animal gathers his strength for the spring, and by a succession of leaps, or by one immense bound, seldom fails in reaching the object. Or if the creature has to be approached, the assailant becomes flattened, as it were, and, crouching, advances swiftly but imperceptibly; the velvetyfeeling pads of the toes touch the ground without noise; the eyes, gleaming on the prey, see no obstruction, but the slightest hindrance is told by the sensitive whiskers. The measured distance is gained, and the muscles of the animal are braced for the fatal spring; a roar or yell thrills through the victim, and overpowers its faculties; an instinctive terror renders strength or swiftness of foot equally unavailing, and it is borne off felled and unresisting to some neighbouring thicket, where it can be devoured in quiet. 
"Some species follow their prey into the trees, as the Leopard and Jaguar, and seize the Monkeys and larger birds, after they have gone to rest for the night. Sometimes, says Humboldt, the cry of the Jaguar comes from the tops of the trees, followed by the long and sharp whistling of the Monkeys, which appear to flee from the danger which threatened them; and this manner of hunting is also pursued by most of the smaller Cats, which vary the size of their prey, according to their strength to seize it."

The external appearance of the Cats is so well-known and so characteristic as to demand but brief notice in this place. The fur with which the entire body is invested is generally short, thick, and close, although frequently longer on the under-parts than elsewhere; and is always kept in the most brilliant and glossy condition by constant licking and cleansing with tongue and paws, as is exemplified by the care and regularity with which the Domestic Cat "washes her face." In species like the Snow-Leopard, inhabiting cold climates, the fur is, however, long and almost shaggy; and the same condition obtains in those races of normally short-haired species ranging into colder regions than ordinary, as exemplified by the Siberian variety of the Tiger. The hair is, however, always short on the face and paws, while it is totally wanting on the tip of the nose, the lips, and the pads on the soles of the feet. In the male of the Lion a large mass, or mane, of long hair is developed on the head, neck, and shoulders; and the True Lynxes have an incomplete ruff of longish hair on the throat, in addition to stiff pencils of elongated hairs on the summit of the ears. The inside of the ear is always lined with long hairs, and each side of the upper lip is furnished with a dozen or so of long tapering bristle-like hairs, projecting horizontally outwards, and known as the whiskers, or vibrissæ, the function of these hairs being to act as organs of touch or per 
ception. A few elongated hairs over each eye correspond to the human eyebrows, but eyelashes are totally absent. The direction of the hairs on the body inclines uniformly backwards from the head to the tip of the tail, while on the limbs it is mainly downwards.

In the majority of species the body is somewhat elongated, and the limbs relatively short; these features attaining their maximum development in the Eyra of South America, which approximates to the Civets in form. The Lynxes, however, differ in their relatively shorter bodies and longer legs; while the typical members of that group are further distinguished by the extreme shortness of the tail. As a rule, however, the tail is long, cylindrical, and tapering; and it is also generally evenly furred throughout its entire length, the hairs being, however, often longer than elsewhere; but the Lion is an exception in having a large tuft of hair at the extremity, in the midst of which, in many individuals, is concealed a horny nail-appendace of unknown use. All Cats walk exclusively on their toes, or, in other words, are digitigrade; and while in the fore-feet the thumb, or pollex, is raised above the level of the other toes, and is not applied to the ground in walking, in the hinder pair its representative, the great toe, or "hallux," is totally absent. In all the typical members of the Family, or those included in the genus Felis, the claws are retractile, and maintained in an efficient state of sharpness during walking, by being withdrawn into horny protecting sheaths, to be exserted when the prey is seized. In regions frequented by Cats the bark of the trunks of trees is seen to be scored by a number of longitudinal streaks, where these animals have exercised their exserted claws by tearing them along it, probably for the purpose of aiding to keep them clean. This habit is still retained by the Domestic Cat.

The mechanism by which the claws are exserted and again 
withdrawn is illustrated by the accompanying figure from Jardine's monograph of the Cats in the original edition of the "Naturalist's Library." As figured, the position of the joints, or phalanges, as they are technically termed, is one of

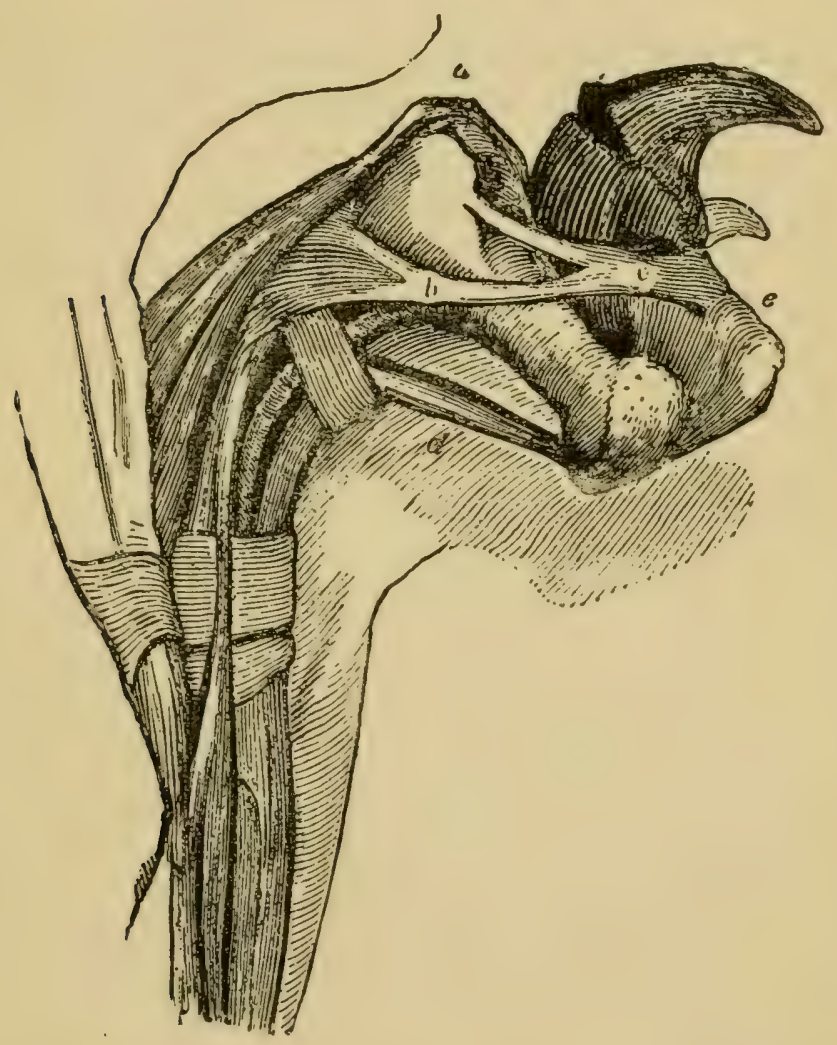

The muscles, tendons, and ligaments of one of the toes of a Lion's foot.

retraction. The claw is supported on the last phalange, which is of a peculiar form; its two portions being united to one another nearly at a right angle. The base of the claw is received into a groove at the body of the bone, to prevent 
its being pushed backwards in the rapid movement of the paws; and the two portions of the bone form a kind of hook, or crochet. In repose, the superior extremity of this phalange is placed almost vertically, while the other end lies nearly parallel to the second joint. The articulation is situated at the upper end of the vertical portion, and the flexor tendons, passing over the upper part of the bone, are firmly fixed to the other portion. The action of the deep-seated flexor-the flexor profundus-causes the whole bone to move through an angle of ninety degrees round the end of the second phalange. This last phalange is kept in its retracted condition by the tendon $a$, which passes from the extensor tendon up to the base of the superior or first phalange, and also by the elastic ligaments $b$ and $c$, proceeding by double heads from the tendinous expansion at the top of the second phalange, and forming bands on each side to unite at the palmar base of the claw. From the twisted form of the second phalange, the first does not move over its end in the same plane, but on retraction falls a little to the outer side. In the figure, $d$ indicates the strong round tendon of the flexor profundus, which passes over the superior extremity of the last phalange to $e$, as over a pulley, thus giving prodigious power to the action of its muscle. This tendon does not arise, as in man, directly from the belly of the muscle, but from a flat irregular cartilaginous body, $23 / 4$ inches long and $I / 2$ broad, attached to the lower end of the muscle, and sliding between the annular ligament and a very thick fascia covering the bottom of the forepaw; from this substance five very strong tendons proceed to the fingers, which perforate the tendons of the sublimus nearly as in other animals. They are strongly strapped down, as seen in the figure.

In all the more typical Cats the head is remarkable for its rounded and shortened form, while the jaws are likewise 
relatively short. The full and large eyes, which are separated from each other by a considerable interval, are directed almost immediately forwards. The ears are comparatively small and short, gradually narrowing from base to tip, and with the deep internal concavity directed forwards and outwards.

In common with the Civets (Viverridce), Hyænas (Hycenide), and the Aard-IVolf (Proteleide), the Cats present certain peculiarities connected with the structure of the skull by which they are distinguished from the other Carnivora, the Dogs (Canida) making the nearest approach to them in this respect. In all these four Families the chamber of the internal ear known as the auditory bulla is dilated into a thin bladder-like expansion, which, except in the Hyænas, is divided into two moieties by a vertical partition of bone. In addition to this, the tube leading from this chamber to the external ear, and known as the auditory mearus, is remarkably short. There are other peculiarities connected with this part of the skull, the consideration of which would involve too many technicalities for a work of the present nature.

As a Family the Cats, both recent and fossil, are distinguished by the strong development of the canine teeth, or tusks; by the number of upper molar teeth never exceeding one, and the lower two on each side of the jaws ; and, likewise, by the three lower incisor teeth of each side being placed in the same horizontal line, instead of the middle one being thrust up above the plane of the other two. If we exclude certain extinct forms, the Family may be further characterised by the following characters, mainly relating to the dentition. Both in the upper and lower jaws, the true molar teeth are reduced to a single pair, the former being a small flat functionless tooth, with its crown considerably wider than long, while the lower one is the carnassial. In the lower jaw, as shown in the accompanying figure, the pre-molars are reduced to two pairs. The 
upper carnassial tooth, or the large tooth on the right of the upper figure in the illustration, consists of an external cutting blade formed by three sharp lobes or cusps placed in the same line, and of a blunt tubercle on the inner side. The lower carnassial (shown on the left of the lower figure in the illustration), on the other hand, consists simply of a cutting blade, formed by two nearly equal-sized lobes, without any cusp on their inner side, or any projecting heel on the hinder border. In the skull the auditory bulla is uniformly smooth and
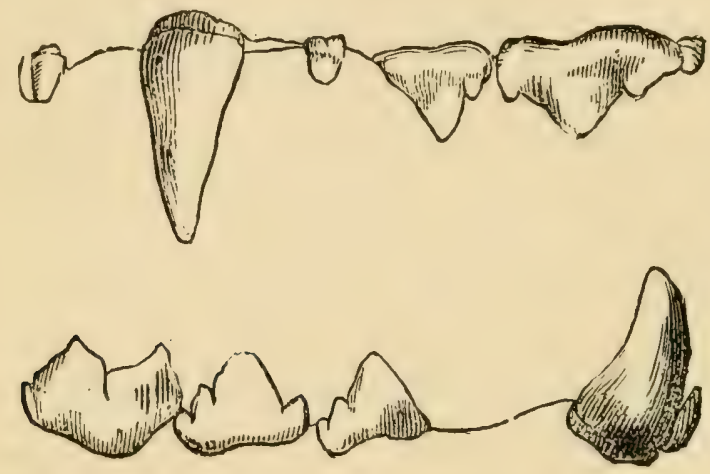

Side View of Upper and Lower Teeth of the Lion. In the upper figure the incisor teeth are turned to the left, and in the lower in the opposite direction.

bladder-like, without any external țrace of a transverse constriction.

In conformity with the contour of the head, the skull of the typical Cats, as shown in the annexed woodcut, has a short facial region; while the zygomatic arches, in order to afford space for the powerful muscles necessary to work the jaws, are very widely expanded. In the figured specimen, as in the skulls of the other large members of the family, the nasal bones, forming the roof to the cavity of the nose, are very short and wide; but in some of the smaller Cats they become narrow, 
and pinched in on the sides. Moreover, in all the large Cats the orbit, or socket for the eye, is partially open posteriorly, as the descending process from the frontal bone is not sufficiently elongated to meet the ascending one from the zygomatic or

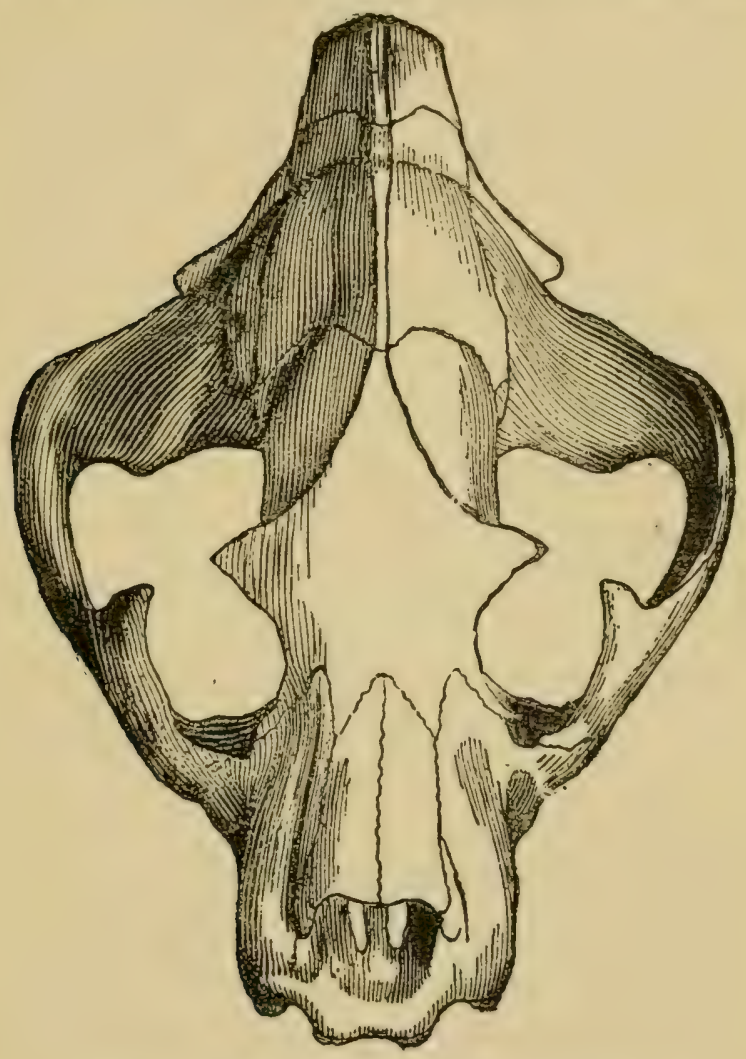

Upper surface of the skull of the Jaguar.

cheek- arch; but in some of the smaller Asiatic species the union is complete.

Another peculiarity of the Cats is to be found in the structure of the tongue, the upper surface of which is covered with numerous horny papillæ, having the points directed backwards, the effect of which may be observed, when a Lion or any large 
animal of the tribe is licking a bone, which is too powerful for his strong jaws to break. It is suited more for laceration, and to retain the food within the mouth, than for an organ of taste; and the gustatory nerves are comparatively small, and distributed principally to the muscles. In the different species, these papillæ have by no means the same arrangement, for some are in straight rows, while others run in straight lines. Most persons are familiar with the peculiar sensation produced on the skin of the hand when licked by a Domestic Cat, but by the Lion or Tiger much more marked traces of the operation would be left.

Allusion has already been made to the alteration in the size of the pupil of the eye of the Cats by the contraction of the iris under the influence of light; and it may be added that the contraction likewise produces an alteration in the form of the exposed pupil, which varies from a circle to a narrow, more or less oat-shaped vertical slit. The subject of the contraction of the iris and the consequent form of the pupil has recently been investigated by Dr. G. L. Johnson, the results of whose observations have been published in the "Proceedings of the Zoological Society" for I894. After examining no less than I80 Domestic Cats, all of whose eyes were subjected to the same degree of illumination, it was found that the shape of the pupil varied from a perfect circle to a pointed oval. No general rule could, however, be established with regard to this variation, except, perhaps, that in the so-called blue tabbies no oval pupils were detected. And it appears that neither the colour of the iris nor the sex of the animal have any bearing on the shape of the pupil.

"The only condition," writes Dr. Johnson, "which appears to have an influence on the shape of the pupil seems to be age. My observations on the above-mentioned Cats, and on a number of others, all lead me to the conclusion that the 
younger the Cats the rarer the cases in which the pupil is round; and, conversely, the older the Cats the greater the prevalence of round pupils. This, I think, may be due to a decrease of the elasticity and consequent contractility of the iris as the animals grow older.

"In no case have I noticed any convergence of the eyes, or any contraction of the pupil in accommodation for near objects. Sudden bright illumination, however, invariably causes contraction.

"The Cat's iris contracts in a very definite and curious way. It may be imitated most accurately by causing two discs to overlap, until the horizontal diameter is equal to half the vertical (acute oval), when the contraction ceases in the vertical direction, but continues horizontally until the sides meet, forming two parallel vertical lines in close contact. At the extremities of this vertical slit there are always two round pinholes, which are caused by the inability of the fibres of the iris to come further together; if examined with a strong magnifying-glass, the radiating fibres of the iris are seen surrounding these points.

"When I held a Cat's face so that the unobscured sun shone directly on the centre of the pupil, and its image could be seen on the cornea, I noticed the pupil immediately contract to the above-mentioned vertical slit. So close was the contact between the free margins of the iris that, so far as I could judge, no light entered the eye except through the two pinholes. In fact, I found I could hold a Cat with the lids held apart so that the sun shone directly on to the pupils, without it showing any sign of discomfort, nor did the animal trouble to use its nictitating membrane. In this respect it had the advantage over the big Felide with pupils that contract in a circular manner, since a circular pupil can never contract completely so long as it remains a circle." 
In this connection brief reference may be made to the well known fact that pure white Cats with blue eyes are generally deaf ; this being probably due to the absence of pigment in the internal ear.

With regard to the coloration of the Cats, it has already seen incidentally mentioned that the ground-colour of the fur raries from some shade of grey, through sandy and chestnut, to orange; and that upon this ground there are very generally dark markings, which may be either brown or black. No Cats are normally black, although melanistic races or individuals of several species are not uncommonly met with; neither, with the exception of albinos, are there any white Cats in nature. Whereas, however, black enters largely into the coloration of the majority of the species, pure white (except on the under-parts, and in small patches about the head) is practically unknown in the Family; and there are no instances of the markings being lighter in tint than the ground-colour. In common with the majority of animals, the Cats generally have the under-parts lighter than the back; in this respect differing markedly from many species of the Weasel Family (Mustelide).

No Cat has complete longitudinal dark stripes throughout the body; although a few such stripes may be met with on the crown of the head and down the middle of the back. The markings may, indeed, be classified under the headings of longitudinal streaks, spots, cloudings, and transverse stripes; while a few species have the fur uniformly coloured, although in certain lights it generally exhibits traces of spots or stripes, while in the young state it is always thus ornamented.

Examples of Cats with longitudinal streaks or flecks are afforded by the Fishing Cat (Felis viverrina) and the Colocolo (F. colocolo), the streaks being darker, larger, and more numerous in the former than in the latter. As may be observed in our illustrations, the streaks in these and other cases are always 
arranged in more or les z continuous lines, as if they had been formed by the breaking up of longitudinal stripes, and it is evident that if this were really their origin, a further continuance of the same process would result in the production of spots. One variety of the Tiger Cat ( $F$. tigrina) affords an instance of the transition from a streaked to a spotted type of coloration.

Spots are the most common type of ornameritation assumed by the Felida, although these vary greatly in form and size in the different species. Simple solid black spots, of comparatively small size, are found in the Serval (Felis serval) and the Hunting-Leopard (Cynclumus jubatus); and these would appear to present the original modification of this type of coloration. In the Leopard ( $F$. pardus) the spots have, however, become broken up into rosettes, formed by imperfect rings of small sfots surrounding a light area, which may or may not be darker than the general ground-colour of the fur. In the Ounce ( $F$. uncia) the rings are larger and more complete, while the central area is decidedly darker than the rest of the fur. A further development is presented by the Jaguar ( $F$. onca) in which not only is the rosette formed by a complete ring and the enclosed area darker, but there is a solid black spot in the centre of each rosette. By the union of two or more rosette-like spots, with the central area darker than the rest of the fur, may be evolved the pattern characteristic of the Ocelot ( $F$. pardalis), in which we have elongated tawny or chestnut blotches, each surrounded by a black border, running obliquely downwards and backwards on the sides of the body. A further step will bring us to the clouded type, as exemplified by the Clouded Leopard ( $F$. nebulosa) and the Marbled Cat ( $F$. marmorata), in which the dark blotches have become larger, broader, and more squared, with the black edgings confined to their hinder borders. 
A complete transition from solid spots to transverse stripes is not observable in any member of the Family, although an indication of the mode in which such a transition might be effected is afforded by the markings on the fore-quarters of some specimens of the Indian Desert-Cat ( $F$. ornata). The most perfect development of transverse dark stripes is to be met with in the Tiger (F. tigris) and the Wild Cat (F. catus). From such fully striped species a transition can be traced through forms like the Caffre Cat $(F$. caffra) and the Flat-headed Cat (F. planiceps), in which, while the limbs remain more or less distinctly striped, the body has become more or less uniformly tawny, to perfectly tawny species like the Bay Cat (F. badius), the Eyra (F. eyra), and the Lion (F. leo). That the Bay Cat was originally a striped form may be inferred from its alliance to the Flat-headed Cat; while that the Licn has originated from a transversely striped species is evident from the occurrence of such stripes in the cubs. On the other hand, the indications of spots persisting on the fur of the Puma (F. puma) prove as clearly that in some instances a uniformly tawny hue has been evolved from the spotted type of coloration.

In a paper on the coloration of animals published by Professor Eimer, of Tübingen, in the "Jahreshefte Vereins für Naturkünde, Württemberg," for $\mathrm{i} 88_{3}$, the author arrives at the conclusion that longitudinal dark stripes formed the primitive coloration of terrestrial vertebrates in general, and that these subsequently broke up into spots, while the latter again coalesced to form transverse stripes; a uniform coloration being finally produced by the disappearance of the latter. Although the coloration of the existing Felide can, as is evident from the foregoing obscrvations, be explained on this hypothesis, yet there are several difficulties in accepting it altogether. In the first place, it has been shown that in the Puma a uniform 
coloration has resulted directly from a spotted coat, without the intervention of a striped stage. This, however, might be an individual exception, not affecting the theory as a whole. A greater difficulty is, however, presented in the case of the Banded Marsupial Ant-eater (Myrmecobius fasciatus), which, although one of the most primitive of living Mammals, is yet transversely barred. The Thylacine (Thylacinus cynocephalus), likewise belonging to the Polyprotodont Marsupials, also presents a similar type of coloration. Then, again, a further objection arises from the circumstance that the coloration of the Felidie appears to be mainly of a protective nature; the uniform tawny hue of the Puma and Lion harmonising with the sand of the open plains, while the vertical stripes of the Tiger resemble the lines of light and shadow formed by the tall grasses of an Indian jungle, the clouded markings of the Marbled Cat and Clouded Leopard assimilating with the gnarled and lichen-clad boughs on which these animals are wont to rest, and the spotted coat of the Indian Desert-Cat rendering the creature almost invisible on the stony deserts it frequents. To suppose that this harmony has always been produced by a regular transition from longitudinal stripes to spots, from the latter to transverse barrings, and these again to a uniform hue, is a theory very difficult to accept.

The whole subject of coloration is, however, one involved in great mystery and obscurity; and even although, as aforesaid, it appears most probable that the coloration of the Felide is in the main due to adaptations to the natural surroundings of its various members, there are not wanting difficulties even here. For instance, we have already said that the coloration of the Tiger harmonises almost exactly with the Indian jungles which the animal now inhabits. From its absence from Ceylon, Mr. Blanford, is, however, of opinion that the Tiger is probably only a comparatively recent immigrant into Southern 
India; and his suggestion is supported by the well-known in tolerance displayed by this animal to the fierce rays of an Indian sun. It is therefore quite probal)le that this Cat may be an immigrant from the west or north; and if Siberia, where it now exists, should prove to have been its original home, what becomes of the theory as to the adaptive harmony existing between its dark and light stripes, and the dark streaks of vertical light and shade in an Indian jungle?

Leaving the subject of their coloration in this somewhat unsatisfactory state, we pass on to the consideration of the geographical distribution of the Cats. Although the Tiger now inhabits Siberia and Amurland, while its fossilised remains have been found on an island still farther north and well within the Arctic Circle, and the Ounce is an inhabitant of the cold plateau of Tibet, yet at the present day the Cats, as a whole, attain their greatest numerical development in the warmer regions of the globe. Indeed, while they are represented in almost all the hottest parts of the world, they have no representatives in the extreme northern countries inhabited by the Arctic Fox and the Polar Bear. With the exception of the Tiger; the larger members of the Family are, in fact, now for the most part denizens of tropical and sub-tropical regions, although the range of the Puma extends southwards to the cold wastes of Patagonia, and northwards to British Columbia and Maine. It is true, indeed, that the Lion, as represented by the so-called Felis spelcea, ranged during the Pleistocene period in Western Europe as far north as England, yet we know too little of the climate of that period to draw any inferences from this former more extended distribution.

With the exception of Australia, New Zealand, New Guinea, perhaps Celebes, Madagascar, the West India Islands (save Trinidad, which may be reckoned as part of South America), and the circumpolar regions, the Cats have a practically 
cosmopolitan distribution. The Cats of the New World are, however, as a rule, markedly distinct from those of the Old, although the Lynxes form a marked exception to this rule. Exclusive of the Old World Caracal, these animals are, however, essentially a northern group; and it is therefore not surprising to find the common Lynx of Europe and Asia so closely allied to the Canadian Lynx as, in the opinion of many competent zoologists, to be no more than a local race. As a whole, the New World is not so rich in Cats as the Old; but it is noteworthy that in both hemispheres spotted, striped, and uniformly-coloured species occur. It is only, however, in the former that we meet with a species (the Jaguar) in which the dark rosettes have a central black spot; while the great tawny American Cat (the Puma) differs from its Old World analogue, the Lion, in having been derived from a spo:ted instead of a striped ancestor. Moreover, the only striped American species is the Pampas Cat, in which the stripes are but poorly developed; and accordingly, if Dr. Eimer's theory of coloration be the true one, it would seem that in this respect the New World Felide are less specialised than their Old World cousins.

Europe at the present day is remarkably poor in species of the Family, having only the Wild Cat, the common Lynx, and the Spanish Lynx. The warmer parts of Asia and Africa, on the other hand, may be regarded as the headquarters of the Family; and it is here only that we meet with the HuntingLeopard, which is not the sole representative of its genus, but is likewise common to the two continents. The only other species found both in Asia and Africa are the Lion, the Leopard, the Jungle Cat, and the Caracal, although a few essentially African species range into Syria. As regards the smaller Cats, several Afri an species appear to be peculiar to the forest districts on the western side of that continent.

As regards their geological distribution, it is not a little 
remarkable that, whereas the typical Cats (Felis) are unknown in Europe before the middle of the Miocene division of the Tertiary period, and in North America not earlier than the Upper Miocene or Lower Pliocene, in France the apparently more specialised sabre-toothed Tigers (Machcerodus) are met with in the Quercy Phosphorites belonging to the antecedent Oligocene division of the Tertiary.

At the present day, as we have seen, the nearest relations of the Felide appear to be the Civets (Viverride); the aberrant Cryptoproctu of Madagascar being the most Cat-like form among the latter. Both these groups agree in the general structure of the base of the skull, while the teeth of the Cryptoprocta are practically indistinguishable from those of the Felide. From this structural resemblance, coupled with the common occurrence of Civet-like animals in the earlier Tertiary strata of Europe, it has been generally considered that the Cats have taken origin from Carnivora more or less closely allied to the Civets. There exists, however, a group of extinct carnivorous Mammals known as Creodonts, the teeth of which differ markedly in structure from those of the existing members of the Order; and it has been recently suggested by North American Palæontologists that the Felidce have originated from one of these Creodonts quite independently of the other existing Carnivora. If this should prove well-founded, the resemblances existing between the skulls and teeth of the Cats and Civets would be due to what is known as parallelism in development, and the apparent relationship existing between the two groups merely an instance of what is termed convergence. Without, however, denying the possibility that the American Palæonto logists may be correct, the writer would submit that mere decisive evidence is required before it can be definitely accepted that there is no intimate relationship between the Cats and the Civets. 
Turning to the subject of classification, all zoologists are agreed that the whole of the existing Cats should be included within a single family - the Felidce. As regards generic divisions there is, however, some difference of opinion; although it is admitted on all sides that the Hunting-Leopard is entitled to stand as a genus (Cyncelurics), apart from all the rest. The question then resolves itself as to whether the whole of the other Cats should be included in the single typical genus Felis, or divided into two or more genera. By the late Dr. Gray, the existing Cats were split up into no less than thirteen generic divisions; but the majority of these were obviously unnatural, and they have been discarded by most recent zoologists. The true, or short-tailed northern Lynxes differ, however, markedly from the more typical members of the Family, and were it not for the existence of more or less completely intermediate forms, there would be much to be said for referring them to a genus apart, under the name of Lyncus. The Caracal, which is nearly allied to the Lynxes, is, however, a long-tailed form, connecting the former with the Jungle Cat and its allies so closely as to render any such divisions very difficult to define. It is true that an attempt to solve the difficulty has been made by referring the former animal to a third genus, as Caracal; but this, in the writer's opinion, does not much mend matters, and accordingly, in the present volume, all the existing Cats, with the exception of the HuntingLeopard, are included in the Linnean genus Felis.

A nearly similar state of uncertainty exists as to the number of species by which that genus is represented. In the sequel forty-five different kinds are provisionally admitted. Several of these are, however, of doubtful specific rank, this being especially the case among the Lynxes; and it is hence not improhable that the number of species, if all were founded upon differences of approximately equal value, might be reduced 
to somewhere about forty. On the other hand, there is a growing tendency among zoologists-especially on the other side of the Atlantic-to regard every well-marked and constant local difference in coloration as of specific value; and if this view were accepted, the result would probably be to split up several of what are here regarded as species (e.g., the Jungle Cat and the Ocelot) into different races. Since, however, a species is absolutely indefinable, as being non-existent, it is merely a matter of individual opinion as to the best manner of using that term ; the writer being very strongly in favour of employing it in as wide a sense as possible.

This introductory dissertation on Cats in general may be fitly brought to a close by a reference to the important part which the larger members of the Family took in the pageants and shows of the ancients, the account being taken from the admirable resumé given by Sir W. Jardine in the original edition of this volume of the "Naturalist's Library."

In the palmy days of ancient Rome various wild creatures were sometimes sent as presents from conquered nations; but, in general, animals were collected from the shores of Africa and India in such numbers and variety, that we are at a loss to conceive how they were overcome, or afterwards transported to the utmost limits of the Roman empire. Those belonging to the tribe we are now about to describe were chiefly Lions, and the larger spotted African and Asiatic Cats, which then went under the different appellations of varii, pardi, pantheræ, \&c. Lynxes were occasionally exhibited, but Tigers only once or twice. At the triumphs they were either led in procession as trophies from the vanquished nation or, in a few instances, having been tamed, they were made to draw the chariot of the conqueror. But the most frequent exhibition of all kinds or animals was in the public amphitheatral shows, an amusement which became a complete passion with the Romans. Immense 
sums were lavished in their arrangement; even the armies, when stationary for a short period, had their circus; and traces of these erections are to be found in the most distant parts of the Roman empire. Training men to these sports became a profession, and persons of rank were emulous to engage in them, because they were thought to keep up the martial spirit of the nation.

The number of fierce animals collected at these shows was immense, and the slaughter no less so. Cornelius Scipio Nasica introduced sixty-three Lions. Scylla exhibited ıoo, which he received as a present from Boschus, King of Mauritania, with some Mauritanians to fight them. Pompey, at the opening of his theatre, exhibited a variety of games and battles with wild beasts, in which 500 Lions were slain in five days; and in another exhibition, the tragedy consisted in the massacre of roo Lions, and an equal number of Lionesses, 200 Leopards, and 300 Bears. In the extravagant theatre built by Scaurus, 500 Panthers were let loose in the-arena on a single occasion.

At a later period, by many of the Indian sovereigns beasts of prey were kept to be hunted; or, being tamed, were placed near the throne upon occasions of pomp. They were also much more frequently employed as the executioners of criminals, or persons who had displeased their despotic masters. The King of Pegu kept a park for Lions, Tigers, and other fierce beasts, called Liparo ; and it was a sad and daily sight to see criminals devoured by them.

But in other parts of these countries, particularly Hindustan, instead of being used to rouse the martial spirit of the youth, the beasts of prey occupy a prominent part in the religious rites. In the mythology of the Hindus, many of them are held as sacred, or as evil spirits which can be propitiated by food. It is therefore a crime to destroy a Tiger; and the teeth and claws are worn as charms against their ravages. Similạ ideas 
prevail in a great part of the East Indian Archipelago, and precautions are scarcely ever taken against a wild beast. In Sumatra, according to Sir Stamford Raffles, when a Tiger enters a village, the foolish people frequently prepare rice and fruits, and placing them at the entrance, conceive that, by giving him this hospitable reception, he will be pleased with their attention, and pass on without doing them harm.

Bringing the history of our knowledge of these wild animals to a still later period, we find them in Britain at the courts of our own kings. Henry the First, for instance, had, at his manor at Woodstock, a royal menagerie, where he kept Lions and Leopards, Lynxes, Porcupines, and other animals. From Woodstock these animals were transferred to the Tower, and formed the foundation of that establishment. "But in all these immense collections," continues Jardine, "we have only seen them as accessories of eastern magnificence, or delighting a barbarous people by their still more barbarous contests. It is true, certainly, that one of the greatest original works derived a great part of its accuracy and value from the numbers of animals which Alexander remitted during the progress of his conquests, and the Natural History of Pliny was partly supplied from the Roman shows; but these are the only instances of great men making use of the advantages which these collections afforded." And it was not till a much later epoch that regular Zoological Gardens were established to promote the study of animals in their living state.

I. THE RETRACTILE-CLAWED CATS. GENUS FELIS. Felis, Linn., Syst. Nat. ed. I2, vol. i. p. 60 ( 766 ).

Characters.-Claws of toes completely contractile within their investing horny sheaths; inner tubercle of the upper carnassial tooth well developed.

This genus includes the whole of the existing members of 


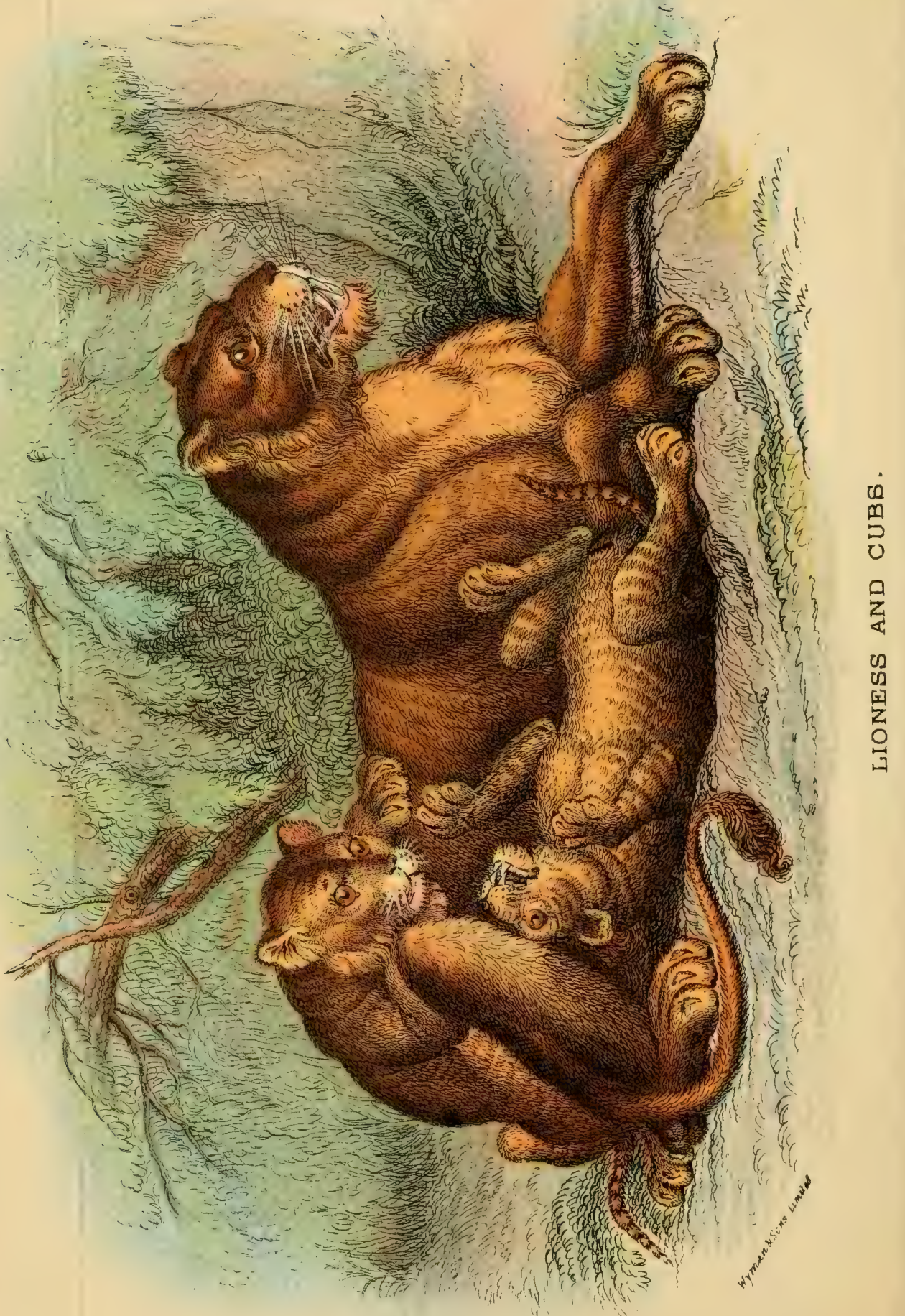


the Family, except the Hunting-Leopard ; and has, therefore, a geographical distribution coëxtensive with that of the Family, as given above.

\section{THE LION. FELIS LEO.}

Felis leo, Linn., Syst. Nat. ed. I2, vol. i. p. 60 ( 1766$)$; Elliot, Monograph of Felidæ, pl. i. (1878-83); Blanford, Mamm. Brit. India, p. $5^{6}$ (I 888).

Felis spelaca, Goldfuss, Nova Acta Ac. Cæs. Leop.-Car. vol. x.

p. 4\&9 (I82I); Owen, Brit. Foss. Mamm. p. I6I (I $8_{46}$ ). Felis leo goojratensis, Smee, Trans. Zool. Soc. vol. i. p. I65 (1833). Leo africanus, Jardine, Naturalist's Library, Felinx, p. I I (1834).

Leo asiaticus, Jardine, op. cit. p. I $2 \mathrm{I}$.

Leo barbarus, Gray, List Mamm. Brit. Mus. p. 39 (I843). Leo nobilis, Gray, Proc. Zool. Soc. I867, p. 263, and Cat. Carniv. Mamm. Brit. Mus. p. 9 (I869).

\section{(Plates $I$. and $I I_{\text {. }}$ )}

Characters.-Distinguished from all the other members of the Family by the presence of a massive mane, of variable length, depending from the neck and sides and crown of the head of the adult; the female and young being mane-less. Tail about half the length of the head and body, with a large tuft of long hair at the extremity, among which is concealed a small nail-like horny appendage. Pupil of the eye circular when contracted. Colour uniform pale yellowish-brown (tawny), except the tuft at the extremity of the tail, the basal portion of the external surface of the ears, and frequently the tips of the hairs of the mane during middle life, all of which are black. Young cubs usually marked with small dark transverse bands, and a longitudinal stripe down the middle of the back, but these markings occasionally breaking up into spots. Faint spots sometimes observable on the flanks and under-parts of the adult, 
especially in the Lioness. Skull connected with the arch of the hyoid bone (supporting the base of the tongue) by a pair of long ligaments. In the Lion the superior extremities of the nasal bones do not extend so far backwards as the frontal processes of the maxillæ, or upper jaw-bones; whereas in the Tiger the former reach far be'lind the latter. In the Lion's skull, again, the fronto-parietal suture is separated by a much shorter interval from the post-orbital process; so that the former, as Mr. IV. L. Sclater remarks, may be termed a short-waisted skull, as compared with that of the Tiger. A further difference between the two animals is to be found in the smaller development of the inner tubercle of the upper carnassial tooth of the Lion, as compared with that of the Tiger. The total length reached by large full-grown males is about ten feet, of which rather more than three feet is occupied by the tail.

In the male Lion the mane commences to grow at about three years of age, and does not attain its full dimensions till the completion of the sixth year. The mane in specimens kept in menageries attains a far greater development than it ever reaches in the wild state; the fringe of hair on the middle of the lower surface of the body, so commonly found in menagerie Lions, being peculiar to them. Unlike the majority of the Family, Lion cubs are born with their eyes open.

As regards coloration, the Lion may be regarded as a more specialised animal than the Tiger, which it otherwise very closely resembles; while the mane of the male and the tailtuft of both sexes are likewise specialised features. There is some considerable degree of variation in the colour of the coat, as well as in the degree of blackness and length of the mane. As a rule, specimens kept in menageries have a marked reddish tinge in the coat ; whereas many wild specimens have a very pale yellow or even a silvery-grey hue. In South Africa, Messrs. Nicolls and Eglington remark that in some instances 
full-grown males have been found "of a fawn-colour so light as to be little removed from dirty-white, and with scarcely any appearance of mane; while others in the same district, although not so advanced in age, may be ornamented with full-flowing manes and dark brown coats, and vice versâ. It is in these Lions with the largest manes that the tips of the hairs of the latter show the most blackness; whereas in the poorly-maned specimens the colour is almost wholly tawny." Hence we hear of "black" and of "yellow" Lions; but since cubs of both kinds may be met with in a single litter, it is quite certain that not even racial, let alone specific, differences can be founded on such variations. Neither is it true that the Indian Lion differs from the African in the absence of a mane. There does, howerer, seem to be a certain amount of local difference in the development of this appendage, some South African and all Somali-land and Algerian Lions being characterised by their full manes.

Distribution.-At the present day, $\Lambda$ frica from Algeria to the Cape; Mesopotamia, on the west flanks of the Zagros Range; Persia, south of Shiraz, but not on the tableland; and India.

Regarding its occurrence in India, Mr. W. L. Sclater, in the "Catalogue of the Mammalia in the Indian Museum," writes that the Lion was much more widely spread formerly than it is at the present day. "The districts in which it occurs or has occurred, are Guzerat in the extreme west of India, Central India, and Bundelcund. Blanford gives accounts of a Lion shot near Rewah in I866; and also of a Lion stoned to death by a Mr. Arratoon, of the Police at Sheorajpur, twenty-five miles west of Allahabad. In the Asian newspaper of June 30 th, I 885 , Colonel Martin, of the Central India Horse, mentions that General Travers and himself in s 860 killed two Lions on a hill to the west of Guna in Gwalior; and in 1862 , with Colonel Beadon, the Deputy Commissioner, he turned out and 
TURAL HISTORY.

killed no less than eight Lions at a place called Patulghar, seventy miles north-west of Guna. The last Lion killed in Central India, of which I can find any record, was shot by Colonel Hall near Guna in 1873 . . . . I have heard too of a Lion being killed in 1888 in Guzerat, so that it is evident that the animal is not yet extinct in India, although it seems probable that it soon will be." Since this passage was written, the present writer has been informed that Lions still exist in Kattiawar (a district of Guzerat), where they are now strictly preserved by the Indian Government. His informant also states that during the Mutiny-time (that is to say, early in the "fifties") Colonel George Acland Smith killed upwards of three hundred Indian Lions, fifty of which were bagged in the Delhi district.

In South Africa, where these animals formerly abounded, Messrs. Nicolls and Eglington write that a few Lions "still remain in the extreme northern confines of the Zoutpansberg district of the Transvaal, and about Delagoa Bay. In British Bechuanaland their presence is now and then reported from the extreme westwardly course of the Molopo river, before its waters become absorbed in the waters of the southern Kalahari. But northward, without mentioning any particular locality, throughout South-Central Africa, wherever large game is plentiful, they are more or less numerous, particularly so in the low-lying countries along the East Coast, and the presence of Burchell's Zebras in quantities is a sure indication that Lions are to be found in the vicinity."

Very similar testimony is given by Mr. H. A. Bryden, who, after mentioning that only occasional traces of their presence are to be met with in British Bechuanaland, states that "not many Lions are nowadays heard of until Khama's country is reached and Palachwe left behind. Along the Botletli they are still numerous, expecially in the busier parts nearing Lake 
Ngami. And round the lake, in the Mabebi veldt, and about the Chebi and Zambesi they are always to be found. In other places, too, between Palachwe and the Zambesi, Lions' spoor is pretty sure to be seen in the vicinity of water. In the true Kalahari country there are few; here water is scarce, and Lions cannot exist without water. In the south-eastern part of Khama's country, along the Limpopo, and near the Shashi and Macloutsi rivers, they are still (or were till very lately) occasionally heard of." At the time that Mashonaland was opened up by the Chartered Company in 1890 , Lions were not only extraordinarily abundant, but likewise remarkable for their boldness and audacity, despatch-riders being often followed by small troops of them at night, while there are several instances of their having pursued men in broad daylight. Cattle and mules were likewise carried off in numbers, in defiance of all ordinary means of protection. With regard to other parts of Africa, our information is not so full. Lions are, however, still abundant in Somali-land, where, as already mentioned, the males, as a whole, are characterised by the fine development of their manes; although, according to Mr. Selous, none of the Lions from that district equal in this respect the very finest specimens from the Cape, where the average size of the mane is less. From lower Egypt the Lion has, we believe, disappeared, although it is still to be met with in considerable numbers in the Sudan, as well as in Algeria and Morocco. In the wooded regions of Senegal it is likewise abundant; and regarding its occurrence in Angola and the Congo district, Professor Barboza du Bocage, in a paper published in the journal of the Lisbon Scientific Society for 1883 , writes as follows : "The Lion appears everywhere where large Ungulates, such as Antelopes and Zebras, abound. To the north of the Zaire its range seems confined to the upper Congo, above Stanley Pool. In Angola it seems to have disappeared from: 
the inhabited districts lying between the Zaïre and the Quariza. In the district of Benguela it is sufficiently common at Quillengues and Caconda, and during its wanderings frequently comes down to the sea-coast. In the district of Mossamedes its presence has been indicated at Capangombe, and more especially on the high plateau extending westwards from the mountain-range of Chella; while in the southern part of this district it has been met with in the littoral zone on the banks of the Rio Coroca."

Turning once more to Asia, it may be mentioned that a few years ago Lions were still numerous in the reedy swamps on the banks of the Euphrates and Tigris; while in Persia, to the south of Shiraz, they haunt a reed-clad valley, from which they make forays on the swine kept in numbers in the neighbouring woods and thickets. Within historic times the western range of the Lion was, however, much more extensive, and while it is known to have ranged over Syria and Arabia, it is probable that it was likewise found in Afghanistan and Baluchistan, whereby its present Indian and Persian habitats would have been connected. It is well-known how Herodotus records that the baggage-camels of the army of Xerxes were attacked by Lions in the country of the Pæonians, one of the races of Macedonia ; and there is evidence that these animals formerly ranged over a considerable portion of South-eastern Europe, including Roumania and Greece.

Many years ago the fossilised remains of a large species of Lion were discovered in the ossiferous deposits of the German caves and described under the name of Felis spelca; the opinion then being that they indicated a species now extinct. Similar remains have been subsequently obtained from the caverns and superficial river-deposits of other parts of Europe, such as France, Italy, Spain, and England; but careful examination and comparison has led to the conclusion 
that the animal to which they belonged cannot be separated from the existing Lion, whose range was, therefore, formerly very extensive. It is, however, very noteworthy that there is no evidence of the Lion having ever inhabited the countries to the eastwards of the Bay of Bengal, where the Tiger is so abundant; and it may thus be concluded that while the one is a western and southern form, the other is an eastern and northern animal; the meeting-place of the two being on the plains of India, where the Tiger, as already mentioned, is not improbably a recent immigrant.

Habits.-Distinguished from the majority of the members of the Cat tribe by its inability to climb, the Lion is essentially a noisy animal, its well-known roar being in undisturbed districts frequently uttered at intervals, from early evening, throughout the night. Even the Lion, however, learns prudence, and in places where they are much molested and harassed by Man, they roar much less frequently than elsewhere. As is wellknown, Livingstone had no very high estimate of the impressiveness of the Lion's roar ; but his opinion is not shared by the majority of more recent observers. Mr. F. H. Jackson, for instance, in the volumes of the "Badminton Library" devoted to big game, observes that, when heard on a still night at a short distance, the Lion's roar is decidedly grand, especially when two or more animals are uttering the sound in concert: Later on in the same volume, Mr. Selous writes that "there is no more magnificent sound in nature than the volume of sound produced by a party of Lions roaring in unison, that is, if one is fortunate enough to be very near to them. It is, however, a rare occurrence to hear Lions roar loudly within a short distance of one's camp, and in all my experience, thotgh I have heard these animals roaring upon hundreds of different occasions, I can count the nights on the fingers of one hand when, all unconscious of my near vicinity, a party of several 
Lions has roared freely within a hundred yards of where I was lying."

Although when lying at rest in one of the spacious open cages at the "Zoo" a well-maned male Lion has certainly an imposing and majestic appearance, those who have had an opportunity of observing the animal in its native haunts are not, for the most part, impressed with the dignity of its bearing and carriage. General Paget, however, informs me that, whereas Tigers are always sneaking and Cat-like in their gait, old Lions are bold and defiant, holding up their heads as if to challenge an attack. But this, is not the experience of Mir. Jackson, who says that Lions as a rule carry their heads low down, and below the line of the back; and as they slouch along, their hind-quarters sway from side to side in an inelegant manner, so as to give a general appearance of weakness and general looseness of build. When standing uroadside on, or facing the intruder with head erect, however, he is fain to confess that an adult male Lion is a grand-looking beast.

Mainly nocturnal in their habits, Lions are very generally found in more or less open sandy districts, with the hue of which their tawny hides so well harmonise; but in certain districts they are found in thorn-jungle, or even forest; while, as we have seen, in the valleys of the Tigris and Euphrates they frequent reed-covered swamps. It has been thought that the nature of the country they inhabit has something to do with the degree of development of the mane-this appendage being alleged to be smaller in Jungle Lions; but this requires confirmation. Although usually met with in pairs, in some parts of Africa Lions associate in parties commonly comprising up to as many as ten individuals, which may represent at least two or three generations. Mr. Selous states, however, that on one occasion he has counted eleven Lions together, and on 
a second, upwards of twenty-three. Not unfrequently these parties combine to pull down large animals, as in the wellknown instance narrated by Vardon and Oswell, where three males united their forces to attack a Buffalo. At the time when Lions where abundant in India, their prey was chiefly composed of Deer, Antelopes, Pigs, Horses, Donkeys, and Camels; and on the Euphrates they live chiefly on the swine in the oak forests adjoining their haunts. In South and East Africa, on the other hand, their favourite game is Zebra and Buffalo; and wherever large herds of the former animals are found, there Lions may confidently be expected. Numbers of the larger Antelopes, such as Hartebeests and Elands, are, however, killed; while the Giraffe more rarely falls a victim. Old Lions will, moreover, take to killing Goats and other domestic animals; and it is probable that many of these would turn into confirmed Man-eaters, were it not that when a Lion exhibits this propensity, the bold natives of Southern Africa promptly turn out and destroy him-no matter at what cost of life. The old idea of the Lion being a clean and dainty feeder has been completely dissipated by modern observers, some of whom state that these Cats will scarcely ever pass by the carcase of a slain animal, even though it be in an advanced state of decomposition, without stopping to make a meal of its flesh. And it is related that where Elephants have been shot and left to fester in the sun, Lions will stay by the decomposing carcases, till the bones are picked clean, despite the fact that there may be herds of their favourite Zebras in the immediate neighbourhood. Moreover, the Lion is not free from an occasional charge of cannibalism.

Although the Lion generally prefers to creep silently up to its victim by night, it will occasionally attack in broad daylight, Mr. Jackson relating two instances where men have been thus attacked without provocation. Equally rare are attacks 
by night on camps, the writer last mentioned stating that only one such instance has come under his personal observation. With regard to the danger of tracking up a wounded Lion, there seems to be some difference of opinion among experts, Mr. Jackson stating that he has only known of two instances where Lions thus followed up have charged home; one of these being a Lioness which attacked Sir Robert Harvey. On the other hand, Mr. Selous speaks very emphatically as to the danger attending such a proceeding; while Messrs. Nicolls and Eglington write "that following up one of these wounded animals in thick bush without the assistance of dogs can only be attended by extreme peril."

On the subject of the manner in which the Lion strikes down its prey, Mr. Jackson writes: "Although I have carefully examined the carcases of several Buffaloes and Zebras, I have never been able to discover anything about them to warrant my expressing an opinion as to how they had actually been killed by the Lions. The most noticeable thing about two freshly-killed Buffaloes and one Zebra was the terrible way in which they were lacerated on the hind-quarters, evidently by the Lions at their first spring and during the subsequent desperate struggle before they actually killed them. In every case where I found a fresh kill, the stomach had been torn open, and the liver, heart, and entrails had formed the first meal." Messrs. Nicolls and Eglington express a more decided opinion on this subject, stating that although Lions have different modes of seizing and killing their prey, yet that the method "usually adopted in the case of the Ox or the Eland, when springing on to the back of one of these animals, is to insert the claws deep into the flesh of the victim, those of the left hind-foot low down on the near flank, almost at the stomach, those of the right hind-paw high on the rump, the right fore-paw in the centre of the off shoulder, and, with the 
purchase so obtained, to bite into the nape of the meck, simultaneously wrenching the head round by grasping the nose with the claws of the left fore-paw. As one of the numerous evidences in support of this assertion as to how they kill their quarry, it may be mentioned that some years ago four Oxen out of a span were killed by Lions on the Botletli river in one night, every one of which on careful examination had its neck broken exactly in the manner described." Although Mr. Selous states that many large animals, such as Oxen, when killed by Lions, undoubtedly have their necks dislocated, yet, in his-opinion, the method of attack is frequently very different from that described above. In such a case deep claw-marks will be found on the muzzle of the victim; and he believes that the animal is seized, while grazing, by the Lion, from the left side, the muzzle being struck by the left front paw of the aggressor, and the head of the Ox pulled beneath its body. The victim being at the same time firmly gripped on the shoulder by the right paw of the Lion, whose hind-feet rest on the ground, it at once plunges forward, with the result that it topples headlong over, and thus breaks its own neck. When several Lions combine to attack a large Buffalo or Ox, they kill it in a less artistic manner, biting and clawing it all over. Zebras, as well as Horses and Donkeys, according to the same intrepid hunter, are killed by being bitten either at the back of the neck immediately behind the ears, or in the throat; whilst Giraffes are probably seized and bitten high up in the throat, whilst lying down. On the other hand, the late Sir Samuel Baker, whose experiences were derived from North Africa, held the opinion that Lions killed their victims by a crushing blow of the paw. From this somewhat conflicting evidence it is quite clear that the last word has not yet been said as to the manner in which the Lion kills its victims. It is, however, evident that the neck of the larger animals is 
very generally dislocated; and it may be suggested, that, as a possible solution of the discrepancy, while in some instances the victims are killed in the manner described by Messrs. Nicolls and Eglington, in other cases the aggressor may employ different tactics and go to work in the way indicated by Mr. Selous.

By the older hunters in Africa stories were told of Lions taking the carcases of animals of the size of Oxen in their mouths, and, thus burdened, springing over the palisades with which kraals in South Africa are surrounded. In spite, however, of its enormous strength, those most capable of forming a judgment on the subject are of opinion that the Lion is utterly incapable of performing any such feat, and that the body of its victim, be it large or be it small, is invariably held in the mouth by the head or neck and dragged along the ground by the side of its slayer. According to Mr. Selous, on the rare occasions when Lions do break into the kraals, they but seldom leap over the fence, not even when it is low, preferring to make their way through the interstices at the bottom; and they will at times walk round and round an enclosure until they find an interval between two poles, which they enlarge by thrusting the latter apart, and thus manage to squeeze their bodies through. When once inside, if suddenly disturbed or fired at, they will often make a speedy exit by leaping the fence.

It is ascertained that a Lion will live for at least thirty years, and there are some reasons for believing that the duration of life will sometimes reach as much as forty years. A Lion and Lioness pair for life; and while, in the wild state, the number of cubs in a litter is generally but two or three (the latter number being the most usual in South Africa), in captivity as many as six are not uncommonly produced. Even in the wild condition many cubs die at a very early age; and it is therefore not 
surprising that many should perish in captivity. Although Lions generally breed preity freely in captivity, there is a great difference in this respect, as also with regard to the rearing of the cubs in different menageries. The most successful results have of late years been obtained in the Zoological Gardens, Dublin; and the following record of this breeding, compiled by Professor Valentine Ball, the Honorary Secretary to that establishment, will be read with interest. Mr. Ball writes that the breeding of Lion cubs commenced in the Gardens in the year 1857 , and has been continued through an unbroken descent to the end of 1893 , or for thirty-seven years; from which, if we subtract the five years from 1874 to 1878 , inclusive-when there was no breeding Lio:ess in the Gardens, and no cubs were born, - the actual period of breeding lasted only thirty-two years, during which the average number of births has been 5.3 per annum.

\section{Parents of the Cubs.} MALES.

\section{Number of}

Cubs.

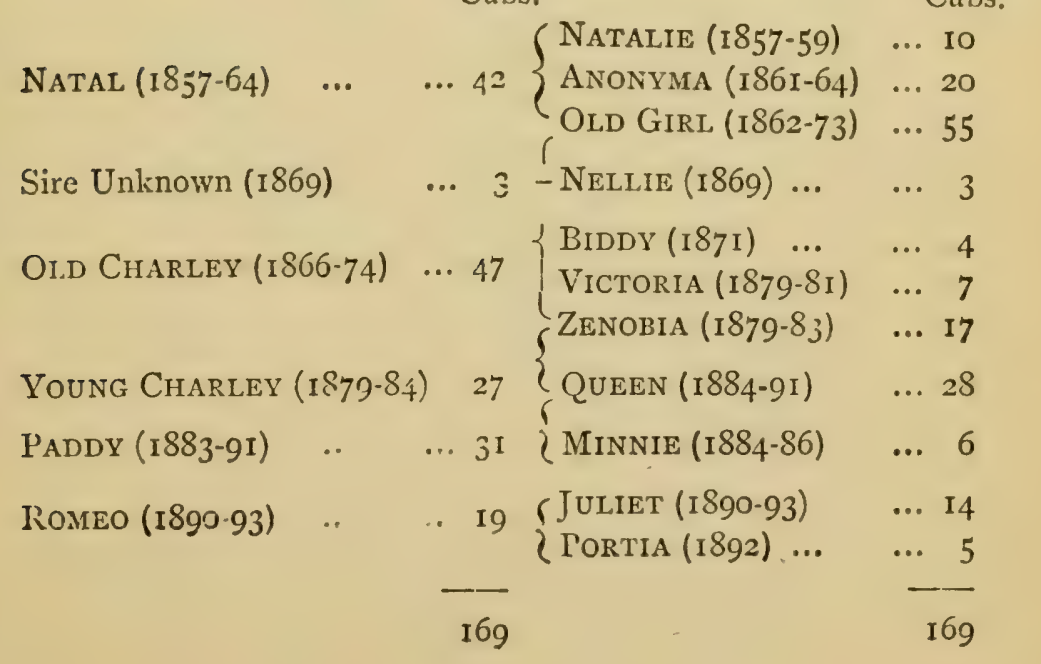

FEMALES,

Number of Cubs. 


\section{Sexes of the Cubs.}

$\begin{array}{lccccccr}\text { Males } & \ldots & \ldots & \ldots & \ldots & \ldots & \ldots & \delta S \\ \text { Females } & \ldots & \ldots & \ldots & \ldots & \ldots & \ldots & \text { So } \\ \text { Unknown } & \ldots & \ldots & \ldots & \ldots & \ldots & \ldots & \text { I } \\ & & & & & & & \text { I } \\ & & & & & & & \text { I } 99\end{array}$

Percentage of males to females $52^{\circ} 4$ to $47^{\circ} 6$, or a majority of $4^{.8}$ males out of every roo.

When captured sufficiently young, the Lion is one of the most easily-tamed of all the Felide-differing very markcdly in this respect from its near ally the Tiger-and some of the specimens exhibited in menageries have shown a most extraordinary degree of docility. Jardine writes that a Lion exhibited in the early part of the century in Wombell's travelling menagerie, known as Nero, "was of a remarkably mild disposition, and allowed his keepers every liberty; strangers were frequently introduced into the den, and when in Edinburgh, this was a nightly exhibition, the visitors riding and sitting on his back. Nero, during the while, preserved a look of magnanimous composure, and on the entrance or exit of a new visitor, would merely look slowly round.

"But the most docile Lion which has occurred to our own observation, was one in a travelling menagerie at Amsterdam, where, it may be remarked, all the animals showed a remarkable degree of tameness and familiarity. The Lion alluded to, after being pulled about and made to show his teeth, \&c., was required to exhibit; two young men in fancy dresses entered the spacious cage, and in the meantime, the Lion, apparently perfectly aware of what he had to do, walked composedly rouid. He was now made to jump over a rope held at different heights; next through a hoop and a barrel, and again through the same covered with paper. All this he did freely, compressing himself to go through the narrow space. 
and alighting gracefully. His next feat was to repeat the leaps through the hoop and barrel with the paper set on fire; this he evidently disliked, but with some coaxing went through each. The animals were now all fed, but the Lion had not yet completed his share in the night's entertainment, and was required to show his forbearance by parting with his food. The keeper entered the cage and took it repeatedly from him, no further resistance than a short clutch and a growl was expressed. His countenance had, however, lost its serenity, and how long his good temper would have continued, is doubtful."

The following account of Lions in Gujrat, in pre-Mutiny days, is given by General IV. Rice, in his book entitled "Indian Game." The General writes that on one occasion "when passing a village near which we had hunted the previous year, the people begged me earnestly to wait while their young men ran off to mark down any sleeping Lions. It seems that after killing several cattle belonging to the place, an old Lion would every evening come out of the forest and lie down, stretched out on a large piece of flat stone or sheet-rock close to the village; presently he would look round, when a Lioness used to follow and lie down by his side; she again was followed by another young half-grown Lion, and there the three would wait. At last one of the men, with the rest of the populace behind him, took a steady kneeling shot with a matchlock at the old Lion, but somehow missed or merely grazed him, for the Lion thereupon bounded forward, and after nearly pulling the marksman's head off, retreated to the woods with his mate and cub.

"Formerly Lions were far more plentiful in this part of the country, and used to live more in the open plains. A cavalry officer a good many years ago told me he had shot eighty Lions in this province in three years, using well-trained horses for the purpose, and following them over the open country. 
"From being so constantly hunted, Lions have almost left the open plains, and betaken themselves chiefly to the forests, where the numerous thorn-bushes must drag out the best part of their manes, until all, except the very old Lions, cease by degrees to have any mane left. This is supposed to be the reason of the 'Maneless Lion of Guzerat' being considered a distinct species.

"Lions wander considerably, travelling all night, and lying up in the daytime at certain, to them, well-known restingplaces. They often go in company, as many as six or more being at times together, and seem to keep to the same rounds in travelling. From this cause the above-named friend told me that his shikari used to watch over a few well-known haltingplaces of the Lions, and bring him news of a fresh arrival, when he would ride out to the spot, shoot the Lion, and again in a few days another Lion would be reported as having taken up its quarters in the self-same bush or den, where it also would be killed. Once he described how his hunter, while they were following up the fresh prints of a Lion, knelt down to look under a thick bush. After a very long silent pause, the man withdrew his head from the bush, when his countenance was observed to be green. The pour fellow had all this time been staring at a Lion asleep, face to face, at almost kissing distance; having been stricken dumb and dazed, he could merely make a few signs by pointing at the bush, where the Lion was shot while asleep.

"When travelling and wandering over the country in this manner, Lions will put up for the day under any kind of shelter, for I have known two turned out from under a haystack, while cane-fields form a temporary refuge. Their usual course is through large patches of dry grass, extending often for many miles, and preserved for feeding cattle. These extensive tracts help to hide the Lions in their journey from 
one sct of hills or jungles to some far distant range or fres'l hunting-grounds."

Our account of the present species may be fitly concluded with the description of a Lion-hunt in South Africa, taken from "Thompson's Travels," at a time when repeating rifles and explosive bullets were things undreamt of. After stating that his party consisted of several Europeans, enforced by a company of the so-called Bastaard Hottentots, the narrator writes: "The first point was to track the Lion to his covert. This was effected by a few of the Hottentots on foot. Commencing from the spot where the horse was killed, we followed the spoor through grass, and gravel, and brushwood, with astonishing ease and dexterity, where an inexperienced eye could discern neither footprint nor mark of any kind; until, at length, we fairly tracked him into a large bosch, or straggling thicket of brushwood and evergreens, about a mile distant.

"The next object was to drive him out of this retreat, in order to attack him in a close phalanx, with more safety and effect. The approved mode in such cases is to torment him with dogs till he abandons his covert, and stands at bay in the open plain. The whole band of hunters then march forward together, and fire deliberately one by one. If he does not speedily fall, but grows angry, and turns upon his enemies, they must stand close in a circle, and turn their horse's rear outward; some holding them fast by the bridles, while the others kneel to take a steady aim at ts? Lion as he approaches, sometimes up to the very horses' heels, couching every now and then, as if to measure the distance and strength of his enemies."

After some hours spent in searching, the Lion was eventually found "couched among the roots of a large evergreen, but with a small space of open ground on one side of it; and they fancied, on approaching, that they saw him distinctly lying 
glaring at them under the foliage. Charging the Bastaards to stand firm, and level fair, should they miss, the Scottish champions let fly together, and struck-not the Lion, as it afterwards proved, but a great block of red stone, beyond which he was actually lying. Whether any of the shot grazed him is uncertain; but, with no other warning than a furious growl, forth he bolted from the bush. The rascally Bastaards, in place of pouring in their volley upon him, instantly turned and ran, helter-skelter, leaving him to do his pleasure upon the defenceless Scots, who, with empty guns, were tumbling over each other, in their hurry to escape the clutch of the rampant savage. In a twinkling he was upon them, and, with one stroke of his paw, dashed the nearest to the ground. The thing was terrific! There stood the Lion, with his foot upon his prostrate foe, looking round in conscious pride upon the bands of his assailants, and with a port the most noble and imposing that can be conceived. It was the most magnificent thing I ever witnessed. The danger of our friends, however, rendered it at the moment too terrible to enjoy either the grand or the ludicrous part of the picture. We expected every instant to see one or more of them torn in pieces; nor, though the rest of the party were standing within fifty races, with their guns cocked and levelled, durst we fire for their assistance. One was lying under the Lion's feet, and the other scrambling towards us, in such a way as to intercept our aim upon him. All this passed far more rapidly than I have described it; but, luckily, the Lion, after steadily surveying us for a few seconds, seemed willing to be quit on fair terms, and, with a fortunate forbearance, turned calmly away, and driving the snarling dogs like rats from among his heels, bounded over the adjoining thicket, like a Cat over a footstool, clearing brakes and bushes, twelve or fifteen feet high, as readily as if they had been tufts of grass, and, abandoning the jungle, retreated towards the mountains. 


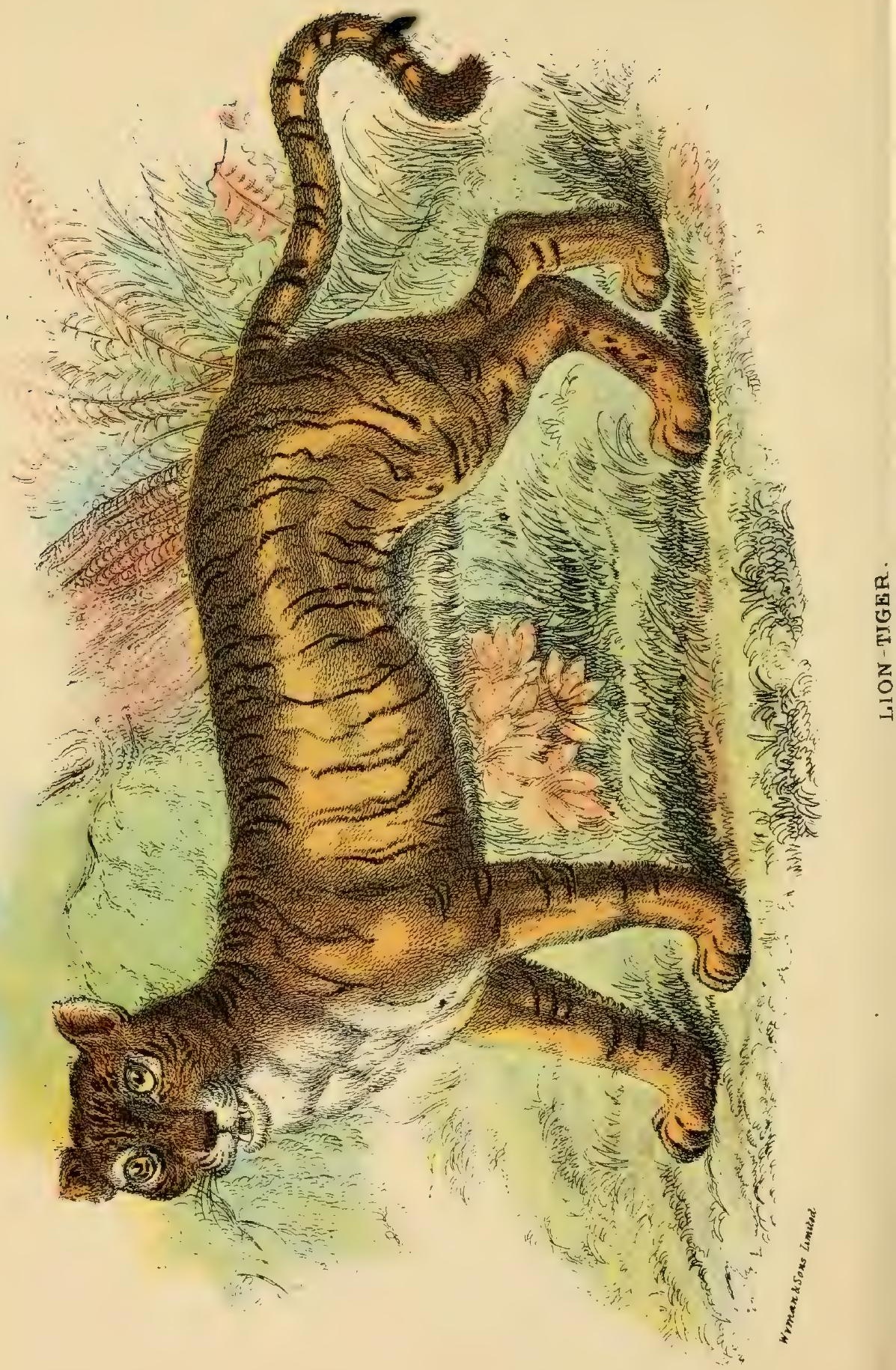


"After ascertaining the state of our rescued comrade, who fortunately had sustained no other injury than a slight scratch on the back, and a severe bruise on the ribs, from the force with which the animal had dashed him to the ground, we renewed the chase, with Hottentots and hounds, in full cry. In a short time we again came up with the enemy, and found him standing at bay under an old mimosa-tree, by the side of a mountain-stream, which we had distinguished by the name of Douglas Water. The dogs were barking round, but afrail to approach him, for he was now beginning to growl fiercely, and to brandish his tail in a manner that showed he was meditating mischief. The Hottentots, by taking a circuit between him and the mountain, crossed the stream, and took a position on the top of a precipice overlooking the spot where he stood. Another party occupied a position on the other side of the glen, and, placing the poor fellow thus between two fires, which confused his attention, and prevented his retreat, we kept battering at him, without truce or mercy, till he fell, unable again to grapple with us, covered with wounds and glory."

\section{LION-TIGER HYBRIDS.}

(Plate III.)

Although there is no record that such cross-breeding occurs in a state of nature, Lions and Tigers will occasionally breed together in captivity; but it is remarkable that the only recorded instances of such interbreeding took place between a single Lion and a Tigress. Attempts have, indeed, recently been made in the Zoological Gardens at Dublin, where, as men tioned above, Lion-breeding is carried on with remarkable success, but hitherto without any successful result.

The history of these hybrids has been very carefully worked out by Professor Valentine Ball, Director of the Science and 
Art Museum, Dublin, from whose papers the following account is taken. The parents of these hybrids were in a travelling menagerie owned at first by Mr. Thomas Atkins, and subsequently by his son Mr. John Atkins; and a total of six litters of hybrids were produced between the years i $\delta_{24}$ and $\mathrm{I} \delta 33$. The parent Lion was bred in the menagerie from a Barbary Lion and a Senegal Lioness; while the Tigress was born in the collection of the Marquis of Hastings at Calcutta, and was purchased when about eighteen months old from a ship's captain, to whom she had been given by her original owner. Being of the same age as the Lion, she was placed with him in the same cage; and in the course of two years proved to be in cub. The following is a record of the six litters produced by the union of this pair.

First Litter.-Born October the $24^{\text {th }}, \mathrm{I} 824$, at Windsor, and comprising two males and a female. They were nourished by a female terrier, but all perished within a year of their birth. These cubs were exhibited to King George the Fourth, at the Royal Cottage, Windsor, on the first of November, by whom they were christened Lion-Tigers.

Second Litter.-Born April 22nd, I 825, at Clapham Common; there were three cubs, sexes not recorded. Reared by the mother, as also were all the subsequent litters. They only lived a short time.

Third Litter.-Born December 3 Ist, I 826 or I $\$ 27$, at Edinburgh; one male and two females. Mr. Ball states that the year is given as 1827 in the handbill of the menagerie from which he quotes, and the other references seem to support that date; but Mr. John Atkins says it is given as I 826 in a printed catalogue in his possession. These only lived a few months. The skin of one of them, forming the subject of Plate III., is preserved in the Science and Art Museum at Ldinburgh, and a 
second is in the British Museum. Sir William Jardine remarks that "the colour was brighter than that of the Lion, and the bands were better marked than they generally are in the young of the true breed." Indeed, from his figure, the animal has more the appearance of a Tiger than of a Lion. Writing of the cubs of the first litter in the "Library of Entertaining Knowledge," where one of them was figured, Griffith observes that "our mules, in common with ordinary Lions, were born without any traces of a mane, or of a tuft at the end of the tail. Their fur in general was rather woolly; the external ear was pendant towards the extremity; the nails were constantly out, and not cased in the sheath, and in these particulars they agreed with the common cubs of Lions. Their colour was dirty yellow or blanket-colour; but from the nose over the head, along the back and upper side of the tail, the colour was much darker, and on these parts the transverse stripes were stronger, and the forehead was covered with obscure spots, slighter indications of which also appeared on other parts of the body. The shape of the head, as appears by the figures, is assimilated to that of the father (the Lion); the superficies of the body on the other hand is like that of the Tigress."

Fourth Litter.-Born October 2nd, IS2S, at Windsor; one male and two females.

Fiftı Litter.-Born May, $1 \delta_{3} \mathrm{I}$, at Kensington, three cubs; sexes not recorded. They were shown to the Queen, then Princess Victoria, and to the Duchess of Kent. The whole group performed in a specially constructed cage at Astley's Amphitheatre, and in $I_{3} 32$ were taken by Mr. Atkins for a tour in Ireland.

Sixth Litter.-Born July i 9 th, I 833 , at the Zoological Gardens, Liverpool; one male and two females. One, the male, lived for ten years in the Gardens. The young male Lion-Tigers 
when about three years ord had a short mane, something like that of an Asiatic Lion; and the stripes became very indistinct at that age

Mr. J. Atkins informed Professor Ball that there was a badly stuffed specimen of one cub which was about a year old in the Museum at Salisbury; and there is another in the Cambridge Museum. From an account quoted by Mr. Harmer it would seem improbable that that particular specimen, had it survived, could have bred. As a matter of fact, it appears, indeed, that none of the cubs ever did breed, though there is no known reason why most of them should not have done so.

Mr. Atkins thinks that the cubs of the earlier litters died from over-feeding, as when he adopted a different treatment he had no difficulty in rearing them.

\section{THE TIGER. FELIS TIGRIS.}

Felis tigris, Linn., Syst. Nat. ed. I 2, vol. i. p. 62 (1766) ; Elliot, Monograph of Fclidæ, pl.iii. ( $\left.\delta_{7} \delta-\delta_{3}\right)$; Blanford, Mamm. Brit. India, p. $5^{8}$ ( I 888 ).

Tigris regalis, Gray, List Mamm. Brit. Mus. p. 40 (I $S_{43}$ );

id., Cat. Carniv. Mamm. Brit. Mus. p. ro (1869).

(Plate IV.)

Charasters.-Size approximately the same as that of the Iion. Fur on the body and limbs of Indian and Malayan specimens short, but that on the checks from behind the ears round the sides of the neck elongated in full-grown males to form an imperfect ruff; in Siberian examples the whole fur longer and rougher. 'Tail tapering gradually to the tip, which is devoid of a tuft; equal in length to about half the head and body. Pupil of the eye round. Skull differing from that of the Lion by the features noticed on page 28 . Ground colour of the fur of the upper-parts varying from pale rufous to brownishyellow; under-parts white; the whole of the head and body 
$\geq$
된
4

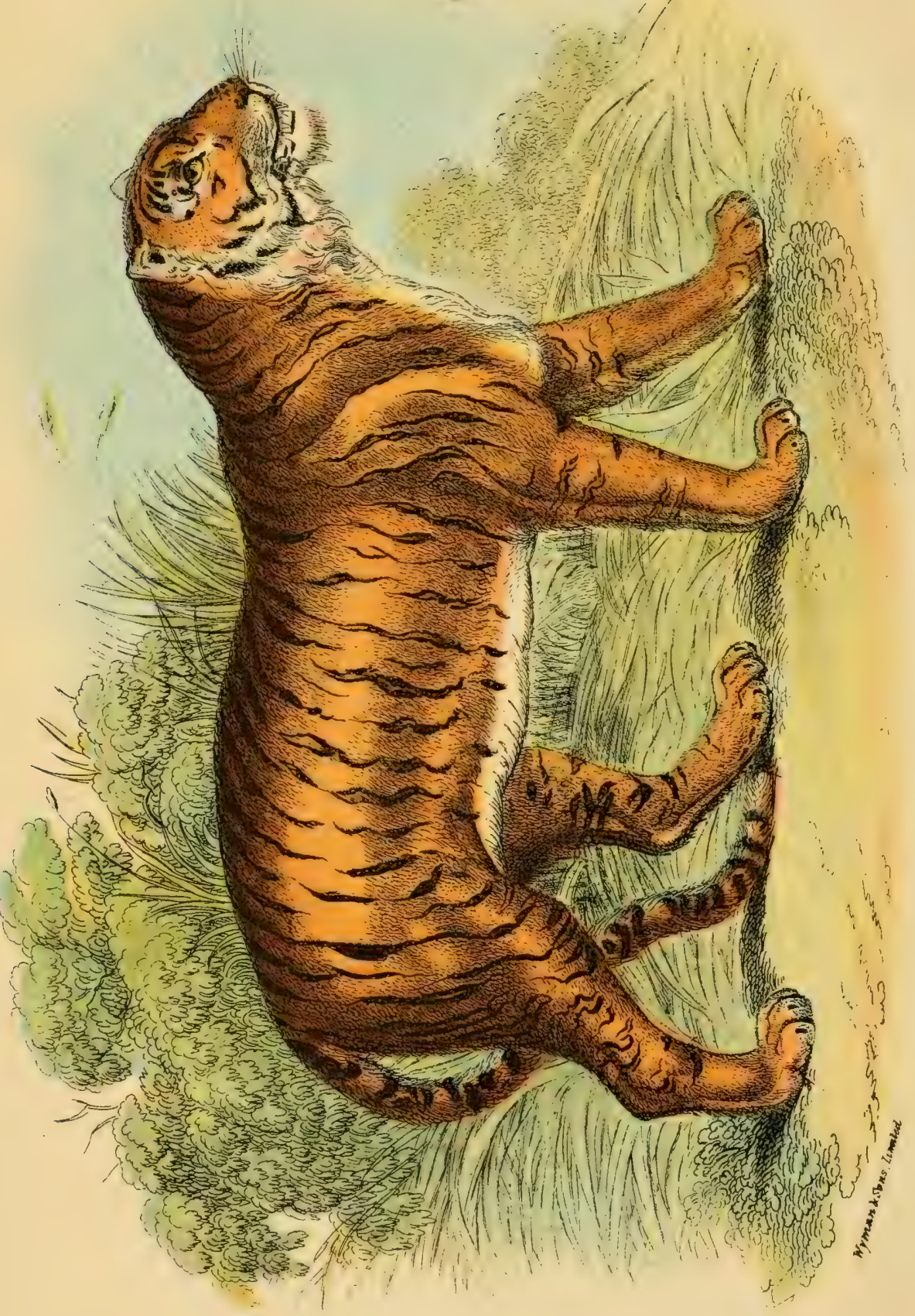


marked by parallel vertical black stripes, and the tail ringed with black. Ears black externally, with the exception of a large white spot. Usual length of large males varying from $8 \mathrm{~T} / 2$ to $9 \mathrm{~T} / 2$ feet, of which 3 feet is occupied by the tail ; but specimens measuring 9 feet I I inches and Io feet 2 inches are on record.

As a rule, old Tigers are less brightly coloured than young

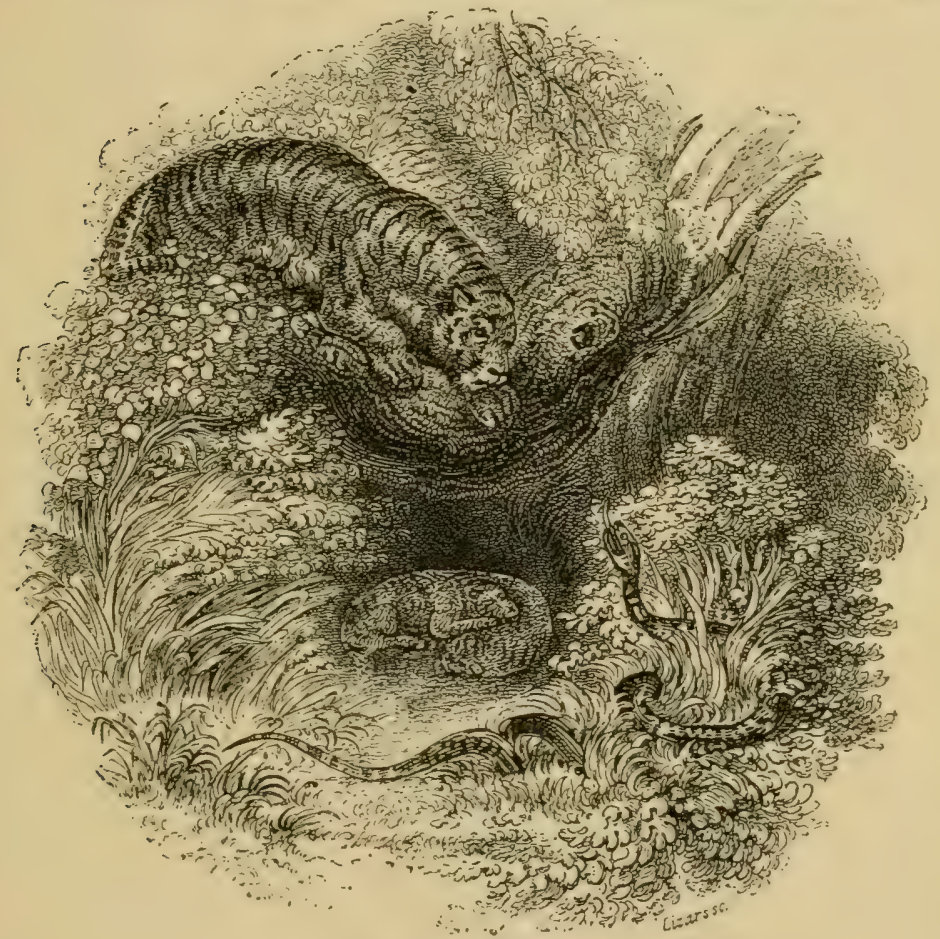

Tiger and Cubs.

ones; while those inhabiting forests appear to have the groundcolour of the fur darker and redder than in those from grassjungles. Although neither black nor white Lions appear to have been recorded, both these colour-variations have been observed in the Tiger. A black example was found dead at Chittagong, North-eastern India, in the year I 846 ; while a pale 
whitish specimen, in which the stripes were very opaque and only visible in certain lights, was cxhibited alive many years ago at Exeter 'Change, and has been figured in Griffith's "Animal Kingdom." Another nearly white specimen, from Northern India, is recorded by Mr. Howard Saunders in the "Proceedings of the Zoological Society" for I89r.

In Central Asia, Siberia, and Amurland the Tiger assumes a more woolly and longer fur-noticeable even in specimens from $\Lambda$ fghanistan, while the ground-colour of the fur is richer, and the stripes of a more jetty blackness. $A$ specimen of the Siberian Tiger, apparently the first brought alive to Europe, was exhibited recently in Hagenbeck's menagerie at Amsterdam. Although an immature animal, with the wintercoat only commencing to grow at the time of its arrival, the hair on the neck was so clongated as to give almost the appearance of a mane; while the tail was almost double the thickness it bears in Indian Tigers. Although apparently less than three years old, this Tiger stood three feet three inches at the shoulder; in the course of three months it grew two inches more, and it was considered likely to rise yct another four inches in stature. As Indian Tigers usually stand from three fect to three feet six inches at the shoulder, it thus seems probable that the Siberian variety attains larger dimensions. Although ferocious in appearance, Hagenbeck's Tiger was in reality of a remarkably gentle disposition, and had probably been reared from infancy by hand.

A certain amount of variation occurs locally even among Indian Tigers; and it appears to be well ascertained that the Bengal animal is larger and more lanky than the race inhabiting the Central Provinces and Southern India; although, according to Mr. Sterndale, the Tiger from the last-mentioned region sometimes has the advantage in an all-round measurement.

Distribution.-From the Caucasus, through Northern Persia, 
Turkestan, Afghanistan, India, Assam, Burma, the Malay Peninsula, Sumatra, Java, and China, to Manchuria and Amurland. In India found almost everywhere, from the Himalaya (where it ascends to the height of 6,000 or 7,000 feet above the searevel) to Cape Comorin ; but unknown in Ceylon. As mentioned above, its absence from the latter island leads to the inference that the Tiger is a comparatively recent immigrant into India from the east or north. It has frequently been stated that the Tiger is found in Borneo; but according to a list of the Mammals of that island published by Mr. Everett in the "Proceedings of the Zoological Society" for 1892 , this is not the case. Sumatra and Java seem, therefore, to mark the limits of its eastern range in this region: a circumstance strongly in favour of its no:thern origin. Associated with those of the Mammoth, fossilised remains of the Tiger have been discovered in the New Siberian Islands, situated some Io within the Arctic Circle, and only slightly to the south of the parallel of the North Cape.

Habits.-Fully equal, if, indeed, not superior to the Lion in strength, activity, and courage, the Tiger is likewise one of the few non-climbing Cats; but it is specially distinguished from its near cousin by its much more silent habits, as well as by its marked partiality for water, in the near neighbourhood of which its lair is always situated. It is this partiality for water that makes Tigers so numerous in the Sandarbans and on Saugor Island, at the mouth of the Hughli, where some of the finest specimens are to be met with. As nocturnal in its general habits as the Lion, the Tiger is a much less sociable animal than the latter, the males generally going about alone, and the sexes only coming together during the breeding-season. Occasionally, however, five or six Tigers have been seen in company; and it appears that these are family-parties which have remained together, instead of dispersing after the usual 
custom. Like the Lion, the Tiger selects but a single partner; although it does not appear to be ascertained whether the union between them is lifelong-like that of the Lion and Lionessor merely temporary. Breeding takes place apparently at almost any season of the year, since young cubs have been taken in India both in March and October, the Tigress generally producing from two to five in a litter, although the number may occasionally reach as many as six. "She is a most affectionate and attached mother," writes Sir Joseph Fayrer, in his volume on "The Royal Tiger of Bengal," "and generally guards and trains her young with the most watchful and attentive solicitude. They remain with her until nearly full-grown, or till about the second year, when they are able to kill for themselves, and begin life on their own account. Whilst they remain with her, the Tigress is particularly vicious and aggressive, defending them with the greatest courage and energy, and when robbed of them, terrible in her rage; but she has been known to desert them when pressed, and even to eat them when starved. As soon as they begin to require other food than her milk, she kills for them, and also teaches them to slaughter for themselves by practising on small animals, such as deer and young calves or pigs. At these times she is wanton and extravagant in her cruelty, killing apparently for the gratification of her ferocious and bloodthirsty nature, and perhaps to excite and instruct the young ones; and it is not until they are thoroughly capable of killing their own food that she separates from them. The young Tigers are far more destructive than the old. They will kill three or four cows at a time; whilst the older and more experienced rarely kill more than one, and this at intervals of from three or four days to a week." In this account it is stated that the cubs reach their full development in the second year, when they generally leave their parent; but according to later observers, the period is nearer three years. Tigresses do not 
appear to breed, at the most, more frequently than once in every two or three years; and it appears that a pair, of which one is a female and the other a male, is by far the most usual number of cubs in a litter. It would seem, however, that a far smaller proportion of males attain maturity than is the case with the opposite sex, since in India adult Tigresses are vastly more numerous than are Tigers.

As mentioned above, it is not uncommon for Tigresses, when pressed or nearly starved, to kill, and even occasionally to devour, their offspring. Tigers, however, appear to kill the cubs still more frequently, and without adequate reason. Although cannibalism appears to be rare, the following instance is recorded by Colonel W. Scott in the "Journal of the Bombay Natural History Society" for I 892. The Colonel wries that on the I 7 th of April in that year he received news "of a Tigress and two fine cubs on a small hill about three miles from my camp, and going out with a friend we had a beat for her, and she was duly shot. The cubs did not appear in the beat at all, but I ascertained from some Bhils that they were about the size of Panthers, and so thinking them too small to be shot at, and too large to be caught alive, we determined to leave them alone, although a congregation of chattering Monkeys round some rocks, half way up the hill, showed very plainly where they were. On the 2 and, my shikari sent in word that he had marked down a Tiger in the same plaze in which the Tigress had been found. I started as soon as I could collect men for a beat, and at the first sound of music out came the Tiger straight for the place where I was posted, giving me an excellent shot. My shikari coming along with the beaters, when he reached the place where he had marked the Tiger down, went to have a look at it, and in a sort of hollow under a rock close by, he came on a dead Tiger-cub, evidently killed that morning, of which the whole of the right hind leg and quar- 
ter had been eaten. There was not a trace of it left anywhere; and the cub had evidently been killed by the Tiger, for there were the marks of its fangs in the throat. On looking about, my shikari found, behind a rock close by, the half-eaten remains of a Goat, and we afterwards found the tracks of the cub having dragged the Goat up the side of the hill to its hiding-place. The theory is that the cub returned to the hill early in the morning, bringing the Goat with him, and whilst he was eating it, the Tiger put in an appearance, and a row ensued which ended in the death of the cub."

Whereas, in the Nipal Terai and the Dehra Dun, Tigers are found in gigantic grass-jungles, which can only be entered on Elephants, in Central and Southern India they frequent densely wooded ravines, of which the banks are often high and precipitous, where they often repose during the daytime on rocky ledges. In such a situation on the Narbada, a Tiger was seen lying by a friend of the writer, who had peered over the edge of the cliff to ascertain its geological structure; needless to say, he promptly selected another site for the continuation of his researches. Tigers are also very fond of the jungle-clad islands and sand-banks in the larger Indian rivers; and in the Sandarbans of Lower Bengal may not unfrequently be seen swimming from island to island. Indeed these animals are never averse to entering the water, in which they have been known to swim very long distances. Whatever be the nature of the country they inhabit, Tigers, like the Indian Elephant, are exceedingly averse to expose themselves to the direct rays of the sun during the hot season, always endeavouring to select the most secluded and shady spot for their daily repose ; this trait indicating in the case of both animals that their ancestors were probably inhabitants of a less burning climate than that of the plains of India. Certain localities seem to be permanently inhabited by Tigers; and when the denizen of 
one of these favoured spots has been killed, or has died in the ordinary course of nature, his place is promptly taken by a newcomer. Preying generally upon animals killed by themselves, although frequently making a meal from any carcase that may lie in their way, and often resorting again and again to their kill till it is in an advanced stage of decomposition, T'igers may be roughly divided, according to the nature of their food, into game-killers, cattle-lifters, and man-eaters ; although, of course, there is no hard-and-fast division between either of these classes. The game-killer preys chiefly upon Deer, Pigs, and Antelopes, although it will also kill Monkeys, Peafowl, and even Porcupines, together with many others of the smaller Mammals; while in populated districts its makes an occasional onslaught on cattle. While young Buffalo and Gaur not unfrequently fall victims to Tigers of this class, adults of both species are commonly left alone; although at times a Tiger will screw up his courage to attack even one of the latter, mostly with successful results. Cattle-lifters are always Tigers inbabiting the neighbourhood of villages; and as they find such animals easy victims, they generally confine their attention to these alone. From the cattle-lifter, a 'Tiger may develop into a man-eater; and as a human prey is still more easily killed and carried off than a Cow or an Ox, a Tiger which has once taken to this kind of livelihood, never forsakes it. The superstitious dread of Tigers, and especially man-eaters, entertained by many Hindu tribes, coupled with the timid nature of many of these tribes, is one reason why so many man-eaters are allowed to carry off their toll of victims with impunity, until a term is put to their existence by the rifle of the European sportsman. Should, however, such aid be not forthcoming, and the ravages of the man-eater become intolerable, it not unfrequently happens that the inhabitants will desert their village, rather than turn out en masse and encompass the destruction of their 
persecutor. Some reference to the enormous destruction of human life by Tigers, and likewise the loss inflicted by them on cattle-owners, is made under the head of the I.eopard.

A Snake seems a rather extraordinary meal for a Tiger, but in the "Journal of the Bombay Natural History Society" for I 893 , Mr. J. D. Inverarity writes that on opening the stomach of a Tigress "he found in it the tail end of a Snake that the Tigress had bitten off and swallowed whole; the portion swallowed measured two feet three inches in length. Though quite fresh, the pattern of the skin was rather spoiled by digestion, and I am not sure what kind of snake it was, but it appeared to me to be a Rock-Snake. There were no teeth marks on it, nor was there any breakage of the bones. It seems somewhat remarkable that a piece of this length should be bolted whole. The natives thought that the Tigress had caught it in the water when she went to drink. I should estimate the piece bitten off at about one third of the Snake's length."

Cattle are killed generally by the Tiger seizing the forequarters with his fore-paws, one of which is generally thrown across the animal's shoulders, while the throat is gripped from below by the jaws; a sudden upward wrench, during which the destroyer sometimes springs to the off side of his victim, results in causing the dislocation of the neck of the latter. Occasionally, however, cattle are seized by the neck; while it is possible that on rare occasions a blow from the powerful paw may be the immediate cause of death. Still more rarely, large animals, such as Gaur and Buffalo, are hamstrung by 'Tigers. In devouring its prey, a Tiger invariably, or almost always, commences its meal on the flesh of the hind-quarters.

Although, as already mentioned, uttered much less frequently, the roar of the Tiger is very similar to that of the Lion; and it has been well described as a prolonged moaning, thrilling sound at the commencement, which is repeated two or three 
times; it then becomes louder and more rapid, and finishes with three or four repetitions of the latter portion. When the animal is suddenly disturbed or surprised, it utters a loud, sharp zunf; when provoked, a growl is emitted; while, in charging, it gives vent to a peculiar gutteral sound, repeated two or three times. It is commonly supposed that when a Tiger is suddenly disturbed by the sportsman, it promptly goes for him forthwith. This, however, is a mistake; and if a Tiger has time to collect its thoughts and see a way of escape, it will promptly avail itself of the same. Generally, however, the animal is as much surprised as the intruder, or even more so; and as the way by which the latter has entered is usually the most obvious road of escape, the Tiger rushes headlong, with a cry of rage, along the path, not unfrequently with only too disastrous results to the unfortunate sportsman.

In the work already quoted, Sir J. Fayrer observes that "the Tiger seems to be particular about the state of his claws; they are always kept sharp and polished, carefully protected within the sheath of integument, and are kept from contact with the ground, and thus remain pointed and clean, being very formidable weapons, with which fearful wounds are inflicted. Probably it is to keep them in order, clean and bright, that the Tiger is so fond of scratching the bark of trees ; and their deep vertical scorings, up to a height of ten or twelve feet, are often seen on the Indian fig or other tree. They have favourites which they select or set apart for this purpose, and the scorings are very deep and numerous. I remember a Ficus venosa by the side of a nut swamp in Parneah, under whose shade I have often rested in the middle of a hot day's Tiger-shooting. It stood alone, and was evidently a favourite resort of the Tigers, for it was deeply and numerously scored by their claws.

"Tigers do not, as a general rule, climb trees; but when pressed by fear, as during an inundation, or when no other 
means of escape offers from real or imaginary danger, they have occasionally been known to do so. They have also been seen to clamber up or even spring to a certain height, where they have scen a man, and whence they thought the shot came, and pull him down. I have heard of authentic instances where this happened. Nor are they wont to spring to any great height from the ground; though an instance occurred recently, reported by an cyc-witness, where a Tiger pulled a native, in one spring, out of a tree at a he:ght of eighteen feet from the ground. The Tiger's usual attack is a rush accompanied by a series of short deep growls or roars, in which he evidently thinks he will do much by intimidation. When he charges home, he rises on the hind-feet, seizes with the teeth and claws, endeavouring, and often succeeding, in pulling down the object seized. Tigers do occasionally leave the ground with a spring, clear a fence or ditch, or even alight on the Elephant's head, his pad, or hind-quarters; but this probably happens in the case of Tigresses or young and active males. The heavy old Tiger seldom, if ever, is so energetic in springing up heights; though he will take a good broad ditch or wall in a bound."

As an instance of the enormous muscular power of the 'Tiger, the same writer goes on to say that on one occasion one of these animals sprang from an elevation at a single bound among a herd of cattle, striking down simultaneously on each side a Cow with his fore-paws. Both Cows were disabled, but whereas the Tiger proceeded to kill and devour the one, the other was left lying with her back broken.

In many districts in India, Tigers were (and in some instances still are) extraordinarily numerous and audacious, and the following account by an anonymous author, taken, with some verbal alteration, from the Asian newspaper of August $3 \mathrm{rd}, \mathrm{IS94}$, of their habits and vagaries in the Cherrapunji 
Hills, on the north-eastern frontier, will be found of more than common interest. "The station of Cherrapunji," writes the narrator, "stands upon a plateau overlooking the plains, surrounded on the three sides by well-wooded ravines, the slopes, or rather cliffs, of which are so precipitous that Deer are seldom found there, and though the Black Bear now and again turns up he generally prefers other lines of country. The visitor to Cherra, in the cold weather, would have been puzzled to account for Tigers patronising the place, but that is easily explained. As the rains set in, almost the whole of the grazing-grounds along the foot of the hills are submerged, though the houses, when not built on piles, are raised on mounds of mud some three to four feet in height, but it would be impossible to keep cattle in the limited area of the raised baree. As the rains approached, therefore, the cattle were driven up to Cherra, upon whose desolate plateau a few inches of rain effects a wonderful transformation scene. These herds were increased by the return of the garrisons of the outposts and stockades for the rains, who also brought their Cows with them, and, as most of the Sepoys owned at least two head, the number of cattle that came up for the benefit of the grass that sprouted so magically after the first shower could not have been far short of $\mathrm{r}, 200$ to $\mathrm{r}, 500$. Hence, washed out of his lair below, and the hillsides being barren, the 'Tiger has no alternative but to follow his commissariat supplies up the mountain; and numerous as these brutes were, it is a marvel that they did not show up in greater force, considering the ample supply of provisions available. The area of the plateau is restricted, and as the central portion was occupied by houses, the grazing-grounds were mostly on the edges of the ravines. On the east side Tigers would lie just below the level, and creeping to the summit with the mists that roll up from the valleys when the hot sun shone down on the sodden 
vegetation, scarce a day passed without one or more Cows falling victims. The western side of the flat had long been abandoned as a grazing-ground, for the coal-mine hill was not only covered with thick second growth but honeycombed with limestone caves and coal-galleries, in which the marauders established their quarters; and so many at one time occupied these refuges that the coal-carriers had to go for their requirements in a body, while, when coal was needed for the mess or officers' bungalows, a guard had to be sent with the coolies. Not that the animals were aggressive in the open, but in the dark recesses of the coal-tunnels, they were apt to resent intrusion, being run into a cul de sac. In addition to the cover named, there were several spots within the station, such as rifts in the sandstone and under slabs, where the brutes could skulk the whole day long, issuing forth in the gloaming to intercept the cattle wending their way home for the night. A Tiger had, indeed, every advantage in Cherra; he fought shy of the traps erected for his special behoof, and, as no trees can be induced to grow on this storm-swept, rock-strewn heath, and machans would be too conspicuous unless you could manage a potshot from the houses, it was difficult to bag one. In the dead of the night people took the yelling of saises from the well-secured stables, as matters of course; and though the roofs of all houses were pitched low on account of the wind, the poaching Tigers were instinctively chary of exposing themselves against the skyline on the ridges; while, owing to the almost incessant rain, clear moonlight nights were the exception; and though few houses were without a trophy in the shape of a hearthrug or two from the hide of the beasts, nearly the whole of these had either been trapped or shot by sheer luck from the bedroom windows or glass-enclosed verandas.

"Many tales have been told of these chance shots, and, though well authenticated, would, to those who had never 
visited Cherra in its prime, be inclined to imagine the relator was drawing freely on his imagination. The sentries, although kept well under cover, were always ordered to load at sunset, for though few people knocked about after dark, unless at dinner-parties, when all went in a body, the native doctor on one occasion, when returning from a sudden call to the hospital, was knocked down opposite the main guard. It being a pouring wet night he, fortunately, had one of those stout Sylhet chattas which saved him, while the sentry let drive through a window, and, though missing, frightened the brute off. The man had a torch in full blaze, but it seemed to have no effect, and as many people imagine that fire will invariably scare a Tiger, I may relate two instances that will prove such is by no means the case. The Officer Commanding the 44th (then the Sylhet L.I.) occupied a house on the very edge of the khud. The place was notorious for being a prowling-ground, as not only were there four Horses and a couple of Cows in the stables, but not far off was the Sheephouse of the station, far too stout a stone building to be burglared; and the shepherds moreover were well armed, having besides their weapons, a pretty good stock of bombs and other fireworks, with a display of which they frequently had to enliven those whose windows commanded a view of the premises. Well, one night in August, when the rain was coming down, as it only knows how to in Cherra, a gentleman was reading in bed, the lamp being on a teapoy placed between his couch and a low window that opened into an unenclosed veranda on the leeside of the house. On the opposite side of the room a bright fire was burning, throwing a strong glare all over and through the window, which had the usual hall horizontal curtain. Once or twice the reader's attention was drawn to a slight noise, but on looking up from his book and noticing nothing he resumed his reading, until a most pro- 
nounced bump against the upper panes caused him to start up, when, to his no small perturbation, there, with his nose pressed against the glass, which the narrow frame prevented his cheek from breaking, stood a full-grown tiger. How long the brute had been there, and what his ultimate intentions may have been, it is impossible to divine, but that the lamp, which was within two feet of him, and the glare of the window full upon him had no deterrent effect upon the gratification of his curiosity is certain. Although the occupant was not quick enough to seize them, guns ready loaded stood against the mantelpiece. So extraordinary was the occurrence deemed that the marks of the animal's paws were allowed to remain on the window-sill until the whole station had seen them; and though most of those who could testify to the correctness of this story have passed away, there are, I think, three still in India who, besides myself, can bear witness to the truth of this statement. The other instance of a Tiger facing fire was at the burning of a Manipuri village near the station of Silchar. We hurried out on ponies to see what assistance we could render; a good many people were about, running to and fro and making the usual hubbub; and the blaze from the burning houses threw a lurid light around for a considerable distance. In the full glare of it were the village cattle, tethered under a shed, when in the midst of the uproar, a Tigress, as it was afterwards found to be, crept up a milla at the back of the shed, bounded in, and made off with a full-grown heifer. But to return to Cherra. Though not aggressive in the daytime the Tigers were rather more familiar than was pleasant, and if, as is mostly the case during the rains, the days were dull and misty, the roads deserted, and your business, or inclination, led you anywhere near the khud, ten to one but what you would see some sneaking cattle-lifter dodging from rock to rock or peeping cautiously from some deep rift. People perambulating their 
own compounds were often stallsed, but from their being no recorded instance of accidents, I fancy that Tigers, like the rest of the Cat-tribe, are imbued with that insatiable curiosity that housewives lament in the domestic puss. The compounds were one and all surrounded with stone walls, some three or four feet in height, and one evening, leaning up against the outside of one of these below the messhouse, while talking to the adjutant and a young civilian, our conversation was brought to an abrupt termination by the former officer suddenly taking to his heels, bolting up the messhouse hill as fast as his legs cnabled him. Left behind we gazed on each other in blank amazement, looked about us and were about to resume our conversation when our friend, having reached his goal, turned round, and though far too exhausted to utter a word, pointed apparently straight at us. 'Something round the corner, may' be,' said my companion, but as we did not know what it might be, we vaulted inside the wall and peeped over, just in time to see a Tiger creeping stealthily along under cover of the wall towards a deep gully.

"A shout soon quickened his movements. It turned out that our friend while talking had caught sight of the brute's face as he peered round the angle of the wall, taking stock of us. Why he did not warn us at the time he started on his flight, he did not seem inclined to explain, but the construction we put on his behaviour was that he preferred saving his own skin at the expense of one or other of us. Dining at the mess was, from its exposed position, rather an infliction, unless you sent your bedding and passed the night there. The compound-wall was rather higher than usual, and as the house occupied a commanding, though solitary, position, with a ruir. between it and the other station-houses, many a startle have people had when leaving the hospitable roof. One night on coming out, I found a Tiger crouched on the walls of the ruin 
aforementioned, and as, instead of bolting, he retained his position, I had to run back. The sentry, a Ghoorka, was in the enclosed portico, but as it was raised some six feet above the beast's lair, he could not see him. With the inherent pluck of his race, however, and heedless of the sin of leaving his post, he accompanied me to the gate from which the animal could be plainly detected in the same position; resting his piece on the coping, and drawing as fine a bead as the uncertain light admitted, the man let fly. A tremendous howl followed, and the wounded beast scuttled off down the very road I had to go. The party residing at the Mess had come out at the report of the sentry's rifle and endeavoured to dissuade me from leaving, but I lighted a torch and sallied forth on my walk of barely 400 yards, waving the torch round and round, thus keeping it in full glow. Nothing occurred on the road, but as I turned into the gateway I almost fell over the prostrate body of the wounded animal, who, as he lay in the list mortal throes right in the path, was qui'e capatle of mischief had I got within his reach. Hastily jumping aside I gained the door and so was safe. The next morning we examined the dead creature, whose lungs were torn to shreds, the bullet lodging in the left hind-leg, yet he had run the above distance in that condition-another instance of the vitality of the Cat-tribe.

"As before said, this house, or rather its environs, was infested by Tigers, and during a residence of nine months, though we caught sight of seven, certainly no dark night passed without unmistakable evidence in the morning of the premises having been visited. Only once did the occupant succeed in bagging an animal from the house; and then only after three previous failures. Twice the visitor put in an appearance at dawn on some rocks well within range, but on both occasions the opening of a door, though the hinges had 
been well oiled, and every precaution taken to avoid attracting attention, the slight creaking, or the mere exposing a gap in the wall, was enough to send the Tiger off his coign of vantage down the khud, amid the brushwood, in which it would have been impossible to detect him, even could one have followed him up quick enough. At length, as he seemed attached to these rocks, we took out one of the panes from the bath-room window, and three mornings after I was roused a little after dawn, and hurried to the scene of action. The rain was coming down heavily, but the animal did not seem to mind it; he certainly presented an unique picture, standing to full height, lashing his sides with his tail, and gazing towards the road down which the cattle from the lines usually came to their grazing-grounds. As he presented his broadside to us, and was certainly not more than thirty yards off, the selection of the vital part was easy enough; the Major fired, while I went to the bedroom window to note the shot. The aim proved true, the ball entering behind the shoulder and lodging in the right shoulder-blade. With a tremendous bound into mid-air, but without any sound so far as we could hear, the Tiger appeared to turn a complete summersault, falling over out of sight. Allowing half an hour to pass, we went down and found him quite dead. Mr. Inglis, a resident in the station, had a pet Sambhar Stag, which was chased all round the house in the most audacious manner in broad daylight by a half-grown male Tiger, and though Mr. Inglis and two guests quickly snatched up guns, it was impossible to fire, as the chased and chaser ran in and out among the outbuildings. Eventually tha Deer dashed into the main entrance, when the Tiger made off, still keeping among the buildings until he had secured a good 'offing,' then turning round to look at his wouldbe destroyers.

"I do not know whether the story has ever been related be- 
fore, but the most comical episode in connection with Cherra Tigers happened, I think, in I 859 . Saturday night's dinner at Inglis' hospitable board had grown into an institution. Coming away from these entertainments, which we did in a body for mutual protection, was rather good fun on account of occasional scares, and as the major portion of the guests lived on the way to the Mess, we saw each other home. The Assistant Commissioner, however, had his house away from all, so left us a few yards from our entertainer's gates, and, being of a somewhat timorous disposition, §enerally brought with him, in addition to his table-servant, a torch bearer for further security, travelling in one of the old-fashioned sedan-chairs carried by a couple of Khasias - a cavalcade sufficient, one would imagine, to frighten the life out of any Tiger. His house was round a bend, and about half a mile distant. One night we parted with him at the junction, where he got into the ancient conveyance, and we each pursued our way, reaching our respective houses in due course. Not so the magistrate, who had scarce reached the bend of the road, when away fled retainers and chairmen, having come suddenly upon a Tiger. The poor man was in fix, for though the chair was stout enough to resist all attempts to open it, the wind was beginning to rise and might not only topple it over, but smash in the panels. The occupant yelled and shouted, but to no purpose; he was far too frightened to come out and make the best of his way home, and at that time of night there was not the remotest likelihood of anyone passing along the lonely road. The best had to be made of matters, and so he passed the night in a dress suit, expecting every moment that the enemy would put in an appearance. Daylight released him at last, but he contracted an attack of rheumatism that lasted his lifetime. Traps were placed all over the station, and a goodly number of Tigers caught in this way, though there is always a feeling of repug- 
nance to resorting to these contrivances on the part of the sportsman. Poisoning the kill had to be very carefully carried out, for Khasias eat both the Tiger and remains of his prey."

Regarding its behaviour in captivity, Jardine, in the original issue of this volume of the "Naturalist's Library," writes that "the Tiger is readily tamed when taken young, but its temper may be said to be scarcely so much depended upon as that of the Lion. Keepers enter the cage and caress them, but they never venture upon those annoying liberties which are generally so freely taken with the Lion; and strangers, I believe, have never attempted to venture within their reach. It may also be remarked, that there is only one instance upon record where the Tiger allowed a Dog to become an inmate of his den. With the Lion it is frequent, and great affection is displayed. On the contrary, however, the inhabitants of India appear to have great power in the management of the Tiger, and it is more frequently seen tame in that country than any of the other Felide. The tame Tigers of the fakirs exhibit great gentleness and confidence, which may in part be attributed to the ample way in which they are fed."

Although many adventurous Indian sportsmen track Tigers to their "kill" or their lair on foot, while others have the patience to endure a long night's watch over a kill or tethered Cow, perched on a machan, or stage, built in some convenient tree, Tiger-shooting is more generally pursued on Elephants, which method, indeed, in the long grass-jungles is the only practicable one. There are, of course, many modern accounts of Tiger-shooting in this manner; but we content ourselves with quoting one given in the early part of the century by Captain Mundy-at that time a well-known Indian sportsman.

After stating the preliminary preparations for the hunt, and the start, the narrator writes that "on clearing the wood, we entered an open space of marshy grass not three feet high; a 
large herd of cattle was feeding there, and the herdsman was sitting under a bush; when, just as the former began to move before us, up sprang the very Tiger to whom our visit was intended, and cantered off across a bare plain, dotted with small patches of bush-jungle. He took to the open country in a style which would have more become a Fox than a Tiger, who is expected by his pursuers to fight and not to run; and as he was flushed on the flank of the line, only one bullet was fired at him ere he cleared the thick grass. He was unhurt, and we pursued him at full speed. Twice he threw us out by stopping short in small strips of jungle, and then heading back after we had passed; and he had given us a very fast trot of about two miles, when Colonel Arnold, who led the field, at last reached him by a capital shot, his Elephant being in full career. As soon as he felt himself wounded, the Tiger crept into a close thicket of trees and bushes, and crouched. The two leading sportsmen overran the spot where he lay, and as I came up I saw him, through an aperture, rising to attempt a charge. My mahout had just before, in the heat of the chase, dropped his ankors, or goad, which I had refused to allow him to recover; and the Elephant, being notoriously savage, and further irritated by the goading he had undergone, became consequently unmanageable; he appeared to see the Tiger as soon as myself, and I had only time to fire one shot, when he suddenly rushed with the greatest fury into the thicket, and falling upon his knees, nailed the Tiger with his tusks to the ground. Such was the violence of the shock, that my servant, who sat behind, was thrown out, and one of my guns went overboard. The struggles of my Elephant to crush his still resisting foe, who had fixed one paw on his eye, were so energetic that I was obliged to hold on with all my strength to keep myself in the howda. The second barrel, too, of the gun which I still retained in my hand, went off in the scuffe, the 
ball passing close to the mahout's ear, whose situation, poor fellow, was anything but enviable. As soon as my Elephant was prevailed upon to leave the killing part of the business to the sportsmen, they gave the roughly used Tiger the coup de grace. It was a very fine female, with the most beautiful skin I ever saw."

Although in this instance the whole party escaped scot-free from the Tiger's charge, such encounters are decidedly risky, and should be avoided when possible. On this subject Colonel R. H. Percy writes as follows in the "Badminton Library": "To hear of Tigers making good their charges and springing on to Elephants' heads sounds very nice and exciting, but nothing is more demoralising to the Elephants, especially at the beginning of a trip, and every precaution should be taken to save your Elephants from getting mauled; for, if injured, many of them never recover confidence, and become absolutely worthless for Tiger-shooting afterwards. Forsyth mentions an instance of an Elephant dying of wounds received from a Tiger. It is all very fine for a sportsman to take a charge, standing in a howda perched on the back of a large tusker; but it is a very different thing for the opium-sodden nerves of an unarmed mahout riding a small timid pad-Elephant. Close order is the only safe formation for pad-Elephants, and should invariably be adopted. If the Tiger is marked into a particular bush, the line may be halted, and the howda-Elephants alone be taken up to engage him; but until the mahouts have thorough confidence in the guns, a fight is better avoided."

Our account of the Tiger may be brought to a conclusion with an extract from Dr. John Anderson's narrative of the expedition to Western Yun-nan, relating to the boldness of a man-eater. "While we were at dinner one evening at Bhamo," writes the narrator, "a cry was raised that a Tiger was in the town, and we at once started with our rifles, and were met by 
a man who inforned us that a woman had been killed; we hurried on, and in a hollow, below a clump of bamboos, came upon the body of the poor woman, over which her niece was crying bitterly. The back of the skull was completely smashed, and part of the scalp torn off. The woman had been sitting in the low veranda of a ground-hut, making thatch, and had evidently been whisked off by one fell swoop of the Tiger's paw, for no marks of the teeth could be discovered. A number of people were seated close beside her, talking loudly; but this only verifies what I have heard about the boldness of man-cating Tigers, that they rather take advantage than otherwise of a noise to secure their prey; and this one, a Tigress, had a decided partiality for human flesh, for she had carried off another woman a year before, when the townspeople attested that she cleared the stockade, nine feet high, with the woman in her mouth. In the present instance she had dragged her prey about fifty yards, but whenever the people discovered what had happened, they rushed from their houses with torches, and, shouting, drove her off. When we arrived, there were fifty men, all armed with spears and guns, and many carried torches, while fires had been lit in every direction, to frighten the brute away. The scene was a most exciting and effective picture; we had the body removed, and beat the thickets, but could discover no trace of the Tigress. The woman was buried the same night, in accordance with the Burmese custom, followed in all cases of persons killed by Tigers. On the following morning we found the tracks of the animal clearly imprinted on fresh bricks laid out to dry, and its sex indicated by the footprints of her cub."

In spite of our having declared the preceding anccdote of Tigers to be the last, we cannot resist quoting a telegram sent some years ago by the Bengali station-master of a small upcountry railway station in India, where a Tiger had taken pos- 

皇

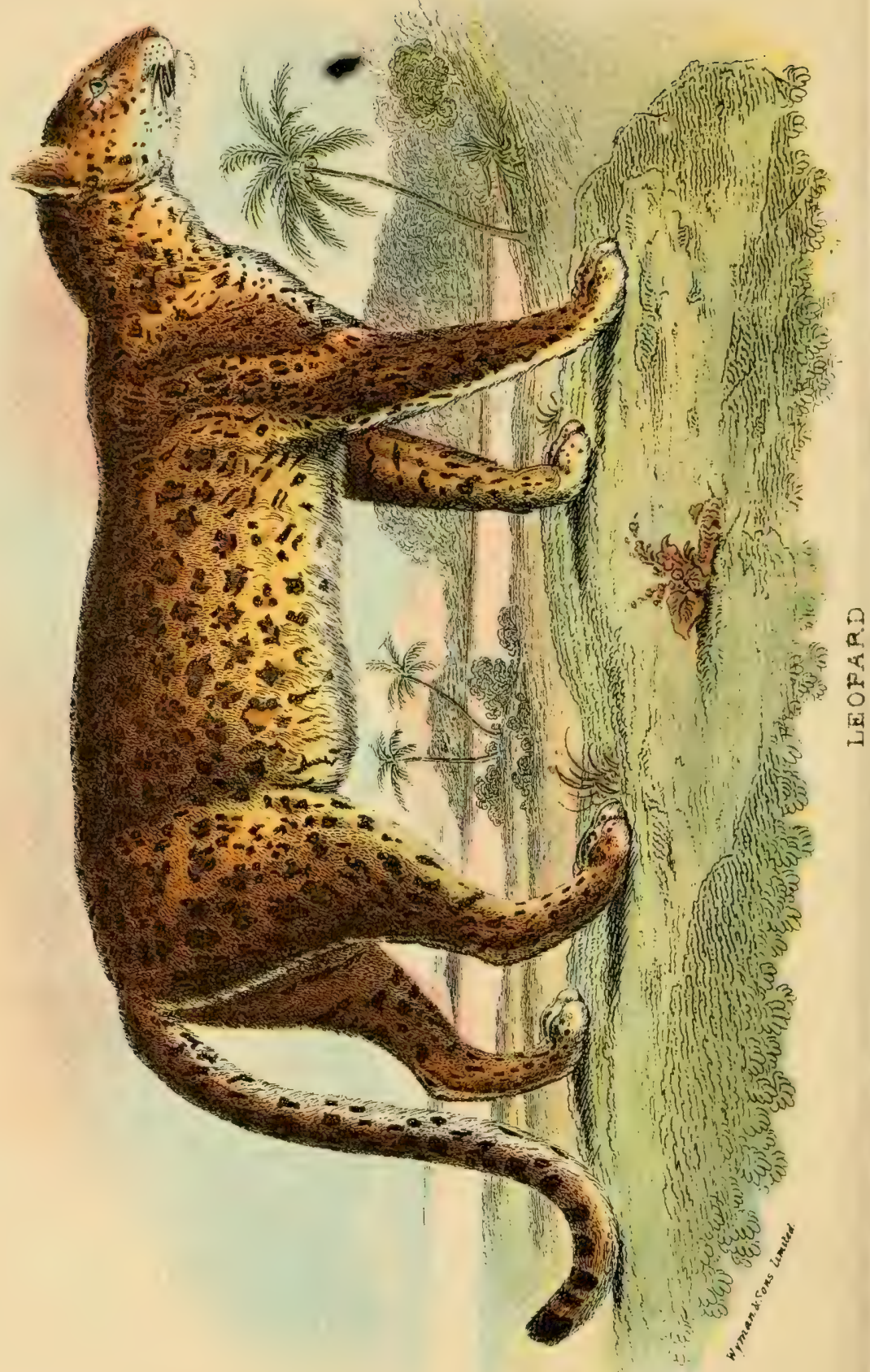


session of the establishment, to the headquarters in Calcutta. The message ran as follows: "Tiger on platform; am safe on roof ; have put signal-man in charge ; please arrange."

\section{THE LEOPARD, OR PANTHER. FELIS PARDUS.}

Felis pardus, Linn., Syst. Nat. ed. г2, vol. i. p. 6r (г766); Elliot, Monogr. Felidæ, pls. vi., vii. (I878-83); Blanford, Mamm. Brit. India, p. 67 (I888).

Felis leopardus, Erxleben, Syst. Règn. Animal, p. 509 (I 777). Felis panthera, Pallas, Zoogr. Rosso-Asiat. vol. i. p. IS (I 8 I I). Felis melas, Desmarest, Mammalogie, p. 233 (1820).

Leopardus v'arius, Gray, List Mamm. Brit. Mus. p. 40 (1843). Felis tulliana, Valenciennes, Comptes Rendus, vol. xliii. p. I039 (I 856).

Leopardus japanensis, Gray, Proc. Zool. Soc. I862, p. 262 ; id., Cat. Carniv. Mamm. Brit. Mus. p. I I (1869).

Felis fontanieri, Milne-Edwards, Ann. Sci. Nat. Zool. ser. 5, vol. viii. p. 375 (I867); id., Recherches Mammif. p. 208 (1868-74); Anderson, Sci. Res. Yun-nan Expedition, p. I62 (1878); Bateson, Proc. Zool. Soc. 1892, p. 106. Leopardus chinensis, Gray, Proc. Zool. Soc. I867, p. 264 ; id., Cat. Carniv. Mamm. Brit. Mus. p. I I (1869). Leopardus pardus, Gray, Proc. Zool. Soc. I867, p. 263 ; id., Cat. Carniv. Mamm. Brit. Mus. p. Io (1869).

\section{(Plate $V$. )}

Characters. - Size large, but very variable, the total length ranging from 5 to $S$ feet; ground-colour of fur normally yellow, upon which are numerous distinct black spots or rosettes; pupil of eye circular; length of tail varying from rather more than half to nearly three-fourths that of the head and body. General ground-colour of upper-parts varying from rufous to yellowish-white, or pale brownish-yellow ; spots or rosettes on upper-parts and superior surface of tail black externally, and 
pale-coloured within, very ariable in form, size, and number, the external ring being generally interrupted, and the central area usually of the same hue as the ground-colour of the fur, although occasionally darker. On the head, lower portions of limbs, under-parts, and extremity of tail, the spots without light centres; those at the tip of the upper surface of the tail taking the form of transverse bars. Young brownish, with the spots indistinctly defined. Skull with broad nasal bones, and the hyoid arch connected with it by ligaments, instead of by a series of small bones.

Distribution.-Africa generally, Asia Minor, Persia, Baluchistan, India, Assam, Ceylon, Burma, Malay Peninsula, Sumatra, Java, and China. During the Pleistocene period the Leopard ranged into Western Europe, where its remains are met with in caverns and superficial formations.

Much discussion has taken place as to whether there is more than a single species of Leopard in India, although all writers seem to be agreed that there is but one in Africa.* It may be mentioned before proceeding farther that the names "Pard" and "Panther" were applied by the ancients to these Spotted Cats, but whether indifferently to these animals in general, or as distinctive specific terms, is not apparent. It does not, moreover, seem at all clear as to whether one or both of these names were first applied to the African or to the Asiatic forms, although it is highly probable that they originally referred to the former.

In addition to the Pard or Panther, the ancients were also acquainted with the animal now commonly known as the Hunting-Leopard; and as this creature was then considered to be a hybrid between the Lion and the Pard it was appro.

The gist of this discussion on the nomenclature and varieties of Leopards originally appeared as an article in "Land and Water." 
priately designated the "Leopard." By a curious misapplication of terms, the name "Leopard" has, however, now been transferred to the Spotted True Cats, and has thus quite displaced the old word "Pard." It would, of course, be utterly hopeless to attempt to reintroduce the latter term, and to restore the term "Leopard" to its original owner; and we are all accordingly agreed to call the True Spotted Cats either Leopards or Panthers.

This transference of the name "Leopard" of course left the animal to which it was originally applied without a distinctive title. To remedy this want, the Hindustani term "Chita" was brought into use in this country to designate the animal which we prefer to call the Hunting-Leopard. Such a use of the term Chita is, however, totally unjustifiable, since that name is applied in India both to the Leopard, or Panther, and the HuntingLeopard, its meaning being merely "spotted." Sometimes, indeed, the Leopard, or Panther, is especially distinguished as the Chita-Bagh (Spotted Tiger), but the simple term Chita is the common attribute of all these animals. It is on this ground that we prefer to reject the Hindustani term altogether, and to employ the English title of "Hunting-Leopard." Attention may be directed here to a statement in the late Mr. G. P. Saunderson's book on the wild beasts of India which we are greatly surprised to meet with in a writer of his Indian experience. It is there written that "of the handsome spotted skins that grace many Indian bungalows, and which are generally referred to as Cheeta skins, at least ninety-nine out of every hundred are those of the Panther or of the Leopard." Now, no one in their senses ever thought that Chita skins in India meant anything else than Leopard or Panther pelts, and we are surprised that Mr. Saunderson actually went out of his way in an earlier sentence of the paragraph quoted to say that the name Chita was incorrectly applied to the Leopard, or Panther. 
As we shall have no more say with regard to the HuntingLeopard, we may dismiss this part of our subject with the following table, showing the various usages of the above-mentioned names :-

Hindustani. Ancient. Modern. Scientific.

Chita $\ldots\left\{\begin{array}{lllll}\text { Leopard } & \ldots & \text { IIunting-Leopard } & \ldots & \text { Cynchurus jubatus } \\ \text { Pard } & \ldots & \text { Leopard } & \ldots & \ldots \\ \text { Panther } & \ldots & \text { Panther } & \ldots & \ldots\end{array}\right\}$ Felis pardus.

This, however, by no means exhausts the subject of the confusion of nomenclatur , for there is an equal discrepancy in the use of the terms Leopard and Panther. As we have already mentioned, there is but one type of these animals in Africa to which it would appear that the name of Panther is probably strictly applicable. In India, on the other hand, two forms are generally recognised. Thus there is, firstly, a large kind, characterised by the tail being shorter than the head and body, by the long head, and by the spots being large and clearly defined, on a pale ground-colour. Secondly, we have a smaller animal, in which the tail is as long as the head and body, the head is short, and the spots are less distinctly defined, of smaller size, and placed closer together.

Now, the latter smaller form was identified by Temminck with the African animal, and accordingly termed the Panther ( $F$. pardus), while the larger kind was called the Leopard ( $F$. leopardus). This usage is followed by $\mathrm{Mr}$. Sterndale in his work on Indian Mammals, and appears undoubtedly to be the right one if we regard the smaller Indian form as indistinguishable from the African animal. On the other hand, we find Jerdon, following the lead of Indian sportsmen, applying the term Panther to the larger form, and Leopard to the smaller one, this usage being adopted by Mr. Saunderson and most other sporting writers. We thus have two diagrammati- 
cal opposite uses of the terms Leopard and Panther, which may be epitomised as follows :-

Temminck.

African form $\quad . . \quad$... Panther

Smaller Indian form $\ldots$ Panther $\ldots$ Panther $\ldots$ Leopard.

Larger Indian form $\quad \ldots$ Leopard $\ldots$ Leopard $\ldots$ Panther.

Now it is admitted on all hands that the larger and smaller Indian forms are very close indeed to one another, Mr. Blanford observing that he finds it frequently impossible to "determine to which of the two supposed forms an Indian skin should be referred." On the other hand, an African skin is, as a rule, distinguished by the spots being very much smaller, and many of them without light centres.

This being so, it may be submitted that if the two Indian forms are regarded as distinct, the African animal is at least equally entitled to distinction. This being admitted, as well as the right of the latter to the title of Panther, it follows that if we take (as appears probably right) the term Leopard as applicable to the larger Indian form, the smaller Indian animal has no name at all!

It is far from our intention to further complicate matters by proposing any new name, or, indeed, for that matter, deciding as to the proper application of the terms Leopard and Panther; our object being merely to show the different senses in which they are commonly used.

We may accordingly pass on to the question as to whether there is really any specific distinction between any or all of the animals above-mentioned. The late Mr. Blyth seems to have been the first of modern naturalists to come to the conclusion that all of them formed but a single species. He was followed, in a somewhat half-hearted way, by Jerdon, and this halfheartedness is even more conspicuous in Mr. Saunderson's book, wherein, while the two Indian forms are spoken of as 
merely varieties of a singlespeses, they are alluded to under separate specific names. On the other hand, Mr. Sterndale is as firmly convinced that there are two distinct Indian species, which he names as above.

With the advantage of all the information accumulated by his predecessors before him, Mr. Blanford-our best and latest authority on Indian Mammals-fully adopts the views of Blyth as to the specific unity of all these forms. We have already alluded to his opinion as to the impossibility of distinguishing between the skins of the larger and the smaller varieties found in India, and he adds the suggestion that even such distinction as there is between these two varieties may, in some cases, be largely due to differences of age. Here it may be mentioned that there is yet another variety, found in Persia, the so-called F. tulliana, characterised by the great length of the fur and the thickness of the tail, this form being, in fact, intermediate in this respect, and also in the shape of its spots, between the ordinary Indian Leopard and the Ounce, or Snow-Leopard. Mr. Blanford sums up the whole question by showing that both the African and the Persian varieties pass by insensible gradations into the ordinary form, and states that he cannot find any difference in the skulls, or evidence to satisfy him that there is any constant distinction between different races of Leopards, Pards, or Panthers. In this conclusion, so far as our own experience admits of our forming a judgment, we fully agree; and we also consider it advisable to adopt the name of Leopard (Felis pardus) for the species of Spotted Cat common both to Africa and Asia. At the same time, we must guard ourselves against it being supposed that we adopt the views of the late Sir Samuel Baker, who seems to consider that every Spotted Cat may be included under the name of Leopard. Thus, when writing on the Leopard, he observes that "different countries adopt special names for the varieties 
which inhabit the localities; the Leopard may be termed a Panther, or Cheetah, or Wild Cat, or even a Jaguar, but it remains a Leopard, differing in size, colour, and form of spots, but, nevertheless, a Leopard. I shall therefore accept that name as including every variety." This, of course, is driving the principle of "lumping" to an absurdity, and if we include a Jaguar under the title of Leopard, we might as well at once class a Tiger and a Puma under the same name.

Leaving, then, those who believe in the distinction between a Leopard and a Panther to assign those terms in the manner which seems to them best, we pass on to consider the chief varieties of these animals.

We have already seen that Asiatic Leopards are characterised by the large size of the spots on the body, which assume a more or less well-defined rosette-like form with a light centre. It appears that the smaller variety of the Asiatic Leopard is the one generally found on the plains of Peninsular India, and is characterised by the small size of the spots and the paler tint of the ground-colour of the fur; these features being generally accompanied by a greater length of tail, and a proportionately short head. On the other hand, the larger Asiatic Leopard, in which the spots are large and distinct, the ground-colour of the fur tending to reddish, and the tail short, more generally frequents the damp forests of Bengal, Assam, the Himalaya, and Burma. A large series of specimens will, however, show a complete transition between these two types.

Occasionally, and more especially in forest-districts at considerable elevations above the sea-level, there is found a black variety of the Asiatic Leopard. These black Leopards, which appear to be more common in Southern India and the Malay Peninsula than elsewhere, were formerly regarded as indicating a distinct species, but the occurrence of both black and 
spotted cubs in one and the same litter clearly shows that they are merely a variety. In certain lights the spots on the skin of a black Leopard can be distinctly seen, owing to the fact that they are of a deeper tinge than the rest of the fur. A white Asiatic Leopard seems to be a very rare creature, although a figure of such an animal is extant.

Secondly, we have the long-haired Asiatic Leopard, of which the leading features have already been indicated; this variety being found not only in Persia, but likewise in the neighbouring district of Baluchistan, and in the mountains of Sind.

Thirdly, there is the African Leopard, readily distinguished by the small size of the body-spots, some of which are often solid, and thus resemble those on the head and limbs of its Asiatic cousin. Curiously enough, it was thought for a long period that there were no black Leopards throughout the length and breadth of Africa. That there are none entirely black seems to be undoubtedly the case; but Dr. Günther has described Leopard-skins from the Albany district, which exhibit a kind of incipient blackness, or melanism. In one of these specimens the blackness takes the form of a broad black stripe, extending from the upper part of the head to the loins; while the tail has an extraordinary number of very small black spots and a black tip. It does not appear that any trace of the spots can be detected in the deep black band on the back. In a second example the blackness was of much larger extent, embracing almost the whole of the skin, with the exception of the under parts of the head and body and the inner surfaces of the limbs. The tail, although not black, is uniformly dark-coloured above. The black portion of the skin presents a beautiful gloss, without the faintest indication of spots.

Writing of the specimen first received, Dr Günther observes that "it is a well-known fact that the Asiatir Leopard ex- 
hibits a decided tendency to melanism; and it is stated that the black Leopards are found chiefly in forest-districts of considerable elevation. So far, the conditions under which melanism appears in the Asiatic Leopard seem to be similar to those under which our specimen was reared. On the other hand, the abnormal coloration affects the ornamental pattern of the Asiatic Leopard in a different fashion from that observable in our specimen. In the former the black colour is equally diffused over the whole body, the rosettes retaining their shape and number, and shining with a more intense black through the ground-colour." It is added that the blackness of these African Leopards may perhaps be considered as an incipient stage of the total melanism of the Asiatic form. We have, however, yet much to learn as to the nature of melanism, and of what advantage (if any) it can be to the individuals in which it is developed.

Since the former of these specimens (which will be found described and figured in the "Proceedings of the Zoological Socicty" for 1883 , p. 244 , pl. xvi.) is so entirely unlike an ordinary Leopard that it might well be taken for a distinct species, or a hybrid, it may be well to quote the original description in extenso. The ground-colour of the fur, writes its describer, "is tawny, with a rich orange gloss about the shoulders. Of the rosettes only a few faint indications are preserved, namely on the haunches, where two are visible on the right side, whilst they form an irregular confluent pattern on the left. Remains of rosettes are also visible on each shoulder, close to the whorls of hairs usually developed in the Leopard and Lion in this place. Two pairs of similar rudimentary rosettes succeed these at intervals of about ten inches. The remainder of the rosettes are broken up into, or replaced by, innumerable small separate spots, which are most distinct on and behind the region of the shoulder, and on the outcr sides of 
the limbs. They are more diffuse on the flanks, where they mix with the ground-colour, producing a brownish tinge. Finally, on the back, from the forehead to the sacral region, they are more or less confluent, so that the whole back appears to be of a black colour, which is most intense above the lumbar region. A few black spots on the upper lip, a conspicuous black spot surrounded by a light yellowish ring above each eye, and a large one on the back of each ear, are present, as in Leopards with typical coloration. On the other hand, the tail differs in a remarkable manner, being fulvous for its first two-thirds, this colour gradually changing into pale grey, and the whole tail being sprinkled with very small and clearly defined spots, while the extreme tip is black. Chin, chest, belly, and inside of the legs white, with large black spots, as in the ordinary Leopard. Whiskers and claws white; hair between the foot-pads black. The hairs are about of the ordinary length, with a very thick under-fur on the sides of the body."

Lastly, we have a very aberrant variety from China known as Fontanier's Leopard ( $F$. fontanieri), regarded by some writers as a distinct species. Not improbably this form is really inseparable from the earlier $F$. japanensis of Gray, founded on a tanned skin procured from a Japanese trader, but which probably came originally from China. Concerning this Chinese Leopard, Dr. J. Anderson, who has devoted great attention to the subject, writes that it "is characterised by the confluence of the black spots, which form rather large complete rings in the adult, as in the Jaguar, but without the central black spot. The fur is also long, soft, and dense. This latter character is also assigned by Swinhoe to the northern race of Chinese Leopards, the fur of which, he states, is confusedly spotted and marked with black rings. Gray also states that the coat of his $F$. japanensis is distinguished by its rounded and unequal- 
sized spots, and by black rings with no central black spot, distributed over the shoulders, back, and sides, while MilneEdwards describes those rings as very distinct on the scapular region, the upper parts of the sides, and the back."

It is added that Professor Milne-Edwards "has pointed out certain characters by which he considers $F$. fontanier to be distinguished from the Leopards of India and Africa, and also from the skull figured by Gray as Leopardus chinensis. He attaches great importance to the short muzzle of the northern Leopard, and states that the distance between the alveolar border of the canine and the summit of the frontonasal process of the maxilla equals the breadth between the external borders of the infra-orbital foramina, while in $F$. pardus the former measurement considerably exceeds the latter; and he records that the relative proportion between these parts is equally observable in the young as in the adult of $F$. fontanieri. I have examined a series of five skulls of $F$. pardus from India, all with reliable histories and of different ages, but without any record of their sex; and although they support the generalisation of the French professor regarding the greater length of the first interval as compared with the second in $F$. pardus, measurements suggest that considerable changes take place with advancing age in the proportions between these two areas of the face in F. pardus, because in the youngest example they are nearly equal, as in $F$. fontanieri, so that these measurements are not very reliable guides to separate the two forms in youth. At the same time, there can be no doubt that in the adult $F$. pardus of India the muzzle is not so deep, but is more elongated than in F. fontanieri, in which the frontals are more arched, with the nasals in the same curve. In Leopardus chinensis, Gray,-a fully adult animal,--there is the same short muzzle as in $F_{0}$ fontanieri." 
As the result of this comparison, Dr. Anderson is led to conclude that the northern Chinese Leopard, if not entitled to rank as a distinct species, is at least a very well-marked race.

In conclusion, it may be mentioned as not a little remarkable, that the only two skulls of this form preserved in the collection of the British Museum, both, as pointed out by Mr. Bateson, exhibit an abnormality in the dentition; the one having a supernumerary last molar on the left side of the upper jaw, while, in the other, the last right lower pre-molar has an additional cusp on its hinder border.

Habits.-In spite of their marked difference in coloration, the three great Cats of the warmer regions of the Old World, namely the Lion, Tiger, and Leopard, are structurally very closely allied to one another. Whereas, however, the two form $2 r$ are not climbers, the third is essentially an arboreal animal, resembling in this respect the majority of the smaller members of the Family. Moreover, according to information kindly supplied by General Paget, there is a marked difference between the Leopard and the Tiger, in the manner in which they commence to devour their prey, the former always beginning on the shoulder of its "kill," whereas the latter invariably takes the first bite at the hind-quarters. Leopards, in common with several others of the larger Cats, attack an animal by springing on its neck. Mr. A. Whyte, who was recently collecting animals in Nyasaland, mentions, however, an instance where a Leopard killed a full-grown denkey by attacking it in the flank and dissmbowelling it. He adds that "another most unusual occurrence in this case was that the Leopard returned to the carcase, and was shot dead on the third night, after having been wounded on the chest the second night with a charge of small shot, which was afterwards found under its skin." The proximity of water is far less essential to Leopards 
than it is to Tigers; and, as a rule, the former animals resort to hilly and more or less broken districts, especially when wellwooded; and, although in many parts of India and Africa numerous in such districts, they are, from their purely nocturnal habits, but seldom seen. Occasionally, however, the traveller on a mountain-path, if accompanied by a Dog, may be surprised by the sudden dash of a Leopard in pursuit of his canine companion, Dogs being a favourite prey of these animals. Capable of hiding completely in a very small amount of cover, Leopards always attack very stealthily, without giving any warning of their proximity by preliminary growls; but when once the attack is determined on, it is made with great suddenness and rapidity, and these animals are said to charge home more frequently than Tigers. Messrs. Nicolls and Eglington write that in South Africa, "except when hunting in couples, it is unusual for them to attack the very large Antelopes, but they are extremely destructive to the smaller varieties, and the young of all, including the Giraffe. When pressed by extreme hunger, Man himself is not free from assault." The victim is invariably seized by the throat. Domestic animals of the smaller kinds are terribly harried by Leopards, and from the ravages inflicted on the flocks of the settlers, these marauders have been pretty well exterminated from those districts of South Africa which have been long settled. A few still remain, however, in the hills and mountains of the Transvaal and Bechuanaland, while farther in the interior they are much more numerous.

When wounded, a Leopard will fight to the last gasp; and on this account the animal is regarded as even more dangerous than the Lion. It is stated, however, that although more men are wounded by Leopards than by either Tigers or Lions, the fatalities caused by the former are less numerous than those due to the latter. 
In addition to I)ogs, Goats, and Sheep, Leopards kill a large number of Jackals, while they are determined foes to Monkeys and Baboons, pursuing the former in India into their haunts in the trees, while the latter they attack among the rocks.

Whatever may be the case in Africa, it is w ll ascertained that, in India, Leopards not unfrequently take to man-eating, and there are many instances on record of the fearful destruction of human life inflicted by such individuals. The following account of one of these man-eating Leopards, which haunted the district of Rampur Bauleah, was recently published in an Indian newspaper. On a certain night the creature broke through the mat-wall of a native hut, and made its way into the interior. Inside the hut were sleeping a man, his wife, two or three women, a goat, and a girl nine years of age. The Leopard seized the girl by the throat, and attempted to drag her through the hole. Being seized tight by the throat, the girl could not scream, but was almost suffocated. The hole was not big enough to allow the girl's body to pass out while the brute held her by the throat, and the Leopard, thereupon, let go his hold upon her throat, and seized her by the foot and dragged her through. As soon as he had let go his hold on her throat, she screamed loudly, awaking the inmates of the hut, and the man, thinking that the goat was being carried off, rushed out with a big stick. The Leopard had, however, carried the girl about a hundred yards before the man came up with her. He then belaboured the animal with his big stick, when the Leopard let go his hold and fled into the jungle. The girl was brought to the medical missionary, but though everything that surgical and medical skill could effect had been done, she was not likely to survive, as her wounds were of a terrible nature. About a year previously the Collector of the same district, with twelve Elephants and a party of Europeans, succeeded in killing another 
man-eating Leopard that had killed about I50 people, some thirty miles from Rampur Bauleah.

Leopards are also not free from the charge of occasionally eating one another, as proved by the following note contributed by Major H. D. Olivier to the "Journal" of the Bombay Natural History Society for I893. The letter runs as follows :

"In I884 I was staying with D., a forest-officer in the Panch Mahals, near to Sodhra. Whilst we were sitting out one evening on the side of a hill, where we had been for a walk, a Panther came along and stood within ten yards of us. D. had a rifle with him, but on my whispering to him that there was a Panther close by him, he turned round so quickly that the Panther saw him and disappeared. IVe decided to tie up a couple of Goats, but nothing came that night except a Hyæna, which D. shot. The next evening, however, D. wounded a Panther, but it was too late to follow it up. During the night we heard one calling for its mate all over the hill, and next morning, whilst searching for tracks, our attention was called by one of the men to something in the fork of a large tree close by, and on nearer inspection this turned out to be the body of the wounded Panther, whose hind-quarters were half-eaten, and the skin, of course, worried. The 'gallant husband' who had performed this act of cannibalism had left the marks of his claws on the tree, where some five feet above the ground he had sprung up on to the trunk.

"Most sportsmen will remember having, in the course of their shooting expeditions, come across trees which, from the marks of blood on some large fork, were evidently regular resorts to which the resident Panther of the neighbourhood was in the habit of taking its prey for consumption, and this tree was a case in point."

To give some idea of the ravages committed by Leopards and Tigers, we may quote from the Government Report for the 
year 1893 , where it is stated the number of cattle destroyed by wild animals and Snakes was 90,253 , compared with 81,658 in the previous year. The total figures are not, probably, ot much value, as such occurrences are frequently not reported, or are ascribed to the wrong cause ; but the figures for damage done by wild beasts are probably more reliable than those regarding Snake-bite. Out of the number $(85$, I3 I $)$ of cattle reported as destroyed by wild animals, the great majority were killed by Tigers and Leopards, the figures $(33,526$ and 34,404 respectively) showing a considerable increase on those of 1892 in each case. Tigers appear to be specially destructive to cattle in Assam, where the number of head destroyed was reported as $\mathrm{I} 2,840$, the next highest figure being $8,7 \mathrm{I} 6$ in Bengal. Leopards destroyed 10,359 cattle in Bengal and 7,765 in Madras.

The number of wild beasts destroyed is returned as 15,309 , as compared with 15,988 in 1892 . The amount paid in rewards for their destruction was Rs. I, $0_{4}, S_{1}$, against Rs. $\mathrm{I}, 07,974$ in 1892 . Rs. 37,024 were paid for destroying $\mathrm{I}, 267$ Tigers, and Rs. 41,236 for destroying 4,088 Leopards.

Unlike both the Tiger and the Lion, the Leopard is a comparatively silent animal; but when surprised, or in a charge, it utters a roar not very dissimilar to that of the former. The cry of the Leopard, which is but very seldom heard, is stated, however, to be quite peculiar. In India the female gives birth to her cubs, which vary from two to four in number, during the months of February and March.

In India, while large numbers of Leopards are captured by the natives in traps, by Europeans they are either shot from machans (platforms supported by poles or built up in trees), being hunted with dogs, when they not unfrequently take to trees, or are beaten out from covert. The following narrative, somewhat abbreviated and amended, by an anonymous author, of 
an exciting Leopard-hunt, is taken from the Asian newspaper of August 25th, I893. On the occasion in question, says the writer, he was sitting in his office, when there rushed in a party of Burmese, with the information that "about a mile faway, close to a village, two men had been coming across the fields, when on passing through a small patch of jungle left as a hedge, one of them had been sprung on by a Leopard, and the other had thereupon cut at the animal with his da una (chopper) and wounded it. The two men had themselves come ; they were scratched about, but not bitten or very badly hurt. I gave them a letter to the Doctor, and then issued invitations to those in the station whom I thought would like to share in the fun. These were McG., B., and J. It was hot, so we got steeds, and arrived on the scene. Open fields enclosed with thorn-hedges, where the hedges met patches of jungle which ran along here and there as a hedge-such was the spot where the villagers had been mauled. We sent the beaters round on to the other side, and posted ourselves, two on one side, two on the other, a thin thorn-hedge running from the jungle in question between us. The first beat in the jungle was unsuccessful, and as the villagers then came along beating the small thorn-hedge, in which one would not have great hopes of finding a hare, we thought there was no chance of finding our Leopard. The villagers thought so too, and came along shouting and jeering, poking about in a desultory sort of way, some getting brave under the circumstances. One of these, on coming to a bit of bush in the hedge which made it look a little more likely, poked his head down and gave a jeer and a prog, and was considerably surprised to hear a reply in the shape of a roar, and still more so, I fancy, to find himself warmly embraced. All the beaters surrounded 'Spots' and laid into him vigorously in the most plucky but confused manner. Poor 'Spots' turned his attention from one to the other and 
had a most exciting time, bey were at him like ants. This was on the opposite side of the hedge to McG. and myself. B. and $\mathrm{J}$. were the men that side, and the former, on hearing the roar and seeing the Leopard come out, stalked up, ready to bag him as soon as the villagers had done with him. This soon happened. 'Spots,' finding things too warm, charged out of the mêlée, and it so happened straight at B., who promptly turned and fled. He was about six feet two inches, and legs in proportion, and through a gap in the hedge I saw first B. flying hard, long legs at their full stride, and the Leopard a good second, with ears back and tail curved. It looked such a close thing for first place that I thought I had better try and handicap 'Spots,' so had a snap shot at him as he flew by. I did not hit him. B. had fled to where J. was ensconced behind a small tree, and when he got there turned at bay and fired with his Snider-carbine in the Leopard's face. He missed him, but it apparently had the effect of turning the Leopard off, and he flew by B. and J. behind their tree.

"The moment B. had fired, he turned to J and implored to be informed as to the mechanism of his intricate weapon, the Snider-carbine. Poor J., with 'how do you open this?' dinned into his ears, said he could have almost kicked the Leopard as it went by, but was so put off by B. that he missed. The Leopard then disappeared, and we accordingly collected the villagers and followed the tracks, which, thanks to open ground and mud, we were able to do. We tracked him for two fields, a considerable distance from the scene of action; and the tracks led into a small hedge of growing bush, which got thicker and thicker till it joined two other hedges and formed a small clump of bush at the junction. I could plainly smell him, and the tracks evidently did not lead out. This time the beaters thought they would like a gun with them, and accordingly I went with them. After scrutiny, we decided 'Spots' 
was in the corner, and so I took up my post about four yards from it, in a direct line. The beaters did not come right between me and the spot, but along the hedge, and threw rocks and mud, and shouted. Behind me I had an ex-dacoit with my tulwar, a great curved thing that would behead an $\mathrm{Ox}$, as I thought it might assist me to bag my enemy and prevent him bagging me. I myself was armed with my Martini-Henri sporting rifle. Another of my entourage, a tall big Burman, who has stuck to me ever since, had got mixed up with the beaters. He carried his own $d a$. After a little persuasion, out came 'Spots,' very angry, showing sideways to me and towards the beaters, who vanished. The tall Burman, however, seemed to have made up his mind not to fly, and stood his ground almost directly in front of me, and on the very edge of the bush in which the animal was, and as it jumped out it passed him in its spring. He held his $d a$ with both hands and gave a blow with no apparent effect, and then, instead of clearing out of the way, bent down on his hands and knees in a stooping posture. The Leopard, on landing from his spring and seeing all fled before him, and receiving the blow, turned round and promptly sprang on him. All this, however, passed like a flash almost, as I stood at full tension ready to get a clear shot. There presented to my eye was the Burman, doubled up, with the Leopard resting one paw on his head, another across his shoulders, his mouth wide open as if to seize him by the back of the neck, and his hindlegs on the ground. My mind was made up in a moment; as quick as my eye could take it in I up and let fly. Bangsmoke, and Leopard rolling over the man's head sideways, kicking; the man rising slowly, not quite sure whether he was whole or not. To make matters sure, as poor 'Spots' did not seem as dead as might be, I stuck my dagger into his throat. The Leopard was hit in the head, just about the joining of the 
jaw, and I am not sure whether he was dying, or only unconscious, although probably done for."

In captivity, writes Jardine, I.eopards "have in a few instances bred in this country; but not so frequently as either the Lion or Tiger. The pair which were in the Tower in 1829 were of very different dispositions ; and in this they resembled their congeners, for scarcely two are found which can be equally trusted. The male, notwithstanding very kind treatment, continued sullen and savage, while the female suffered herself to be patted and caressed by the keepers. She possessed a singular propensity, however, for the destruction of umbrellas, parasols, muffs, hats, and such other articles of dress as happened to come within her reach, seizing them with the greatest quickness, and tearing them into pieces, almost before the astonished visitor had become aware of his or her loss."

Although it has been several times quoted, the following account of a tame I.eopard at Coomassie, communicated by Mrs. Bowditch, is sufficiently interesting to bear, in an abbreviated form, one more repetition. The animal in question was sent to Mr. Hutchison, then resident at Coomassie, who, "observing that the animal was very docile, took pains to tame him, and, in a great measure, succeeded. When he was about a year old, Mr. Hutchison returned to Cape Coast, and had him led through the country by a chain, occasionally letting him loose when eating was going forward, when he would sit by his master's side, and receive his share with comparative gentleness. Once or twice he purloined a fowl, but easily gave it up to Mr. Hutchison, on being allowed a portion of something else. On the day of his arrival, he was placed in a small court, leading to the private rooms of the Governor, and, after dinner, was led by a thin cord into the room, where he received our salutations with some degree of roughness, but with perfect good-humour. On the least encouragement, he laid his paws 
upon our shoulders, rubbed his head upon us, and his teeth and claws having been filed, there was no danger of tearing our clothes. He was kept in the above court for a week or two, and evinced no ferocity, except when one of the servants tried to pull his food from him ; he then caught the offender by the leg, and tore out a small piece of flesh; but he never seemed to owe him any ill-will afterwards. He one morning broke his cord, and, the cry being given, the castle gates were shut, and a chase commenced. After leading his pursuers two or three times round the ramparts, and knocking over a few children by bouncing against them, he suffered himself to be caught, and led quietly back to his quarters, under one of the guns of the fortress.

"By degrees the fear of him subsided; and orders having been given to the sentinels to prevent his escape through the gates, he was left at liberty to go where he pleased; and a boy was appointed to prevent him from intruding into the apartments of the officers. His keeper, however, generally passed his watch in sleeping; and Sai, as the Panther was called, after the royal giver, roamed at large. On one occasion he found his servant sitting on the step of the door, upright, but fast asleep, when he lifted his paw, gave him a blow on the side of his head, which laid him flat, and then stood wagging his tail, as if enjoying the mischief he had committed. He became exceedingly attached to the Governor, and followed him everywhere like a dog. His favourite station was at a window of the sitting-room, which overlooked the whole town; there, standing on his hind-legs, his fore-paws resting on the ledge of the window, and his chin laid between them, he appeared to amuse himself with what was passing beneath. The children also stood with him at the window; and one day, finding his presence an incumbrance, and that they could not get their chairs close, they used their united efforts to pull him down by the tail, 
"This interesting animal as well fed twice every day, but never given anything with life in it. He stood about two feet high, and was of a dark yellow colour, thickly spotted with black rosettes; and from the good feeding, and the care taken to clean him, his skin shone like silk. The expression of his countenance was very animated and good-tempered, and he was particularly gentle to children. He would lie down on the mats by their side when they slept, and even the infant shared his caresses, and remained unhurt. During the period of his residence at Cape Coast, I was much occupied by making arrangements for my departure from Africa; but generally visited my future companion every day, and we, in consequence, be came great friends before we sailed. He was conveyed on board the vessel in a large wooden cage, thickly barred in the front with iron. Even this confinement was not deemed a sufficient protection by the canoe-men, who were so alarmed at taking him from the shore to the vessel, that, in their confusion, they dropped cage and all into the sea. For a few minutes I gave up my poor Panther as lost; but some sailors jumped into a boat belonging to the vessel, and dragged him out in safety."

After having safely survived the long voyage to England, Sai was eventually deposited in the menagerie at Exeter 'Change, where he unfortunately died after a few weeks' confinement.

\section{THE OUNCE. FELIS UNCIA.}

Felis uncia, Schreber, Säugethiere, vol. iii. p. 386 (г778); Elliot, Monog. Felidæ, pl. iv. (1878-83); Blanford, Mamm. Brit. India, p. 7I (I888).

Felis irbis, Ehrenberg, Ann. Sci. Nat. vol. xxi. p. 394 (1830).

Leopardus uncia, Gray, List Mamm. Brit. Mus. p. 4I (1843). 

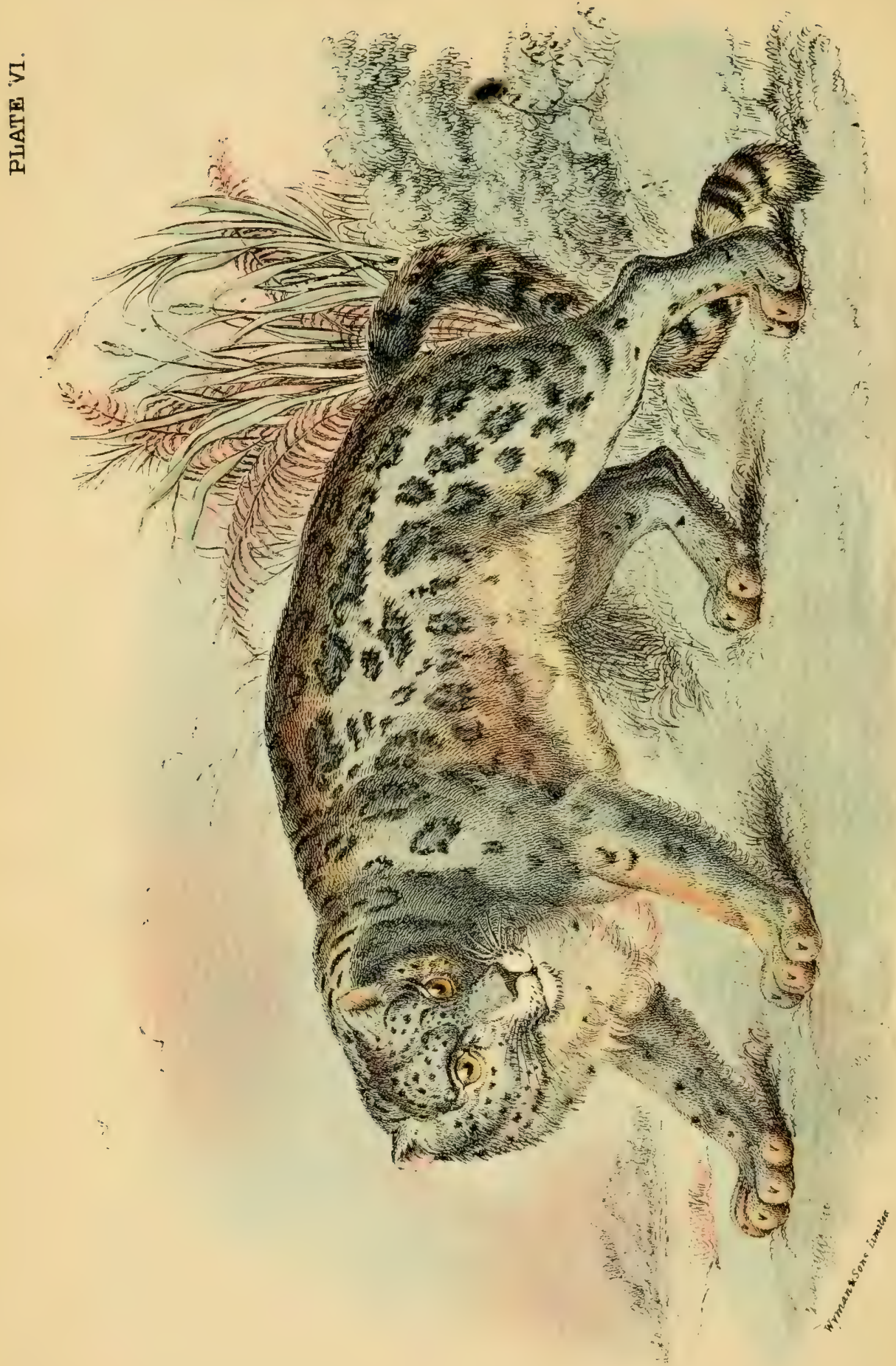
Uncia irbis, Gray, Ann. Mag. Nat. Hist. ser. 2, vol. xiv. p. 394 (1854); id., Cat. Carniv. Mamm. Brit. Mus. p. 9 (I 869).

Felis uncioides, Horsfield, Ann. Mag. Nat. Hist. ser. 2, vol. xvi. p. 105 (1855).

\section{(Plate VI.)}

Characters. - Although in respect of coloration and the length of the pelage, the light coloured variety of the Leopard ( $F$. tulliana) is somewhat intermediate, the Ounce, or SnowLeopard, may be distinguished from the Leopard by the following characters.

Ground-colour white, with the spots larger and not well defined, except on the head. Skull with a more swollen palate, flatter tympanic bulla, and the nasals shorter and more like those of the Lion.

Tail thick, scarcely tapering, and about three-quarters the length of the head and body. "The spots on the back, sides, and tail are large black interrupted rings or rosettes of rather irregular shape, much larger than in Leopards, the space inside each ring being usually rather darker than the ground-colour; spots on the head, limbs, and terminal portion of the tail without pale centres; those on belly few in number and rather indistinct. From near the middle of the back to the root of the tail is a median dark band. Ears black, each with a large yellowish spot." (Blanford.)

Distribution.-All the high ranges of Central Asia, including Gilgit, Hunza, Turkestan, Trans-Baikalia, Amurland, and Western China; generally at elevations of over 8,000 feet, although in Gilgit descending as low as 6,000 during the winter. It is also supposed to occur in Persia.

Habits.-From the arid and inaccessible nature of the country where it dwells, not much is known of the mode of life of the 
Ounce; and the creature is but seldom even seen by European sportsmen. It is known, however, to prey largely upon the smaller kinds of wild Sheep, such as the Bharal and the Sha, a well as upon Ibex; and from its partiality for the flesh of the first-named of these three animals, in the Simla district the Ounce is commonly known as the Bharal-Hay, or BharalTiger. Domestic Sheep, Goats, and even Ponies, also fall victims to the Snow-Leopard; and Colonel R. H. Percy relates that a farm belonging to the Moravian mission at Kailing, in Lahul (where the present writer once enjoyed a welcome rest on his return from the desert altitudes of Tibet), was much harassed by a pair of these Leopards, one of which was eventually shot by an officer of the Royal Artillery. The writer last mentioned states that in 1874 a sportsman in the Pangi district, on the Chinab, came across the bodies of five or six male Ibex lying within a few yards of each other; all of which had doubtless been killed by Snow-Leopards. From the number of Ibex destroyed in this instance, it is highly probable that the Ounce hunts in couples.

Till within the last few years the Ounce was known to European naturalists only by skins and skulls; b'ut recently importers have been successful in bringing this fine Carnivore to Europe. The first living example brought to England was a young animal from Bhutan, purchased by the Zoological Society in I891. In spite, however, of every care and attention it did not long survive its arrival at the Gardens in the Regent's Park. A second and older specimen was, however, received in the same menagerie at the beginning of 1894 . During the voyage to England this Leopard became a favourite of the ship's cook, by whom it was taught to drink tea and milk; although its favourite food was mutton-broth. A third Snow. Leopard was living in the Zoological Gardens at Amsterdam during 1893 . 



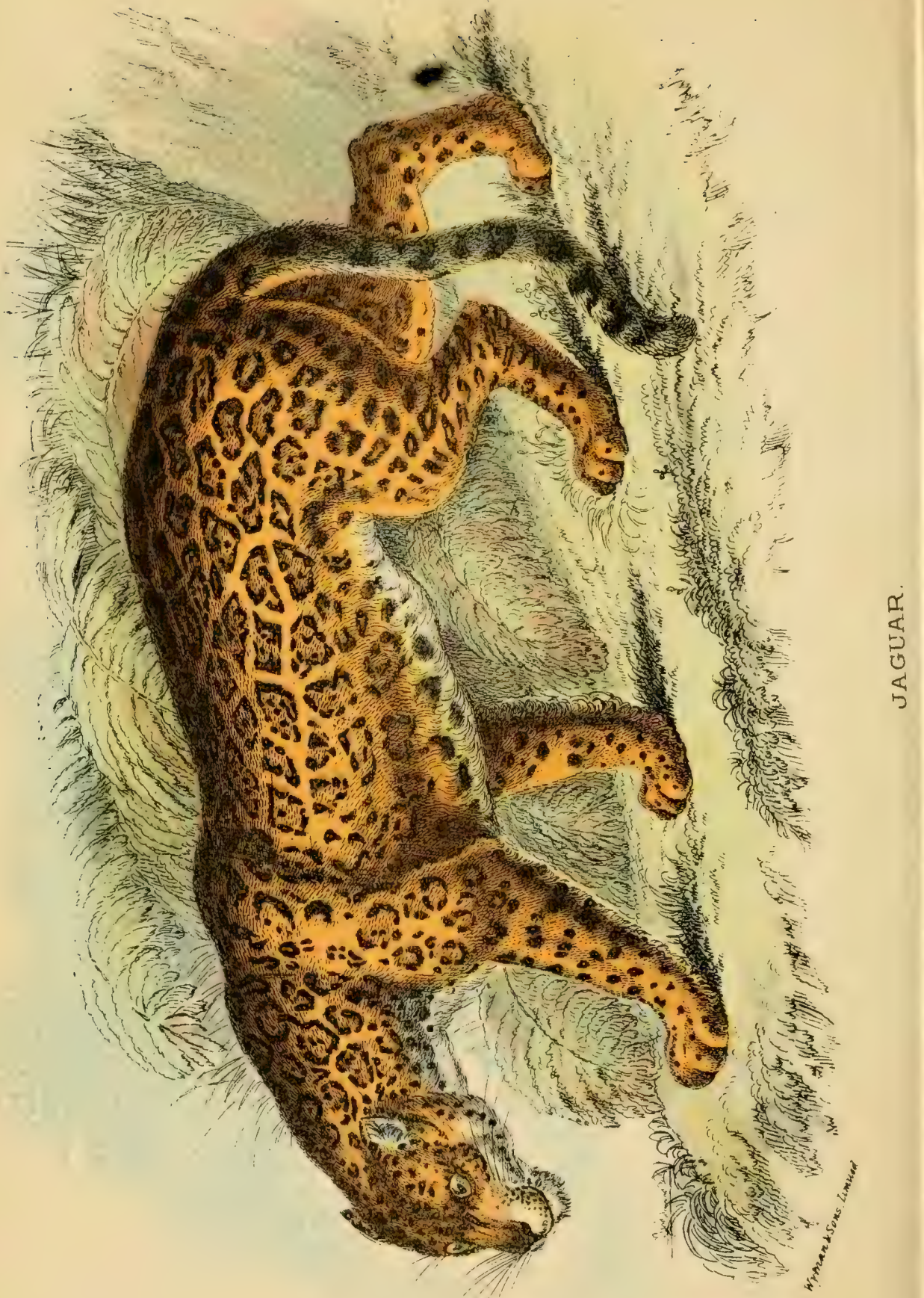


A specimen killed by Captain Dawkins in $\mathrm{ISS}_{4}$ measured 5 feet II $1 / 2$ inches in total length; of which 36 inches was occupied by the tail. In this instance, therefore, the length of the tail was a fraction in excess of that of the head and body. Another specimen, in which the tail also measured $3^{6}$ inches, had a total length of 6 feet 4 inches; while Sterndale gives the total length of a very large individual as 7 feet 4 inches, out of which 3 feet were taken up by the tail.

\section{THE JAGUAR. FELIS ONCA.}

Felis onca, Linn., Syst. Nat. ed. I2, vol. i. p. 6r (г766); Elliot, Monograph of Felidæ, pl. v. (1878-83).

Leopardus hernandesii, Gray, Proc. Zool. Soc. I857, p. 278. Leopardus onca, Gray, op. cit. 1867, p. 264, and Cat. Carniv. Mamm. Brit. Mus. p. I I (I S69).

Uncia onca, Cope, American Naturalist, vol. xxiii. p. I43 (1889).

\section{(Plate VII.)}

Characters.-Size equal to, or perhaps rather superior to, that of the Leopard. Culour and markings generally similar to those of the latter, but the dark rings larger and arranged more definitely in groups, each ring generally enclosing one or more dark spots, and its enclosed light area being of the same hue as the general ground-colour of the fur, which is typically of a rich tan. On the sides of the body the rosettes are usually arranged in seven or eight more or less definable longitudinal rows. Considerable variation exists, however, in the coloration, specimens having been described in which the fur is blackish-brown, with the markings of a still deeper shade, while other individuals are completely black. These dark specimens appear to be most common in the northern parts of South America, whereas, in the southern portions of the animal's range, a yellow or even whitish tinge not un- 
frequently occurs; one mple described by Azara being so pale-coloured that the rosettes were only visible in certain lights.

Pupil of the eye round. Skull distinguished from that of either of the preceding species by the presence of a distinct tubercle of variable size in the middle of the inner side of the rim of the orbit. Length usually about 6 feet 2 inches, of which about 2 feet $I$ inch are taken up by the tail.

Our illustration is taken from the skin of a very fine specimen, in which the markings were of a deep chocolate-brown, upon a yellowish ground, and were remarkable for their clearness. Along the middle line of the back there was almost a line of open spots, only occasionally interrupted, and the next two lines were of an oval or diamond shape, producing a very beautiful appearance. Upon the sides the rings became more defined and distinct, and many of them possessed the small spot or spots in the centre, forming one of the characters of the species.

The skin forming the type of Leopardus hernandesii came from Mexico, and indicates a variety or local race of the species distinguished by the distance at which the small spots are placed from one another, so that it is only here and there that they form anything like a distinct ring or row.

Distribution.-America; from Louisiana, Texas, and Northern Mexico to about the Rio Negro, on the northern confines of Patagonia, in latitude $40^{\circ} \mathrm{S}$.

Habits.-Although in the greater part of its range the Jaguar is an inhabitant of vast primeval forests, where it climbs among the branches with the facility and agility of a Monkey, yet it was formerly found in considerable numbers on the open grassy pampas of Argentina, where, however, it has now been well nigh exterminated. Throughout South America, the 
Jaguar is commonly known as the Tiger (Tigré of the Spaniards).

In Paraguay, writes Darwin, "the wooded banks of the great rivers appear to be the favourite haunts of the Jaguar; but south of the Plata I was told that they frequented the reeds bordering the lakes : wherever they are, they seem to require water. Their common prey is the Capybara, * so that it is generally said, where Capybaras are numerous, there is little danger from the Jaguar. Falconer states that near the southern side of the mouth of the Plata there are many Jaguars, and they live chiefly on fish; this account I have heard repeated. On the Parana they have killed many woodcutters, and have even entered vessels at night. There is a man now living in the Bajada, who, coming up from below when it was dark, was seized on the deck; he escaped, however, with the loss of the use of one arm. When the floods drive these animals from the islands, they are most dangerous. I was told that a few years since a very large one found its way into a church at Santa Fé, two padres entering one after another were killed, and a third, who came to see what was the matter, escaped with difficulty. The beast was destroyed by being shot from a corner of the building, which was unroofed. They commit also, at these times, great ravages among cattle and horses. It is said that they kill their prey by breaking their necks. If driven from the carcase, they seldom return to it. The Gauchos say that the Jaguar, when wandering about at night, is much tormented by the Foxes yelping as they follow him. . . . The Jaguar is a noisy animal, roaring mu h by night, and especially before bad weather."

In Uruguay trunks of trees were observed by the same traveller to be marked with scorings made by the claws of

* An aquatic Rodent, the largest living representative of its Order, and the sole member of the genus Hydrocharus. 
Jaguars. In reference to the statement as to the former abundance of these animals in the neighbourhood of the Rio de La Plata made in the foregoing account, it may be observed that the Rio Tigré, a short distance from Buenos Aires, probably derives its name from the numbers of Jaguars which once haunted the beautiful willow-woods with which its valley is fringed. Although from Darwin's account, it would look, at first sight, as if the attacks on the woodcutters and the man on board ship were unprovoked, yet the general testimony of observers is to the effect that, unless when pressed by hunger, as in the case of the priests in the church at Santa Fé, the Jaguar does not generally make unprovoked attacks on human beings. Indeed, from the fact that in the Argentine, where many individuals used to be seen with their backs lacerated from such attacks, the Jaguar allows himself to be attacked and beaten by its smaller cousin the Puma, we may regard it as somewhat of a cowardly creature than otherwise.

As confirming the fishing propensities of the Jaguar referred to in Darwin's account, we may quote the following passage from Humboldt's narrative of his experiences on the Orinoco, where he writes that "we were shown large shells of Turtles emptied by the Jaguars. These animals follow the arrans towards the beaches, when the laying of eggs is to take place. They surprise them on the sand; and in order to devour them at their ease, turn them in such a manner that the under shell is uppermost. In this situation the Turtles cannot rise, and as the Jaguar turns many more than he can eat in one night, the Indians often avail themselves of his cunning and malignant avidity. When we reflect on the difficulty that the naturalist finds in getting out the body, without separating the upper and under shells, we cannot enough admire the suppleness of the Tiger's paw, which empties the double armour of the arraus is if the adhering parts of the muscles had been cut by means 
of a surgical instrument. The Jaguar pursues the Turtle quite into the water, when not very deep. It even digs up the eggs; and, together with the Crocodile, the Herons, and the Galli. nago Vulture, is the most cruel enemy of the little Turtles recently hatched." Jaguars have also been known to prey on Alligators and Caimans.

In another part of his narrative the traveller last-mentioned relates how "two Indian children, a girl and a boy, the one about seven, the other about nine years old, were at play on the outskirts of the same village, when a large Jaguar, about two o'clock in the afternoon, came out of the woods and made towards them, playfully bounding along, his head down and his back arched, in the manner of a cat. He approached the boy in this way, and began to play with him; nor was the latter even sensible of his danger, until the Jaguar struck him so hard on the head with his paw as to draw blood, whereupon the little girl, with a small switch, which she had in her hand, struck him, and he was already bounding back again, not at all irritated, to his retreat, when the Indians of the village, alarmed by her cries, came up to them."

Regarding the strength of the Jaguar, a remarkable account is given by Azara, and as the statements of this naturalist are in general thoroughly trustworthy, it may, in all probability, be regarded as true. He states that on one occasion when shooting on the plains of Paraguay or the Argentine, he was informed that one of these animals had just killed a Horse. Proceeding to the spot indicated, he found the victim partially devoured, but no trace of the Jaguar, and the carcase was accordingly dragged near a tree, to which Azara proposed to return. Scarcely, however, had he gone half-a-mile, when he was overtaken by the man left to keep watch, with the information that the Jaguar, after swimming a broad river, had taken up the carcase in his mouth, and, after dragging it along. 
without apparent effort for seventy paces, re-entered the river, and swam with the burden to the opposite bank. Azara states that although he did not follow across the river, he saw the marks where the Horse had been dragged down to the bank.

By night, especially during the breeding-season, the Jaguar's roar is constantly to be heard, and it has been compared to the syllables $p u, p u, p u$, very frequently repeated, and uttered in a very deep and hoarse tone. The cubs are born about December, and vary from two to four in a litter, the percentage of females being greater than that of males. The fur of the cubs is longer and less smooth than that of the adults, with the markings ill-defined. It is said that they will follow their dam when only about a fortnight old, at which age they are about the size of an ordinary Cat. When irritated, the cubs mew and snarl like a Cat, wrinkling the forehead, opening the mouth, and moving the tip of the tail slowly from side to side. According to Azara, a Jaguar never ascends a perpendicular treetrunk; neither does he descend from those which are inclined by a spring, but walks or runs down, in the same manner as he ascended, like a Cat.

In the wooded districts of Paraguay and the neighbouring countries, Jaguars were formerly hunted with large packs of Dogs, by whom they were generally driven up a tree, where they could easily be shot. On the open pampas the animal is more generally lassoed, the Gaucho who has first lassoed it setting off at a gallop, and dragging the animal after him, until a comrade can succeed in throwing another noose round the hind-limbs, when the unfortunate creature is killed by the two men pulling in opposite directions.

When these animals were abundant on the Argentine pampas, Mr. IV. H. Hudson relates that at Saladillo, a "Gaucho had so repeatedly distinguished himself by his boldness and dexterity in killing Jaguars, that he was by general consent made the 
leader in every Tiger-hunt. One day the Commandante of the district got twelve or fourteen men together, the Tiger-slayer among them, and started in search of a Jaguar which had been seen that morning in the neighbourhood of his 'estancia.' The animal was eventually found and surrounded, and as it was crouching among some clumps of tall pampas-grass, where throwing a lasso over its neck would be a somewhat difficult and dangerous operation, all gave way to the famous hunter, who at once uncoiled his lasso and proceeded in a leisurely manner to form the loop. While thus engaged, he made the mistake of allowing his horse, which had grown restive, to turn aside from the hunted animal. The Jaguar, instantly taking advantage of the oversight, burst from its cover and sprang first on to the haunches of the horse, then seizing the hunter by his poncho, dragged him to the earth, and would no doubt have quickly despatched him, if a lasso, thrown by one of the other men, had not closed round its neck at this critical moment. It was quickly dragged off, and eventually killed."

The same writer tells that on another occasion a party of Gauchos started a Jaguar on the pampas, which tonk refuge in a patch of dry reeds. Being unable to lasso the animal, they set fire to the reeds, in the natural expectation that it would break covert. To their astonishment and disgust, the Jaguar, however, whose eyes could be seen glaring among the reeds, preferred to perish miserably in the flames and smoke, rather than face an encounter in the open.

VI. THE PUMA. FELIS CONCOLOR.

Felis concolor, Linn., Mantissa Plantarum, p. 52 ( 777 I); Elliot, Monogr. Felidæ, pl. ii. (1878-83); Mivart, The Cat, p. 397 (I88 I); True, Rep. U.S. Nat. Mus. I888-89, pp. $59 \mathrm{I}-608$ (1891).

Felis couvuar, Lesson, Man. Mamm. p. I 90 (1827).
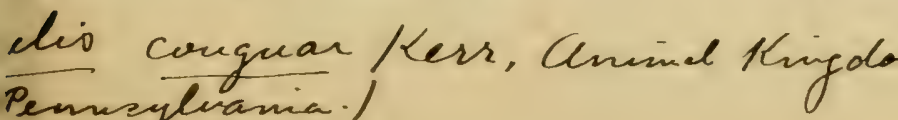
Felis unicolor, Lesson, loc. cit.

Leopardus concolor, Gray, List Mamm. Brit. Mus. p. 43 (1843); id., Cat. Carniv. Mamm. Brit. Mus. p. I 2 (1869)

Uncia concolor, Cope, American Naturalist, vol. xxiii. February, p. I93 (I889).

\section{(Plate VIII.)}

Characters.-Size somewhat inferior to that of the Jaguar. General colour of fur tawny, tending to whitish on the underparts; but the summer coat tending more to a reddish, and the winter one to a greyish hue. Middle line of back darker than the sides, and the end of the tail dusky-brown. Ears black externally, with a central whitish area; upper lip white from the nostrils to the middle of the mouth, where there is a conspicuous black spot; nostrils flesh-coloured. Pupil of eye circular when contracted. Skull of great vertical depth, connected with the arch of the hyoid bone by a chain of bones, as in the Domestic Cat. Total average length about 7 feet I inch, of which $2 \mathrm{~T} / 2$ feet are taken up by the tail. Cubs with the upper-parts and limbs marked with large blackish-brown spots, and the tail ringed with the same colour; these markings disappearing in about six months after birth.

There is considerable individual variation in the coloration of the Puma, but this has not yet been correlated with local distribution. Burmeister, in his "Description of the Argentine Republic," remarks that "very rarely individuals of this species of a brown or nearly black colour have been found; while variations bitween yellowish-brown and yellowish-grey are not uncommon. I am aware that individuals nearly white, and others nearly black, have been observed, but I hav at seen them myself."

With regard to the coloration of the young, Mr. True observes that although the markings disappear more or less completely about the period indicated above, yet they persist 


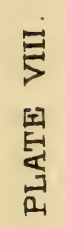

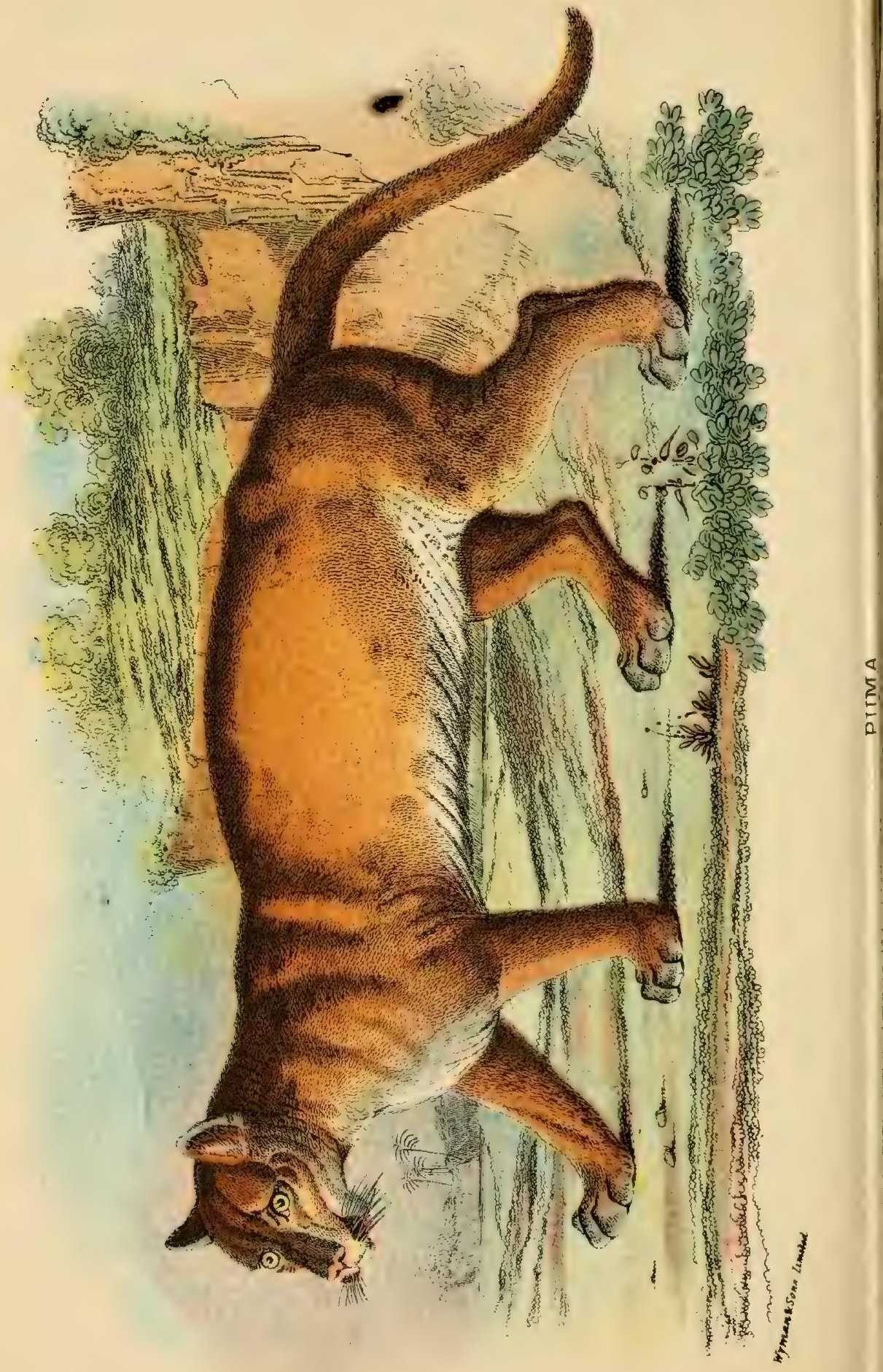


more or less indistinctly until the animal has attained its full dimensions, or possibly in some cases throughout life. Nevertheless, the term "spotted" cannot be applied to the Puma in the same sense as to the Jaguar or Leopard. It is added that in some instances Lions, which to the eye appear of a perfectly uniform colour, come out spotted in photographs.

Distribution.-America; from British Columbia and Maine in the North to the Straits of Magellan in the south. Stragglers may, however, occasionally range as far north as the sixtieth parallel of latitude. In the Andes it is reported to range as high as 9,000 feet above the sea-level.

Regarding its distribution in North America, Mr. True writes that "on the Atlantic coast the Puma has not apparently been found in the States of New Hampshire, Rhode Island, New Jersey, or Delaware. On our northern boundary I find no mention of its having been found in Michigan or Indiana. In Ohio it was extirpated prior to 1838 , and probably more recently in Illinois and Indiana. I find no record of its occurrence in Nevada, but, as it has been found in the surrounding States, it seems improbable that it should be entirely absent here. With these exceptions, there are recorded instances, more or less numerous, of the occurrence of the Puma in every State and Territory of the Union, dating from the beginning of the century. Like many other large American animals, however, the Puma has retired before the dvance of civilisation, and in many of the more thickly populated States it is improbable that even stragglers could be found at the present day." In Minnesota, according to Mr. Herrick, the last Puma was killed in 1875 .

Over the greater part of South America there appears to be a dearth of information as to the distribution of this animal. Writing in the "Proceedings of the Zoological Society" for 1894, Mr. Aplin observes that in Uruguay "the Puma is now 
extinct in many parts of the country, but in the monte along the Uruguay River it is still found. An estanciero living at Cordova in Argentina tells me he had seen both Pumas and Jaguars coming down the big river on tree-trunks. In this way stray examples might very well turn up in a district long after the native breed was extinct. I heard that it was still found, although very rarely, in the monte of the Rio Negro on that part of the coast of the river which I visited in the Department of that name; but all I could hear of it in South Soriano was a report that one had been seen on the Arroyo de Monzon some years ago."

On the pampas of Argentina where it was formerly very numerous, it is now extremely scarce, although more common in the wooded chaco-country of the interior. On the Rio Negro, in Upper Patagonia, Mr. Hudson states that a few years ago they infested the settlements. "At all seasons a few of these sly but withal audacious robbers haunt the river-side; but in winter a great many lean and hungry individuals come down from the uplands to slay the Sheep and Horses, and it is extremely difficult to track them to their hiding-places in the thorny thickets overhanging the valley. I was told that not less than a hundred Pumas were killed annually by the shepherds and herdsmen." Further south they appear even at the present day to be equally numerous.

Habits.-As the Jaguar in South America has usurped the name of the Tiger, so the Puma is commonly called by Europeans in the same country the Lion (Leon of the Spanish), although the natives always call it by its proper name of Puma, in which, by the way, the $u$ should be pronounced as 00 . Although frequently termed in the States the American Lion, the animal is there more commonly known as the Panther, generally corrupted into "painter"; although the native Indian name "Cougar" is likewise in common use. When the natural 
products of North America were first made known to the Old World, the Puma was indeed believed to be specifically identical with the Lion, and the early explorers were accordingly puzzled to account for the absence of maned individuals. Thus, in the second edition of the "Description of the New Netherlands," published in 1656 , Van der Donck writes as follows: "Although the New Netherlands lay in a fine climate, and although the country in winter seems rather cold, nevertheless Lions are found there, but not by the Christians, who have travelled the land wide and broad and have not seen one. It is only known to us by the skins of the females, which are sometimes brought in by the Indians for sale, who on enquiry say that the Lions are found far to the south-west, distant fifteen or twenty days' journey, in very high mountains, and that the males are too active and fierce to be taken."

From its extensive geographical range, probably greater in a north and south direction than that of any other member of the class to which it belongs, the Puma may be regarded as par excellence the characteristic Mammal of the New World; while for the same reason the creature is remarkable for its power of adapting itself to different climates and surroundings. Thus, whereas in the more northern portion of its range it inhabits the depths of the impassable forest-glades of Florida, it is sometimes found on the open prairies of Texas ; while in mountainous regions it dwells amongst the most rocky and barren peaks. "He endures," writes Mr. True, "severe cold during the winter in the Adirondack Mountains, and other parts of our northern frontier, and tracks his prey in the snow. $\mathrm{He}$ is equally at home in the hot swamps and cane-brakes along the rivercourses of our southern States. In South America he inhabits the treeless grass-covered pampas as well as the forests. In the Rocky Mountains he ascends to the high altitudes in which the Mountain Sheep are found. Mr. Stone saw tracks of the Puma 
on the summit of Mount Persephone, in California, at an elevation of 3,000 feet. Similarly, Darwin states that he saw the footprints of the Puma on the Cordillera of Central Chili at an elevation of at least 10,000 feet. According to Tschudi, the Puma is found in Peru in the highest forests, and even to the snow-line, although seldom at the latter level." And it has been stated that the animal is still common in the forests of Central America at a height of from 8,000 to 9,000 feet above the sea-level.

Wherever it be situated, however, the Puma always selects for its lair the most sheltered and solitary situations; in wooded districts generally frequenting thick bushes and copses, rather than tall forests. Such spots as have rocks, with crevices and caverns well-suited for the maternal requirements, are, however, those most favoured. Although occasionally hunting its prey by day, the Puma is mainly nocturnal in its habits, especially in thickly populated districts, where constant persecution has taught it the prudence of caution; and its favourite times for being on the prowl are evening and early dawn. When supplies are abundant, it is stated to drink only the blood of its victims, although this statement stands, perhaps, in need of confirmation, and it will frequently kill far more than it can possibly consume, a case being recorded where no less than half-a-hundred sheep were destroyed in the course of one night by a single Puma. With such a bloodthirsty and destructive disposition, it is little wonder that the animal is detested by all settlers in the districts it frequents, and persecuted by them with unrelenting pertinacity. The cubs, which in the wild state vary from two to five in number, although in captivity there are generally two, but occasionally one, are produced in some secure and sequestered situation, varying locally according to the nature of the country. In the Adirondack Mountains of New York, for instance, the breeding-lair is generally 
situated in a cave on the face of some almost inaccessible cliff or ledge of rock; whereas in the Southern United States it is usually in a dense thicket or cane-brake, while in the Argentine a mass of tall pampas-grass may form the shelter. In the Southern States the lair consists of a rude kind of bed, formed of sticks, leaves, twigs, grasses, or mosses, frequently protected from rain by the long, pointed leaves of the overarching canes. In the more northern United States the cubs are brought forth at the close of winter, or the beginning of spring ; but in South America during the summer, that is to say, towards the latter part of December. In North America, at least, it is believed that the female Puma does not breed more frequently than once every two years.

As regards food, in North America the Puma preys chiefly upon the various kinds of Deer, but also kills and eats many of the smaller Mammals, such as Raccoons and Skunks, together with Porcupines, and such birds as it may be able to capture. Writing of its habits in South America, Mr. W. H. Hudson, in the "Proceedings of the Zoological Society" for I 872 , observes that "to the insatiable, bloody appetite of this animal nothing comes amiss; he takes the male Ostrich (Rho: by surprise, and slays the wariest of wild things on its nest; the captures little birds with the dexterity of a Cat, and hunts for diurnal Armadillos; he comes unaware upon the Ileer n:: Guanaco, and springing like lightning on them, dislocat. necks before their bodies touch the ground. Oft. has slain them he leaves their bodies untouched for tinc $\mathrm{Cu}_{\text {. }}$ caràs and Vulture to feast on, so great a delight does he take in destroying life. The Viscacha falls an easy victim to this subtle creature, and it is not to be wondered at that it becomes wild to excess and rare in regions hunted over by such an enemy, even when all other conditions are favourable to its existence." 
Throughout its range, be it north or be it south, the Puma is a terrible foe to stock-rang of all kinds; and, although in North America it is reported only to attack such adult Horses and cattle as are maimed, feeble, or mired, the number of colts and calves it will destroy, to say nothing of Sheep, is almost incredible. In South America, however, Mr. Hudscn states that it not unfrequently kills full-grown Horses and cattle. Pigs are likewise killed in great numbers by these insatiate marauders. In certain districts, indeed, as in the Shasta County Hills of California, horse-breeding became at one time practically impossible owing to the ravages of Pumas; and much the same state of affairs has been reported from parts of Patagonia. The enmity existing in South America between the Puma and the Jaguar, and how the latter is either killed or terribly mauled by its less powerful but more active antagonist, has been already alluded to under the heading of the species last named.

In spite of its otherwise ferocious and bloodthirsty nature, the most curious trait in the habits of the animal under consideration is the rarity with which it attacks human beings, unless driven into a corner or otherwise provoked; this being fully attested by observations made both in North and South America. This, however, is not all ; for in the latter country, according to Mr. Hudson, it not only never attacks Man, but has been known to defend him against the assaults of other animals. In countries where trees and rocks abound, it is the general habit of the Puma to spring upon his prey from an elevation; and if it fails to strike its victim at the first bound, the pursuit is generally at once abandoned. From an elevation of twenty feet, one of these animals has been known to spring upon a Deer upwards of sixty feet distant at one bound ; the impetus knocking the quarry a distance of several yards farther. During the winter in the Northern United States, Dr. 
Hart Merriam observes that "under certain conditions of the deep snows the Deer cut in so deeply that the poor animals can make but slow progress. At such times a Puma, by spreading the toes of his great broad paws, simulates a man on snow-shoes, and sinks but a short distance in the snow. He then gains a vital advantage over his prey, and will now give chase to and capture one that he missed at his first spring. Under no other circumstance will a Puma pursue a Deer, for he is too well aware of the uselessness of an attempt to overtake so fleet an animal. Immediately upon killing one, he drags it bodily into some dense thicket or windfall, where he will not be likely to be observed. He has thus been observed to drag a full-grown Deer considerably over a hundred feet before reaching a satisfactory covert."

In North America, except when pursued by dogs, or in ascending precipitous cliffs, it appears that Pumas do not frequently climb trees; and when hunted by hounds, they generally spring straight from the ground into the branches, instead of climbing up the trunk. In Paraguay, however, these animals are much more arboreal in their habits; and, like the Jaguar, have been reported to chase Monkeys from tree to tree without once descending to the ground. Like the Jaguar, the Puma is in the habit of scoring the bark of treetrunks with its claws.

Regarding the disputed question as to the cries of the Puma, Mr. True, in the monograph quoted above, writes as follows: "Many reliable authorities are agreed that the Puma does not ordinarily emit loud cries or screams, but Kennerly, one of the naturalists of the Mexican Boundary Survey, states that on one or two occasions the cry of the Puma was heard at a distance, and Scholt writes as follows: 'After dark his mournful note is heard resounding through the solitudes of the desert. The note, listened to once attentively, is apt to 
make a deep, lasting impression. The different native namcs, as pronounced in Spanish, sound very appropriately to the note, and it is likely that the cry of the animal forms the base of its names. The note itself is often several times repeated, with intervals of from two to four minutes. As night advances, the cry is heard but rarely.' $\mathrm{He}$ also writes: 'A Puma was killed on the Rio Brava, between Fort Duncan and Laredo. During his struggles with the hunters and Dogs he raised a terrible cry, twice or thrice, to express his rage, and perhaps also to give his family the notice of danger.' Dr. J. A. Allen reports that he once heard the Puma's cry near his camp in Montgomery, Colorado. Elliot likewise states that he heard the cry of the Puma at night, whilst camping on the St. John's River, Florida. He did not, however, se: the animal." Darwin writes that the Puma "is a very silent animal, uttering no cry, even when wounded, and only rarely during the breeding-season."

In captivity, the Puma, when pleased, purrs after the manner of the Domestic Cat ; and the female has been heard to utter a kind of mewing noise. The Puma is one of the most easily tamed of the Cat tribe, becoming not only perfectly harmless, but even much attached to its owner. A wonderfully tame individual formerly in the possession of Kean the actor, used to follow its master about like a Dog, and was often introduced into the company of strangers. Writing of the specimen depicted in Plate VIII. of the present volume, Jardine observes that "it was extremely gentle and playful, and showed no symptoms of ferocity to the strangers who came to see it. Its motions were all free and graceful, and it exhibited the greatest agility in leaping and swinging about the joists of a large unoccupied room in the old college of Edinburgh." For the following additional particulars we are indebted to the account given by Mr. Wilson. "It rejoices greatly in the society of 
those to whose company it is accustomed, lies down upon its back between their feet, and plays with the skirts of their garments, entirely after the manner of a kitten. It shows a great predilection for water, and frequently jumps into and out of a large tub, rolling itself about, and seemingly greatly pleased with the refreshment. While in London, it made its escape into the street during the night, but allowed itself to be tiken up by a watchman, without offering even a show of resistance. It was brought from the city of San Paulo, the capital of the district of that name in the Brazilian Empire." Pumas are generally hunted with packs of Dogs, and, when brought to bay, fight with the most determined ferocity, biting and clawing at their antagonists till the last breath. The following account of a Puma-hunt is taken from Audubon, who, after detailing the preparations for the sport, writes that-

"Few words were uttered by the party until we had reached the edge of the swamp, where it was agreed that all should disperse, and seek for the fresh track of the Painter, it being previously settled that the discoverer should blow his horn, and remain on the spot until the rest should join him. In less than an hour, the sound of the horn was clearly heard; and, sticking close to the squatter, off we went through the thick woods, guided only by the now and then repeated call of the distant huntsman. We soon reached the spot, and in a short time the rest of the party came up. The best Dog was sent forward to track the Cougar, and in a few minutes the whole pack were observed diligently trailing, and bearing in their course for the interior of the swamp. The rifles were immediately put in trim, and the party followed the Dogs, at separate distances, but in sight of each other, determined to shoot at no other game than the Panther.

"The Dogs soon began to mouth, and sudienly quickened their pace. My companion concluded that the beast was on 
the ground; and putting our Horses to a gentle gallop, we followed the curs, guided by their voices. The noise of the Dogs increased, when, all of a sudden, their mode of barking became altered, and the squatter, urging me to push on, told me that the beast was treed, by which he meant that it had got upon some low branch of a large tree, to rest for a few moments, and that should we not succeed in shooting him when thus situated, we might expect a long chase of it. As we approached the spot, we all by degrees united into a body; but on seeing the Dogs at the foot of a large tree, separated again, and galloped off to surround it.

"Each hunter now moved with caution, holding his gun ready, and allowing the bridle to dangle on the neck of his Horse, as it advanced slowly towards the Dogs. A shot from one of the party was heard, on which the Cougar was seen to leap to the ground, and bound off with such velocity, as to show that he was very unwilling to stand our fire longer. The Dogs set off in pursuit with great eagerness, and a deafening cry. The hunter who had fired came up, and said that his ball had hit the monster, and had probably broken one of his fore-legs, near the shoulder, the only place at which he could aim. A slight trail of blood was discovered on the ground; but the curs proceeded at such a rate, that we merely noticed this, and put spurs to our Horses, which galloped on towards the centre of the swamp. One bayou was crossed, then another still larger and more muddy; but the Dogs were brushing forward, and, as the Horses began to pant at a furious rate, we judged it expedient to leave them, and advance on foot. These determined hunters knew that the Cougar, being wounded, would shortly ascend another tree, where, in all probability, he would remain for a considerable time, and that it would be easy to follow the track of the Dogs. We dismounted, took off the saddles and bridles, set the bells 
attached to the Horses' necks at liberty to jingle, hobbled the animals, and left them to shift for themselves.

"After marching for a couple of hours, we again heard the Dogs. Each of us pressed forward, elated at the thought of terminating the career of the Cougar. Some of the Dogs were heard whining, although the greater number barked vehemently. We felt assured that the Cougar was treed, and that he would rest for some time to recover from his fatigue. As we came up to the Dogs, we discovered the ferocious animal lying across a large branch, close to the trunk of a cotton-wood tree. His broad breast lay towards us; his eyes were at one time bent on us, and again on the Dogs beneath and around him; one of his fore-legs hung loosely by his side; and he lay crouched, with his ears lowered close to his head, as if he thought he might lay undiscovered. Three balls were fired at him, at a given signal, on which he sprang a few feet from the branch, and tumbled headlong to the ground. Attacked on all sides by the enraged curs, the infuriated Cougar fought with valour ; but the squatter, advancing in front of the party, and almost in the midst of the Dogs, shot him immediately behind and beneath the left shoulder. The Cougar writhed for a moment in agony, and in another lay dead."

By some of the Indians of South America, as well as by certain native tribes in the northern half of the New World, Puma-flesh is largely eaten; and Darwin, who essayed the same dish, reported of it favourably.

Fossil remains of the Puma have been discovered in the Pleistocene deposits of several parts of North America.

VII. THE CLOUDED LEOPARD. FELIS NEBULOSA.

Felis nebulosa, Griffith, Descript. Vert. p. 37 ( $182 \mathrm{I}$ ); Blanford, Mamm. Brit. India, p. 72 (I 888 ); Hose, Mamm. Borner p. I 7 (I $\left.s_{93}\right)$. 
Felis diardi, Cuvier, Oss. Fossiles, 2nd ed. vol. iv. p. 437 (I823); Elliot, Monogr. Felidæ, pl. viii. (1878-83).

Felis macrocelis, Horsfield, Zool. Journ., vol. i. p. 542 (1825). Felis macroceloides, Hodgson, Calcutta Journ. Nat. Hist. vol. iv. p. 286 (I 844 ).

Uncia macrocelis and $U$. macroceloides, Gray, Ann. Mag. Nat. Hist. ser. 2, vol. xiv. p. 394 (r854).

Leopardus brachyurus, Swinhoe, Proc. Zool. Soc. 1862, p. 352 Felis brachyura, Blyth, Proc. Zool. Soc. 1863, p. I83.

Neofelis macrocelis and $N$. brachyurus, Gray, Proc. Zool. Soc. I867, p. 266 ; id., Cat. Carniv. Mamm. Brit. Mus. pp. I3, I4 (r869).

(Plate IX.)

Characters.-Size that of a small Leopard; markings clouded, that is, in the form of large blotches or patches exceeding a couple of inches in diameter. Ground-colour of fur pale yellow to grey, with blackish cloudings. Tail very long and thick, measuring from 2 feet 2 inches to 3 feet ro inches. Skull long and narrow, with the upper tusks, or canines, relatively longer than in any other Cat, their length equalling half that of the palate; anterior upper pre-molar tooth frequently wanting. Pupil of eye oval and vertical. Total length, from 6 to $6 x / 2$ feet.

The under-parts of the body, as well as the inner sides of the limbs, are white or pale tawny. On its upper surface the head is spotted; two broad black streaks, separated by narrower bands or elongated spots, start at the ears and run backwards to the shoulders, whence they are continued as more or less ill-defined bands of oval markings along the middle of the back. As a rule the sides of the body are ornamented with a number of large irregularly-shaped, ovoid, or quadrangular dark blotches or patches, frequently edged in places, especially on their hinder borders, with black; in 


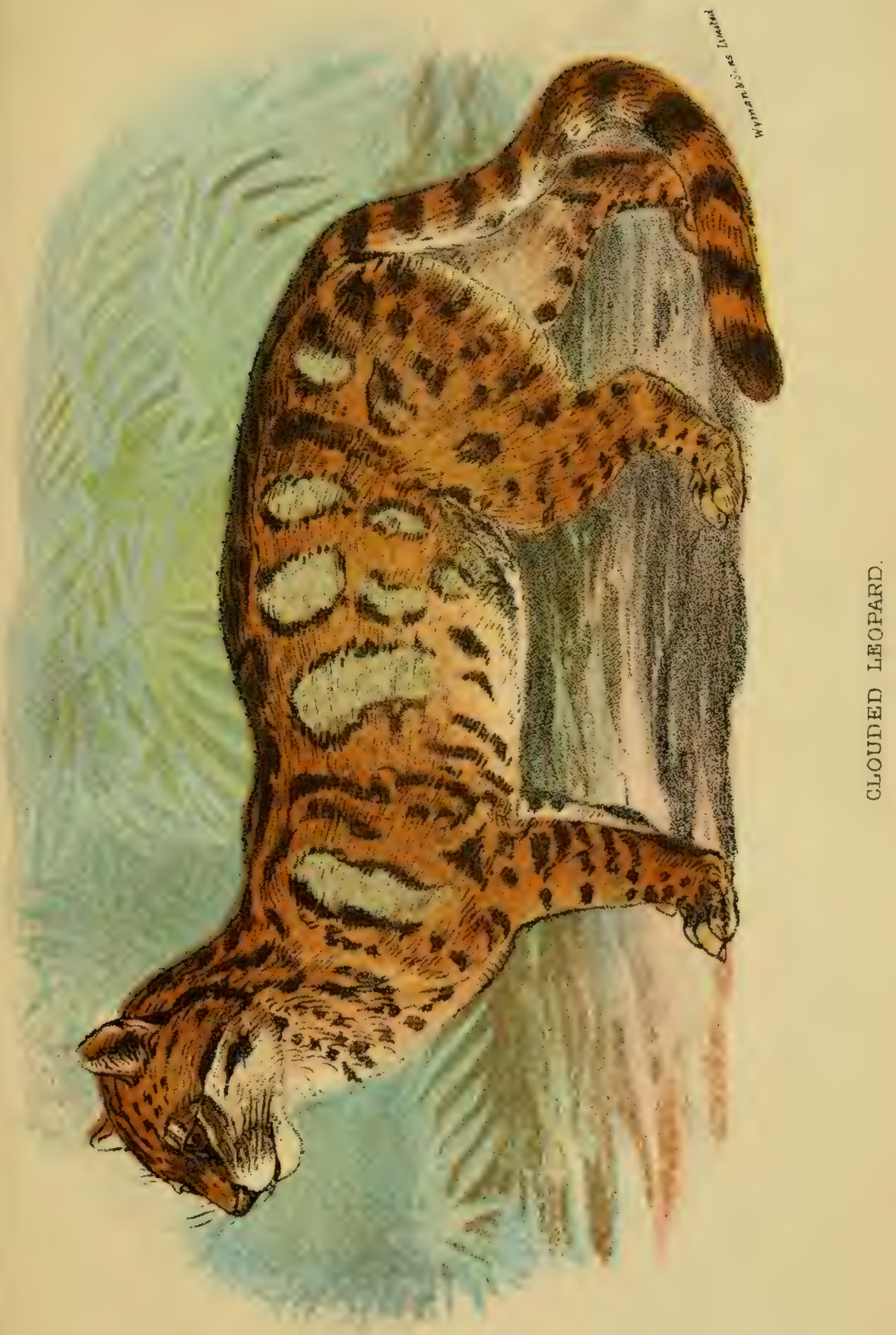



old animals the blotches tending to disappear, and thus leaving only the darker borders. The tail is marked by numerous dusky rings, frequently interrupted on the sides, and on the upper surface near the body traversed by a longitudinal band. The black outer surface of the ear is frequently marked with a grey spot in the middle; and there are two black horizontal stripes on the cheek, the uppermost of which runs from the eye; while in some instances the margin of the upper lip may be likewise black. In addition to these markings, an irregular black band traverses the chin, while another crosses the throat. In the Formosan variety - the so-called Leopardus brachyurusthe tail is shorter than usual; although such a difference does not seem of specific importance.

Distribution.-The Himalaya, from Nipal to Sikhim and Assam; the hill regions of Burma and Siam; the Malay Peninsula; Sumatra, Java, Borneo, and Formosa.

Habits.-The Rimau-Dahan (Tree-Tiger), as this animal is termed by the Malays, is the last of the more typical Old World members of the Family entitled to rank among the large Cats. Beyond the fact that it is an arboreal species, living on birds and smaller mammals, practically nothing is known as to its habits in the wild state; such accounts as have appeared being derived from native sources, and thus of the usual untrustworthy character. Three specimens (all males) had been exhibited in the London Zoological Gardens up to 1883 , the first of which was obtained in 1854 , and the third in 1875 . These are said to have been tamed without difficulty; and passed most of their time in sleep.

Writing of some specimens in captivity, Sir Stamford Raffles observes that they were remarkable for their good-temper and playfulness, "no domestic kitten could be more so ; they were always courting intercourse with persons passing by, and in 
the expression of their countenance, which was always open and smiling, showed the greatest delight when noticed, throwing themselves on their backs, and delighting in being ticklcd and rubbed. On board ship there was a small Musi Dog, who used to play round the cage with the animal, and it was amusing to observe the playfulness and tenderness with which the latter came in contact with his inferior-sized companion. When fe:- with a fowl that had died, he seized the prey, and after sucking the blood and tearing it a little, he amused himself for hours in throwing it about and jumping after it, in the manner that a Cat plays with a Mouse before it is quite dead.

"He never seemed to look on man or children as prey, but as companions, and the natives assert that, when wild, the Leopards live principally on poultry, birds, and the smaller kinds of Deer. They are not found in any numbers, and may be considered rather a rare animal, even in the southern part of Sumatra. Both specimens were procured from the interior of Bencoolen, on the banks of the Bencoolen River. They are generally found in the vicinity of villages, and are not dreaded by the natives, except as far as they may destroy their poultry. The natives assert that they sleep and often lay wait for their prey on trees; and from this circumstance they derive the name of Dahan, which signifies the fork formed by the branch of a tree, across which they are said to rest, and occasionally stretch themselves.

"Both specimens constantly amused themselves in jumping and clinging to the top of their cage, and throwing a somerset, or twisting themselves round in the manner of a Squirrel when confined, the tail being extended, and showing to great advantage when so expanded."

One of these animals, upon its arrival in this country, was sent to Exeter 'Change, where the noise and novelty of the 
menagerie appear to have rendered it very intractable for a few days; but it soon became perfectly familiar, and fond of the persons who were employed about it. It was rather less voracious than a Leopard, and was fed with beef and the heads of fowls.

Mr. Hose, who found this species on the Baram River, on Mount Dulit up to 5,000 feet, and on Mount Batu Song to 2,000 feet, writes that "this animal is constantly procured by the natives of Borneo, the canine teeth being used by the Kayans and Keniahs as ear-ornaments, and the skin for the purpose of a war-coat. It is found both in the low country and on the mountains to a height of 5,000 fect."

VIII. THE MARBLED CAT. FELIS MARMORATA.

Felis marmorata, Martin, Proc. Zool. Soc. 1836, p. I07 ; Elliot, Monogr. Felidæ, pl. ix. (I878-83) ; Blanford, Mamm. Brit.

India, p. 74 (1888); Hose, Mamm. Borneo, p. 18 (1893). Felis diardi, Jardine, Naturalist's Library, Felinæ, p. 22 I (1834; nec Cuvier).

Felis longicaudatus, De Blainville, Ostéographie, vol. ii. Felis, p. 47 (I 839-64).

Leopardus marmoratus, Gray, List Mamm. Brit. Mus. p. 42 (I843).

Felis charltoni, Gray, Ann. Mag. Nat. Hist. vol. xviii. p. 44 (I846).

Felis ogilbyi, Hodgson, Calcutta Journ. Nat. Hist. vol. viii. p. 44 (I 846$)$.

Uncia marmoruta, Gray, Ann. Mag. Nat. Hist. ser. 2, vol. xiv.

p. 394 (1854).

Uncia charltoni, Gray, loc. cit.

Lecpardus dorsul, Grav, Cat. Hodgrson Coll. and ed. p. 3 (1863). 
Catolynx marmoratus and C. Garltoni, Gray, Proc. Zool. Soc. I 867, pp. 267, 268; id., Cat. Carniv. Mamm. Brit. Mus. p. I6 (I 869).

\section{(Plate X.)}

Characters.-From the preceding species the Marbled Cat may be distinguished not only by its inferior size (somewhat exceeding that of an ordinary Domestic Cat), but by the much shorter upper tusks, or canines, which are less than half the length of the palate; and likewise by the shorter and more rounded skull, in which the nasal bones are very broad and flat, while the orbit, or socket of the eye, is generally surrounded by a complete bony ring. Moreover, the anterior upper pre-molar tooth is almost always wanting. Externally, the characters are very similar to those of the Clouded Leopard, the long tail being of the same bushy nature, and the ground-colour of the fur varying from fulvous to grey, with black cloudings and mottlings; the under-parts being paler. Length of head and body, from $18 \mathrm{I} / 2$ to 23 inches; of tail, from 14 to $15 \mathrm{I} / 2$ inches.

The coloration is described by Blanford as follows: "Sides divided by narrow pale streaks into large, irregularly-shaped darker patches, black on the hinder edges. Along the back are angular black blotches or irregular rings, arranged more or less in longitudinal bands. There are black spots on the outside of the limbs, the upper surface of the tail, and usually on the lower-parts; but those on the belly are very variable, being sometimes large and distinct, sometimes almost imperceptible. The inside of the limbs and the chest are banded or spotted, and there are the usual cheek-stripes. Two interrupted bands, one from the inner corner of each eye, over the head are continued as well-marked black stripes on the hindneck, spots or bands intervening between them on the head, but not on the neck. The under-fur is rich brown."

Distribution,-The Eastern Himalaya, from Sikhim to Assam ; 


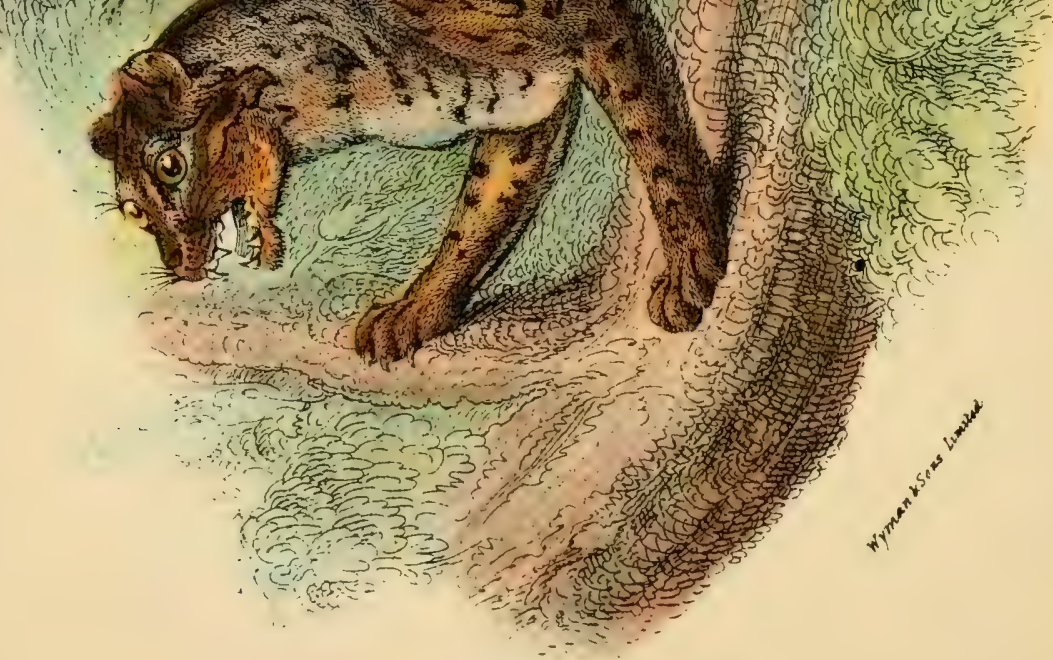


Burma to the Malay Peninsula ; N. Borneo*; Baram River, Sarawak; Sumatra; and perhaps Java.

Habits.-Nothing definite is known as to the habits of this prettily-marked Cat, although, like the last species, it is probably arboreal. Mr. Hose says that it frequents the clearings in Sarawak, and is more often found in the low country than on the mountains. It is very fierce, when caught, and will not live long in captivity.

IX. THE TIBETAN TIGER-CAT. FELIS SCRIPTA.

Felis scripta, Milne-Edwards, Nouv. Archiv. Mus. Bull. vol. vii. p. 92 (1876); id., Recherches des Mammif. p. 34I ; Mivart, The Cat, p. 400 (I88I).

Characters.-As suggested by Mr. W. L. Sclater in his Catalogue of Mammals in the Indian Museum, Calcutta (part ii. p. $22 \mathrm{I}$ ), it is not improbable that this form will prove to be identical with the last. Its general colour is described as pale g:ey, with reddish-brown spots margined more or less completely with black. In the region of the shoulders these markings take the form of longitudinal wavy bands, with a distant resemblance to Chinese letters. The largest of these dark lines commences near the inner corner of the eye, then passes above the ear to the withers, after which it widens out as it descends obliquely; and a similar, but more highly-placed band extends from the forehead to the shoulder. On the sides of the body are large, irregularly-shaped blotches, forming bands and bars at the hinder parts, and incomplete rings on the tail; and there are likewise black spots and bars on the outer sides of the limbs. A portion of the cheeks, as well as the chest, are white, with transvers a black $\mathrm{m}$ ırkings; and the yellowish under-parts like-

* A. H. Everett, Proc. Zool. Soc. 1893, p. 495. 
wise carry longitudinal black streaks. Length of head and body of type, $2 \mathrm{I} \mathrm{T} / 2$ inches; of tail, $10 \mathrm{I} / 2$ inches.

Distribution.-Moupin, Eastern Tibet.

\section{FONTANIER'S CAT. FELIS TRISTIS.}

Felis tristis, Milne-Edwards, Recherches Mammif. p. 223 (I868-74); Elliot, Monogr. Felidæ, pl. xxii. (I878-83); Mivart, The Cat, p. 400 (I88I).

This is also a little-known species, distinguished from the other Cats of the regions it inhabits by its large size, whitishgrey ground-colour, large spots, and rather short tail. It is described as having soft and long fur, of a whitish-grey groundcolour, upon which three or four blackish-brown lines, commencing on the head between the ears, run the whole length of the back, the remainder of the upper-parts, as well as the flanks and limbs, being marked with large dark brown solid spots. Chest with two bars of rufous-brown running across it. Tail bushy, less than half the length of the head and body; rufous-brown above, and yellowish-brown below ; with a series of obscure dark brown bars on the upper surface. Length of head and body, 331/2 inches; of tail, 16 inches.

Distribution.-The interior of China; the skin of the type specimen having been purchased in Pekin.

XI. THE GOLDEN, OR BAY CAT. FELIS TEMMINCKI.

Felis temmincki, Vigors and Horsfield, Zool. Journ. vol. iii. p. 45 I (I828); Elliot, Monogr. Felidxe, pl. xvi. (I878-83); Blanford, Mamm. Brit. India, p. 75 (I888); Hose, Mamm. Borneo, p. I9 (1893).

Felis moormensis, Hodgson, Gleanings in Science, vol. iii. p. I 77 ( 1831$)$.

Leopardus moormensis, Gray, List Mamm. Brit. Mus. p. 4I (1843). 
Felis aurata, Blyth, Proc. Zool. Soc. 1862, p. I85 (nec Temminck).

Felis nigrescens, Gray, Cat. Hodgson Coll. 2nd ed. p. 4 (1863). Leopardus auratus, Gray, Proc. Zool. Soc. 1867, p. 265 ; id., Cat. Carniv. Mamm. Brit. Mus. p. I 2 (1869).

Characters.-Distinguished from all the Asiatic Cats described above by its medium size (rather less than that of Felis nebulosa) and uniformly-coloured fur, devoid of either distinct spots or stripes. General colour varying from bright ferruginous red to dark brown ; tail short and not bushy; cheeks and forehead horizontally streaked with white and brown ; indistinct vestiges of spots occasionally apparent on the flanks and under-parts. Length of head and body in a male, $31 \mathrm{r} / 2$ inches; of tail, 19 inches.

Distribution.-The Eastern Himalaya, at moderate elevations, from Nipal and Sikhim to the Tippera Hills; Burma; Malay Peninsula; Borneo ; and perhaps Sumatra.

Habits.-In Borneo, Mr. Charles Hose says that this species is very rare. Nothing has been recorded of its habits.

XII. THE FLAT-HEADED CAT. FELIS PLANICEPS.

Felis planiceps, Vigors and Horsfield, Zool. Journ. vol. iii. p. $45^{\circ}$ (I 828 ); Elliot, Monogr. Felidæ, pl. xvi. (I878-83); Mivart, The Cat, p. 4I7 (188I); Hose, Mamm. Borneo, p. 20 (1893).

Ailimura planiceps, Gervais, Hist. Nat. Mamm. vol. ii. p. 87 (1855).

Viverriceps planiceps, Gray, Proc. Zool. Soc. I867, p. 269. Ailurogale planiceps, Fitzinger, S.B. Ak. Berlin, I869, p. 249.

Characters.-General coloration similar to that of the Bay Cat, but of about half the size, and having the skull of different shape, with the nasal bones forming a ridge, as in the under- 
mentioned Fishing Cat, and the anterior upper pre-molar tooth unusually large and furnisfed with two roots; orbit of eye completely encircled by bone. The body is much elongated; and the tail and limbs are very short. In colour, the fur, which is soft, thick, and long, is dark reddish-brown on the top of the head, with two yellow lines extending from between the eyes to the ears, while on the body it is dark brown, gradually lightening on the sides, each hair having a white tip, which communicates a silvery-grey tinge to the entire coat. Face below the eyes light reddish, with two narrow dark lines running across the cheeks to beneath the ears. Chest and under-parts white; the latter spotted and streaked with rufous. Inner surfaces of limbs rufcus-brown, becoming lighter near the feet; tail reddish-brown. Length of head and body, from 2 I to 24 inches; of tail, from 6 to 8 inches.

Distribution.-Malay Peninsula, Sumatra, and Borneo; on the Baram River, Sarawak; Mount Dulit, at 2,000 feet.

Habits.-Of the habits of the little Fire-Cat, as this species is sometimes called, little is known; although, from the similarity in the anterior pre-molar tooth, it has been suggested that they may be similar to those of the Fishing Cat. Mr. Hose writes that in Borneo "this Cat is common in the low country, and is often very destructive in the gardens. It is very fond of fruit, and has constantly been known to dig up and eat the sweet potatoes which are grown by the natives."

XIII. THE BORNEAN BAY CAT. FELIS BADIA.

Felis badia, Gray, Proc. Zool. Soc. I874, p. 322 ; Elliot, Monogr. Felidæe, pl. xiv. (ı $878-83$ ); Mivart, The Cat, p. 4I9 (I8S I) ; Hose, Mamm. Borneo, p. 20 (I893).

Characters.-A small, unifo:mly-coloured Cat readily distinguished from the preceding by the small size and single 
root of the anterior upper pre-molar tooth, as well as by the incomplete closure of the socket of the eye by bone. The fur of the type specimen is described as being of a bright chestnut hue, becoming paler on the under-parts, while the limbs and tail are both redder and paler. The elongate and tapering tail has a whitish median streak down the terminal half of its lower surface, this streak expanding and becoming pure white at the tip, which is marked by a small black spot. The rounded ears have short blackish-brown fur on the outer side, while internally they are pale brown, with narrow pale margins. The sides of the upper lips, as well as a spot at the front angle, and another at the edge of the eyelid are pale brown; while the chin, the margin of the lower jaw, and the gullet are whitish.

\section{Distribution.-Borneo.}

Originally described by the late Dr. Gray upon the evidence of a very imperfect skin preserved in the British Museum, this Cat is now known from several specimens obtained by Mr. Everett, and another procured by Mr. Hose on the Suai River in Sarawak. Nothing seems to have been recorded of its habits.

XIV. THE FISHING CAT. FELIS VIVERRINA.

Felis viverrina, Bennett, Proc. Zool. Soc. I833, p. 68 ; Elliot, Monogr. Felidæ, pl. xxii. $\left(\mathrm{I}_{7} 8-83\right)$; Blanford, Mamm. Brit. India, p. 76 (1888).

Felis himalayana, Jardine, Naturalist's Library, Felinæ, p. 230 (1834).

Felis viverriceps, Hodgson, Journ. Asiat. Soc. Bengal, vol. v. p. $232(1836)$.

Leopardus viverrimus, Gray, List Mamm. Brit. Mus. p. 43 ( 1843 ).

Felis celidogaster, Blyth, Cat, p. 6 r (1863; nec Temminck). 
Viverriceps bennettii, Gray, Proc. Zool. Soc. 1867, p. 268 ; id., Cat. Carniv. Mamm. Brit. Mus. p. I6 (I 869).

(Plate XI.)

Characters.-Coming under the denomination of a "spotted" Cat, this species may be distinguished from the larger Indian forms with the same general type of coloration by its inferior dimensions, and the sharp ridge formed by the nasal bones of the skull. Superior in size to the undermentioned LeopardCat and Rusty-spotted Cat, it differs from both by the grizzled grey fur of the upper-parts being marked with dark brown spots formed by broken-up longitudinal lines, passing into small blackish spots on the hind-quarters. The short and thick tail is marked above with dark brown bars, and is about one-third the length of the head and body. The nasal region of the skull is remarkably narrow, and the socket of the eye generally completely surrounded by bone. The anterior upper pre-molar tooth is very small. Length of head and body, from 30 to 32 inches; of tail, 9 to 12 inches. Specimens are occasionally met with in which the ground-colour of the fur is reddish-grey.

The specimen herewith figured, which was described by Jardine under the name of Felis himalayana, an 1 has the spots more confluent into streaks than is generally the case, was identified by Dr. Gray with his so-called Pardalina warzeicki. The latter, although really identical with the South American Geoffroy's Cat, described in the sequel, was supposed to come from Asia; and the similarity between the coloration of the present species and that of the latter is not a little remarkable.

Distribution.--India, Ceylon, Lower Burma, Tenasserim, Formosa, and Southern China. In India the species has been recorded from the valley of the Indus, the outer ranges of the Himalaya, the Nipal Terai, $\Lambda$ ssam, Bengal, and it, perhaps, 


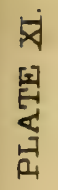

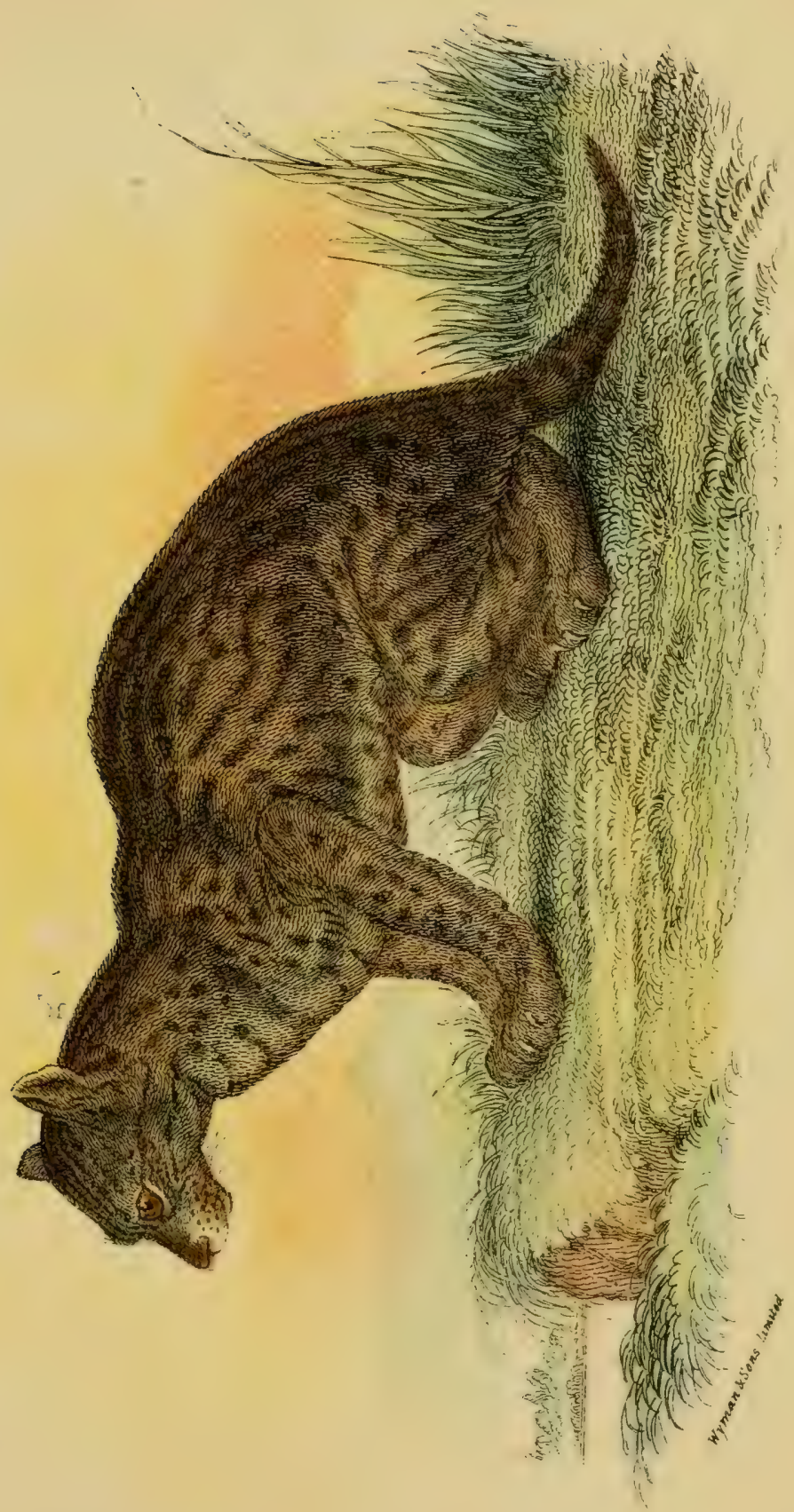

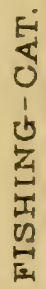




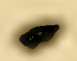


inhabits the Malabar and Travancore coasts; but in Central India it appears to be unknown.

Habits.-A dweller in the thickets and jungles, on the borders of marshes, rivers, and tidal creeks, this Cat differs remarkably from the great majority of its kindred by its habit of preying upon fish; although the manner in which it catches them appears to be quite unknown. This trait has given rise to its popular name, while its scie:tific title has been derived from its somewhat Civet-lik ? coloration and general appearance. In addition to fish, this Cat is stated to feed largely on the large amphibious snails known as Ampullarie, to be met with in thousands in every marsh or "jhil" in Lower Bengal; but here, again, we have no information as to how the succulent morsels are extracted from their somewhat solid shells. Probably also small mammals, birds, and reptiles contribute to the diet of this Cat; while, in spite of its comparatively small size, it is known to be in the habit of killing sheep and calves. Extreme ferocity is, indeed, a distinctive trait of the Fishing Cat, although, somewhat curiously, when captured, this species is stated to be tamed with facility.

An observer, quoted by Mr. Sterndale in his work on the Mammalia of India, writes: "A pair of these Cats broke one night into a matted house, and went off with a brace of ewes, which had a half-a-dozen lambs between them, born only a short time before their mothers met their end. I have caught this species in traps, and when let loose in an indigo-vat with a miscellaneous pack of Dogs, they have invariably fought hard, and at times proved too much for their canine adversaries, so that I have had to go to their rescue, and put an end to the fight by a spear-thrust or a heavy blow on the back of the head with a stout stick. Some years ago one got into my fowl-house at night, and as I opened the door to go inside, it made a fierce jump at me from a perch on the opposite side." 
XV. THE LEOPARD-CAT. FELIS BENGALENSIS.

Felis bengalensis, Kerr, Linn. Anim. Kingdom, p. I 5 I ( I 792) ; Elliot, Monogr. Felida, pl. xxi. ( $878-83$ ); Blanford, Proc. Zool. Soc. I 887 , p. 627 ; id., Mamm. Brit. India, p. 78 (i 888); Hose, Mamm. Borneo, p. ig (i 893).

Felis jaranensis, Desmarest, Nouv. Dict. d'Hist. Nat. vol. vi. p. I 5 (I8I6); Elliot, Monograph of Felidæ, pl. xxviii. ( $1878-8_{3}$ ).

Felis sumatrana, Horsfield, Zool. Research. pl. xxiii. (I82 r). Felis minuta, Temminck, Monogr. Mamm. vol. i. p. I30 (I827). Felis nipalensis, Vigors and Horsfield, Zool. Journ. vol. iv. p. 382 ( 1829 ).

Felis chinensis, Gray, Mag. Nat. Hist. vol. i. p. 577 (1837); Swinhoe, Proc. Zool. Soc. I870, p. 629.

Leopardus ellioti, Gray, Ann. May. Nat. Hist. vol. x. p. 260 (1 842).

Leopardus horsfieldi, Gray, loc. cit.

Chaus servalinus, Gray, List Mamm. Brit. Mus. p. 45 (I 843). Leopardus javnnensis, L. sumatranus, L. chinensis, Gray, op. cit. p. 43 (1843).

Leopardus reevesi, Gray, op. cit. p. 44.

Felis pardochrous, Hodgson, Calcutta Journ. Nat. Hist. vol. iv. p. 286 (1844).

Felis jerdoni, Blyth, Proc. Zool. Soc. I863, p. 185 . Felis servalina, Gray, Proc. Zoo!. Soc. I867, p. 40 I. Felis tenasserimensis, Gray, op. cit. p. 400. $\mathrm{Fe}$ is wagati, Gray, loc. cit.

Viverriceps ellioti, Gray, op. cit. p. 269.

Felis herschelli, Gray, Cat. Carniv. Mamm. Brit. Mus. p. 28 ( 1869$)$.

$$
\text { (Plates XII., XIII.) }
$$

Characters.-Generally slightly smaller than a well-grown I)omestic Cat, but with relatively longer legs, this spotted 


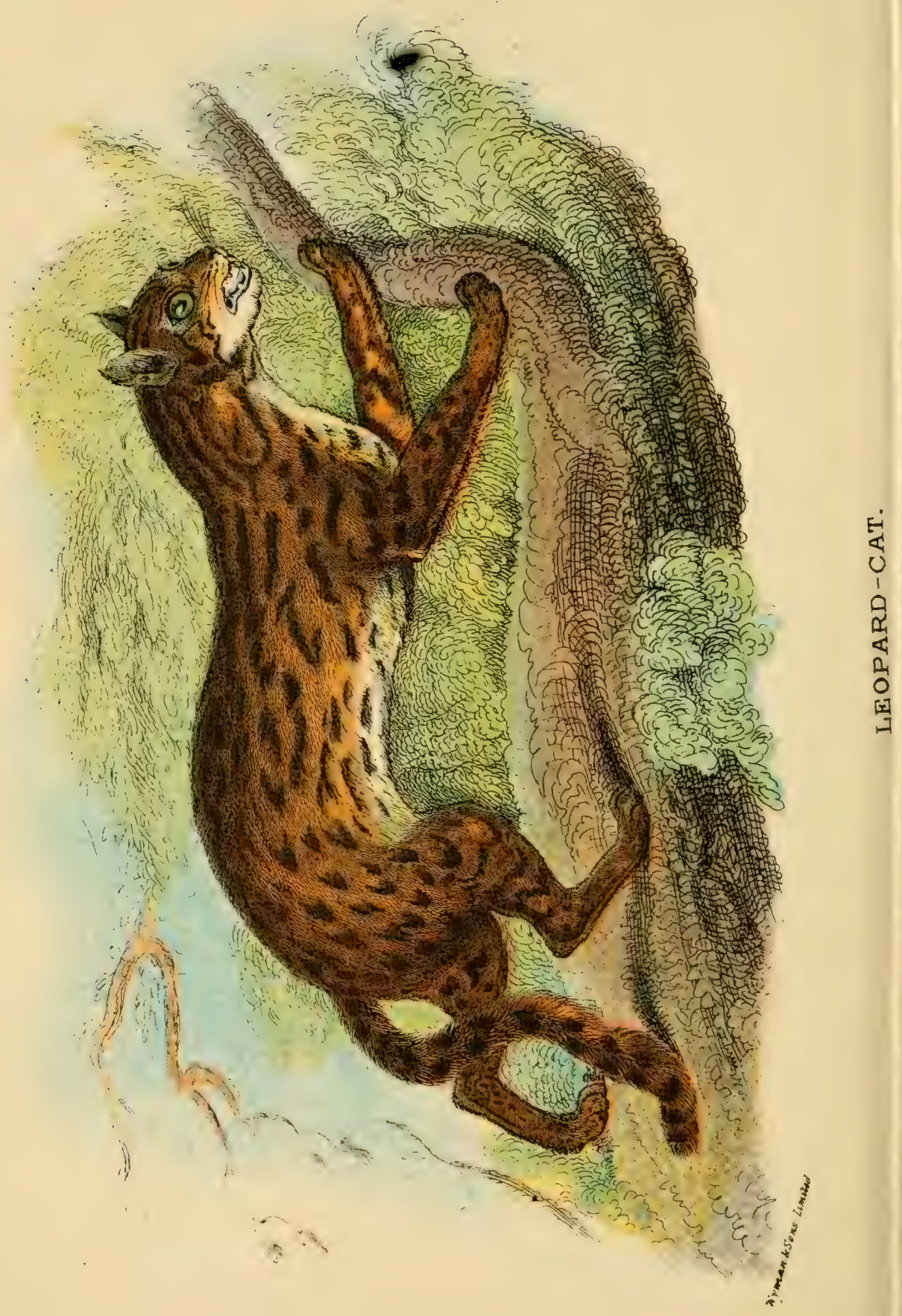


Asiatic species is inferior in size to the last. With the markings extremely variable, the ground-colour of the fur on the upper-parts shades from yellowish-grey to bright yellow, while on the under-parts it is white, the ornamentation taking the form of dark brown markings. Tail long and spotted; its length being about half that of the head and body. Skull shorter and rounder than in the last, with the nasal region only slightly narrowed, the orbits incomplete behind, and the anterior upper pre-molar tooth present. Ears moderate, and rounded at the tips; pupil of the eye generally circular.

The spots extend over both the upper- and under-parts, but towards the end of the tail usually assume the form of transverse bars. According to Mr. Blanford, "there is almost always a white band running up to the forehead from the inside of each eye. Four longitudinal black bands commence on the forehead, and are continued over the head to the hind-neck, breaking up into short bands and elongate spots on the shoulders ; less distinct bands of spots occasionally come in between the two median head-stripes on the forehead and shoulders, but these two stripes frequently coalesce on the back of the neck, diverging again between the shoulders, and being continued as rows of spots to the tail. There are generally two well-marked horizontal cheek-stripes, the lower of which is often joined to a transverse stripe across the throat; other transverse stripes, sometimes broken into rows of spots, cross the lower neck and breast. There are the usual two dark bands inside the fore-arm, and a large whitish spot on the black outer surface of each ear." I.ength of head and body, from 24 to 26 inches; of tail, from I I to 2 inches, or more.

Nearly allied to the under-mentioned smaller Indian species known as the Rusty-spotted Cat (Felis mbiginosa), the LeopardCat is one of the most variable, and, therefure, one of the most difficult species the zoologist has to deal with. That it 
can be divided into several more or less well-defined local races may be considered toubted; but whether to regard such races as species or sub-species may be open to question, although personally we prefer to follow Mr. Blanford in adopting the former view. Other writers have, however, thought differently; Professor Mivart, for instance, in addition to the perfectly distinct $F$. nubiginosa, regards the forms described under the names of $F$. chinensis, $F$. jaz'anensis, $F$. jerdoni, $F$. minuta, and $F$. zurgati, as entitled to specific rank.

On this subject Mr. Blanford writes: "Felis rubiginosa is classed by all as distinct, and of its distinctness there can be no question. The anterior upper pre-molar is always wanting, at all events in adults, and the bony orbit in the skull is complete behind. In $F$. bengalensis and its varieties, on the other hand, out of more than forty specimens examined, I have only seen two in which the anterior upper pre-molar is absent on both sides, and the orbit is never complete behind. There is also a character in the external coloration by which every specimen I have examined of both forms can be at once distinguished. In all these Cats a variable number of interrupted dark lines pass from the forehead over the head and hind-neck to the interscapulary tract. Usually there are four well-marked bands on the head. Of these, the two innermost are continued between the shoulders in $F$. rubiginosa by two long, straight, slightly-diverging dark lines or spots between them. In $F$. bengalensis and its allies, there are never these two lines alone; either the markings are all broken and interrupted, or other lines and spots intervene between the continuations of the two inner frontal bands. The tail, too, in F. rubiginosa is unspotted above; in all forms of the Leopard-Cat distinctly spotted.

"There is in the Natural History Department of the British Museum a very fine series of these Indian and Malayan Spotted 
Cats; no less than six specimens of Felis rubiginosa, all but one of which are from Ceylon, and the remaining specimens from Nellore in Southern India; and forty-two skins of $F$. bengalensis and its allies. In going through the latter, while I have been struck by the great variety exhibited, I have been unable to trace a single character, external or cranial, by which the various races can be distinguished. There are doubtless several races, and, except that I cannot see how $F$. jerdoni is to be separated, even as a variety, from F. javanensis of Horsfield, those accepted as kinds by Professor Mivart are fairly recognisable. There is perhaps one to be added, the true Wagati of Sir IV. Elliot, not the form that was (I believe erroneously) described under that name by Dr. Gray. The variation in dimensions is not nearly so great as in the Leopard, and that in the markings is less than in the Ocelot.

"Accepting, then, the view that all the forms of Leopard-Cat are varieties of one species, which must be called Felis bengalensis, the next question for determination is, whether the Cat called $F$. jerdoni by Blyth is a distinct form, as it has been considered by Blyth and Mivart; whether, as Jerdon suggested, it is a small race of $F$. bengalensis, or whether, as stated by Mr. D. G. Elliot, it is identical with a form of F. rubiginosa. $F$. jerdoni was founded by Blyth upon three specimens, as he writes that, 'I first detected an adult male and a kitten of this species in the Museum at Madras, and find that there is an adult specimen also in the British Museum.' There is now a second specimen in the latter Museum, obtained from the East India Museum, and labelled F. jerdoni in Mr. Blyth's handwriting. On the stand of the original specimen the name $F$. jerdoni has also been written by Mr. Blyth. The two specimens are precisely similar, and that first in the Museum may be taken as the type of the species. "The markings of this specimen, as already mentioned, 
are scarcely distinguishablefrom those of Horsfield's type of F. javanensis. In both the characteristic points mentionedthe marks in the interscapulary region, and the spots on the tail-the two skins agree with $F$. bengalensis, and not with F. rubiginosa. To complete the evidence, Mr. Thomas has had the skull of one of the skins of F. jerdoni extracted, and it proves to possess the anterior upper pre-molar and imperfect orbit of F. bengalensis. I have, therefore, not the least hesitation in assigning $F$. jerdoni, as a variety, to that species, and I believe it to be identical with the form commonly known as $F$. javanensis. The locality of neither specimen of $F$. jer doni in the National Collection is known; but, considering, that so closely similar a form has been described from Java, whilst there is no evidence as to the derivation of the Madras Museum specimens, it is far from improbable that Mr. Blyth was mistaken in his supposition [as to their Indian origin], and that these skins were really brought originally from Malacca or the neighbourhood."

In the Himalayan variety of this species ( $F$. pardochroa), as represented in our first illustration, the ground-colour of the upper-parts is pale rufescent, with the spots usually more or less angular in form, and with their front border brown and the hinder margin black. Whereas, however, in some examples the spots are large and almost triangular, with the apex directed backwards, in others they take the form of small elongated ovals. The so-called Nipal Cat (F. mipalensis) was founded on a grey phase, which there is some reason for believing may have been a hybrid. In another Indian variety the black spots tend to form longitudinal lines, enclosing rich bands of rufous-brown between them ; the bands being broken up more or less completely into large rosettes, dark brown at the centres, with imperfect black rings on the margins. This form is perhaps the handsomest and most striking of all, 
罗

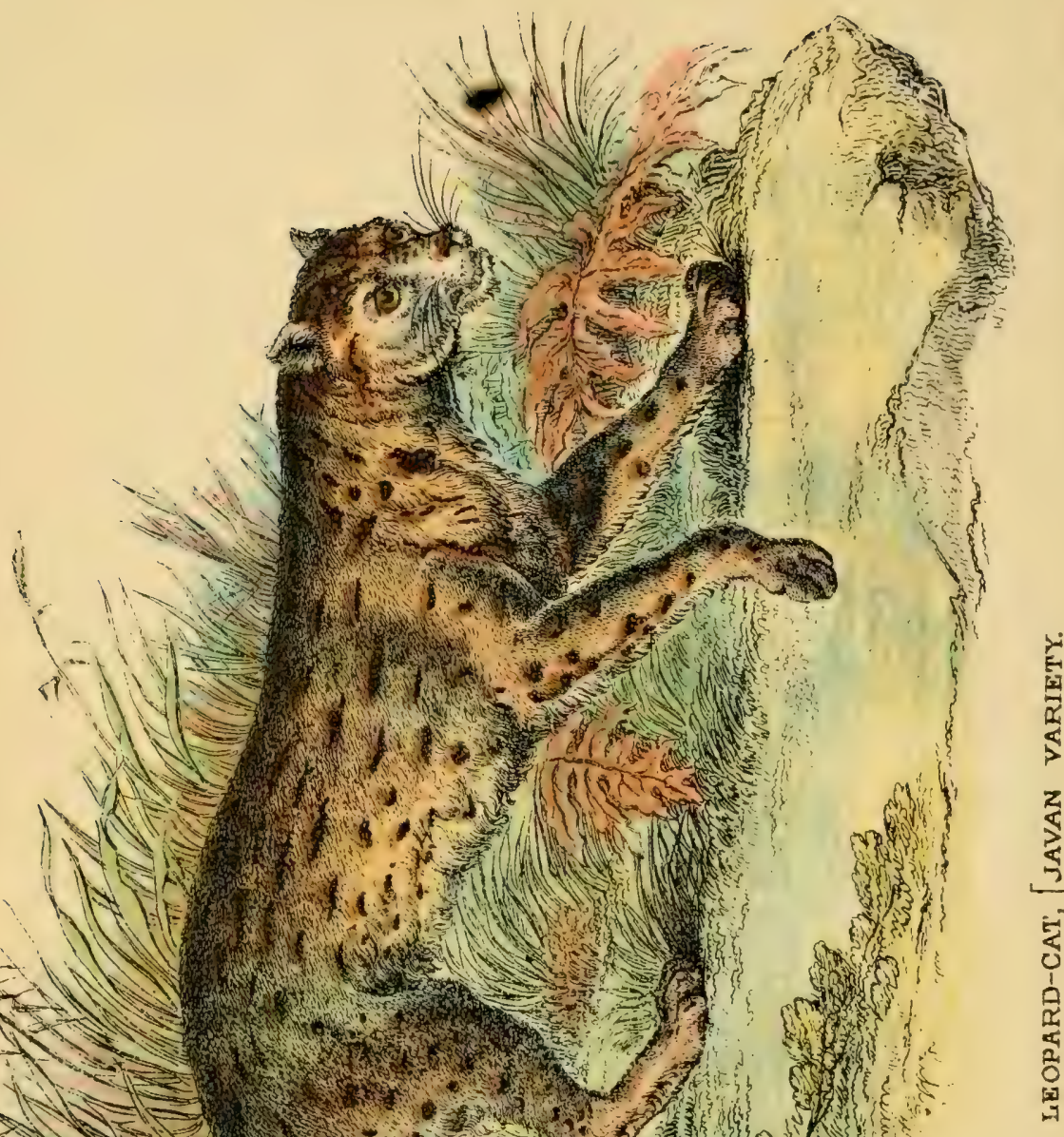


In the Malayan region, as well as the Philippine Islands, we meet with the smaller races described as $F$. minuta and $F$. sumatrana, in which the spots are more numerous and rounded than ordinary; while in some, although not all, cases the tail is shorter than usual. The Javan race ( $F$. javanensis) is a well-marked local form, easily recognised by its small size, grey ground-colour of the fur, and small spots, those on the back being elorgate in form and blackish-brown in colour, while those on the sides are brown. As already mentioned, the so-called $F$. jerdoni seems indistinguishable from this variety, and probably came from some Malayan locality.

Distribution.--India, from the outer Himalaya to the extreme south, but exclusive of Ceylon, Assam, Burma, the Malay Peninsula; the islands of Java, Sumatra, and Borneo; the Philippines, Formosa, China, and Amurland.

Habits. - IVith a geographical distribution almost as extensive as that of the Tiger, the Leopard-Cat, with its numerous varieties, is essentially a forest-dwelling species, subsisting on the smaller mammals and birds, which it captures with the stealth and agility of all its kind. In disposition, it displays the usual Catlike ferocity ; Mr. Blyth observing that of many specimens kept by himself in confinement, none ever displayed the slightest disposition to become tame and confiding. None of these examples were, however, captured at a very early age. Frequently taking up its residence in the hollow trunk of a decayed forest-tree, the Leopard-Cat prowls forth at night to commit depredations on the nearest poultry-roost, and is consequently destroyed by the natives whenever an opportunity occurs. The young, of which there are either three or four in a litter in India, are born during the month of May, the breeding-lair being generally either in a cavern or beneath the protection of some orerhanging mass of rock. Dr. J. Anderson describes this Cat as essentially arboreal in its habits, and was told by the 
natives that its prey largely consisted of Squirrels and TrceShrews (Tupaia).

"In Sarawak," writes Mr. Hose, "this pretty little Cat is found in the low country, and on the mountains up to 3,000 feet. It is constantly trapped by the natives, and is very fond of stealing fowls, going into the villages and taking chickens from beneath the houses. The Dyak name is 'Kuching Batu.' It usually lives amongst the rocks and in holes of trees."

XVI. BUSHY-TAILED RED-SPOTTED CAT. FELIS EUPTILURA.

Felis euptilura, Elliot, Proc. Zool. Soc. 1871, p. 760 ; id., Monogr. Felidæ, pl. xxvi. (1878-83); Mivart, The Cat, $p$ 4I6 (I88I).

? Felis microtis, Milne-Edwards, Recherches Mammif. p. $22 \mathrm{I}$ (I868-74); Mivart, The Cat, p. 4I7 (I88I).

Characters.-This is a pale-coloured spotted species from China, apparently allied to the Leopard-Cat, but with a shorter and more bushy tail. The type specimen is preserved in the British Museum, and is described as follows: "Ground-colour of the body light brownish yellow, strongly mixed with grey, covered with reddish-brown spots rather oblong in shape, and darkest and most conspicuous on the hind-quarters. Head grey, with a white line under the eyes and on the side next to the nose; two dark brown si pes in the centre, commencing at the tip of the nose, and one on each side, beginning at the eye, pass over the top of the head, and down the back of the neck to the shoulders; a dark red stripe runs from the corner of the eye, across the cheek, to the base of the ear, and another, rather lighter in colour, starting below the eye, passes across the cheek and curves back under the throat. The centre of the back is much darker than the sides, with spots of dark brown. Under lip white.as are also the throat and under-parts. Across 
the upper part of the breast are four broken bands of foxy-red; belly covered with large brown spots, becoming rufous between the hind-legs. Inner sides of hind-legs buff, with cross-bands of foxy-red, and covered with small reddish spots to the toes. Tail thick, rather short, bushy, darker than the body, with several incomplete broken rings of blackish-brown. Inside of ear buff, behind black." In the skull the nasal region is much narrowed, the orbit is slightly incomplete behind, and there is a small anterior pre-molar.

The Felis microtis, from Pekin and Mongolia, is identified with this form by Mr. Elliot in his "Monograph of the Felidæ," although Professor Mivart regards it as not improbably distinct. Having the general coloration of the Chinese variety of the Leopard-Cat, it has very small ears, long, soft, and abundant fur, with reddish and somewhat confluent spots; the white spot behind the ear divided into two moieties by a dark vertical streak, and the tail is not distinctly spotted.

Further evidence as to the unity or distinctness of these two forms is required, while the writer is by no means assured whether either are more than well-marked races of the Leopard-Cat. As in the case of other forms from the same region, nothing has been recorded in regard to the habits of this Cat.

XVII. THE RUSTY-SPOTTED CAT. FELIS RUBIGINOSA.

Felis nubiginosa, I. Geoffroy, in Bélanger's Voyage Indes Orient. p. I40 (I834); Elliot, Monogr. Felidæ, pl. xxix. (1878-83) ; Blanford, Mamm. Brit. India, p. 8 I (I888).

Viverriceps rubiginosa, Gray, Proc. Zool. Soc. 1867, p. 269; id., Cat. Carniv. Mamm. Brit. Mus. p. I8 (1869).

Characters.-This pretty little Indian Cat has had its distinctive characteristics so fully noticed under the head of 
the Leopard-Cat that only very brief mention is necessary here. In size it is consideras less than an ordinary Domestic Cat; the fur is grizzled grey, marked with reddish-brown elon gate spots ; tail without spots ; skull of the short and rounded type characterising the Leopard-Cat, but with the nasal bones more distinctly narrowed, the orbit of the eye completely encircled by bone, and the anterior upper pre-molar wanting. Length of head and body, from 16 to 18 inches; of tail, $91 / 2$ inches.

Distribution.-India and Ceylon, in the former country the species being recorded from the coasts of Madras, the hills of Southern India, Seoni, and perhaps Central India. The peculiarly restricted distribution of this Cat, which may be considered essentially a Singhalese and Southern Indian form, when contrasted with the wide range of its cousin the Leopard-Cat, is very noteworthy. It is, in fact, suggestive that while the piesent species was an inhabitant of Ceylon and Southern India, when the latter was cut off by sea from the more northern part of the country, the Leopard-Cat is a comparatively recent immigrant into India from the countries lying to the eastward of the Bay of Bengal, a view which would well account for the absence of the species from Ceylon.

Habits.-The smallest member of the Family inhabiting the Old World, the Rusty-spotted Cat, according to Jerdon, "frequents grass in the dry beds of tanks, and occasionally drains in the open country, and is said not to be a denizen of the jungles. I had a kitten brought to me, when very young, in 1846 , and it became quite tame, and was the delight and admiration of all who saw it. When it was about eight months old, I introduced it into a room where there was a small fawn of the Gazelle, and the little creature flew at it the moment it saw it, seized it by the nape, and was with difficulty taken off. I lost it shortly after this. Sir Walter Elliot notices that he has 
seen several undoubted hybrids between this and the Domestic Cat, and I have also observed the same." Later observations indicate that this Cat does not invariably shun jungles, since it has been taken in the forests of Ceylon. The exceeding gracefulness of the movements of the kittens in captivity has been noticed by all who have seen them, and their activity far surpasses that of domestic kittens of the same age.

\section{THE SERVAL. FELTS SERVAL.}

Felis serval, Erxleben, Syst. Règn. Animal, p. 523 (1777);

Elliot, Monogr. Felidæ, pl. xxvi. (1878-83).

Felis capensis, Gmelin, Syst. Nat. vol. i. p. 8I ( т 788 ).

Felis galeopardus, Desmarest, Mammalogie, p. 227 (1820).

Felis senegalensis, Lesson, Mag. Zool. I839, pl. x. ; Mivart, The

Cat, p. 407 (I88I).

? Felis servalina, Ogilby, Proc. Zool. Soc. 1839, p. 94; Bocage,

J. Sci. Lisb. ser. 2, vol, iii. p. I76 (1889).

Leopardus serval, Gray, List Mamm. Brit. Mus. p. 4I (I843)

\section{(Plate XIV.)}

Characters.-Size medium; legs long; tail short. General colour reddish-orange or tawny, approaching brown along the middle of the back, and paling to whitish on the under-parts. Body marked with black or dark brown spots, some of which are circular, and others irregularly shaped; towards the middle of the back the markings tending to unite into two longitudinal stripes; no dark streaks on the cheeks; two strongly-marked transverse bars on the inner sides of the fore-legs; tail ringed with black. Pupil contracting into an oblong vertical slit. In the skull the anterior pre-molar tooth present, and the second of unusually large size. Length of head and body reaching to 40 inches; of tail, to 16 inches.

With regard to the Servaline Cat $(F$. servalina) of West Africa, there is some difference of opinion among zoologists as 
to whether it is a distinct species, or whether it is identical with the Serval. The latter vie is adopted by Mr. Elliot in his "Monograph of the Felidx," and he is followed by Mr. W. L. Sclater in his Catalogue of the Mammalia in the Indian Museum, Calcutta. On the other hand, Professor Mivart regards it as a distinct species, and this view is strongly advocated by Professor Bocage. The latter writer observes that in this form the height is considerably inferior to that of the Serval, while the spots on the body in place of being large, black, and widely separated, are small, dark brown, and approximated. The ground-colour of the fur is also different, being paler and greyer in the Servaline Cat. The comparison of two young individuals of both forms leaves no doubt in the mind of this writer of their specific distinctness. Whichever view be adopted depends largely on the personal bias of the observer as to the amount of difference necessary to constitute a species. $F$. senegalensis, from the same region, is believed to have been founded on a young Serval, but if the Servaline Cat be really distinct, it is probable that this is the name by which it should be known.

Distribution.-Africa, from Algeria to the Cape.

Habits.-Writing of the Serval in "The Sportsman in South Africa," Messrs. Nicolls and Eglington observe that "at the present time it is only on extremely rare occasions that this very pretty and graceful animal is found any considerable distance south of the Tropic of Capricorn; northward throughout South-Central Africa it is fairly common, frequenting the thick bush in the vicinity of rivers. The karosses [mantles] made from its skin are only worn by the chiefs and the very high dignitaries amongst the native tribes, and are, in consequence, eagerly sought after, on which account the species runs a chance of rapid extermination. Its usual prey consists of the young of the smaller Antelopes, Francolins, and Guinea-fowls, to the 
latter of which it is a most destructive enemy in the breedingseason. When obtained young, the Serval can be tamed with little trouble, and makes an exceedingly beautiful and docile pet; but it is at first difficult to rear, and even in a state of domestication always bears a singular and most unaccountable aversion to black men, its otherwise even temper being at once aroused at the appearance of a native. When in anger, it is by no means a despicable antagonist, and very few Dogs will engage in a combat with it single-handed." Like the majority of the Felide, the Serval is a completely nocturnal animal. To the Dutch it is known as the Tegree Cat, while by the natives of Bechuanaland it is termed Tali.

XIX. THE TOGO SERVAL. FELIS TOGOENSIS.

Felis (Serval) togoënsis, Matschie, S.B. Nat. Fr. Berlin, I893, p. 109.

Felis togoënsis, Matschie, M.T. deutsch. Schutz. vol. vi. art. 3, p. Io (1893).

Characters.-This form is described as of the size of a Wolf, with the upright black ears marked by a white spot on the backs. Tail one-third the length of the body. Upper-parts reddish-yellow; the back marked with from five to seven rows of dark streaks broken up more or less into spots, and sometimes seven rows of blacker and smaller spots on the flanks. Fore-limbs with small, and hind-limbs with larger spots. English naturalists have not yet had an opportunity of comparing this form with the Common Serval.

Distribution.-Togo-land, West Africa.

XX. THE RED TIGER-CAT. FELIS CHRYSOTHRIX.

Filis chrysothrix, Temminck, Monogr. Mamm. vol. i. p. 25 I (i 827 ); Elliot, Monograph of Felidæ, pl. xxiv. (1878-83); Mivart, The Cat, p. 406 (I88I); Matschie, M.T. deutsch. Schutz. vol. vi. art. 3, p. 10 (1893). 
Felis aurata, Temminck, op. cit. p. I 20 (withdrawn).

Felis mutila, Waterhouse, Proc. Zool. Soc. 1842, p. I30; Mivart, The Cat, p. 406 (I88I).

Characters.-This may be characterised as a rather small, long-tailed Cat, with the upper-parts reddish-brown, marked on the sides with black spots; under-parts white, with black spots ; tail reddish-brown above and white beneath, without either spots or bands; no dark streaks on the face.

Of rather smaller size than the next (with which it was identified by Mr. Elliot), this species seems sufficiently distinguished by the reddish hue of the fur and the general absence of distinct dark markings on the tail. The Felis rutila of Waterhouse was founded on an imperfect skin in the British Museum. It is described as reddish-brown, with indistinct small darker spots on the sirles; back medianly dark brown; under-parts white, with large dark brown spots; tail reddish-brown, with a dark central line along its upper surface, while at each side it is pale, with obscure indications of darker bands. In the skull the orbit is incomplete behind, and the anterior pre-molar of very small size. Length of head and body, about 28 inches; of tail, $\mathbf{r} 6$ inches.

Distribution.-Interior of 'Togo-land, West Africa. This species is frequently known by the name of the Golden-haired Cat.

XXI. THE GREY TIGER-CAT. FELIS CELIDOGASTER.

Felis celidogaster, Temminck, Monogr. Mamm. vol. i. p. I40 (1827), and Esquisses Zool. p. 87 ; Mivart, The Cat, pp. 406, 407 (188I) ; Matschie, M.T. deutsch. Schutz. vol. vi. art. 3, p. 10 (1893).

Felis neglecta, Gray, Ann. Mag. Nat. Hist. vol. i. p. 27 (1838); id. Cat. Carniv. Mamm. Brit. Mus. p. 24 (1869); Mivart, The Cat, p. 407 (I88I). 


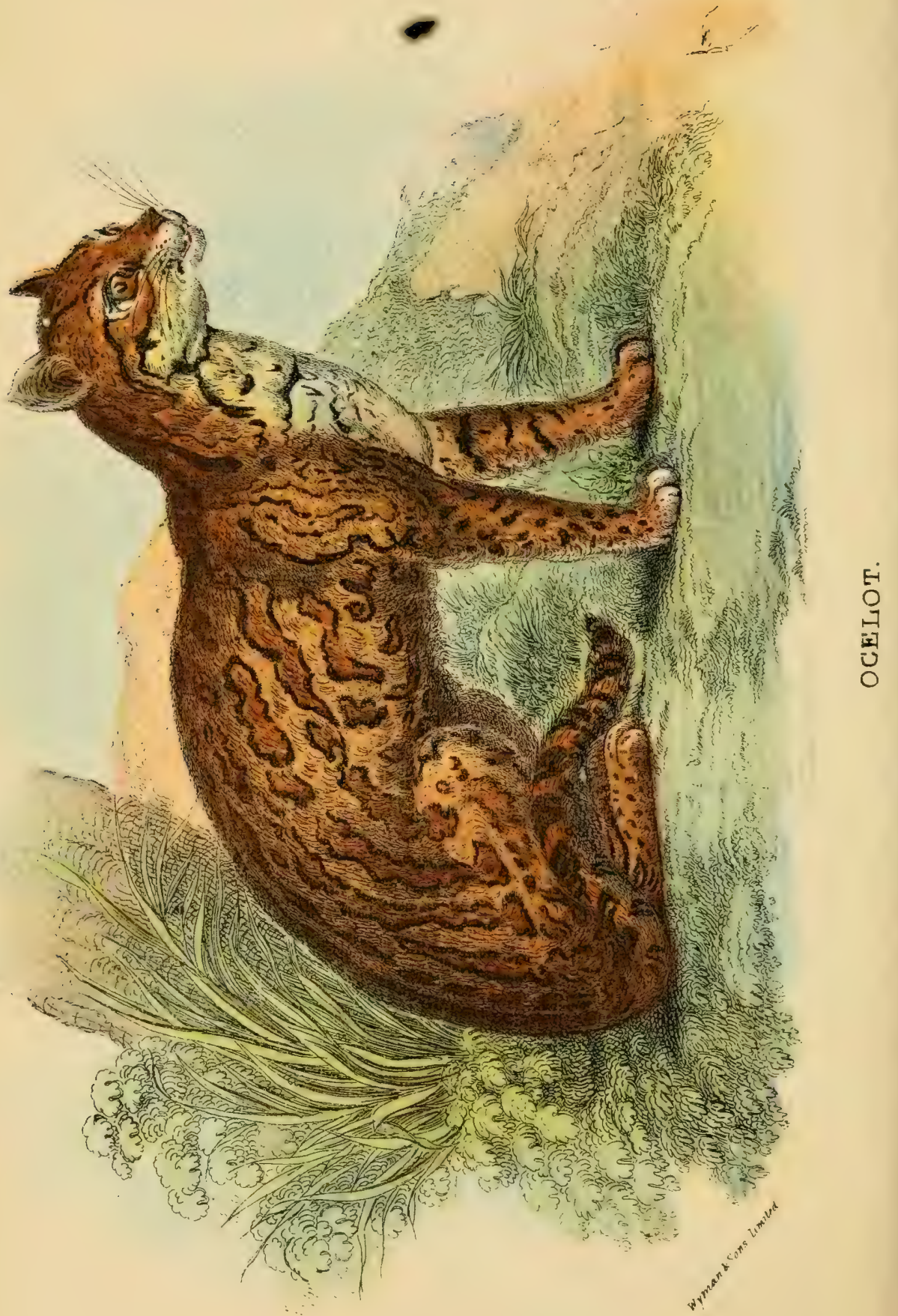


Characters.-According to Herr Matschie, this rather slenderly-made Cat is distinguished from the last by its slightly superior size, grey colour of the upper-parts, and distinctly ringed tail, the under-parts being white, and, like the back, spotted with black. With this form may doubtless be identified the type of Felis neglecta, now preserved in the British Museum, which was originally described as follows: "Grey; head and body marked with numerous small darker spots ; spots of the lower parts of the sides rather larger; belly white, with large blackish spots; tail quite half the length of the body, with a dark line along the upper surface; sides paler, with obscure indications of darker streaks." It will be seen that so far as regards the markings on the tail, the description of this specimen does not differ from that of the type of Felis rutila; and it is not impossible that Mr. Elliot may be right in regarding this form merely as a grey phase of the Red TigerCat. If this eventually prove to be the case, the name $F$. celidogaster will have to be adopted for the species.

Distribution,-The Gold Coast.

As is the case with so many of the West African Mammals, which inhabit districts more or less inaccessible to Europeans, we have no information as to the habits of either the Red or the Grey Tiger-Cat.

XXII. THE OCELOT. FELIS PARDALIS.

Felis pardalis, Linn., Syst. Nat. ed. I2, vol. i. p. 62 (г766);

Elliot, Monogr. Felidæ, pl. xvii. $(1878-83)$; Alston, in

Godm. and Salv. Biol. Centr. Amer. Mamm. p. 60 (I880). Felis ocelot and $F$. catenata, H. Smith, in Griffith's Animal Kingdom, vol. v. p. 169 ( 1827 ).

Felis canescens, Swainson, Anim. in Menag. p. I18 (1838). Leofiardus pardalis and L. griseus, Gray, List Mamm. Brit.

Mus. p. 42 (I843).

Leopardus pictus, Gray, op. cit. p. 43. 
Felis melanura, Ball, Proc. Zool. Soc. I844, p. I28.

Felis albescens, Pucheran, Vyage Vénus, Zool. p. I 37 (I 855 ). Felis picta, Severtzoff, Rev. Mag. Zool. ser. 2, vol. x. p. 194 (1858).

Felis grisea, Gray, Proc. Zool. Soc. I867, p. 270.

Felis pardoides, Gray, Proc. Zool. Soc. I867, p. 403.

\section{(Plates $X V \cdot, X V T_{0}$ )}

Characters.--Even more variable in coloration than the Leopard-Cat (to some varieties of which it approximates in hue and markings), the small South American species known as the Ocelot is one of the most difficult members of the whole family to describe adequately. The markings take the form of obliquely placed spots elongated into streaks; such spots being bordered with black, and having the enclosed area generally of a darker and richer hue than the general groundcolour of the fur. The effect thus produced is very rich and striking; and it will not fail to be noticed that this type of coloration is only a modification of that obtaining in the Jaguar, the rosettes of the latter being elongated into streaks, and the bordering spots united into unbroken lines.

Including some of the varieties, the ground-colour of the Ocelot may be described as ranging from tawny-yellow to reddish-grey; the dark markings running into chain-like streaks and blotches, generally forming oblique elongated spots, severally bordered with black, and enclosing an area more or less darker than the ground-colour. The head and limbs are marked by small solid black spots, while there are two black stripes on the cheek, and one or two dark transverse bars on the inner surface of the fore-leg. The tail may be either ringed or marked with dark bars on its upper surface; and the under-parts and inner surfaces of the limbs are whitish. The pupil of the eye contracts to a vertical slit; and in the skull the ring of bone round the orbit is incomplete behind. 
In the more typical forms the length of the head and body ranges from 26 to 33 inches, and that of the tail, from II to as much as 15 inches.

Of the varieties, local races, sub-species, or whatever they may be called, the form described as $F$. grisea takes its name from the grey hue of the ground-colour of the fur, which may even tend to whitish on the flanks. Another grey phase is presented by the variety $F$. pardoides, which differs from the preceding in that the spots on the flanks are less ring-like, while the stripes on the neck are shorter and less distinct, the ground-colour in that region being redder. This form is of small size, the length of the head and body being 25 inches, and that of the tail, 15 . In both these grey phases the characteristic tinge exists at birth. The Leopardus pictus of Gray has the coloration less brilliant than in the typical race, less closely approximated spots, and a smaller difference between the shade of the central areas of the latter and the general ground-colour. On the other hand, the variety $F$. melanura is characterised by the intensity and brilliance of its coloration, the ground-colour being bright fulvous, the black markings very numerous and deep, and the white under-parts standing out in bold contrast to the rest.

Lastly, we have the so-called Chained Ocelot ( $F$. catenata $)$, described by Hamilton Smith in the following words: "It is about the size of a Wild Cat; the legs are, in proportion, shorter than in the Ocelot; the head and body heavier; the mane, forehead, under the eyes, arms, shoulders, back, rump, hind-legs, and tail are of a reddish-yellow colour; the temples ochreous ; the cheeks, throat, belly, and inside of the legs white. Several rows of black spots from the ears converge on the forehead. There is a single streak from the outer angle of the eye to below the ear. On the shoulders, back, sides, rump, and hams there are long chain-like streaks of black and reddish- 
brown intermixed; the belly and throat have black streaks, and the tail has imperfect black annuli."

From the marked difference in these varieties, and the fact that they breed true, it is probable that each has a definite local distribution; and hence those zoologists who are inclined to rank every well-marked variation as of specific importance, would probably regard them as representing as many species.

The specimen depicted in our first illustration was a female, measuring 2 feet $9 \mathrm{~T} / 2$ inches to the root of the tail, our plate being copied from Wilson's "Illustrations of Zoology." In this example "the upper part of the head is deep tawny, streaked with blackish-brown. A blackish streak passes from the upper and inner canthus of each eye to the forehead, between the ears, in a converging manner; and between them there are several delicate lines of the same colour. Another strongly expressed stripe passes from the outer canthus of the eyes to the angles of the lower jaw, where an irregular blackish bar passes upwards, to within an inch of the outer edge of the ears. From the angles of the jaw, two stripes pass downwards, and meet in front of the throat. The ears are thin, and blackish externally, with a spot of pure white on the back of each. There is a patch of pure white at the angles of the mouth, beautifully speckled with three rows of black dots, which lie at the roots of the vibrissæ; chin and throat white, with blackish bars; the ground-colour of the breast less pure; that of the belly and insides of the legs dull grey. Around the eye are white marks, nearly enclosing the orbit, but interrupted by the blackish stripes above described. There are four chains of open lengthened spots on each side, more or less distinct, sloping down from the shoulder towards the flanks. The legs are irregularly marked with numerous black spots, differing in size and shape. The tail is barred with black on its sides and dorsal line, but is not annulated as in some of the varieties." 



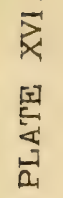
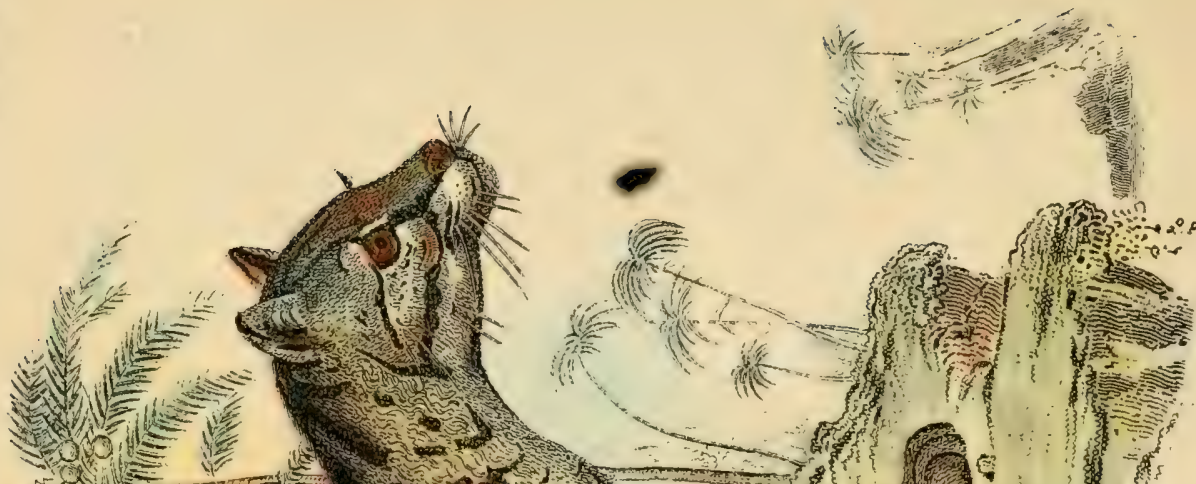

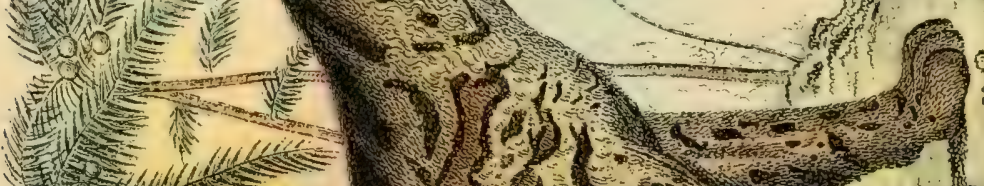
Why 等地,

㰃

H.

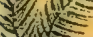

, inthe

in dist

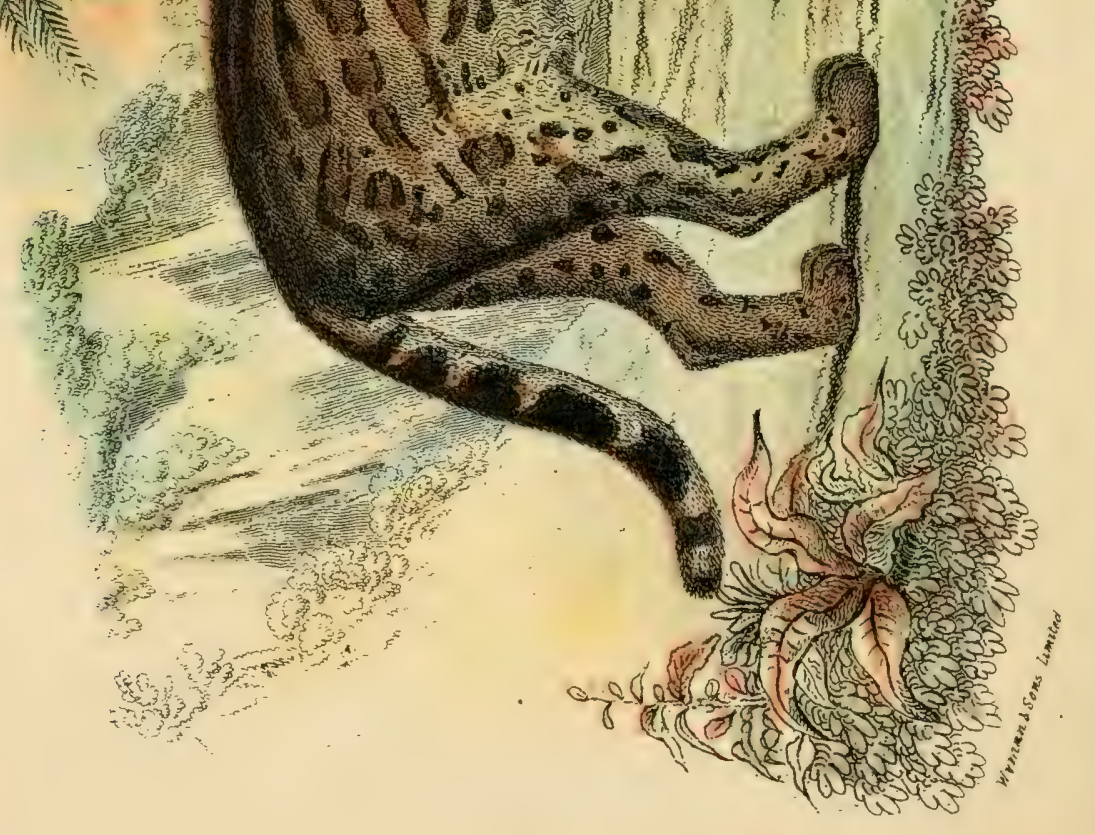


Other specimens have the ground-colour of the fur paler, and of a tawny-yellow tinge.

Distribution.-America, as far north as Arkansas, Louisiana, Texas, and Mexico; thence through Central America to South America east of the Andes, where it is said to extend southwards into Patagonia.

Habits.-Essentially a forest animal, and hence unknown on the open pampas of Argentina, the Ocelot is an excellent climber, and is said to be characterised by its ultra-fierce and bloodthirsty disposition, although in confinement it can be tamed without much difficulty.

The following particulars of the habits of the female Ocelot, forming the subject of our first illustration, are taken from Wilson, who writes: "She is remarkably playful, much inclined to climb up the legs of those who approach her (an inconvenient tendency, from the length and sharpness of her claws), and delights in being carried about in people's arms like a Cat. She is an extremely powerful animal, but gentle through the influence of domestication, and attached to those who feed her. She one day seized a chamois-leather glove, which she tore to pieces, and swallowed immediately. The person to whom the glove belonged could not rescue it with the strength of both his hands. While young, this animal was fed on oatmeal-porridge and milk, and has been all along sustained chiefly by milk and vegetables, with occasionally a bit of boiled liver, or other offal. The nature of the diet has obviously a considerable influence on her disposition. When farinaceous food and milk prevail, she is certainly more tractable than when animal food is given in any considerable quantity; and when treated with live birds or raw flesh, she is observed to assume greater fierceness in her aspect, and to strike more forcibly with her fore-paws at passing animals. 
She has sometimes made her escape from confinement, and exhibited a power of climbing trees with great ease and activity. She has occasionally committed considerable havoc in the poultry-yard, and has more than once greatly alarmed a horse by jumping on its back in the stable. In this last feat, however, the Ocelot seemed to be actuated rather by a desire for society than the love of mischief, for she coiled herself up on the hind-quarter, evidently with the view of effecting a settlement for the purpose of repose ; but the plunging of the horse induced her to use her claws to render her seat more secure. Upon this the steed, as might be expected, redoubled his exertions to dislodge the enemy, and the Ocelot was at last thrown, receiving in her descent a kick which she never forgot, for it has been observed that, on seeing a horse, she immediately betakes herself to her den. . . . . A few days before her departure from Liverpool to London, she occasioned a serious alarm. Being secured by a long chain in front of a cottage door, she suddenly threw down a young girl of four years old, and, to the horror of the beholders, appeared to seize the child by the throat. This was, however, intended merely as play, for neither her sharp teeth nor crooked talons inflicted the slightest injury, and, after tumbling over each other more than once, the child was taken up severely frightened, but no way hurt."

XXIII. THE TIGER-CAT. FELIS TIGRINA.

Felis trgrina, Schreber, Säugethiere, vol. iii. p. Iо० (1778); Elliot, Monogr. Felidæ, pl. xviii. (I878.83); Alston, in Godm. and Salv. Biol. Centr. Amer. Mamm. p. 6I (I880); Mivart, The Cat, p. 409 (I88I).

Felis mitis, F. Cuvier, Hist. Nat. Mamm.vol. ii. pl. I 37 (1820); Matschie, S.B. Nat. Fr. Berlin, r 894, p. 59.

Felis chati, H. Smith, in Griffith's Animal Kingdom, vol. v. p. 479 (1827).

Felis macrura, Neuwied, Beitr, Naturg. Bras.vol, ii. p. 37 I (1836). 


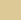


呿

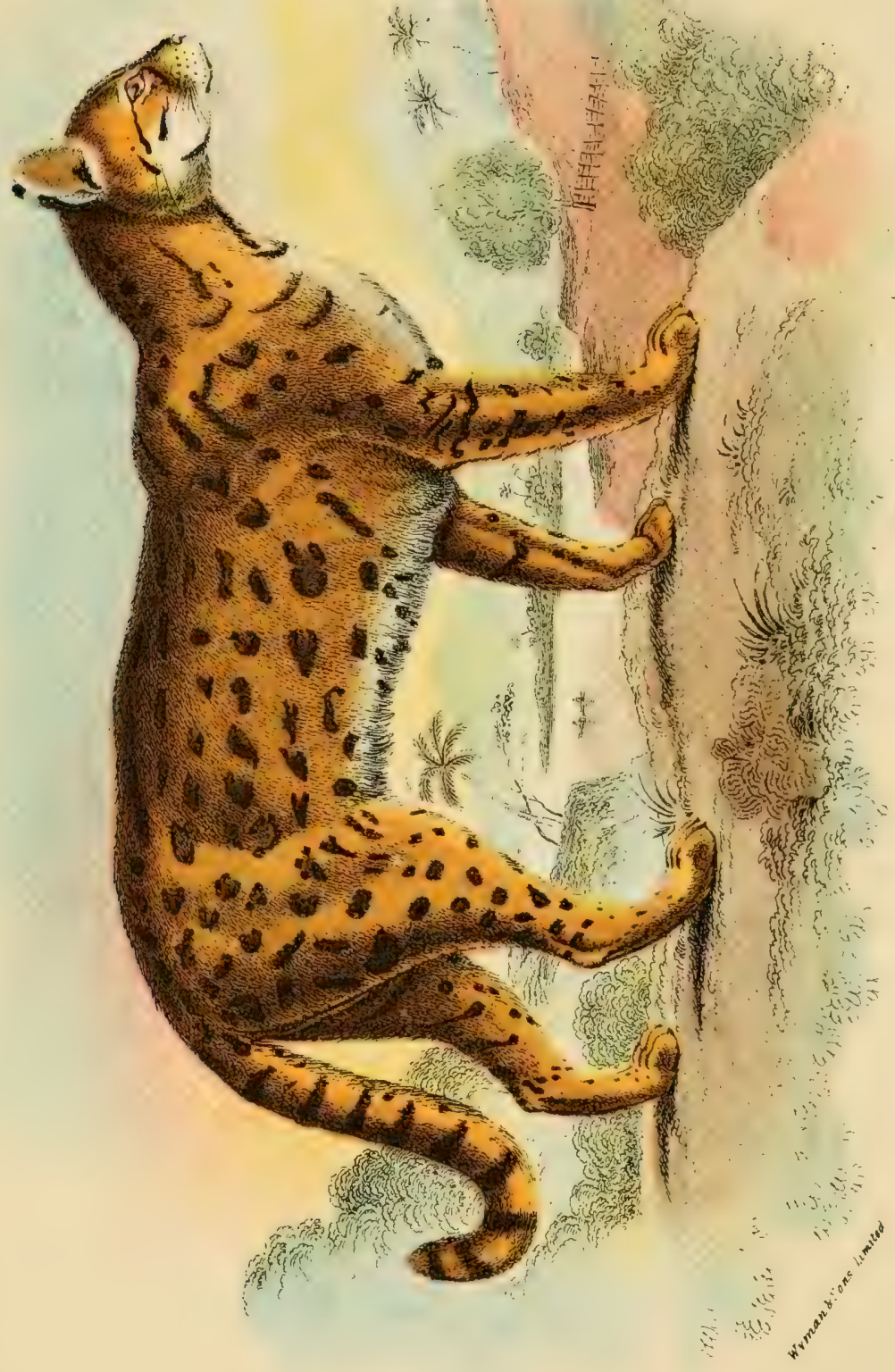

$E$
0
1
1
0
I
0
0
E- 
Felis margay, Azara, Nat. Hist. Quad. Paraguay, p. 237 (1838). Leopardus tigrinoides, Gray, List Mamm. Brit. Mus. p. 42 (1843).

? Felis guttata, Hensel, Abhandl. Ak. Berlin, I872, p. 73; Mivart, The Cat, p. 4ro (I88I ; nec Hermann).

(Plate XVII.)

Characters. - The Tiger-Cat, of which there are three more or less well-marked races, is another variable American species, distinguished from the last by the shorter and frequently solid spots, which are not aggregated into oblique chains. In the typical form, or Margay, the somewhat harsh fur is dull grizzled grey in ground-colour, ornamented with elongated black spots and rings; the tail being likewise marked above with black spots, which frequently coalesce into transwerse bars, although not forming complete rings. The cheek is marked with three transverse black bars. In length the head and body measure rather more than 20 inches, and the tail I I inches.

The variety known as the Chati (F. mitis), which is the one represented in our illustration, is a somewhat larger animal, with soft, bright fulvous fur, and black-bordered short spots of variable size, in which the centres are sometimes pale-coloured. The Long-tailed Cat (F. macrura) is likewise a yellow-coloured form, characterised by the length of the tail. In these forms the length of the head and body may reach nearly 27 inches, while that of the tail varies from 14 to 19 inches. It does not appear that the Cat from Rio Grande do Sul, described by Hensel as $F$. guttata, can be distinguished from the present species.

According to Herr Matschic, in the wooded districts of - Argentina there may be found in a single neighbourhood a complete transition as regards colour between specimens in which the ground-colour of the fur is greyish and the blackbordered spots are elongated, and those in which the ground- 
colour is yellow and the spots are short. Both the late Mr. Alston, in the "Biologia Cen li-Americana," and Mr. Elliot, in his "Monograph of the Felidæ," are likewise of opinion that the three varieties above-mentioned cannot be regarded as species.

Distribution.-America; from Mexico southwards on the east side of the Andes as far as Paraguay and the wooded interior districts of Argentina. Perhaps Trinadad.

Habits.-From the little that has been recorded, it appears that the Tiger-Cat is an inhabitant of warm, well-wooded districts, where it spends a considerable proportion of its time in climbing among the forest-trees. In parts of Paraguay the Indians are in the habit of hunting these Cats through the forest with Dogs till they take to a tree, when they are shot or shaken out. In captivity, if taken young, they readily become exceedingly tame and gentle; and it was from this trait that Cuvier gave the name of mitis to the Chati. Their prey is doubtless of the same nature as that of the other smaller Cats.

Writing of the variety of the Chati, which he says is termed by the natives of Paraguay the Chibi-guazu, or Great Cat, Azara states that in that country it was formerly so common that he knew of eighteen being captured in a couple of years at a single house. "Few persons, notwithstanding, are acquainted with it, nor can people penetrate into its lurkingplaces; and I very much doubt whether any $\mathrm{s}_{2}$ eccies of quadruped more effectually conceals itself. It passes the day in the most impenetrable fastnesses, and goes out to hunt after dusk, especially if the night be dark and stormy; at such times these Cats enter boldly into the corals and courtyards, in all cases without being perceived by the watch-dogs. On moonlight nights they neither approach inhabited places nor fall into traps; and it is in vain to wait for them with a gun, since thev 
are so vigilant as invariably to detect the hunter and flee before they can be approached. They climb trees in search of domestic fowls, and carry off as many as six in a night, sometimes leaving several dead behind them. They avoid men and Dogs with extreme caution, and each pair inhabits a separate district, as may be inferred from the fact of the male and female, and no more, being always caught on the same spot."

Referring to some specimens kept in captivity, the same author observes that "they spent almost the whole day rolled up in the shape of a ball, and the one which wished to stretch himself did not do so until he had first licked the "Chibi-guazu" at his side. Whenever we put straw into the den, or within their reach, so that they could seize it by putting their paws through the bars, we always found on the day following that they had placed it in a heap, after dividing it into chips a quarter of an inch long; and on these they reposed. In the same manner they broke and tore in pieces all the small sticks or twigs with which the inside of their den was furnished. They spent the twilight and night in walking to and fro close to the sides of their den ; and if another "Chibi-guazu" crossed or interrupted this exercise in any way, they puffed and made gestures like a Cat when irritated, without using their paws ; but they never quarrelled, except when very much irritated, and then they struck at each other with their fore-paws. When first caught, they devoured five pounds of flesh each day, although they were subsequently satisfied with three. We prepared a ration for each of the twelve or fourteen individuals, and each took it with its paws according to the length of time they had been in captivity, without the others offering the slightest molestation, but if the Cat, whose turn it was to receive a portion, disregarded, or did not devour it immediately, another snatched at it, and the lawful proprietor made no defence, save by sneezing, and occasionally by giving blows with its fore-paws 
We made a walk for them, enclosed by a kind of hurdle, in which we could introduce Bats, Fowls, Ducks, or young Dogs, and upon opening their cage we found that usually only a single Cat came out in pursuit of each victim, and almost always in precedence, according to the length of time they had been in confinement. They caught Cats and Dogs by the nape of the neck in their mouths, and throwing them to the ground, overlaid them, without permitting any movement, until they were quite dead. Cat's flesh seemed to produce the itch, which fretted them, making them mew like Domestic Cats, and finally leading to their death. They also ate Snakes-both innocuous and poisonous-and Toads, but these disagreed with them to such an extent that, after being reduced almost to skeletons, they perished in the course of a few days. If a Dog were as big as themselves they did not touch him, for they do not come to one another's assistance; and if one alone cannot overcome any prey which may present itself, he leaves it. They catch birds by the head and neck, and thoroughly strip them of their feathers with their teeth before eating them. It appears that they are not unnecessarily cruel; my friend at least observed that one did not kill a fowl enclosed in his den till the third day. We frequently shut the doors of the yard and opened the den that they might leave it; those which had been most recently caught moved first, and on some occasions the old ones would not come out, even when the boy entered the den to sweep it out. We left them at liberty for several hours, during which time they examined every crevice and then lay down to sleep; on the boys persecuting them with sticks and canes they went back to the den without turning on their pursuers, although severely beaten. On a certain occasion, one of them becoming exceedingly lazy, on entering the den he was abused and bitten by his female, as if she would punish him. Their eyes shone at night like those of the Domestic Cat, which animal they resemble in form and 
habits, in lying down, in licking and cleansing themselves, washing their faces with their paws, in puffing, sneezing, and all other particulars. My friend caught a young whelp, and it became so thoroughly domesticated as to sleep in the skirts of his clerical gown, and went about loose, and he affirmed that no animal could be more tractable ; the neighbours, however, killea it, as it destroyed their poultry."

XXIV. GEOFFROY'S CAT. FELIS GUIGNA.

Felis guigna, Molina, Saggio Storia Nat. Chili, vol. i. p. 295 ( 782 ); Mivart, The Cat, p. 41о (I88I).

Felis geoffroyi, D'Orbigny, Voyage Amér. Mérid. vol. iv. pl. xii. (I847); Elliot, Monogr. Felidæ, pl. xix. (IS78-83);

Matschie, S.B. Nat. Fr. Berlin, I894, p. 59.

Pardalina warwickii, Gray, Proc. Zool. Soc. IS67, p. 267; Sclater, Proc. Zool. Soc. 187o, p. 706, 1872, p. 203.

? Felis pardinoides, Gray, Proc. Zool. Soc. I 867 , p. 400, and

Cat. Carniv. Mamm. Brit. Mus. p. 27 (IS69); Mivart, The Cat, p. 4 I I (I88I).

Characters.-This species, which is sometimes known as the Spotted Tiger-Cat, has the ground-colour of the fur varying from yellowish-grey to grey, the chin and a streak on the crown of the head being white, and the under-parts paler. There are four black streaks on the crown of the head, two on each cheek, and one between the shoulders; the fore-limbs and body are covered with numerous small and nearly equal-sized solid black spots placed at equal distances from one another. The throat and chest, as well as the upper part of the limbs, are barred with black; the tail is spotted at the base, and ringed towards the tip; and the black ears have a large white spot behind.

There appear to be two races of this Cat, which some regard as distinct species. Firstly, the typical F. guigna, extending from Chili to Tucuman, in which the general colour is greyish, while the spots are small and show some tendency to 
aggregate in rosettes; and, secondly, the more southern and eastern F. greoffroyi of the Argentine, in which the colour is yellower and the spots are larger. The skull is remarkable for its shortness, width, and convexity, the orbit being open behind, and the anterior pre-molar very minute.

Distribution.-South America, from Chili to Paraguay and Argentina. In Uruguay, according to Mr. Aplin, the MonteCat (Gato del monte), as it is locally called, is now becoming very rare, being trapped by the Sheep-farmers on account of the damage it inflicts on the lambs. In Tucuman the typical Chilian form is abundant; while in the wooded district of Tornquist, lying to the north of Bahia Blanca and south of the Sierra de la Ventana (Sierra de Curumalan), in the south of Argentina, it is replaced by the true $F$. geoffroyi. This form is also found on the Argentine pampas.

\section{BOGOTÁ TIGER-CAT. FELIS PARDINOIDES.}

Felis pardinoides, Gray, Proc. Zool. Soc. I867, p. 400; id., Cat. Mamm. Brit. Mus. p. 27 (IS69); Mivart, The Cat, p. 4II (I88I).

Characters.-Originally described as of Indian origin, this Cat was identified by Mr. Elliot, in his "Monograph of the Felidæ," with the preceding, but is regarded by Professor Mivart as distinct. It differs from the typical Geoffroy's Cat in the larger size of the spots, which take the form of dark blackbordered blotches. Of the two known skins, one has the ground-colour greyer than the other. Length of head and body, about 18 inches; of tail, ro inches.

Distribution.-Bogotà, U.S. of Colombia.

XXVI. THE JAGUARONDI. FELIS JAGUARONDI.

Felis jaguarondi, Fischer, Zoognosie, p. $22 \mathrm{~S}$ (I8I4); Elliot, Monogr. Felidæ, pl. xii. (I878-83).

Felis mexicana, Desmarest, Nouv. Dict. d'Hist. Nat. vol. vi. p. I 12 (I816). 
Felis unicolor, Traill, Mem. IVern. Soc. vol. iii. p. i 70 (1819). Felis yagouarondi, Desmarest, Mammalogie, p. 230 (1820). Felis yaguarundi, Wagn. Suppl. Schreb. Saug. I I, p. 4I, pl. ciii. B ; Alston, in Godm. and Salv. Biol. Centr. Amer. Mamm. p. 63 (1880).

Felis darvinii, Martin, Proc. Zool. Soc. 1837, p. 3. Leofardus yasouarondi, Gray, List Mamm. Brit. Mus. p. 42 ( 1843 ).

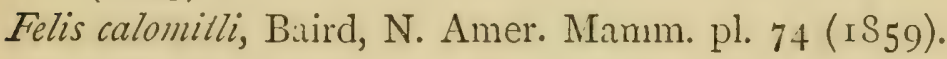

Characters.-Of relatively small size, this species is readily distinguished by its uniform coloration, which is generally blackish- or brownish-grey, with a tendency to a reddish or greyish phase in some specimens; the lower parts of the limbs being blackish. The body is long, the limbs short, and the tail much elongated, the head being also long and low. Blackish-grey at their bases, the hairs are black in the midd: and greyish at their extremities. Female skins are reported to be lighter and brighter in colour than those of males. Pupil of eye circular when contracted. Skull elongated and flattened, with the nasal region very strongly compressed. Length of head and body, about 30 inches; of tail, 25 inches.

Distribution.-Brazil, Paraguay, Guiana, to North-eastern Mexico.

Habits.-According to Azara, the names "Jaguarondi" (or "Yaguarundi") and "Eyra" are applied indifferently in Paraguay to the present species and the one here described under the latter title; and it is accordingly merely a matter of convenience that the two names are respectively assigned to the two species by naturalists. The same naturalist writes: "I have never seen the Yaguarundi except in Paraguay and the Guaranese missions, where I procured two specimens precisely similar; experienced persons have assured me that they were adults, that the sexes only differed in the male being rather the 
larger, and that they brought forth only two young ones in a year. They inhabit the borders of woods, thickets, enclosed cardales, and ditches, without venturing into open places. They climb trees with facility, and remain long in them, subsisting in the same manner as other Cats; if they find an opportunity, they also attack poultry in farmhouses. Their body is longer and their ears are shorter and smaller than tho e of the common Cat; from which they also differ in having a more bushy tail, and in the pupils of their eyes preserving the circular form when exposed to the sun, as I observed in one of the females which, being caught young, allowed herself to be handled and scratched within twenty-eight days. The Yaguarundi, it is said, pounces upon Deer, and does not loose his hold, although they gallop off at full speed, until he kills them; but I believe this to be true only of young fawns."

XXVII. THE SMALL-FOOTED CAT. FELIS BRACCATA.

Felis braccata, Cope, American Naturalist, vol. xxiii. February, p. 144 (1889).

Characters.-Closely allied to the preceding species, from which, according to its describer, it is distinguished by the following features: The feet are smaller, and the toes of more equal length than in $F$. jaguarondi; while the claws are very much smaller. Both the inner and outer toes are relatively shorter in both limbs in $F$. jaguarondi than in the present species. In $F$. braccata the tail is rather shorter than in the former, being less than the length of the body, and only an inch in excess of the hind-limbs when extended to their full length; whereas in $F$. jaguarondi it equals the body in length, and reaches two inches beyond the limbs. Finally, while the ears in $F$. jaguarondi are broadly rounded, in $F$. braccata they are so prominently angulated as to present an apex less than a right angle. The fur of the muzzle has a truncate border, 


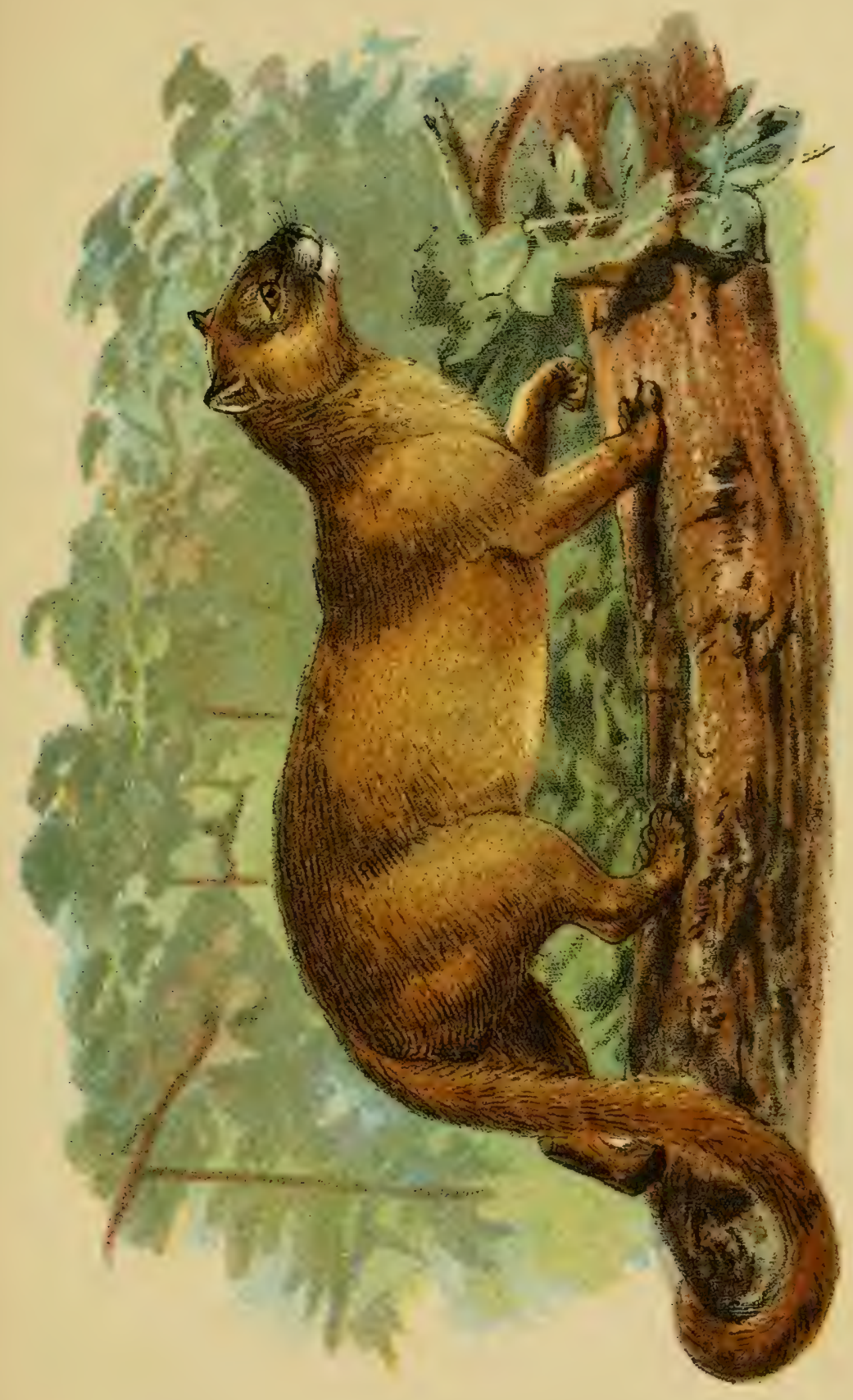

(x) 

while in $F$. jaguarondi the border presents an acute angle forwards, as it follows the upper border of the nostrils above.

As regards coloration, the hinder surfaces of the ears resemble the top of the head in F. jaguarondi, whereas in F. braccata they are of two contrasting colours, both different from that of the head. In $F$. jaguarondi the internal surfaces are like the hinder ones; whereas in the present species they are totally different, resembling those of various spotted Cats. The legs of F. juguarondi are coloured on their outer surfaces like the back, and are black inferiorly; whereas in the present form they are marked by cross-bands superiorly, and on their lower halves are totally black.

After mentioning that the difference in the length of the tail in the two forms may prove to be a character of small importance, Professor Cope observes that "the aggregate of characters indicates the specific distinctness of F. braccata from $F$. jagzurondi. The only approach to any of the peculiar characters of F. braccata in descriptions of $F$. jaguarondi, which I can find, is in that by Mr. Alston in the 'Fauna CentraliAmericana,' who states that there are transverse bars on the inside of the legs."

Distribution.-South Brazil. The species was established on the evidence of a single skin, obtained either from Rio Grande do Sul or in Matto Grosso, the loss of the label having left the precise locality a matter of uncertainty.

\section{THE EYRA. FELIS EYRA.}

Felis eyra, Fischer, Zoogn. p. 228 ( $18 \mathrm{r}_{4}$ ); Elliot, Monogr. Felidæ, pl. xiii. $\left(\mathrm{I}_{7} \mathrm{~S}_{-} \mathrm{S}_{3}\right)$; Alston, in Godm. and Salv. Biol. Centr. Amer. Mamm. p. 64 (ISSo); Mivart, The Cat, p. 4I 2 (I88I).

Felis unicolor, Baird, N. Amer. Mamm. pl. 74 (I S59). (Piaie XVIII.) 
Characters.-Readily distinguished from all the other members of the Family by its extremely elongated and IVeasel-like body, short limbs, very long tail, and long and flattened head, this South American species is also one of the comparatively few uniformly-coloured forms. In colour the soft fur is uniform reddish-yellow or chestnut, with a whitish spot on each side of the upper lip. Pupil round. Skull much elongated and flattened, with the nasal region somewhat compressed laterally, and the anterior upper pre-molar present. In size the species may be compared to a rather small Domestic Cat, but with the limbs proportionately much shorter, and the body longer.

Distribution.-Brazil, Guiana, and Paraguay, extending northwards to the Rio del Norte between Mexico and Texas; but much more rare to the north than to the south of the Isthmus of Panama.

Habits.-Information is still required as to the habits of this Cat in a state of nature. It is, however, known to be a denizen of forests, and is extremely fierce in disposition, while its movements are extremely active and lithe. Five specimens had been exhibited in the London Zoological Gardens up to $18 S_{3}$, the first of which was purchased in 1860 . The latter was extremely gentle in disposition, although one of the others proved untameable. Azara writes: "I had one nearly full-grown which had been captured young, and was as gentle and playful as any kitten could be ; but I kept it chained, as it was a great enemy to poultry. It slept in the skirt of my garments, purring, or making the rum of the Cats; Rats were an easy prey to it, and no one of the nine Paraguayan species could surpass it in the certainty with which it captured, or the promptitude with which it despatched, the largest Rats, as well as birds of all kirds."

With regard to the restriction to the name Eyra to the present species, the reader is referred to the Jaguarondi, on page I 5 . 


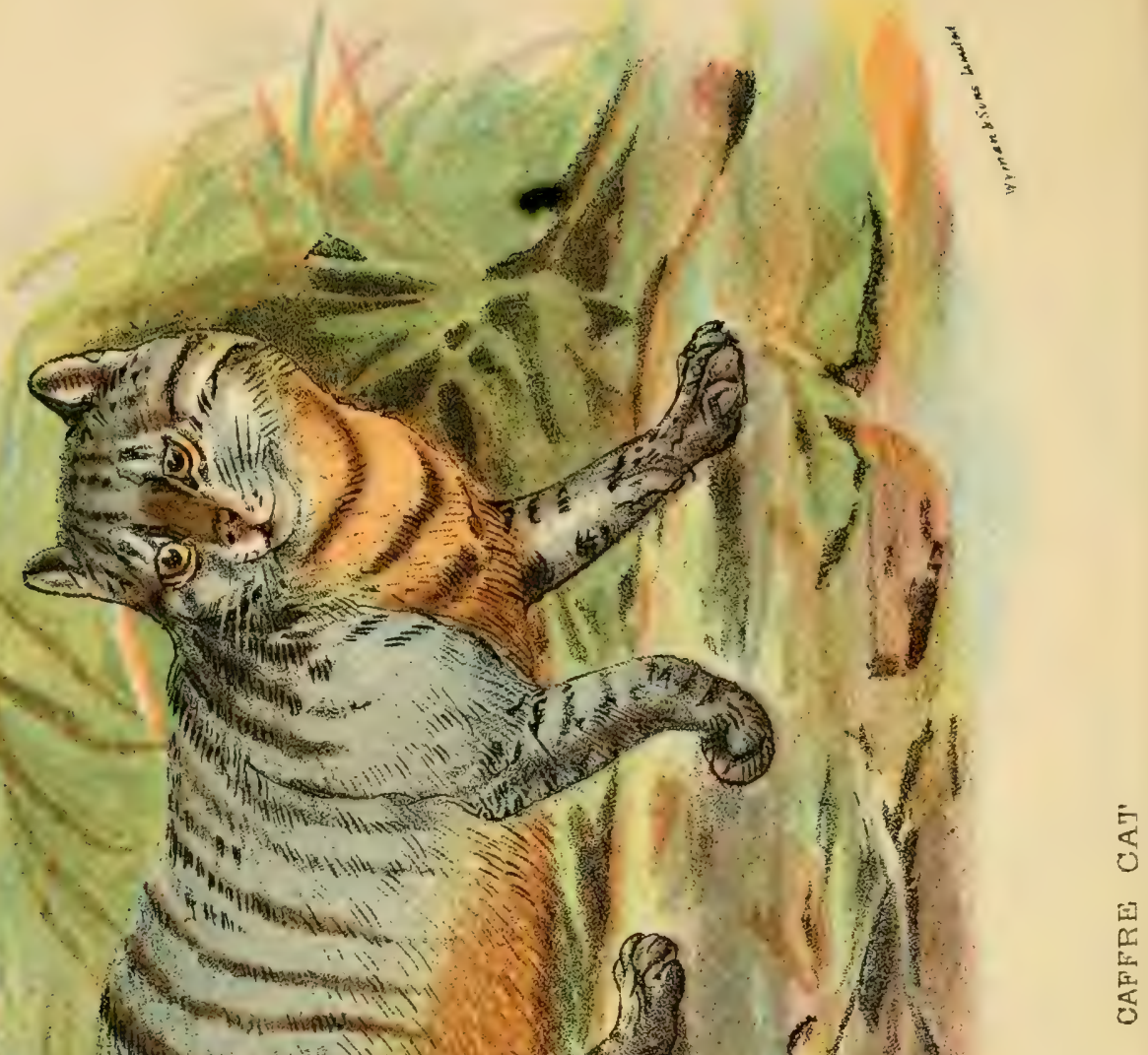

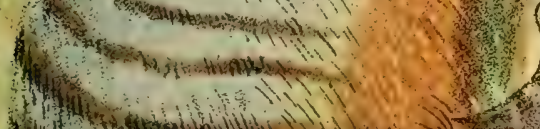

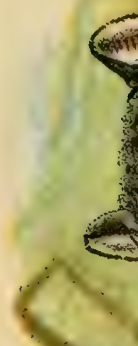

Honthet

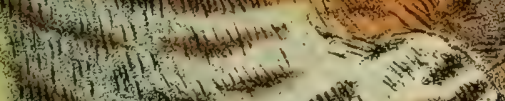

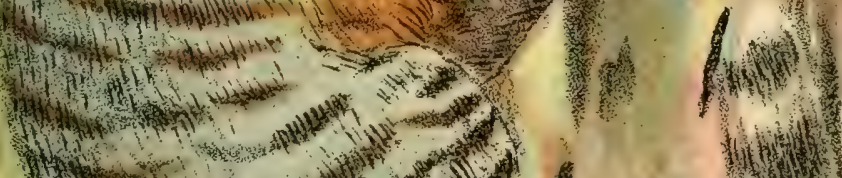
(hit) (1)

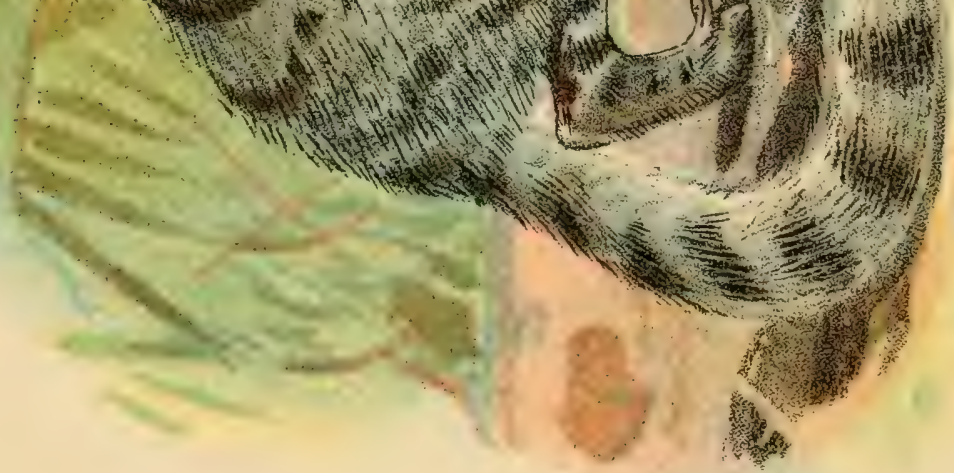


XXIX. THE CAFFRE CAT. FELIS CAFFRA.

Felis caffra, Desmarest, Nammalogie, Suppl. p. 5to (1 222 );

Elliot, Monograph of Felidæ, pl. xxxi. ( $\left.\delta_{7} \delta_{-} S_{3}\right)$.

Fielis obscura, Desmarest, op. cit. p. 230.

Felis migripes, Burchell, Travels, vol. ii. p. 592 (IS24).

Felis maniculata, Cretzschmaer, in Rüppell's Atlas, vol. i. pl. i.

( 1826$)$.

Felis pulchella, Gray, Mag. Nat. Hist. vol. i. p. 577 (1837).

Chaus caffer, Gray, List Mamm. Brit. Mus. p. 45 (I $S_{43}$ ).

Leopardus inconspicuns, Gray, op. cit. p. 44.

Felis caligata, I. Geoffroy, Jacquemont's Voyage, p. 49 ( $18+4$ ).

Felis lybica, I. Geoffroy, op. cit. p. 56.

Felis margarita, Loche, Rev. Mag. Zool. ser. 2, vol. x. p. 49 ( 1858 ).

Felis inconspicua, Gray, Proc. Zool. Soc. IS67, p. 273.

\section{(Plate X1X.)}

Characters.-IVith this species we once more revert to the Cats of the Old World. Somewhat larger than an ordinary Domestic Cat, it may be characterised as follows: Colour varying from pale fulvous to grey or pale yellowish, with dark transverse markings on the limbs and towards the end of the tail, and two transverse bars of the same colour on the check; tip of tail black. Frequently the hinder part of the soles of the hindfeet black; but in the paler varieties this part not darker than the back. In some specimens from South Africa there are indistinct traces of transvarse stripes on the back. Tail and limbs relatively long. Length of head and body, from 24 to 30 inches; of tail, I4 to I 5 inches.

Distribution.-Africa, from Egypt and Algeria to the Cape; Syria and Arabia.

Habits.-This is the common IVild Cat of most parts of Africa; and although it is now well nigh exterminated in the 
more populated districts of the Cape Colony, it is still abundant in the interior. As its habits appear to be generally similar to those of the common Wild Cat, they require no detailed notice.

This Cat was tamed by the ancient Egyptians, and vast numbers of its remains embalmed and preserved. Although some writers hold a different view, the black sole of the foot suggests that the Caffre Cat is the chief stock from which the Domestic Cats of Europe have been derived; but in different countries there has been more or less subscquent crossing with the various indigenous species. On this subject more will be said under the heading of Domestic Cats.

It is noteworthy that the fossilised remains of the Caffre Cat have been obtained from the carern-deposits of the rock of Gibraltar, in company with those of various kinds of extinct Mammals, and it may be inferred that at the time when these creatures flourished, Spain was still connected by land with Africa.

XXX. DOMESTIC CATS. FELIS DOMESTICA.

Felis domestica, Gmelin, Syst. Nat. vol. i. p. So (I $7 S S$ ).

Felis torquata, F. Cuvier, Hist. Nat. Mamm. pl. 54 ( $\left.\mathrm{I} S_{2} 6\right)$;

Blanford, Mamm. Brit. India, p. 85 (1888).

Felis megalotis, Müller, Verh. Nat. Gesch. Zool. pp. 29, 54 (I839-44); Sclater, Cat. Mamm. Ind. Mus. pl. ii. p. 233 (1891).

Feiis huttoni, Blyth, Journ. Asiat. Soc. Bengal, vol. xv. p. 69 ( 1846$)$.

Although Domestic Cats are commonly spoken of as constituting a "species," yet this term must be used in quite a distinct sense from that in which it is employed when speaking of the wild members of the Family. For instance, if all the breeds of Domestic Cats were descended from the Caffre 
Cat just described, they could not be specifically separated from that form, and one name should be applied to both. As a matter of fact, it is, however, much more probable that Domestic Cats have a complex origin, and that the Wild Cats of each country have had more or less to do with the origin of the domesticated breeds found there. Consequently, when we speak of Domestic Cats as forming a species, such species must be regarded as being what may be termed a convergent one.

That the African Caffre Cat, together with the Leopard-Cat, Rusty-spotted Cat, and Desert Cat of India, will freely breed with Domestic Cats has been well ascertained; and the same is true of the Wild Cat of Europe. It has been already mentioned that the Caffre Cat was tamed by the ancient Egyptians, and that from the dark colour of the sole of the hind-foot, and the comparatively long tail, this species was probably the chief ancestral stock of the domesticated Cats of Europe. The Domestic Cats of China, have, however, been regarded as originating from an exclusively Asiatic source, and the same has been suggested for those of India. It may be remarked here that in Europe, before the introduction of a Persian strain, "Tabby" Cats, that is, those with dark transrerse markings, were the most common in Western Europe, whereas in India they are quite unknown. This suggests most strongly that whilst in Europe, the original stock has been largely crossed with the Wild Cat, in India, where Domestic Cats are generally spotted, it is more probable that the Desert Cat (F. ornata), described in the sequel, has been, to a great extent, or entirely, the parent stock. That the European Wild Cat was not the direct descendant of the domesticated breeds of the western part of that continent is rendered pretty evident by its short and clubbed tail, to say nothing of the absence of dark soles to the hind-feet. 
The late Mr. Blyth distinguished two races of Domestic Indian Cats, namely, the spotted and the fulvous types. In the former the spots tend to aggregate into streaks, especially on the front regions of the body, while the tail is slender, of uniform thickness, and marked with dark rings. Cats of this type are frequently met with, which have reverted to a wild state, and it seems probable that it was from the skin of such a feral Cat that the so-called Waved Cat (Felis torquata) of Frederic Cuvier was named. Consequently, following the lead of Mr. W. L. Sclater, that name, which Mr. Blanford, in his "Mammals of British India," provisionally allowed to stand as indicative of a wild species, is here included as a synonym of $F$. domistica. As already said, it is highly probable that this spotted type was largely evolved from the Desert Cat, with more or less crossing with the Rusty-spotted and Leopard-Cat.

The second, or fulvous type, was termed by Blyth the "Chaus-coloured" Cat, and this breed he believed to have been derived from the other domestic type by crossing with the Jungle Cat (F. chaus), to be described later on. This breed is of a uniform fulvous colour, with barred legs and a ringed tail ; and thus far it closely resembles the Jungle Cat. In its proportions it is, however, considerably different, the legs and ears being much shorter, and the tail considerably longer than in the latter.

As the subject of the origin of the domestic breeds is a very complex one, and also one in which there is still much diversity of view among zoologists, we leave it with the foregoing brief observations, to pass in review some of the betterknown and more noteworthy types. Defore doing so we may, however, quote from an American newspaper the following very remarkable instance of the adaptability of Cats to abnormal and changed conditions, since such capacity for change 
must largely have affected the domesticated breeds of widely different climates.

From the account referred to, it appears that in the coldstorage warehouses of Pittsburg there were originally no Cats or Rats. The temperature in the cold rooms was too low. The keepers soon found, however, that the Rat is an animal of remarkable adaptability. After some of these houses had been in operation for a few months, the attendants found that Rats were at work in the rooms where the temperature was constantly kept below the freezing point. They were found to be clothed in wonderfully long and thick fur, even their tapering, snake-like tails being covered by a thick growth of hair. Rats whose coats have adapted themselves to the conditions under which they live, have thus become domesticated in the stcrage warehouses in Pittsburg. The prevalence of Rats in these places led to the introduction of Cats. Now, it is well known that Pussy is a lover of warmth and comfort. Cats, too, have a great adaptability to conditions. When Cats were turned loose in the cold rooms they pined and died because of the excessive cold. One Cat was finally introduced into the rooms of the Pennsylvania Storage Company which was able to withstand the low temperature. She was a Cat of unusually thick fur, and she thrived and grew fat in quarters where the temperature was below $30^{\circ}$. By careful nursing, a brood of seven kittens was developed in the warchouse into sturdy, thick-furred Cats that love an Icelandic climate. They have been distributed among the other cold-storage warehouses of Pittsburg, and have created a peculiar breed of Cats, adapted to the conditions under which they must exist to find their prey. These Cats are short-tailed, chubby pussies, with hair as thick and full of under-fur as the IVild Cats of the Canadian woods. One of the remarkable things about them is the development of their "feelers." Those long stiff hairs that 
protrude from a Cat's nose and eyebrows are, in the ordinary domestic feline, about thre inches long. In the Cats cultivated in the cold warehouses the feelers grow to a length of five and six inches. This is probably because the light is dim in these places, and all movements must be the result of the feeling sense. The storage people say that if one of these furry Cats be taken into the open air, particularly during the hot season, it will die in a few hours. It cannot endure a high temperature, and an introduction to a stove would send it into fits.

Of the more ordinary varieties of the Cat, the best known and most common in England, before crossing with the Per sian breed was introduced, was undoubtedly the Tabby; this type of coloration consisting of a grey ground colour, with subconcentric vertical black bands on the body and thighs, longitudinal streaks of the same on the top of the head, a black stripe down the back, and bars on the upper surface of the tail. In some individuals the whol fur is of deep black, with the markings visible only in certain lights. From this type there is a transition to Black Cats, in which the coat shows no trace of markings in the adult, although stripes are more or less distinctly displayed in the kittens. Even these Cats are, however, seldom totally black, there being usually some white hairs on the throat. The eycs of Black Cats are of a peculiar clear yellow, standing out in striking contrast to the sable fur. As mentioned above, it is probable that Tabby Cats owe their stripes to crossing with the Wild Cat.

A Domestic Cat, brought home by Darwin from South America, is remarkable, according to Gray, for its striking resemblance to the Caffre Cat. From that species it chi:fly differs in the tail being more slender and tapering, the colours more intense and defined, and the throat pure white. In 
colour, it is dark grey, grizzled with black streaks and spots; the streaks on the limbs being broad, and those on the forelegs more or less confluent. The tail is grey for two-thirds its length, with black rings, of which the hindmost is the broadest; while the terminal third is black with a small white tip. Instead of having the sub-spiral arrangement of the ordinary Tabby, the stripes on the loins are straight and parallel; and the streaks on the cheeks, of which the lowermost is indistinct and interrupted, are black.

Grey Cats, which are very rare, may be regarded as Tabbies from which the stripes have disappeared, save for two black bars on the fore-limbs; these being very constant among the smaller wild species of the family.

Tabbies, again, are met with, in which the coat is varied with a larger or smaller amount of white; and from these there is a transition to pure White Cats, which form, however, a breed by themselves. That these White Cats are not albinos, is evident from their eyes, which may be either blue, or the usual greenish-yellow tinge. In some instances one eye may be blue and the other greenish-yellow; and in white Persian Cats this peculiarity is highly admired by the natives of the East. As mentioned in the portion of this work devoted to the consideration of Cats in general, White Cats with blue eyes are generally deaf, although this is not invariably the case.

Another well-marked breed is characterised by the male being usually sandy, and the female of the so-called "tortoise-shell" colour; although at least one instance of a true "Tortoise-shell Tom" has been recorded. The true Tortoise-shell should be a mixture of fawn-colour and black; but there are numerous parti-coloured Cats, such as white, fawn, and black, and greyishwhite and sandy, which are frequently termed "tortoise-shell"; and it is probable that the majority of so-called "Tortoise-shell Toms" belong to this class. 
The Carthusian or "Blue" Cat is a very beautiful long and soft-haired breed with fur of a dark greyish-blue colour, the lips and the soles of the feet retaining, however, the normal black hue.

Mention having been already made of the ordinary Domestic Cats of India, we pass on to what is known as the Siamese Cat, characterised by its uniformly fawn-coloured fur, which becomes darker on the muzzle, its blue eyes, and the occasional presence of two bare spots on the forehead.

More esteemed than all is the beautiful Angora or Persian Cat. Characterised by their large size, the length and softness of the fur-especially that of the under-parts,--and the bushy tail, these Cats are generally either uniform white, yellowish, or greyish in colour, with the lips and soles of the feet frequently flesh-coloured. It has been suggested that this breed is descended from the wild Pallas's Cat of Central Asia.

In Gray's "Catalogue of Carnivorous Animals in the British Museum," it is stated that in some Chinese Cats the ears are pendulous, but subsequent observers have been led to doubt the truth of this statement.

The Malay Cat, from Siam and Burma, is characterised by the tail being only half the usual length; while in some specimens, owing to a deformity in the bones, it is twisted up into a kind of knot, from which it cannot be uncurled.

More remarkable than all are the Tail-less Cats of the Isle of Man, a bread with the same peculiarity being recorded from the Crimea. Bell states that Tail-less Cats were likewise common in his time in Cornwall; while a small village in Dorsetshire also possessed a breed lacking the same appendage. In the latter case it was stated that the race was known to be descended from a Cat accidentally deprived of its tail ; and as another instance is on record of a Cat, whose tail had been amputated, giving birth to stump-tailed kittens, it is not im- 
probable tnat the origin of the Manx Cats is due to the same cause. At the present day, probably owing to crossing with Cats introduced from the mainland, Cats with tails of all lengths are to be met with in the Isle of Man.

The Mombasa Cat, from the eastern coast of Africa, near Zanzibar, is reported to have the fur short and stiff, instead of the ordinary structure.

Finally, we have the Paraguay Cat of South America, which is but one-fourth the size of the ordinary domestic breed, and is further characterised by its elongated body, and its covering of short, shiny, and close-lying hair, more especially on the tail. In the same continent there is stated to be another breed lacking the discordant nocturnal cries which render the ordinary Cat such an unmitigated nuisance in all parts of the world.

With regard to the date of the introduction of Domestic Cats into Europe, there is a considerable amount of uncertainty; and it has been considered that the so-called "Cat" of the ancient Greeks was really the Marten. Be this as it may, "there can be no question," writes Professor Mivart, "as to the Cat having been domesticated in Europe before the Christian era. There are signs that it was domesticated amongst the people of the Bronze period, and the supposition that it was first introduced into Western Europe by the Crusaders, is of course an altogether erroneous one. They may, however, have introduced a distinct race, for if it be true that our Domestic Cats have mainly descended from the Egyptian Cat, it does not follow that blood from other sources may not have mingled with that of the Egyptian breed. Pope Gregory the Great, who lived towards the end of the sixth century, is said to have had a pet Cat; and Cats were often inmates of nunneries during the Middle Ages. The great value set upon the Cat at this period is shown by the laws which in Wales, Switzerland, Saxony, and other European countries, imposed 
a heary fine on Cat-killers. As compensation, a payment of as much wheat was required as was needed to form a pile sufficient to cover over the body of the animal to the tip of the tail, the tail being held up vertically, with the Cat's muzzle resting on the ground."

Habits. - IVith regard to the habits of Domestic Cats, Jardine, in the original issue of this volume of the "Naturalist's Library," writes as follows:-_"There is perhaps no animal that so soon loses its cultivation, and returns apparently to a state nearly wild. A trifling neglect of proper feeding or attention will often cause them to depend on their own resources; and the tasting of some wild and living food will tempt them to seek it again, and to leave their civilised home. They then prowl about in the same manner as their wild congeners, crouching among covert, and carefully concealing themselves from all publicity. They breed in the woods or thickets, and support themselves upon birds or young animals. Fewextensive Rabbit-warrens want two or three depredators of this kind, where they commit great havoc, particularly among the young in summer. They sleep and repose in the holes, and are often taken in the snares set for their prey. I once came upon a Cat, which had thus left her home; she had newly kittened in the ridge of an uncut corn-field. Upon approaching, she showed every disposition to defend her progeny, and beside her lay dead two half-grown Leverets. We have also known Cats, which, though they sought their prey in the woods and fields, regularly carried it home before devouring it, and in this way various young game and Hares were brought in.

"Cats are also particularly fond of fish, and in a few instances have been known to catch them from shallow streams. There is generally, however, a dislike to water, and the examples of this departure from their general habits are rare. They will often pursue and feed upon some of the larger insects. There 
is one mentioned by Bingley, who was a great enemy to Cockroaches; and we have often seen them catch the common Cricket, and the white Ghost-Moth, which may be seen flying about a foot from the ground in the summer evenings. One individual used to hunt these insects regularly, and about dusk might be seen looking along the lawn for them; when one was perceived, she crouched and approached rapidly, and when within a proper distance, always sprung, and generally brought the insect to the ground with her paws or breast.

"The Domestic Cat is capable of great attachment to, and long recollection of, those who have been kind to it, but not more so than many of its congeners; for the very limited number of those which are subjected to the care and tuition of Man, have in many instances shown as strong feelings towards their keepers.

"One of the most singular instances of attachment or fancy, in the common Cat, took place with one which we have often seen in attendance upon the watchman in St. James' Square, Edinburgh. When the man commenced his rounds, the Cat was as regularly at his post, and continued walking with him during the whole night. This continued, we believe, for nearly two years; and when we last saw the man, the Cat was in his company. Upon the approach of any person, the Cat would run up to the guardian of the night, and rub against his legs until the individual had passed. In the quieter hours, towards morning, he ventured to a greater distance, but would always appear at the call or whistle of his protector."

Fond of warmth, and generally ensconcing themselves in the cosiest corner near the fire, Cats are very light sleepers, awakening and becoming alert at the slightest sound. In spite, however, of their partiality for warmth, they are not deterred from setting forth on their nocturnal wanderings by the coldest winter night, when their screams and "caterwaulings" are only too well- 
known. During such excursions they are fond of rolling in beds of certain highly-scented pants, such as valerian and cat-mint, and will then work themselves up into an extraordinary degree of excitement. The purring sound uttered by a contented Cat when caressed is known to all ; but the contrast between the animal when in this state, and when standing with arched back, ruffled tail, and exposed teeth, spitting and snarling at a Dog, is perhaps more marked than in the case of almost any other creature. It is scarcely necessary to allude to the stealthy, creeping movements of a Cat stalking its prey, when the tail is held stiffly, with only its tip moving in a curiously worm-like manner, since these traits are exhibited by nearly all the wild members of the genus.

Notwithstanding that they seldom eat those animals (except when very young), Cats are most determined foes to Rats, and will watch a Rat-hole for hours; while, when they have seized their victims, they will not unfrequently deposit them at their owner's feet with a triumphant and self-satisfied air. Their mousing qualities need no mention. The female usually breeds two or three times in the course of a year, the number of kittens in a litter generally varying from five to six. Gilbert White relates an instance where a Cat deprived of her kittens suckled and brought up three young Squirrels; and there are several cases known where young Rats have been similarly treated.

The following anecdotes of Cats are taken from Jesse's "Gleanings in Natural History." In the first case, a gentle. man in Jamaica being in want of a Cat, "one was given him which was not full-grown. It was put into a canvas-bag, and a man on horse-back brought it a distance of five miles from the place where it was bred, and from which it had never been removed before. In doing so, he had to cross two rivers, one, named the Mino, which was about eighty feet wide and two and 
a half fect deep, rumning strong. The other, called Thomas River, was wider and more rapid, but less deep. Over these rivers there are no bridges. The Cat, when it arrived, was shut up for some days, and when supposed to be reconciled to her new dwelling, she was allowed to go about the house. The next day, however, she was missing, and was found shortly afterwards at her old abode.

"A family residing at Newcastle-on-Tyne went one summor to Tynemouth, leaving their house in the care of two female servants. One evening, when the servants were sitting together in the kitchen, their attention was attracted by a Cat, which went up into a laundry over the kitchen, and then returned to them and mewed. The Cat did this so often that the servants were induced to go upstairs to see what she wanted. When they got into the laundry, they found a man concealed in the chimney.

"A favourite Cat, much petted by her mistress, was one day struck by a servant. She resented the injury so much, that she refused to eat anything given her by him. Day after day he handed her dinner to her, but she sat in sulky indignation, though she eagerly ate the food as soon as it was offered her by another individual. Her resentment continued undiminished for upwards of six weeks. The same Cat, having been offended by the housemaid, watched for three days, until she found an opportunity for retaliation. The housemaid was on her knees, washing the passage, when the Cat flew at her, and left indubitable proofs on her arms that no one could ill-use her with impunity. It is, however, but fair to record the good qualities of this Cat as well as her bad ones. If her resentment was strong, her attachment was equally so, and she took a singul.ar mode of showing it. All the tit-bits she could steal from the pantry, and all the Mice she could catch, she invariably hrought and laid at her mistress's feet. She has been 
known to bring a Mouse to her door in the middle of the night, and mew till it wopened, when she would present it to her mistress."

Cats not unfrequently make friends with other animals, notably Horses; but perhaps the most curious instance of such a friendship is one related by the author just quoted. An enginecr in the United States once caught a young Alligator, which he took home with him, and made so perfectly tame, that it would follow him about like a Dog. "Its great favourite however, was a Cat, and the friendship was mutual. When the Cat was reposing herself before the fire, the Alligator would lay himself down, place his head upon the Cat, and in this attitude go to sleep. If the Cat was absent the Alligator was restless ; but he always appeared happy when the Cat was near him." So far as the present writer is aware, this is the only instance on record of the existence of an attachment between a Mammal and a Reptile.

Commercial Value.-The pelage of the Cat forms an article of considerable commercial importance; and the following particulars in regard to the trade in Cat-skins are taken from Mr. Poland's valuable work on "Fur-bearing Animals." The fur, which is stated to be one of the warmest, is extensively employed for coat-linings, muffs, trimmings, and rugs. Black skins are the most valuable; the best examples coming from Holland. American skins, of which some three thousand are annually imported into England, are generally white, blue, black, or tabby, but are of rather inferior quality; the price varying from threepence to eighteenpence per skin. Austra lian skins, which are generally red-tabby, are the least esteemed of all. There is considerable annual fluctuation in the marketvalue of Cat-skins; but the very best black Dutch pelts sometimes command as much as from six to eight shillings each As is well-known, when rubbed, the fur of the Cat is highly 
electrical, giving off sparks which in a dark room are casily visible.

In this place a few particulars, taken from the same work, may be given in regard to the commercial value and uses of the skins of some of the species of Cats already noticed. In the case of the Lion, a fine black-maned skin may be worth from $£_{50}$ to $£_{70}$; whereas yellow-maned, or menagerie, skins will not fetch more than from $£ 5$ to $£ 30$; those of Lionesses selling at from Ios. to $30 \mathrm{~s}$. The value of a Tigerskin is much less, a good Bengal specimen being obtainable at from $£ 4$ to $£^{6}$; while the claws vary in value from 9 d. to 5 s. Some idea of the enormous numbers in which these animals exist, may be gathered from the statement that in the year I 886 no less than 1,464 Tigers are reported to have been killed in British India alone. The Siberian Tiger is, however, much more valuable, Mr. Poland stating that skins will fetch from $£$ ro to $£ 40$; while as much as $£ 66$ has been paid for an unusually fine specimen. Upwards of 135 of these skins were imported into this country in $189 \mathrm{I}$.

Leopard-skins, of which a few thousands are annually imported into England, vary in value from 12 to 52 shillings each. They are extensively used as housings by some of our cavalry regiments, while they are also made into rugs, footmuffs, wrappers, slippers, \&c. Ounce-skins are more valuable; the price generally ranging from $£_{2}$ to $£ 6$ ros., although $£ 7$ has been paid for a particularly fine one. Black Lcopard-skins are always highly prized. No details are given by Poland regarding Jaguar-skins; but he states that Puma-skins are only worth about five shillings each, their chief use being for wrappers or rugs. The handsome skins of the Clouded Leopard, on the other hand, sell for between $\mathcal{E}_{3}$ and $£_{4}$ each; while those of the Ocelot vary from $2 \mathrm{~s}$. to $4 \mathrm{~s}$. $6 \mathrm{~d}$. None of the other smaller Cats are of much commercial im- 
portance, the comparatively small number of skins sold realising small prices.

\section{THE WILD CAT. FELIS CATUS.}

Felis catus, Linn., Syst. Nat. ed. I 2, vol. i. p. 62 (1 766 ) ; Elliot, Monograph of Felidæ, pl. xxx. (I878-83).

Felis sylvestris, Schreber, Säugethiere, vol. iii. p. 397 (I 778 ).

(Plate XX.)

Characters.*-General colour yellowish-grey, with an interrupted longitudinal dark stripe down the back, two dusky bands on the cheeks, and numerous obscure transverse stripes of the same colour on the body and limbs; tail of equal thickness throughout, less than half the head and body in length, and ringed and tipped with black. Length of head and body of male, about 34 inches ; of tail, I I $1 / 4$ inches.

In general aspect, form, and coloration, the Wild Cat resembles large "Tabbies" of the domestic breed; from which it differs in the proportionately longer body and limbs, and the shorter and thicker tail ; the fur being also more abundant than in the original English breed. Conforming in its general external configuration and appearance to the type characteristic of the great majority of the members of the family to which it belongs, the Wild Cat has the general ground-colour of its soft and long fur yellowish-grey, tending in some individuals to pale reddish-brown. In addition to some black spots near the muzzle, the face is marked with two black stripes, commencing between the eyes, and gradually increasing in width, and diverging as they pass backwards between the ears to the hinder part of the neck. Commencing between the shoulderblades, a broad irregular black or blackish longitudinal stripe traverses the whole length of the back, from which diverge numerous paler transverse bands, gradually becoming lighter in

* Our account of the Wild Cat is abbreviated from the one already pub. lished in "British Mammals." 



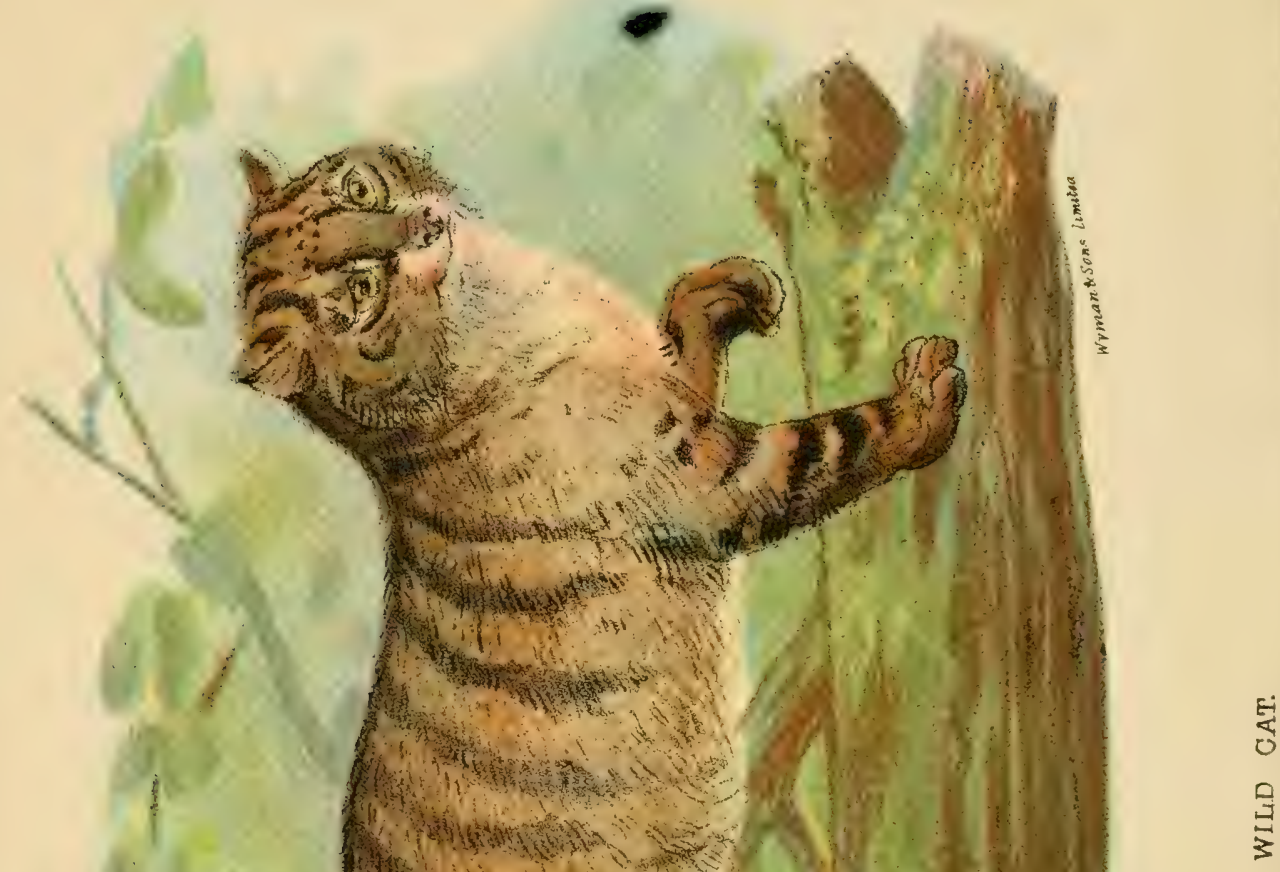


tint as they descend the flanks, until they are finally lost in the nearly white area of the under-parts. Usually the tail is ringed with nine black bands upon a grey ground, the first five of these bands being the narrower, and not meeting inferiorly, while the terminal black area is the largest of all, being often as much as two inches in length; it is at the same time the deepest in tint. Barred externally with horizontal bands of black, the limbs have their inner surface yellowish-grey, like the upper surfaces of the feet, while the soles of the latter are black. The claws are yellowish-grey.

Distribution. - Ranging over a considerable portion of Continental Europe, namely, France, Germany, Poland, Switzerland, Hungary, Southern Russia, Spain, Dalmatia, Greece, and part of Turkey, and thence extending eastwards into the forest regions of Northern Asia, the Wild Cat was formerly widely distributed in Britain, although it appears never to have been a native of Ireland. At the present day it is restricted only to the northern districts of our islands, and is there becoming year by year more rare. This sole British representative of the feline family is proved, both by tradition and by the discovery of its fossilised remains in cavern and superficial deposits, to have originally ranged over the whole of such parts of England as were suited to its habits. Such remains have been discovered in the Pleistocene brick-earths of Grays, in Essex, in company with the remains of Mammoths, Hippopotami, Rhinoceroses, and other Mammals now either totally cxtinct, or long since banished from Britain to warmer climates. They also occur, in association with similar creatures, in the caves of Bleadon (in the Mendips), Cresswell Crags (Derbyshire), Kent's Hole (near Torquay), Ravenscliff (Glamorganshire), Uphill (in the Mendips), and the Vale of Clywd, while quite recently they have been discovered in a fissure in the Wealden rocks near Ightham, in Kent.

Habits.-Like the rest of its family, truculent and savage in 
its disposition, and endowed with, in proportion to its size, singular strength and activ of body, the Wild Cat is now the only really formidable wild animal to be met with in the British Islands, where it always inhabits wooded, and generally mountainous, districts. In the most secluded and inaccessible parts of such regions the Wild Cat makes its lair, which may be situated either in some dense thicket, in the hollow stem of a decayed tree, or in a cleft or crevice of the rocks, and rears its young. Sometimes, however, the female selects in preference the deserted hole of a Badger or Fox in which to litter; and we have heard of the nest of one of the larger birds being chosen as a nursery. The young, which are born during the early summer, ar usually five or six in number, and closely resemble ordinary domestic kittens. After being suckled by the female till such a period as milk no longer satisfies the needs of their appetites, they are fed by her on Mice and small birds until they are capable of taking care of themselves and capturing larger prey, when they are freed from parental control.

Those who have had experience of game and game-preserving are well acquainted with the enormous amount of damage that an ordinary Domestic Cat, which has taken either to occasional poaching or to a thoroughly wild life, will inflict on the denizens of their coverts, moors, or warrens. From its larger size and more powerful build, the Wild Cat is a still more serious enemy to game of all kinds; while in the neighbourhood of human habitations it is likewise a foe to poultry and pigeons. No wonder, therefore, that gamekeepers wage incessant war against the Wild Cat, shooting and trapping it whenever the opportunity presents itself ; indeed, the marvel is that the creature has managed to survive as long as it has. From the extreme boldness and ferocity of its disposition, an angry and wounded Wild Cat, when brought to 
bay, is no mean antagonist, even for an armed man; and several instances are on record where these creatures have inflicted considerable harm on their assailants before finally succumbing.

One of the most vivid descriptions of the habits of the IVild Cat is given by St. John, in his "Natural History of the Highlands," who writes as follows:- "In the hanging birch-woods that border some of the Highland streams and lochs, the Wild Cat is still not uncommon, and I have heard their wild and unearthly cries echo far in the quiet night as they answer and call each other. I do not know a more harsh and unpleasant cry than that of the IVild Cat, or one more likely to be the origin of superstitious fears in the mind of an ignorant Highlander. These animals have great skill in finding their prey, and the damage they do to the game must be very great, owing to the quantity of food they require. When caught in a trap, they fly without hesitation at any person who approaches them, not waiting to be assailed. I have heard many stories of their attacking and severely wounding a man when their escape has been cut off. I was once fishing in a river in Sutherlandshire, and, in passing from one pool to another, had to climb over some rock and broken kind of ground. In doing so, I sank through some rotten heather and moss up to my knees, almost upon a Wild Cat, who was concealed under it. I was quite as much startled as the animal herself could be, when I saw the wild-looking beast so unexpectedly rush out from between my feet, with every hair on her body standing on end, making her look twice as large as she really was. I had three small SkyeTerriers with me, who immediately gave chase, and pursued her till she took refuge in a corner of the rocks, where, perched in a kind of recess, she stood with her hair bristled out, spitting and growling like a Common Cat. Having no weapon with me, I laid down my rod, cut a good-sized stick, and pro- 
ceeded to dislodge her. As soon as I was within six or seven feet of the place, she sprang straight at my face, over the Dogs' heads. Had I not struck her in mid-air as she leaped at me, I should probably have got some severe wounds. As it was, she fell with her back half-broken among the Dogs, who, with my assistance, despatched her. I never saw an animal fight so desperately, or one so difficult to kill."

\section{PALLAS'S CAT. FELIS MANUL.}

Felis mamul, Pallas, Reise, vol. iii. p. 692 (1776); Elliot, Monogr. Felidæ, pl. x. $\left(8_{7} 8-8_{3}\right)$; Blanford, Mamm. Brit. India, p. 83 ( 1888 ).

Felis nigripectus, Hodgson, Journ. Asiat. Soc. Bengal, vol. xi. p. $276\left(18_{42}\right)$.

Characters.-Somewhat smaller than the domestic species, Pallas's Cat is easily recognised by the abundant coat of long and soft halr with which it is clothed, the short ringed tail, and the few transverse dark bars on the hinder part of the body. General colour of fur pale whitish, with some slight black markings on the chest and upper parts of the limbs; a few narrow black transverse bars, widely separated from one another across the loins; tail ringed with black. A white streak, bordered both above and below with black, runs obliquely downwards and backwards from behind the eye; while there is also a black mark behind each ear. Skull very broad, and much elevated in the region of the eyes; nasal bones very narrow posteriorly, and suddenly expanded at their terminal third; anterior pre-molar apparently wanting. Length of head and body, about 2 I inches; of tail, Io inches. The hairs are yellowish-grey at the base, yellowish in the middle, and white at the tips.

Distribution.-Tibet, extending westwards into Ladak, and northwards through Mongolia to Siberia. In beds of Pleisto- 
cene age in Central Europe remains of this species have been discovered by Dr. Nehring, of Berlin, and described by him (S.B. Nat. Fr. Berlin, for 1889 , p. 10э).

Habits.-An inhabitant of the deserts of Central Asia, Pallas's Cat lives among rocks, where it preys on the smaller Mammals and birds. From the rigours of the severe climate of these regions, it has an ample protection in its abundant coat of hair; and the fact of its remains occurring in the Pleistocene deposits of Europe associated with those of other desert Mammals, has led to the inference that at that epoch steppelike conditions prevailed over portions of the Continent. In Siberia the chief food of this species is stated to consist of Picas, or Tail-less Hares (Lagomys).

\section{THE PAMPAS CAT. FELIS PAJEROS.}

Felis pajeros, Desmarest, Mammalogie, p. 23I (I820) ; Elliot, Monograph of Felidæ, pl. xi. (1873-88) ; Mivart, The Cat, p. 423 (I88I); Matschie, S.B. Nat. Fr. Berlin, I894, p. 60. Pajeros pampanus, Gray, Proc. Zool. Soc. 1867, p. 269 ; id., Cat. Carniv. Mamm. Brit. Mus. p. I8 (1869).

Felis passernm, Sclater, List Vert. Anim. Zool. Gardens, p. 40 (I872); Aplin, Proc. Zool. Soc. I894, p. 298.

Characters.-Curiously similar in general appearance, as well as in the length of its hair, to the preceding species the South America Pampas Cat, Grass-Cat, or Paja-Cat (Gato pajero of the Portuguese) may be distinguished as follows: Size about equal to that of the Wild Cat, but the build more robust, the head smaller and the tail shorter. The long hair yellowishgrey in colour, marked with transverse bands of yellow or brown, running obliquely from the back to the flanks. From the eyes two bars cross each cheek to meet beneath the throat; legs and tail marked with darkish bands; under-parts whitish. Skull very convex and short; the nasal region much com. 
pressed, and the nasal bones very narrow superiorly; anterior upper premolar absent. Length of head and body, 25 inches; of tail, $\mathbf{2} 2$ inches.

According to Herr Matschie, specimens obtained from Tornquist, in Argentina, lying north of Bahia Blanca and south of the Sierra de la Ventana, were almost uniformly yellowish-grey, with scarcely any traces of dark banding; the inner sides of the limbs showing a single band; while the under-parts were white, and the legs and ears yellowish. Some examples showed elongated spots like $F$. colocolo.

Mr. Aplin observes that two kittens of this species brought to him in Uruguay "were spotted on the legs and lower-parts, and it was suggested that they might be the result of a cross with the Monte-Cat (F. gligna); but as the skins of two more kittens, brought in with that of the old female a few days before, were just the same, the spotted dress in youth is evidently natural to this species. Exactly the same thing happens in the case of the Puma."

Distribution.- - South America, on the east side of the Andes from Uruguay through the Argentine pampas to Patagonia, anging as far south as the Straits of Magellan. In many of the wilder parts of the Argentine, as in Patagonia, this species is still common; but in the more settled districts of the former country, as in those of Uruguay, systematic trapping has greatly diminished its numbers.

Habits.-Except that its ferocity is extreme, little definite has been recorded of the habits of this Cat. In the Argentine it lurks among the pampas- or paja-grass. Azara writes that "the natives call this animal Gato pajero, because it lives on the plains, concealing itself in the jungles, without entering into the woods and thickets which the Eyra inhabits. I know not, nor have I heard, that it exists in Paraguay, although it may formerly have been seen there; but as the country be- 

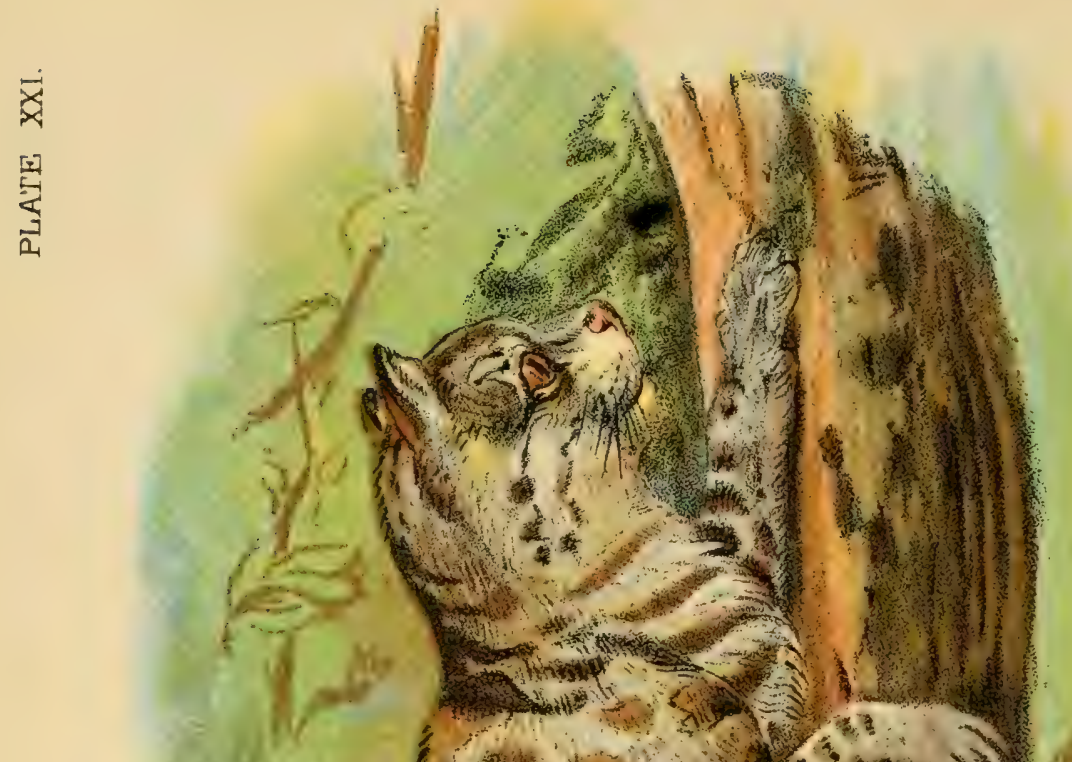

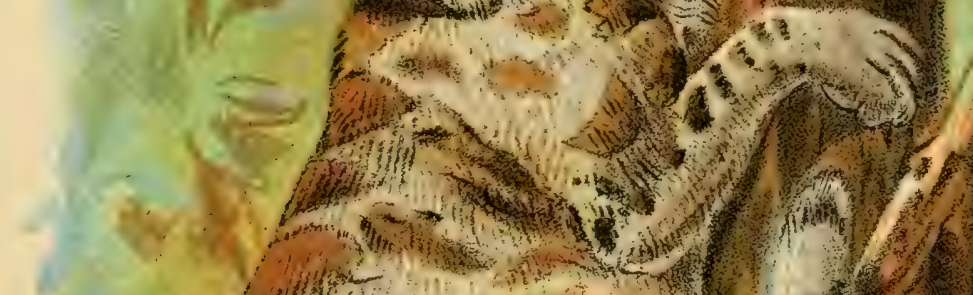

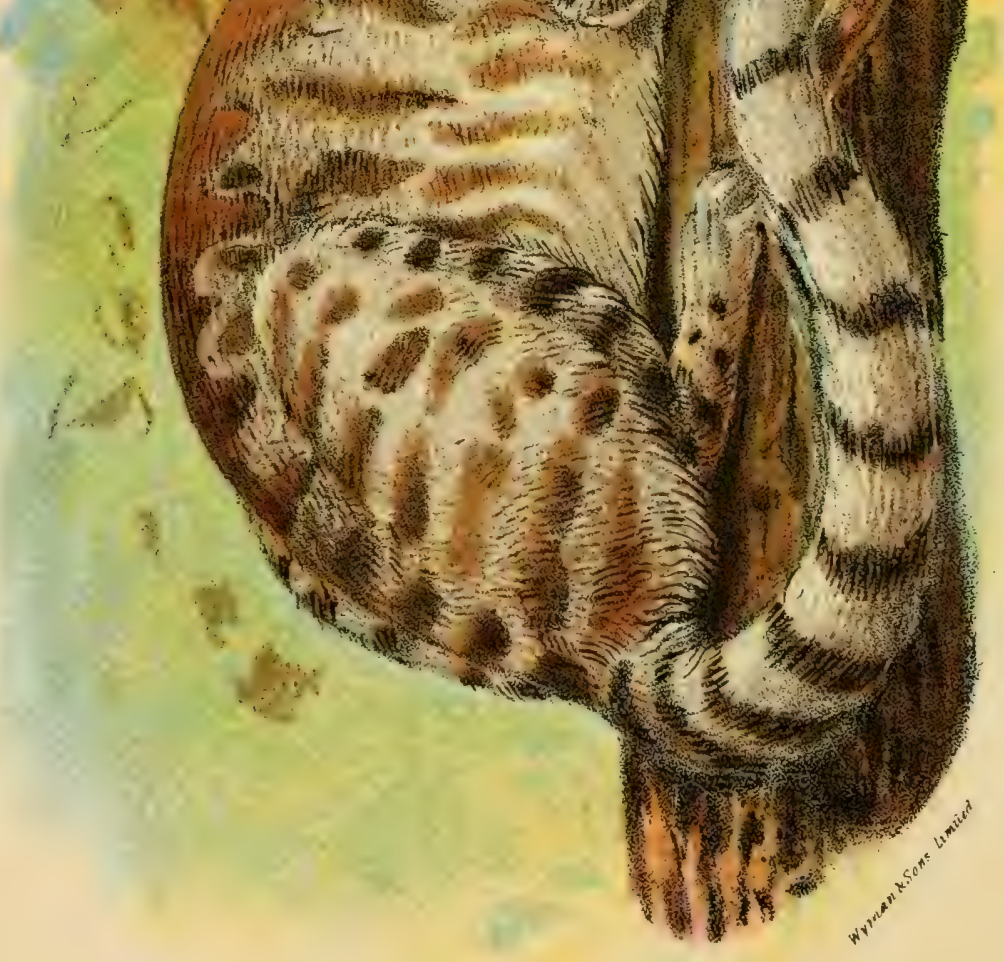

b 
came tolerably well peopled, and there are fewer plains, it was probably exterminated by the inhabitants. I caught four on the pampas of Buenos Aires, between the 35th and 36 th parallels of latitude, and three others on the Rio Negro, without any of them retreating to caves. I know not whether this was owing to there being none at hand, or that they have a natural dislike to them. On one occasion in April, I took from the uterus of a female Paja-Cat a single young one, with hair just commencing to grow; it is said, notwithstanding, that they bring forth two, and even three, at a birth. They subsist on the same food as the other species, principally on Apereas (Cavies)."

\section{THE COLOCOLO. FELIS COLOCOLO.}

Felis colocolo, H. Smith, in Griffith's Animal Kingdom, vol. ii. p. 479 (1827); Mivart, The Cat, p. 41 3 (I88I); Matschie, S.B. Nat. Fr. Berlin, I894, p. 60.

Felis strigilata, Wagner, in Schreber's Saïgethiere, Suppl. vol. ii. p. 546 (I $84 \mathrm{I})$.

\section{(Plate XXI.)}

Characters.-Although by previous writers the Colocolo of the western side of South America has been widely sundered from the Pampas Cat, the two are, according to Herr Matschie, very closely related. Indeed, that observer considers that the relationship between the two is similar to that obtaining between the typical Felis suigna of Chili and the so-called $F$. geoffroyi of the eastern side of South America. As we have considered the two latter as mere local races of a single species, it would perhaps have been more logical to follow the same course in the present instance; especially since, as noted above, specimens of the Pampas Cat have been described as having markings like the Colocolo. Nevertheless, for the present at least, it seems preferable to allow the latter to rank as a species. 
Of the approximate size of a large Domestic Cat, the Colocolo has the fur of a whitish-grey colour, with elongated dark spots or streaks on the upper-parts, and a black mark extending from the eye to the jaw. The tail is partially ringed; and the lower portions of the limbs are dark.

Although the anterior upper pre-molar is wanting, and the nasals are narrowed superiorly, the description of the skull of the Colocolo given by Professor Mivart does not accord in all respects with that of the Pampas Cat.

Distribution.-Worth-eastern and Western South America; the species being recorded from Guiana and Chili, and doubtless occurring in the intermediate countries.

The typical specimen was obtained in Guiana, and is thus described by Hamilton Smith, who observes: "The head was remarkably flat and broad; the ears large and round; the body slender; the tail just touched the ground when the animal was standing; the legs were very strong; the colour of the neck and back was whitish-grey ; the head, throat, shoulders, sides, belly, and inside of limbs white. The back was marked with lengthened streaks of black, edged with tawny; and towards the shoulders and thighs, with streaks of tawny. There was a black streak from the corner of the eyes to the jaws, and some bar-like marks on the forehead. The outside of the ears were dark grey, the insides pink and naked as well as the nose. The tail was semi-annulated with black, having a black tip, and it exhibited a great pecularity in the legs, which were all of hem of a very dark grey colour up to the knees.

"During his journey down country, the gentleman by whom the animal had been shot, placed the skin on the awning of the boat to air, as he was descending the river Paramaribo. The boat often passed under the branches of large trees, which overhung the river, and on which were the resting-places of 
numerous Monkeys, sometimes hanging to the extremest branches above the water. Although the vessel would on other occasions excite but little attention, no sooner was the stuffed specimen in sight, that the whole community would troop off with prodigious screams and howlings. It was of course surmised, from the excessive terror of these animals, that this species of Cat must be an active enemy to them."

Practically nothing is known as to the habits of the Colocolo in a state of nature; although it is evident that it must differ from the Pampas Cat in being an arboreal, instead of a purely terrestrial species.

XXXV. THE DESERT CAT. FELIS ORNATA.

Felis ornata, Gray, Ill. Indian Zool. vol. i. pl. ii. (1830); Elliot, Monograph of Felidæ, pl. xxxii. (IS78-83); Blanford, Mamm. Brit. India, p. 84 (I888).

Felis servalina, Jardine, Naturalist's Library, Felinæ, p. 232 (1834).

Chaus pulchellus, Gray, List Mamm. Brit. Mus. p. 45 (1 $\mathrm{S}_{43}$ ). Chaus servalinus, Gray, loc. cit.

Chaus ornatus, Gray, Proc. Zool. Soc. IS67, p. 275.

(Piate XXII.)

Characters. - With the present species we come to the first representative of what may be termed the Lynxine group of Cats, which includes the whole of the remaining members of the genus. As a group, they are characterised by the presence of a larger or smaller pencil of hair at the tip of the ear; while the tail is short; and in the skull the orbits are always incomplete behind, and the anterior pre-molar is generally wanting.

In the present species the tail reaches the hocks; the groundcolour of the fur is pale yellow, upon which there are small round black spots; while the pencils on the ears are reduced to a few short brown hairs. Skull as in F. chans (infrà, p. 182). 
Length of head and body, from is to 22 inches; of tail, 9 to io inches. The species may be compared in size to an ordinary Domestic Cat.

The coloration is described by Mr. Blanford as follows:"Very pale sandy (fulvescent grey or light isabelline), with numerous small black roundish spots on the body, and still smaller elongate spots on the crown and nape, those on the crown having a tendency to form longitudinal bands Fur of back dusky-grey near the base, thence to the end pale rufescent, tip still paler. There are some narrow black cross-lines outside the limbs, and two distinct black bars inside each fore-arm; also the usual cheek-stripes, which are brown. The lower-parts are pale rufescent, with a few black spots; the chin, throat, and front of the breast white and unspotted, the fore-neck rufescent. Ears externally the same colour as the back, with a few elongate brown hairs at the end. Tail with some black transverse bands above, which form rings towards the end ; the tip being black. Paws black beneath."

This and the four next forms, namely, Shaw's Cat, the Jungle Cat, the Pale Cat, and the Steppe Cat, are all very closely allied, being distinguished by the slight pencil of hairs at the summit of each ear. Felis chans, writes Mr. W. L. Sclater in the "Catalogue of Mammals in the Indian Museum, Calcutta," "can be distinguished at once by its black pencil, and its pepper-and-salt colour, with no trace of lines or spots on the body. F. coudata is very indistinctly spotted, but has a long tail, twice the length of that of F. chans. F. ornata and F. shaniinna secm to resemble each other in every respect, although Mr. Blanford distinguishes the latter from the former by its shorter tail, its more rufous coloration, and the presence of distinct black spots on the tail. With regard to the first distinction, the tails of the two known specimens of $F$. shareiana are certainly shorter than those of the specimens of F.ornata; 
灵

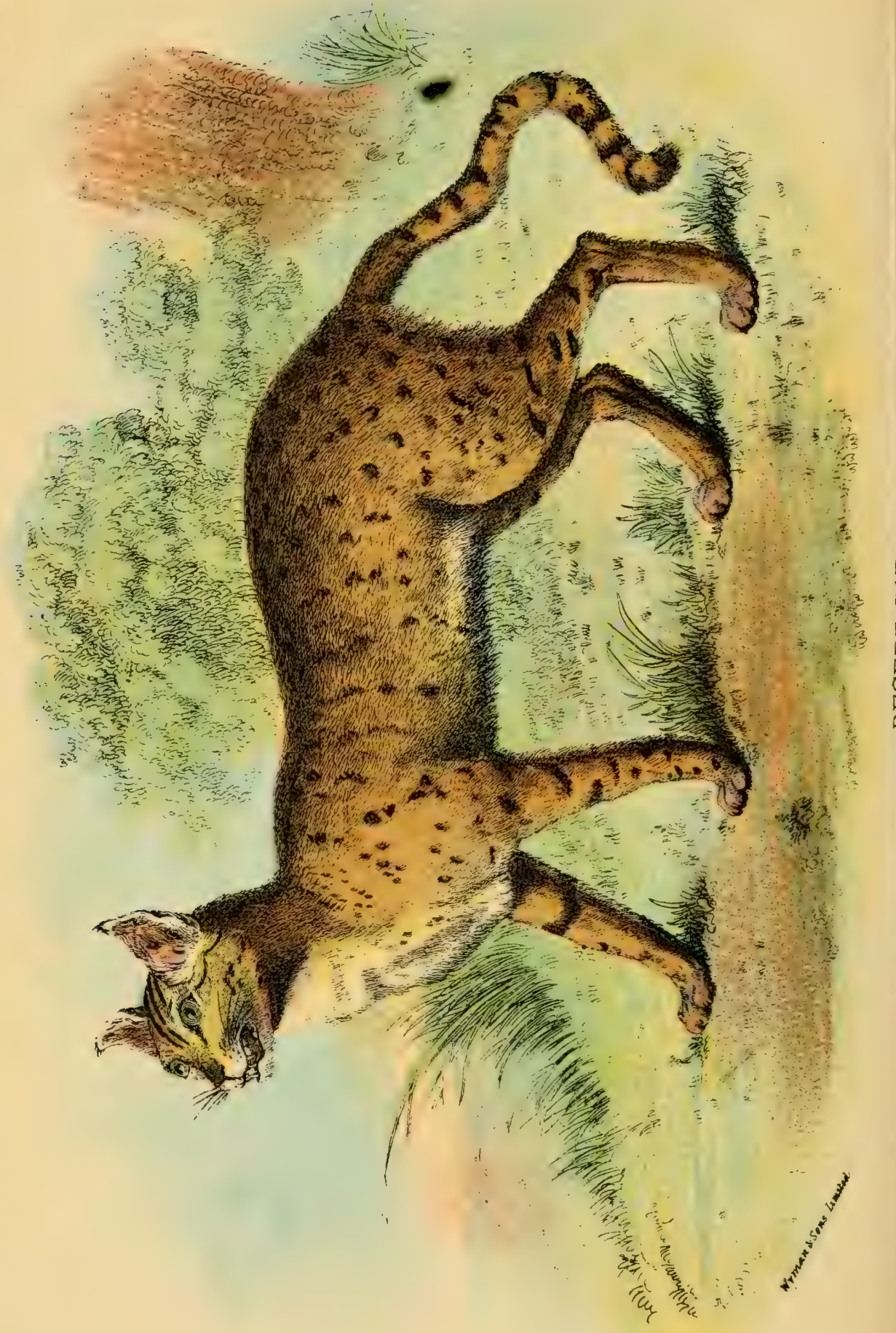


but the former are furriers' skins, having been bought in the bazaars at Yarkand and Kashgar, and the tails in both cases seem mutilated. The tails, too, of F. ornata in the Museum collection vary considerably in length, and range from eight to thirteen inches in specimens of approximately the same size. With regard to the second point, that of colour, the difference of shade is so slight that it is only perceptible in a strong light. Finally, there are in the Museum collection many specimens of F. ornata with quite as distinct spots on the abdomen as in $F$. shawiana. With regard to the skulls of F. ornata, F. chanus, and $F$. shawiana (there is no skull in the only known skin of F. caudata), there does not seem to be any real substantial difference. Although there are minor points of distinction which have been indicated by Mr. Blanford, yet it does not appear that any of these differences are sufficiently important to be due to anything but individual variations."

Distribution.-India; confined to the dry rocky districts of the north-west from Banda, through the North-west Provinces to Agra, Sambhar, and Sind, where the species is very common.

Habits.-As its name implies, the Desert Cat is an inhabitant of open sandy districts (with the colour of which its spotted yellow coat admirably harmonises), never resorting to forests, and being to a considerable extent diurnal in its habits. As already mentioned, it breeds freely with Domestic Cats, and is probably the parent form of the spotted breed of India. A correspondent of Jerdon writes that in the district of Hurriana it is very common, "frequenting open sandy plains where the Field-Rat [Gerbillus hurriana] must be its principal food. I hardly ever remember seeing it in what could be called jungle, or even in grass. One of these spotted Cats lived for a long time under my haystack, and I believe it to have been the produce of a tame Cat by a wild one. The wild one I have seen of half a dozen shades of colour, and you frequently see a ten- 
dency in these Cats to run into stripes, especially on the limbs.' It was on such a half-breed that the so-called Waved Cat ( $F$. torquata) was named. Jerdon observes that at Hissar the Desert Cat is almost always found among the low sand-hills, although occasionally in bare fields, frequently in company with the Desert Fox.

\section{SHAW'S CAT. FELIS SHAWIANA.}

Felis shazeiana, Blanford, Journ. Asiat. Soc. Bengal, vol. xlv. p. 49 (I 876); id., Scientific Results 2nd Yarkand Mission, Mamm. p. I 7 , pls. i. 6 , i. $c$ (1879).

The distinctive features of this species or variety having been already given under the heading of the Desert Cat, it will suffice to mention that is is known only from a few skins and a skeleton, mostly purchased in the bazaars of Kashgar and Yarkand.

Distribution.-Eastern Turkestan (Yarkand and Kashgar).

\section{THE JUNGLE CAT, FELIS CHAUS.}

Felis chans, Güldenstadt, Nov. Comm. Ac. Petrop, vol. xx. p. 483 ( 776$)$; Elliot, Monograph of Felidæ, pl. xxxiii. (1 $\left.878-8_{3}\right)$; Blanford, Mamm. Brit. India, p. 86 (I8S8). Felis catolynx, Pallas, Zoogr. Rosso-Asiat. vol, i. p. $S_{3}$ (I 8 I I). Lynx chaus, Fischer, Zoognosie, p. 230 (18I4).

Felis kutas, Pearson, Journ. Asiat. Soc. Bengal, vol. i. p. 75 ( 1832 ).

Felis affinis, Gray, Illustrations Indian Zool. vol. i. pl. iii. $(1832)$.

Felis erythrotis, Hodgson, Journ. Asiat. Soc. Bengal, vol. v. p. $233(\mathrm{I} 836)$.

Felis inconspicue, Gray, Ann. Mag. Nat. Hist. vol. i. p. 577 (1837).

Chans libycus, Gray, List Mamm. Brit. Mus. p. 45 (1 $8+3$ ). 
Felis jacquemonti, Geoffroy, in Jacquemont's Voyage, p. $5^{8}$ (I 844 ).

Chaus jacquemonti, Gerrard, Cat. Bones Mamm. Brit. Mus. p. 66 (1862); Gray, Cat. Carniv. Mamm. Brit. Mus. p. 34 (I869).

Felis libycus, Loche, Explor. Scient. Alger. Mamm. p. 42 (I867).

Characters.-From the two preceding forms the present species may be distinguished by the colour of the adult being generally of a uniform tawny, without spots, while the ears are yellow, with very small pencils of black hairs; limbs with faint indications of dark transverse bars. In the skull the anterior upper pre-molar may be present or absent; while in the upper carnassial tooth the tubercle on the inner side is well developed. Tail short, varying from one-third to two-fifths the length of the head and body. Pupil of the eye circular. In Indian specimens the fur is variable in length, being short in those from the plains, and long in Himalayan examples.

The coloration of the upper-parts varies from sandy or yellowish-grey to greyish-brown, the back being darker or even dusky, with, in some cases, a shade of red, while the underparts are fulvescent or reddish-white. The individual hairs are fulvescent white till near the tips, where they become greyish-white, the tips themselves being black. In some cases the under-fur is brown. Although the aforesaid dark bars are generally present on the limbs, they may be wanting. The under surface of the foot and ankle is brown, while the tail has black rings near the extremity, the tip being also black. Occasionally pale ferruginous stripes on the cheeks, and a band on the chest may be present; while in some specimens more or less distinct vertical rows of spots or wavy lines may be detected on the sides, and a black variety has been recorded from Ind:a. The ears are pale rufous externally, with the tips gener- 
ally black or blackish. Length of head and body, from 22 to 26 inches; tail, with the hair at the end, ro to I I inches; height at shoulder, I4 to I 5 inches.

Distribution.-The Jungle Cat is one of the few Cats common to Africa and India, and has the following extensive range: North Africa, inclusive of Egypt, Nubia, and Barbary; South Africa, at least as far as the Orange River; Asia Minor and Palestine; shores of the Caspian, and West and Southern Persia; Afghanistan, Candahar, India, Ceylon, Assam, and Burma. In India the species is universally distributed from the Himalaya and Sind to the extreme south. Neither by Mr Blanford, in his "Mammals of British India," nor by Mr. W. L. Sclater, in his "Catalogue of Mammalia in the Indian Museum," is the Jungle Cat spoken of as from Southern Africa. It is, however, recorded from that region by Messrs. Nicolls and Eglington, in the "The Sportsman in South Africa," who write as follows :- "This species, which is rarely found south of the Orange River, but is common within the tropics, seems to be often confounded with the Booted Lynx (Felis caligata), which does not appear to be known south of the Zambesi." Although their description accords exactly with that of the present species, it is a little difficult to determine the animal referred to as the Booted Lynx, Felis caligata being a synonym of F. caffra, and that species being recorded by the authors from the Cape district. During the Pleistocene period the Jungle Cat appears to have ranged into Western Europe; remains from Germany having been assigned to this species by Professor Nehring of Berlin.

Fabits.-In South Africa, where it is known as the Reed Cat (Reit-Kat of the Dutch), the Jungle Cat, according to Messrs. Nicolls and Eglington, may "be found frequenting low marshy ground in which there is plenty of cover in the shape of reeds, or in the thick bush bordering the rivers and lakes; 
its food consisting not alone of such water-fowl as can be snatched by it when they are resting on the margin of the water, but also of fish; and its spoor may be constantly observed imprinted on the soft mud surrounding such pools in the periodical watercourses which are constantly becoming desiccated, and in which many of the finny tribe may probably be imprisoned without the possibility of escape." Evidence of the crab- or fish-eating propensities of this species in Burma is afforded by a statement of General MacMaster, to the effect that when shooting he killed a Jungle Cat walking in deep black mud, as though in pursuit of fish or crabs.

In India, where it is known to the natives by the name of Jangli-billi (Jungle Cat), this species is very common. Jerdon writes that it is the common wild Cat "from the Himalayas to Cape Comorin, and from the level of the sea to 7,000 or 8,000 feet of elevation. It frequents alike jungles and the open country, and is very partial to long grass and reeds, sugar-canefields, corn-fields, \&c. It does much damage to game of all kinds-Hares, Partridges, \&rc.,-and quite recently I shot a Peafowl at the edge of a sugar-cane-field, when one of those Cats sprang out, seized the Peafowl, and after a short struggle (for the bird was not dead) carried it off before my astonished eyes, and, in spite of my running up, made good his escape with his booty. It must have been stalking these very birds, so immediately did its spring follow my shot. It is occasionally very destructive to poultry.

"It is said to breed twice a year, and to have three or four young at a birth. I have very often had the young brought to me, but always failed in rearing them, and they always evinced a most savage and untameable disposition. I have seen numbers of Cats about villages in various parts of the country, that must have been hybrids between this Cat and tame ones." 
The domestic breed of Indian Cats showing evidence of a cross with the Jungle Cat has already been alluded to under the heading of Domestic Cats.

In Southern Persia, where it is very common, the late Sir O. B. St. John writes that he has shot the Jungle Cat "at Shapur ( 3,000 feet), in a ravine of the hills near Borajun (500 feet), and on the Karagatch, more than 6,000 feet above the sea, showing that this Cat is not particular about climate. In the last-mentioned place I found three kittens, so young as to be unable to drink milk. I reared them with some difficulty till about three months old, by which time they became very tame and playful, climbing up on to my knees when at breakfast, and behaving very much like ordinary domestic kittens. Unfortunately one was killed by a greyhound and another by a scorpion, within a few days; on which the survivor became morose, and refused to be comforted, even by the society of a kitten of his own age, which I procured as a companion to him. When I left Persia, in $\mathrm{I} 867$, he was a year old, and very large and powerful. Two English Bull-Terriers I had, who made short work of the largest Domestic Cat, could do nothing with my wild Cat. In their almost daily battles, the Dogs always got the worst of it."

Again, Blyth writes that "in India the Chaus does not shun, but even affects populous neighbourhoods, and is a terrible depredator among the tame ducks and poultry, killing as many as it can get at; but I have not known it attack geese, of which I long kept a flock out day and night, about a tank where ducks could not be left out at night on account of these animals.

XXXVIII. THE PALE CAT. FELIS PALLIDA.

Felis pallida, Büchner, Bull. Ac. St. Petersburg, ser. 2, vol. iii. p. 433 (IS93); id., Wissensch. Result. Reis. Przewalski, p. 228 (IS94). 
Characters.-Nearly allied to the Jungle Cat, this species is stated to be distinguished by the following differences. Whereas in the Pale Cat the colour of the outer surface of the ear is similar to that of the back, being brownish-yellow, thickly mingled with black, in the Jungle Cat the outer surface of the ear is almost invariably rusty-red or reddish-yellow, with the short pencil of hairs black; the pencil in $F$. pallida being brownishyellow mixed with black. Then, again, the present species is characterised by the generally pale yellowish-grey hue of the fur; from which the rufous tinge-most conspicuous on the head, under-parts, and limbs-of F. chaus is entirely absent. Indeed, those parts of the body of the latter which are rufous or reddish-yellow, in the Pale Cat are whitish or grey. The tail of $F$. pallida is also longer and more bushy than in $F$. chans.

For a detailed account of the coloration of this form, the reader may refer to the original description; but the foregoing is sufficient to indicate its extremely close relationship with the Jungle Cat. Indeed, it is probable that many zoologists would regard it merely as a pale coloured local race of the latter.

Distribution.-Kansu, N.W. China.

XXXIX. THE STEPPE Cat. FELIS CaUdata.

Chaus caudatus, Gray, Proc. Zool. Soc. IS74, p. 3 I. Felis caudata, Elliot, Monograph of Felidæ, pl. xxxiv. ( $1878-S_{3}$ ). Felis caudatus, Mivart, The Cat, p. 42 I (I88I).

Characters.-As mentioned under the heading of the Desert Cat, this species may be distinguished from the Jungle Cat by being very indistinctly spotted, and by the tail being considerably longer.

The type specimen is described as follows:-Fur close, soft, pale yellowish (the hairs blackish-brown at the base), with very 
indistinct spots. The spots are roundest and smallest on the middle line of the back, oblong on the sides, and forming interrupted lines on the shoulders and thighs, these lines being most distinct on the outside of the fore-legs, while there are four well-marked broad cross-streaks on the front edge of the thighs. 'Tail cylindrical, reaching to the ground, spotted at the upper part of the base, and with eight or nine interrupted rings on the upper part of the remaining portion, with a black tip. Nose brown, with short hair. Forehead and cheeks like the back, but with smaller spots, and without any distinct dark streaks from the back edge of the eye. The ears ovate, acute, pale brown externally, with a terminal pencil of blackish hairs, and whitish on the edge within. Chin, hinder parts of the upper lip, under parts of the head, throat, chest, belly, inside of legs, and hind-feet whitish-brown ; the chin being whitest, and the inside of the hind-legs and fect darkest. There is a large blackish spot on the upper part of the inside of the forelegs, as well as two small cross-bars on the front edge of the inside of the thighs, the hinder part of the hind-feet being blackish. In the one described skull, the anterior pre-molar, although small, is present. I.ength of head and body, $23 \%$ inches; of tail, I $2 \mathrm{I} / 2$ inches; height at shoulder, I 2 inches.

Distribution.-Transcaspia, eastwards to Afghan and Russian Turkestan.

\section{THE CARACAL. FELIS CARACAL.}

Felis caracal, Güldenstadt, Nov. Comm. Ac. Petrop. vol, xx. p. 500 ( I 766); Elliot, Monograph of Felidæ, pl. xli. (I $87 S-$ $8_{3}$ ) ; Blanford, Mamm. Brit. India, p. SS (rSSS). Lynx caracal, Fischer, Zoognosie, p. 200 (ISI 4 ). Caracal melanotis, Gray, List Mamm. Brit. Mus. p. 46 (i $S_{+3}$ ). Caracal berberomm, Matschie, S.B. Nat. Fr. Ges. Berlin, I ¿92, p. I44. 

$\overline{8}$
$\frac{8}{2}$

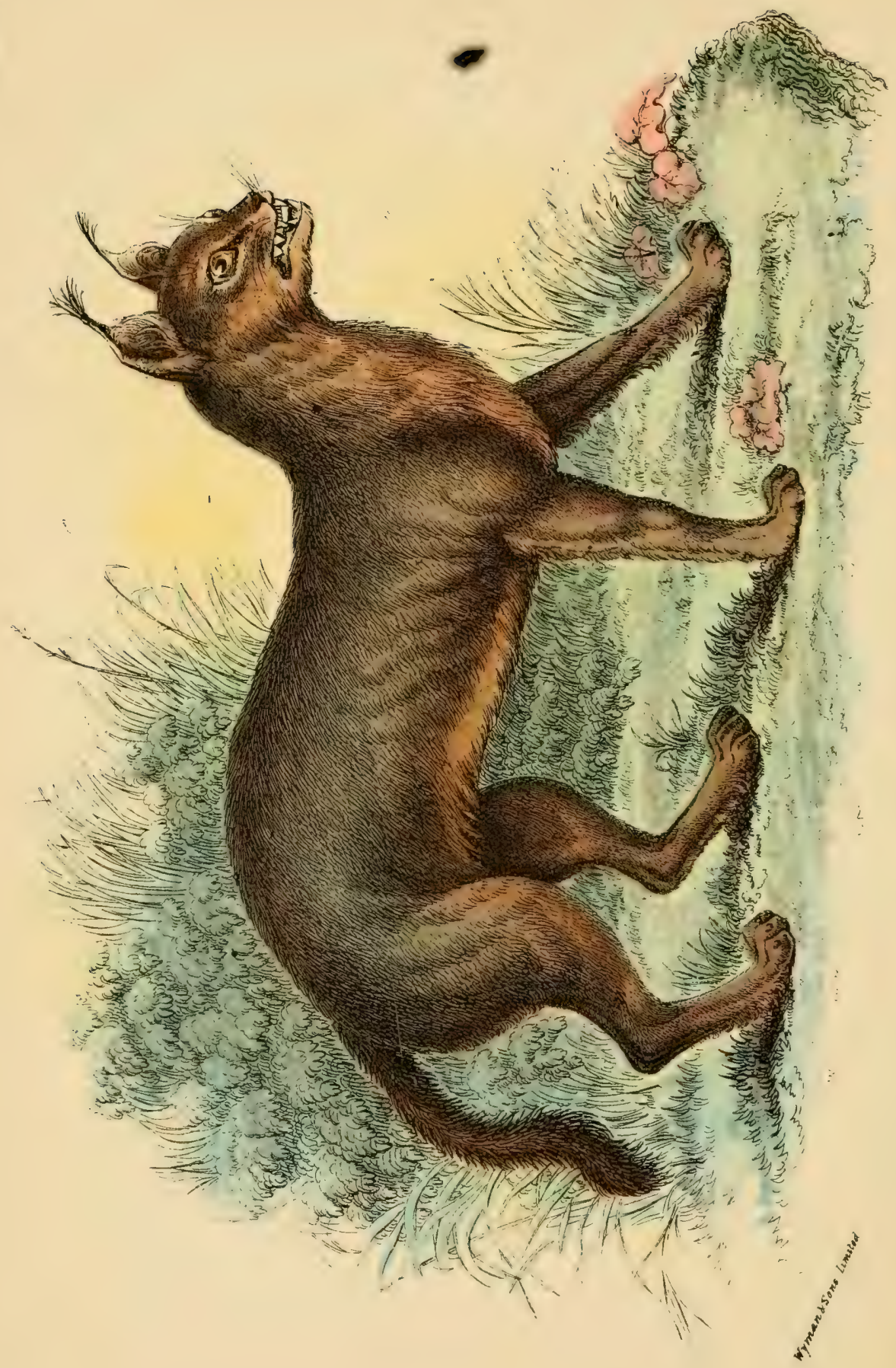

$\underset{\mho}{\longleftarrow}$ 
Characters. - With this species we come to the first of the True Lynxes, all of which are characterised by the long and wellmarked pencil of hairs at the tip of the ears, the absence of the anterior upper pre-molar tooth, and the slight development of the tubercle on the inner side of the upper carnassial tooth. Were it not for their connection with the more typical members of the family by means of the Jungle Cat and its allies, there would be much to be said in favour of referring them to a genus apart. As it is, however, such a course cannot be justified, especially when we recall the fact that in its greater length of tail the Caracal connects the other Lynxes with the Jungle Cat.

From the other Lynxes the Caracal is at once distinguished by the greater length of its tail, which reaches down to the hocks; while it is further characterised by its uniform red colour and long and pointed black ears. In point of size it is intermediate between the Jungle Cat and the common Lynx; the build is slender, the limbs are relatively long, and the tail equals one-third the length of the head and body.

Mr. Blanford describes the colour of the upper parts as varying from rufous-fawn to brownish-rufous, "generally the former in Indian specimens, unspotted; below paler rufous or white, often with indistinct rufous spots. Fur nearly the same colour throughout, slightly paler near the roots, some white tips intermixed on the back, and in dark specimens black tips also, giving a peculiar grizzled appearance. Limbs and tail the same colour as the body, the tip of the tail being sometimes, but not always, black. Ears outside black, often mixed with white; inside white. A blackish spot on each side of the upper lip, and others, not always distinct, above each eye and on each side of the nose. A white or pale spot inside, and another below each eye." Length of head and body, 26 to 30 inches ; of tail, from 9 to ro inches; height, 16 to $\mathrm{I} \delta$ inches. 
Distribution.-Africa genely, Palestine, Arabia, Syria, Taurus, Mesopotamia, Persia, Transcaspia, and India. Generally distributed in the latter country, it is found more abundantly in the west, especially in Sind, Kach, Dehra Dun, and the Nipal Terai.

The Caracal of Northern Africa has recently been separated by Herr Matschie under the name of Caracal berberorum, but further evidence is required before its right to specific distinction can be definitely accepted.

Habits. - The Caracal is believed to be the animal which gave origin to the term "Iynx-eyed," although there does not appear to be any evidence that it is more keen of sight than other members of the Family to which it belongs. In South Africa, where it is pretty well exterminated in the regions lying to the southward of the Orange River, the Caracal, according to Messrs. Nicolls and Eglington, is generally found in open country at considerable distances from water, thus differing markedly from the Serval. Rapid in its movements, and an excellent climber, its strength and activity make it a match for the best Dog ; and instances are on record where females with young have boldly attacked natives, by whom they have been with difficulty driven off. Indeed, for its size, the Caracal is held in this part of Africa to be the most savage of all the Cats. "Even when obtained young and brought up by hand," write the observers last named, "it gradually develops a character, so to speak, of pure 'cussedness,' that any attempts to tame it have invariably proved unsuccessful. The Boers hold to the belief-which is often treated with ridicule-that the skin of this Lynx, when made into and used as karosses [mantles], is a sovereign remedy against an attack of rheumatism. Whether they really possess any curative virtues, it is not within our province to determine, but their general use is greatly favoured in South Africa; and it is certainly a fact that the fur of the dead animal is highly electrical." 
In India but little has been recorded as to the habits of the Caracal in a wild state. Apparently resorting to low bushes and tall grass, it avoids dense forests, and is reported to prey on Gazelles, the smaller kinds of Deer, Hares, and other small animals, as well as Peafowl, Florican, \&c. So active are its movements, that the Caracal is actually able to capture birds flying over it, springing up to a height of six or eight feet from the ground, and striking them down with a blow from one of its fore-paws.

Being easily tamed, the Caracal in some parts of India was formerly (and, for all we know to the contrary, may be still) trained to chase and capture various wild animals, such as small Deer, Gazelles, Hares, Foxes, Peafowl, or Cranes; while another pastime was to pit two or more against one another to kill pigeons out of a flock. As the birds are feeding on the ground, the Caracals are suddenly loosed in the midst of them, when each will not unfrequently strike down as many as ten or a dozen before the pigeons can make their escape. According to Vigne, the number of Caracals kept by some of the Indian princes in the first half of the present century was very large; and, in proportion to their size, their speed is described as exceeding even that of the Hunting-Leopard.

Although agreeing with the typical Lynxes in general characters, the Caracal lacks the ruff of long fur round the throat so distinctive of the form; while its short and close fur is better adapted to the climate of the regions it inhabits. In allusion to its black ears, the Caracal is known in Persia by the name of Siya-gush, while in Turkish the name Karakal has the same signification.

XLI. THE LYNX. FELIS LYNX.

Felis ynnx, Linn., Syst. Nat. ed. I2, vol. i. p. 62 (г 766); Elliot, Monograph of Felidæ, pl. xxxix. (I878-8 3 ); Blanford, Mamm. Brit. India, p. 8) (I888). 
Felis lupulina and F. vnlfin $\iota s$, Thunberg, Denkschr. $A k$. München, vol. ix. p. I89 (I825).

Felis virgata, Nilsson, Illum. Fig. till. Faun. pls. iii. iv. (1 \$29). Felis borealis, Temminck, Monogr. Mamm. vol. i. p. Io9 (1827); Keyserling and Blasius, Wirbethiere Europ. p. 63 (1840).

Lyncus anugaris, Gray, Cat. Hodgson Coll. p. 7 ( $\left.\mathrm{I}_{4} 6\right)$.

Felis isabellina, Blyth, Journ. Asiat. Soc. Bengal, vol. xvi. p. I 78 (1 847 ).

Lyncus lynx, Severtzoff, Rev. Mag. Zool. ser. 2, vol. x. p. 385 (1858).

Lyncus isabellinus, Gray, Proc. Zool. Soc. 1867, p. 267.

Lyncus borealis, Gray, loc. cit.

\section{(Plate XXIV.)}

Characters.-Readily distinguished from the Caracal by the shortness of the tail, which is less than one-fourth the length of the head and body, and does not reach the ankle; by the abundant ruff cf long hair round the throat, as well as by the more or less distinctly spotted coat.

Build strong; limbs relatively long; the long and pointed ears surmounted by a large tuft of black hairs; fur soft and thick, that of the hinder part of the cheeks being lengthened so as to form a ruff partially encircling the throat; pads of feet more or less completely covered with hair. Pupil of eye circular. Skull much vaulted, with a short and broad facial region, the orbit incomplete behind, and the anterior upper pre-molar absent in the adult.

The colour varies from pale sandy-grey, or isabelline, to rufous-fawn with a tinge of grey, and in some European specimens even to ferruginous-red; the under-parts being white. In the summer coat the upper-parts are marked with small black spots, which, at least in young individuals, are also persistent through the winter in the European race; but 


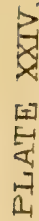

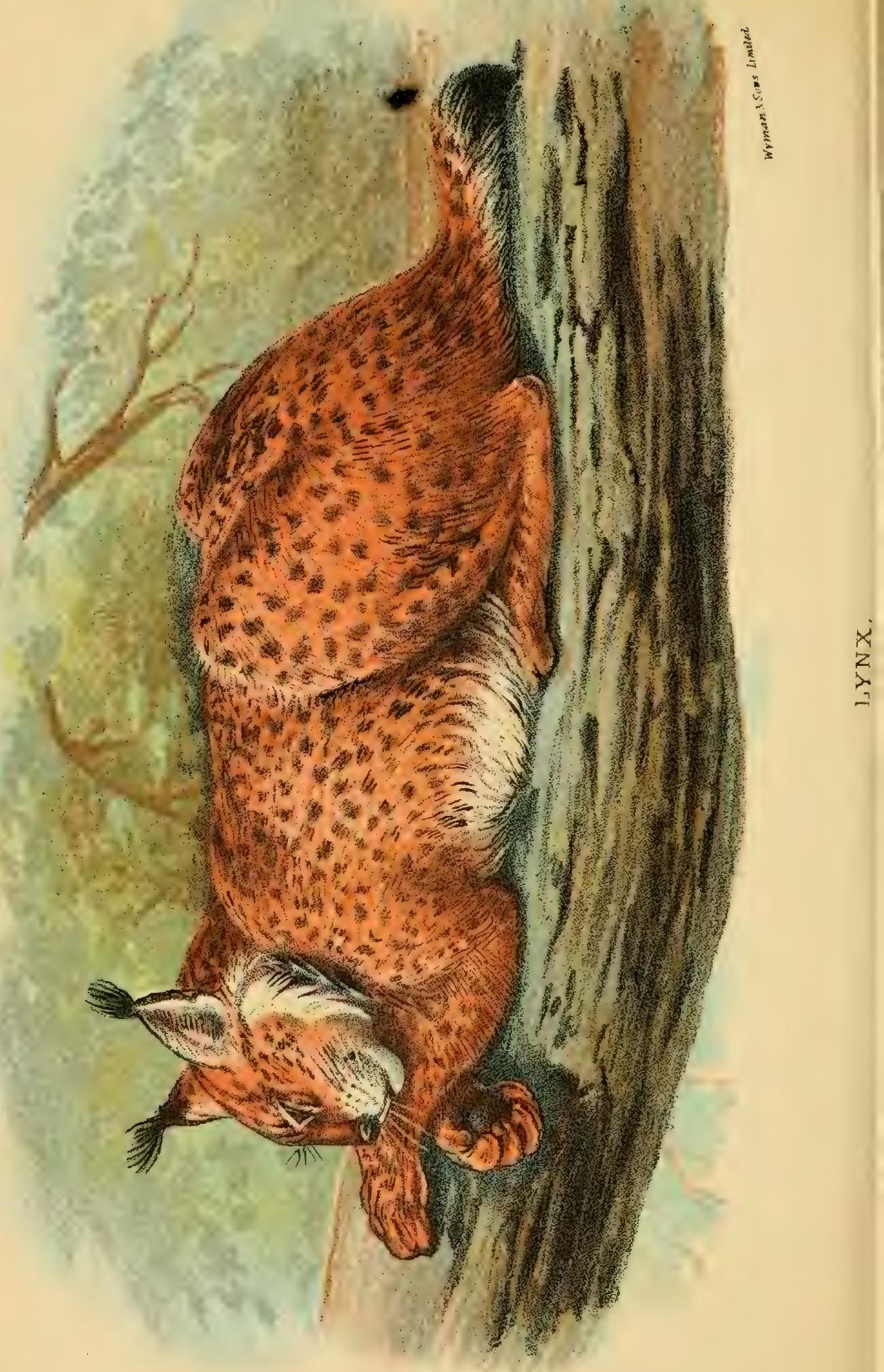


in the Asiatic form these spots disappear, except on the flanks and limbs, and even there they may ke wanting in some examples. Towards their roots the individual hairs are brownish; and the tips of the longer ones are whitish, some of those on the middle of the back being often black at the extremity. Ears externally grey, with black margins, tips, and terminal tufts; terminal portion of tail black; a variable number of black hairs intermingled with the ruff; in some cases an imperfect dark band across the throat, and occasionally blackish or black spots on the under-parts. Length of head and body, 33 inches; of tail, $73 / 4$ inches.

The Lynx is very variable as regards coloration, and more especially in respect to the spots; and the pale-coloured Lynx of Ladak and Tibet was long regarded as a distinct species, on account of its lighter-coloured fur and the shorter hairs on the toes, under the name of $F$. isabellina. On this subject, Mr. Blanford, in his "Mammals of British India," writes that "both these differences are probably due to the Tibetan Lynx living in open ground among rocks, whilst the common Lynx of Europe dwells chiefly among forests. The Lynx of Gilgit, where there is some forest, is intermediate in coloration, and I can find no constant character of importance by which F. isabellina is distinguishable from the common Lynx. Some skins procured from Tibet are indistinguishable from Gilgit and 'Turkestan specimens."

Distribution.-Northern Europe, Siberia, Baikal, Amurland and Saghalien, Eastern and Western Turkestan, Gilgit, and Western and Eastern Tibet. As mentioned in the sequel, it is by no means certain that the Canadian Lynx is anything more than a local race of this species. Still far from uncommon in Northern Scandinavia, Russia, and Northern Asia, the Lynx also lingers in some of the mountainous districts of Centr.l Europe, although in the lowlands it has been pretty 
well exterminated. In Baden the last Lynx was killed in 1834; but an example was shot in Württemberg so late as 1846. Another Lynx was killed in the Department of HauteLoire, France, in the year 1822 . The species never inhabited Britain during the historic period. In Tibet the Lynx lives at great heights, its culs having been taken in Spiti at an elevation of between 14,000 and 15,000 feet; but at Gilgit it descends as low as 5,000 feet above the sea.

Internal Structure.-It is worthy of mention that the Lynx differs from all the spzcies of Cats described above, in the relative shortness of its intestine, which is only twice the length of the body. As in the common Cat, the arched bone, supporting the base of the tongue, is connected with the under surface of the hinder part of the skull by a continuous chain of small bones.

Habits.-Although generally inhabiting forest-clad districts, where it captures much of its prey by climbing the trees, the Lynx, as we have seen, in Tibet, dwells in the open, among rocks. That it is by no means a common animal is not to be regretted, seeing that in the wild state it is one of the most bloodthirsty and rapacious of the Felidce, frequently killing more than it can devour, and thus being detested by the owners of Sheep and Goats. In Tibet it preys chiefly upon the Hares that are so abundant in the patches of bush along the watercourses; but it also kills Pigeons, in addition to Sheep and Goats. In Europe it subsists upon the smaller mammals and birds; but the reports of its onslaughts on Red Deer are not to be credited. An excellent climber, the Lynx frequently lies stretched out at length on the bough of a tree, from whence it springs suddenly on its unsuspecting prey; and the writer has witnessed the extraordinary rapidity with which a tame individual would spring on Pigeons on the roof of a house in Leh. The female produces two or three young in a littur, 
which are usually concealed either in a cave, in a crevice among fallen rocks, or in the hollow trunk of a large tree. In spite of their ferocity, Lynxes, if taken sufficiently young, can be readily tamed, and are susceptible of showing much attachment to their owners.

XLII. THE CANADIAN LYNX. FELIS CANADENSIS.

Felis canadensis, Desmarest, Nouv. Dict. Hist. Nat. vol. vi.

p. Iо8 (I8I6); Elliot, Monograph of Felidæ, pl. xxvii. (1878-83); Mivart, The Cat, p. 425 (I88I).

Lynx canadensis, Rafinesque, Amer. Month. Mag. vol. ii. p. 46 (I 8 I 7 ).

Lyncus canadensis, Gray, List Mamm. Brit. Mus. p. 46 (I 843 ). Lyncus burealis, De Kay, New York Zool. p. 5 (r8 $8_{42}$ ).

Characters.-As already mentioned, it seems highly probable that this Lynx can only be regarded as a local race of the preceding; but since it is generally recognised by American zoologists as a distinct species, it is provisionally allowed to retain that rank in the present work. Professor Mivart, who regards the Canadian Lynx merely as a variety, states that its skull is indistinguishable from that of the common Lynx; and that the chief difference from the spotted variety of the latter consists in the inferior size of the American form, the length of the head and body being about 30 inches, and that of the tail 5 inches. Some writers are, however, of opinion that the spotted Felis borealis of Temminck, from the north of Europe, should be separated from the typical $F$. lynx, and united with $F$. canadensis, which would then have a circumpolar distribution.*

Distribution.-North America, as far south as Pennsylvania and California.

Habits.-In habits the Canadian Lynx apparently agrees in

* See IV. L. Sclater, Cat. Mamm. Ind. Mus. pt. ii. p. 233 (I89r). 
all respects with its relative. In his "Mammals of the Adirondack Region," Dr. Hart Merriam writes that "it preys upon the northern Hare and such other small animals as it can catch, and upon the Ruffed Grouse and Spruce-Partridge. It has also been known to devour pigs, lambs, and young fawns, but the accounts of its attacking full-grown Deer are not to be credited. Its haunts are in the deep forests and burnt districts, remote from the paths of Man; and consequently it rarely intrudes upon the barn-yard. Its ordinary gait when in a hurry is a long gallop, like that of the Hare; and it is said to swim well. The female commonly has two young at a birth, her lair being usually located in a cavern or hollow tree."

After mentioning that it is found on the Mackenzie River as far north as latitude $66^{\circ}$, Sir John Richardson writes that this Lynx "is a timid creature, incapable of attacking any of the larger quadrupeds, but well armed for the capture of the American Hare, on which it chiefly preys. Its large paws, slender loins, and long but thick hind-legs, with large buttocks, scarcely relieved by a short thick tail, give it an awkward, clumsy appearance. It makes a poor fight when it is surprised by a hunter on a tree, for though it spits like a Cat, and sets its hair up, it is casily destroyed by a blow on the back with a slender stick, and it never attacks a man. Its gait is by bounds, straightforward, with the back a little arched, and lighting on all the feet at once. It swims well, and can cross the arm of a lake two miles wide, but it is not swift on land. It breeds once a year, and has two young at a time. The natives eat its flesh, which is white and tender, but rather flavourless, much resembling that of the American Hare."

Every two to four years there appears a sudden isicrcase in the number of Lynxes in parts of North America; these animals associating at such times in troops, and forsaking their favourite haunts to follow the IVood-Hare (Lefus sylzutious); and it is 
further stated that whenever the latter animals are unusually plentiful, Lynxes will be sure to be proportionately numerous.

Pelage.-Lynx-skins, according to Mr. Poland, are a rather important article in the fur-trade, the Huds on Bay Company usually selling from 8,000 to 40,000 annually, although in $1 S 87$ the number was swelled to over 70,000 . Many skins are dyed black, and others brown or grey, while others, again, are silvered. The long fur of the under-parts is much used for boas and muffs, when these articles are in fashion, as it is for trimmings to coats and jackets; while officers' busbies in the English Hussar regiments are made of Lynx-skin dyed dark brown. The price varies considerably according to the demand, fine skins realising from forty to forty-two shillings each, while those of inferior size and quality sell at about from four to fifteen shillings.

\section{THE RED LYNX. FELIS RUFA.}

Felis mufa, Güldenstadt, Nov. Comm. Ac. Petrop. vol. xx. p. 499 ( $7_{776)}$; Elliot, Monograph of Felidæ, pl. xl. ( ( $\$ 7$ S- 83 ). Felis curolinensis, Desmarest, Mammalogie, p. 234 (I820). Lynx floridanus, Rafinesque, Amer. Month. Mag. vol. ii. p. $4^{6}$ (I8I7).

Lynx montanus, Rafinesque, loc. cit. Ly'nx rufus, Rafinesque, loc. cit. Lynx aureus, Rafinesque, loc. cit. Lynx fasciatus, Rafinesque, loc. cit. Felis maculata, Vigors and Horsfield, Zool. Journ. vol. iv. 1) $3^{8}$ I (1829).

Lyncus mufus, Gray, Proc. Zool. Soc. IS67, p. 276 ; id., Cat. Carniv. Mamm. Brit. Mus. p. 38 (1869).

Characters.-This more southern form, which is likewise regarded by Professor Mivart as a mere variety of the ordinary Lynx, is distinguished by the American zoologists on account of the rufous tinge assumed by the whole pelage in summer. 
Commonly known in A rica by the name of "Vild Cat," the Red Lynx was long ago described from Minnesota by Carver as follows: "The Cat of the Mountains. This creature is in shape much like a Cat, only much larger. The hair or fur resembles also the skin of that domestic animal ; the colour however, differs, for the former is of a reddish or orange cast but grows lighter near the belly. The whole skin is beautified with black spots of different figures, of which those on the back are long, and those on the lower-parts round. On the ears are black stripes. The creature is nearly as fierce as a Leopard, but will seldom attack Man."

With this somewhat vague description may be contrasted the detailed one given by Mr. C. I. Herrick, in his "Mammals of Minnesota" ( 1892 ), which runs as follows:- "The base of the fur is tawny-black, the middle buffy-yellow; terminal portion white, or white followed by a longer or shorter black band. Ear-tips black; pencil well developed. Below, the terminal white portion is long, concealing the others. Thighs externally spotted and lighter, obscurely barred within. The upper arm is slightly barred externally, while internally there are several wide black bars. In the middle of the back the whole base of the fur is black, the tips only being white. The tail is tipped with white. The ruff is moderately long, and composed of rather stiff harsh hairs. The above description applies to the winter pelage. As early as February the whole skin takes on the rufous tint before nearly confined to the flanks. In spring specimens the base of the fur is pale Vandyke-brown. In the yearling the head is of nearly the same size as in the adult. The colour seems independent of sex." Length of head and body, 30 inches; of tail, 6 inches.

Distribution.-North America, as far south as Mexico. More common southwards than to the north, and probably unknown in the extreme north, 
Habits.-From the account given in Dr. Hart Merriam's "Mammals of the Adirondack Region," it would appear that in habits this Lynx differs to a certain extent from the preceding, a circumstance which, so far as it goes, is in favour of its right to specific distinction. Frequenting rocky hills and ledges, the Red Lynx does not exhibit that antipathy to the neighbourhood 'of human habitations which is such a characteristic trait of the Canadian Lynx; and it is accordingly quite common in thickly populated districts, where it carries off lambs, young pigs, and poultry from the farmyard. In the wilds its food consists, however, of Rabbits, Squirrels, Mice, Grouse, and such small birds as it can contrive to capture. The young, generally three in number, although there may be as few as two and as many as four in a litter, are generally produced in some hollow tree or log, where a moss-lined cradle is prepared by the mother for their reception. When enraged, the Red Lynx hisses, spits and snarls in the most menacing manner.

An anecdote quoted under the head of the Jungle Cat is paralleled by the following experience of Dr. Merriam. "In I 873 or I 874 ," writes this naturalist, "I shot a Grouse as it was flying along the north side of Mount Tom, in Massachusetts. Scarcely had it touched the rocky slope when a IVild Cat sprang upon it from behind a neighbouring bush, and, in a succession of rapid leaps, started up the side of the mountain with the Grouse in its mouth. The contents of the other barrel of my gun caused him to change his mind as well as direction."

Mr. Herrick relates that in Minnesota "during severe weather the IVild Cat is often forced to feed upon the Porcupine, and it is of no unfrequent occurrence that she pays for her temerity with her life. I have several times secured them with the head and throat filled with the spines, rendering the animals helpless. Such specimens were invariably poor 
and emaciated." We have feard of other kinds of Cats taking to the same kind of prey.

Although we are not generally disposed to regard the flesh of carnivorous animals as affording a palatable dish, yet Dr. Merriam assures us that Red Lynx flesh is most excellent eating, resembling veal both in appearance and taste.

Xliv. The Plateau LyNX. FElis BaIleyi.

Ly'nx baileyi, Merriam, North American Fauna, No. 3, p. 79 (1890).

Felis baileyi, Lydekker, Royal Nat. Hist. vol. i. p. 44I (I S93).

Characters.-Said to differ from the Red Lynx of the Eastern United States in being uniformly paler on the upper-parts, as well as by its shorter tail and softer fur. The upper-parts are everywhere suffused with a buffish tint, and the dark markings are either smaller or altogether wanting. Thus, the blackish marblings of the face and forehead of the Red Lynx are obsolete; and the black band on the upper surface of the tip of the tail has not half the width it has in the latter. On the other hand, the anterior border of the ear is distinctly whitish, in marked contrast to the black immediately behind it, while in $F$. rufus the same border is dark tawny-brown. The white hindtoes so conspicuous in the latter are also wanting.

In spite of certain not very important differences in the skulls of the two forms, the writer finds it difficult to regard the features above described as entitling the Plateau Lynx to rank as a distinct species.

Distribution.-Colorado, Utah, and Arizona.

Xl.V. THE SPANISH LYNX. FELIS PARDIN .

Felis pardina, Temminck, Monogr. Mamm. vol. i. p. i 16 (1827); Elliot, Monogr. Felidæ, pl. xxxviii. (1878-83); Mivart, The Cat, p. 426 (I88I).

Ly'nous pardinus, Gray, List Mamm. Brit. Mus. p. 46 (I 843 ). 
Characters. - This southern Old World Lynx, of which the colour is rufous on the upper-parts and white beneath, with numerous rounded black spots on the body, limbs, and tail, appears to be a well-marked species distinguished from all the preceding forms by the characters of the skull. According to Professor Mivart, when the skull is viewed in profile, it will be seen to differ from that of the common Lynx and its allies by being raised and convex between the orbits; while a further difference is to be found in the more backward extension of the nasal bones.

Distribution.-Southern Europe, including Turkey, Greece, Sicily, Sardinia, and Spain. That it is a very ancient inhabitant of the latter country is proved by the occurrence of its fossilised remains in the ossiferous deposits of the caverns of Gibraltar, in association with those of extinct Mammals.

I have not come across any good accounts of the habits of the Spanish Lynx, but it is probable that these differ in no essential degree from those of the other representatives of the group.

II. TIIE NON-RETRACTILE-CLAIVED CATS. GENUS CYNELURUS.

Cynailurus, Wagler, Syst. Amphib. p. 30 ( 1830 ).

Characters.-Claws only partially retractile, their extremitics being always protruded from their sheaths; the tubercle on the inner side of the upper carnassial tooth rudimental. Body slender, and limbs relatively longer than in the retractileclawed cats. Skull with the foramen below the socket of the eye very small, and frequently represented by two or more minute apertures.

The genus is at the present day represented solely by the under-mentioned species, although it is probable that an extinct form occurs in the Pliocene rocks of the Siwalik Hills in the north of India, 
I. THE HUNTING-IEORR. CYNELURUS JUBATUS. Felis jubata, Erxleben, Syst. Règn. Anim. p. 5 ro (r 777 ). Felis gittata, Hermann, Observ. Zool. p. 38 (1804). Cynailurus jubatus, Wagler, Syst. Amphib. p. 30 (I830); Elliot, Monogr. Felidæ, pl. xliii. (I $878-83$ ).

Cynofelis jubata and C. guttata, Lesson, Nouv. Table. Règn. Anim. p. 49 (1842).

Gueparda guttata, Gray, Proc. Zool. Soc. I867, p. 277 ; id., Cat. Carniv. Mamm. Brit. Mus. p. 39 (1869).

Felis megaballa, Heuglin, Zeitschr. Allgem. Erdkunde, vol. iii. p. 53 (1868).

Felis lanea, Sclater, Proc. Zool. Soc. 1877 , p. 532 ; Mivart, The Cat, p. 429 (I88I).

Cyncelurus jubatus and C. laneus, Blanford, Mamm. Brit. India, pp. 90, 91 (r888).

\section{(Plate XXV.)}

Characters.-Size about the same as that of the Leopard, but form more slender, and limbs longer. Ears short and rounded; fur coarse, hair of neck somewhat lengthened, and that of the under-parts rather long and shaggy; tail more than half the length of head and body. Ground-colour of upper-parts varying from tawny to bright rufous-fawn, becoming paler beneath ; marked almost throughout with small solid black spots; chin and throat buffish-white without spots; a black streak from the outer corner of each eye to the lip, and another (or a line of spots) from the inner corner to below the ear; ear black externally, with tawny base and margin; tail spotted on upper surface, the spots towards the tip passing into imperfect rings. Cubs covered with uniformly grey long hair, but with spots showing on the under-fur. Pupil of eye circular when contracted. Skull vaulted and broad, very convex at the crown, and the facial portion short with the nasals broad and wide; orbits incomplete behind; anterior upper pre-molar tooth generally 

这

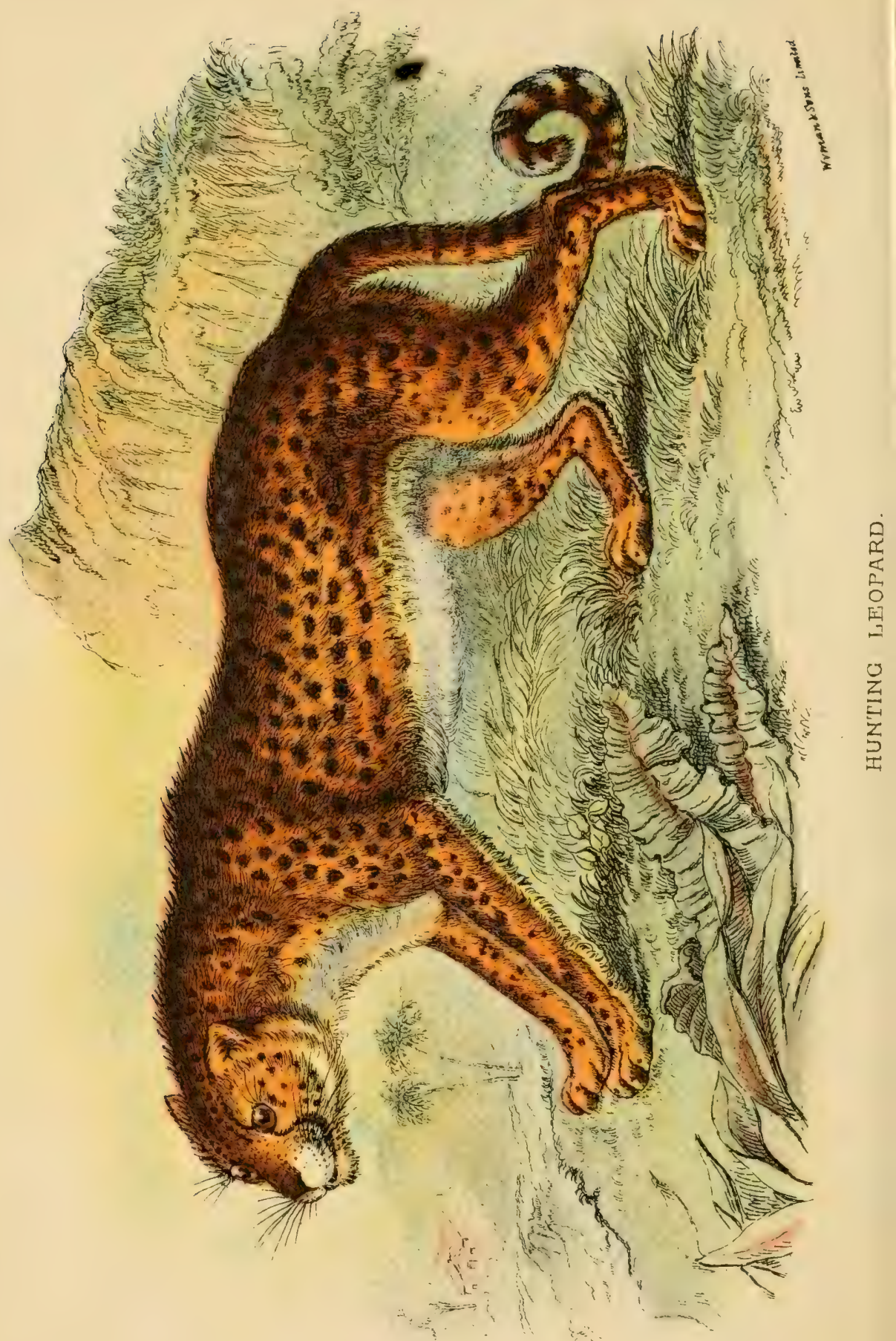


present. Length of head and body, about $4 \mathrm{~T} / 2$ feet ; of tail, $2 \mathrm{I} / 2$ feet ; height, about $2 \mathrm{I} / 2$ feet.

Distribution.-Africa and South-western Asia, ex.ending from Persia to Western Turkestan and the countries east of the Caspian, and eastwards into India. In the latter country ranging over a considerable portion of the peninsula, from the Punjab, through Rajputana and Central India, to the confines of Bengal ; unknown on the Malabar Coast and in Ceylon, as well as to the north of the Ganges. In Africa the species is reported to be probably exterminated in Natal, and nearly so in the Cape Colony, althnugh a few individuals still linger in the extreme north-western districts. Some also remain in the more remote unsettled parts of the Transvaal; but in the waterless portions of the Kalahari, as well as in parts of Bechuanaland, and throughout South Central Africa, it is less uncommon.

The so-called Woolly Chita (C. laniger) of Africa appears to be merely a variety in which the fur is more woolly and dense than in the typical form, with the spots taking the shape of blotches of a dark fulvous tint. As mentioned under the heading of the Leopard, the name Chita is properly no more restricted to the present than it is to the latter species, and it is accordingly preferable to adopt the term "Hunting-Leopard."

Habits. - While in South Central Africa this animal usually haunts flat bush-clad districts, in India its favourite resorts are low, isolated, rocky hills. In the former country its prey includes the smaller Antelopes and the fawns of the larger kinds, together with Hares, the Cape Jumping-Hare (Pedetes), and Guinea-fowl; while in India it subsists chiefly upon Black Buck, although it also kills Gazelles, Nilgai, and probably Deer and other large Mammals. Although in both continents it occasionally carries off a stray Sheep, Goat, or Calf its depredations on domesticated animals are not very serious; and it 
has never been known to ack human beings. Indeed, its disposition cannot in any way be said to be ferocious or sanguinary; and when the natives of South Africa meet with a Hunting-Leopard, they have no hesitation in closing with it, armed only with a club. For a short spurt, the speed of this animal far surpasses that of any other member of the Family; and it also differs from the other species, in that it generally hunts in pairs or small family parties. After a meal, it usually rests for a couple of days, and then repairs to a particular tree, where it cleans and sharpens its claws in the manner characteristic of the Family, preparatory to another foray. It can be tamed with great facility, all the individuals employed in hunting in India being captured when full-grown, the natives asserting that it is essential for the cubs to be trained in capturing their prey by their parents.

Regarding the employment of these animals in the chase, Jardine writes that at an early period of the Mogul Empire it is stated that Leopards and Lynxes were kept for chasing Deer, and Tigers for seizing Boars. "Although it is not likely that it was the real Tiger which was employed, it is evident that there were at least three animals so distinct as to entitle them to various denominations. It is said that some of the emperors, in their great hunting expeditions, were accompanied to the field by a thousand Hunting-Leopards.

"At the present period this sport is confined entirely to India and Persia, and the Hunting-Leopard alone is employed in it. These animals are so tame and gentle, as to be led about in a leash like Greyhounds, but when brought to the hunting-field, they are carried either on an Elephant or on horseback on a pad behind the rider, but more generally on a cart made for the purpose, and drawn by oxen. This carries both the sportsman and his attendants, and upon approaching the game, the animal is unhooded and slipped. But the description of a 
chase by one who has enjoyed the sport, wiil give the best iclea of the manner in which it is condtcted.

"Just before we reached our ground, the camel-courier, who always moved on our flanks in search of game, reported a herd of Antelopes about half a mile out of the line of march, and the Chitas being at hand, we went in pursuit of them. The Leopards are each acconmodated with a flat-topped cart, without sides, drawn by two bullocks, and each animal has two attendants. They are loosely bound by a collar and rope to the back of the vehicle, and are also held by the keeper by a strap round the loins. A leathern hood covers the eyes. The Antelopes being exceedingly timid and wild, the best way to enjoy the sport is to sit on the cart alongside the driver; for the vehicle being built like the carts of the peasants, to the sight of which the Antelopes are accustomed, it is not difficult, by careful management, to approach within two hundred yards of the game. On the occasion in question there were three Chitas in the field, and we proceeded towards the spot where the herd had been seen, in a line, with an interval of a hundred yards between each cart. On emerging from a cotton-field, we came in sight of four Antelopes, and my driver managed to get within a hundred yards of them, ere they took alarm. The Chita was quickly unhooded and loosed from his bonds; and as soon as he viewed the game, he dropped quietly off the cart, on the opposite side to that on which they stood, and approached them at a slow crouching canter, masking himself by every bush and inequality which lay in his way. As soon, however, as they $\mathrm{b}$.gan to show alarm, he quickened his pace, and was in the midst of them in a few bounds. He singled out a doe, and ran it close for about two hundred yards, when he reached it with a blow of his paw, rolled it over, and in an instant was sucking the life's-blood from its throat. One of the other Chitas was slipped at the same time, but after making four or 
five enormous bounds, by which he nearly reached his prey, suddenly gave up the pursuit, and came growling sulkily back to his cart.'

"As soon as the Antelope is pulled down, a keeper runs up, hoods the Chita, cuts the victim's throat, and securing some of the blood in a wooden ladle, thrusts it under the Leopard's nose. The Antelope is then dragged away, and placed in a receptacle under the cart, while the Chita is rewarded with a leg for his pains."

\section{THE CIVETS. FAMILY VIVERRIDA.}

This extensive Family, which includes not only the typical Civets, but likewise the Palm. Civets, Mungooses, \&c., may be distinguished from the Felide by two leading characteristics. In the first place the auditory bulla of the skull is marked by a transverse external constriction, indicating the position of the internal bony partition; and, in the second, the middle incisor tooth on each side of the lower jaw is raised above the level of the other two. From all existing Felide the Viverrida are further distinguished by the greater number of pre-molar teeth in the lower jaw, these varying from three to four pairs. As a rule, the teeth of the cheek-series differ considerably from those of the Cats; but as the genus Cryptoprocta forms a connecting link between the two groups in this respect, dental characters cannot be relied on to distinguish between them. The number of pre-molar teeth varies from three to four pairs in each jaw, and there are generally two pairs of molars in each, although in a few instances these may be reduced to a single pair. In most cases the feet, which may be either digitigrade or partly plantigrade, are each furnished with five toes; but the number may be reduced to four in either the front or the hind pair, or in both. The degree of retractility of the claws varies in the different genera, as does the extent to which the hair ext snds on to the hinder part of the sole of the foot. 
Although they are approached to a certain degree in these respects by the Eyra, the Civets and their allies differ from the , Cats in the more elongate form of the head and body, the sharper muzzle, and the shorter limbs; the skull being also elongated and narrowed in conformity with the shape of the head. The majority of them have scent-glands situated beneath the tail. In the predominance of spots and stripes on the fur, these animals resemble the Cats; a few of them, however, have continucus longitudinal stripes on the whole of the upper-parts - a feature unknown in the latter, - while the peculiar "pepper-and-salt" coloration of the typical Mungooses is likewise a peculiarity. A few forms, such as the Fossa and Miller's Mungoose, have uniformly tawny or reddish fur. Unlike the IVeasel tribe (Mustelida), the Vizerride are of no commercial value on account of their pelts; such furs as are used at all selling at very low prices, and being employed for common articles.

The members of the Family do not present that striking general similarity so conspicuous among the Cats, and they are consequently divided into numerous genera, which may be grouped in three Sub-families. Unknown both in Australasia and America (so far as can be ascertained, not only at the present day, but likewise in past epochs of the earth's history), the Civets and their allies are confined to the warmer regions of Africa, Madagascar, and South-eastern Asia; one species extending, however, into Spain, and a second into France. Some of the most peculiar and aberrant forms are confined to Madagascar; and it may be noticed that nearly all the species from that island pertain to peculiar genera. During the Tertiary epoch Civet-like animals were extremely abundant in Europe in strata antecedent to the Pliocene age, their downward range extending to the Oligocene period, at which date their remains are met with in great numbers in the Quercy Phosphorites of Central France. 
Many of the Family aress completely carnivorous in their feeding than the Cats; but their habits may be more conveniently noticed under the various groups. Since these animals are, for the most part, less generally interesting than the Cats, they will be treated of more briefly than the latter.

\section{THE FOSSAS. GENUS CRYPTOPROCTA.}

Cryptoprocta, Bennett, Proc. Zool. Soc. I 832 , p. 46.

This genus is the sole representative of a Sub-family characterised by the absence in the skull of the channel known as the alisphenoid canal, by the auditory bulla being somewhat intermediate between that of the Civets and Mungooses, by the feline structure of the teeth, and by the sharp and completely retractile claws, of which there are five to each foot. As regards the teeth, there are four pairs of pre-molars and a single one of molars; but the anterior pre-molar in each jaw is shed at an early period. The upper carnassial tooth has a three-lobed blade, like the Cats, and a small internal tubercle, while the lower carnassial differs from that of the Felide solely in having a small ledge or heel on its hinder border, the rudiment of such a heel being found in the corresponding tooth of the Lynxes. The upper molar is a small, transversely elongated tooth, placed internally to the carnassial. Although generally resembling that of the Felida, the skull is proportionately longer and narrower, its orbit not being completely closed by bone behind. The feet are sub-plantigrade, with the tarsus and metatarsus naked, and the nose and upper lip have a median groove.

That the genus constitutes a distinct Sub-family is perfectly certain, the only question being whether it should not be assigned to a Family apart. It is represented solely by

I. THE FOSSA. CRYPTOPROCTA FEROX.

Cryptoprocta ferox, Bennett, Proc. Zool. Soc. I $S_{32}$, p. 46 ; id., Trans. Zool. Soc. vol. i. p. I37 (1833); Mivart, Proc. Zool. Soc. ז882, p. 194 . 


$$
\text { . }
$$


告

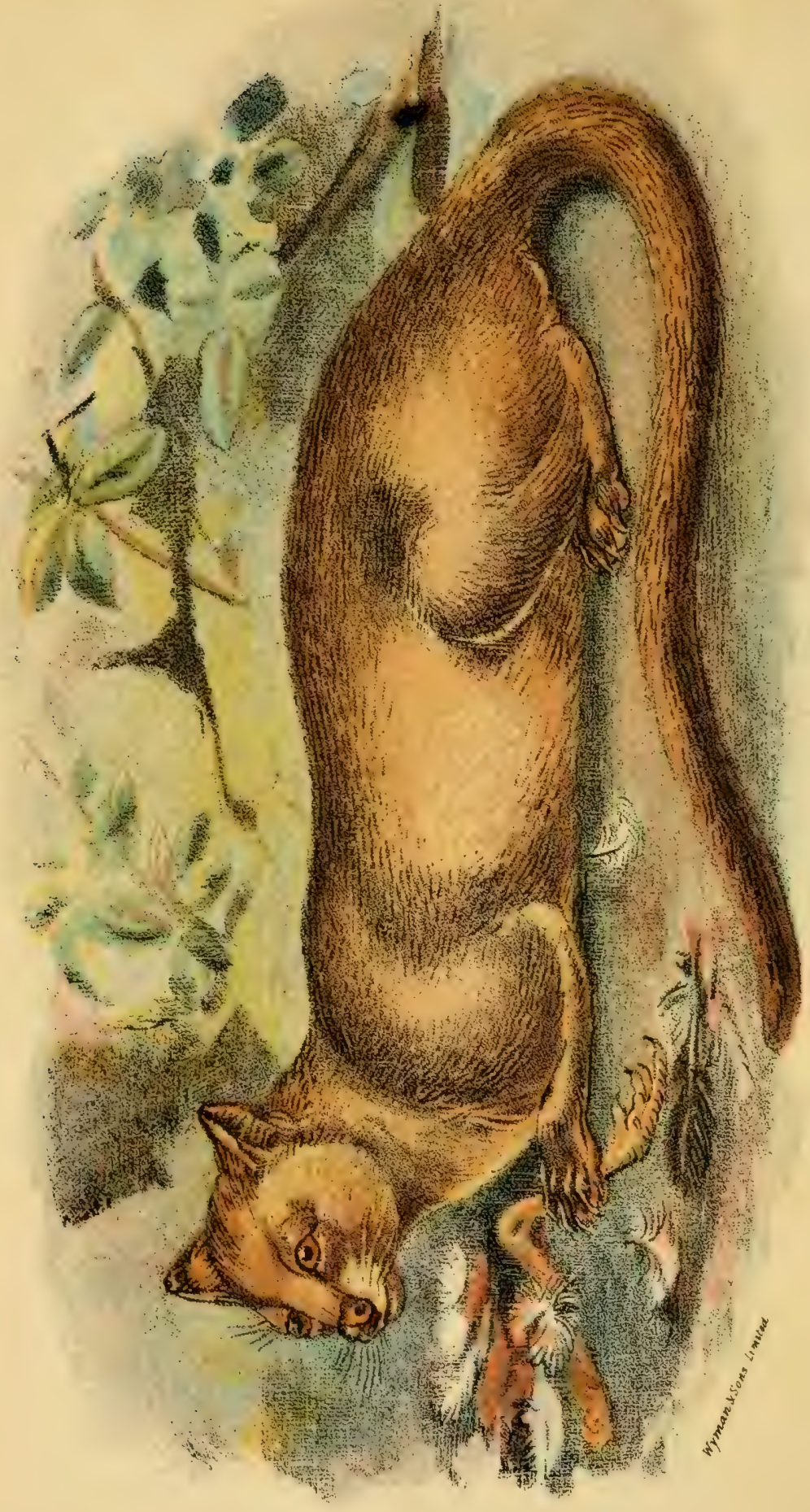


Cryptoprocta typicus, A. Smith, S. African Quart. Journ. vol. ii. p. I 34 (1835).

\section{(Plate XXVI.)}

Characters.-Size about twice that of an ordinary Cat ; ears moderate ; tail long and cylindrical ; fur short, close, and erect. Colour nearly uniform pale sandy-brown. Total length, about 5 feet.

\section{Distribution.-Madagascar.}

Habits.-The largest Carnivore in its native island, the Fossa is noted for the ferocity of its disposition, frequently carrying off Goats and kids, and fighting desperately when wounded. Beyond the fact that it is purely nocturnal, we have, however, scarcely any definite information with regard to its habits; the following account, sent by an orchid-hunter named Hamelin to his employers, being apparently somewhat highly coloured. Monsieur Hamelin, writing of the Fossa, states that "during the daytime it is extremely dangerous, for it crouches in the forks of trees, hidden among the rich tropical foliage and climbing plants, and watches for its prey. It is exceedingly agile, and the moment its victim approaches, it slides silently down, and in one bound is on top of it - a picture of horrible ferocity. At night big fires had to be constantly kept up, and men had to take the watch, as we were thus exposed to the observation of no less savage human enemies.

"The favourite haunt of the Cryptoprocta seemed to me to be amongst the masses of foliage where the Eulophiella grew. Here they were numerous, and I was happy to be able to capture two young ones. This animal is not big, but extremely ferocious. The capture of these two cubs was attended by a terrible adventure-no less than the death of the brother-inlaw of the king, a fine, handsome, well-built man. It came about in this wise. Whilst we were busy with the young ones the mother returned, and, m.ldened with rage, pounced on the shoulders of the king's brother-in-law, rending the flesh 
from back and shoulders, and mangling him in a frightful manner. Tsiampohé fell as if struck by lightning. The next moment thirty 'zagaies' were quivering in the carcase of the fierce creature that had wrought such mischief."

II. THE TRUE CIVETS. GENUS VIVERRA.

Viverra, Linn., Syst. Nat. ed. I2, vol. i. p. 63 ( I 766).

This, together with several other genera, constitutes a second Sub-family (Viverrince), distinguished by the following features: Skull with the auditory bulla conically oval in form, its hinder border being broad, truncated, and non-everted, while in front it is narrow and compressed, its anterior chamber being very small and flat. An alisphenoid canal generally present. Usually glands in front of the scrotum. Claws curved and generally more or less retractile. Teeth more or less Doglike; there being always four pairs of pre-molars, and generally two pairs of molars in each jaw. The upper carnassial tooth has only two lobes to the blade and a large internal tubercle; while the corresponding lower tooth consists of a blade and a large tubercular posterior heel. The upper molars are triangular in form ; the anterior one being placed entirely behind the carnassial.

The present genus is distinguished by the upper lip being medianly grooved; the tail is of considerable length, and marked by dark and light rings; the feet are completely digitigrade, the tarsus and metatarsus being entirely hairy; and the ears are without tufts. There are two pairs of upper molar teeth; the throat is marked by a black gorget; and there is generally an erectile crest of elongated hairs down the back; the whole fur being long and loose. The claws are rather short, blunt, and only partially retractile; and the pupil of the eye contracts to a circle.

The Civets include the largest representatives of the Sub- 
$\therefore$ How 7 W

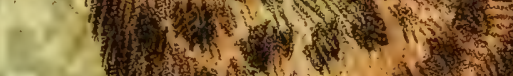

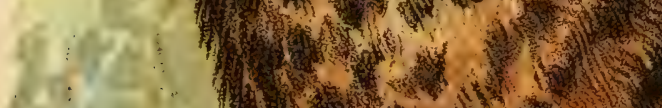
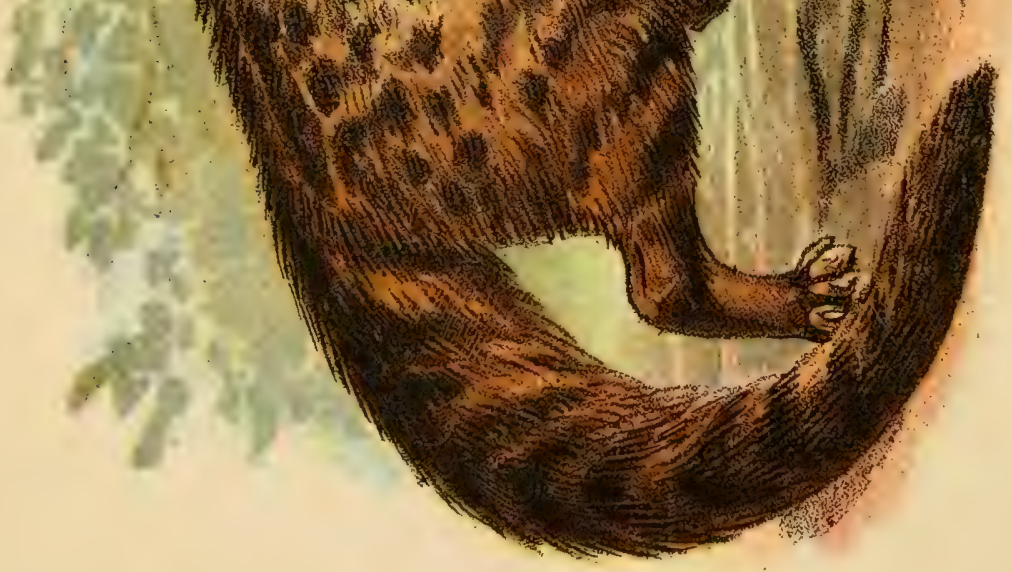
family, and have comparatively short, stout, and somewhat compressed bodies, and the limbs relatively longer than in some of the allied genera. They are all highly odoriferous; one of their secretions being employed in perfumery. Mainly an Oriental group, they are represented only by a single species in Africa.

\section{THE AFRICAN CIVET. VIVERRA CIVETTA.}

Viverra civetta, Schreber, Säugethiere, vol. iii. pl. cxi. ( 7778 ); Gray, Cat. Carniv. Mamm. Brit. Mus. p. 46 (1869).

? Viverra poortmanni, Pucheran, Rev. Mag. Zool. vol. vii. p. I 54 (1853).

Viverra orientalis, Matschie, Mittheil. deutsch. Schutzgebieten, vol. vi. pt. 3, p. II (I893).

\section{(Plate XXVII.)}

Characters. - Back with a strong erectile crest of black hairs, continued on to the tail; general colour of fur ashy-grey, marked with dark streaks and blotches; sides of neck marked by two dark streaks, separated by a white one, running backwards from the ear, and the black ones meeting to form a gorget under the throat. Tail roughly haired, with the rings well defined on the basal half, but the terminal half almost uniformly black. Lower part of limbs uniformly dark.

Distribution.-Africa ; apparently distributed widely over the tropical portions of the continent, having been recorded from Abyssinia, Fernando Po, Guinea, and the Gaboon, but seems unknown in the south, not even being recorded from Nyasaland.

Habits.-So far as known, a non-arboreal species, this Civet probably agrees closely in habits with its Indian ally, and, therefore, need not be further noticed.

II. THE INDIAN CIVET. VIVERRA ZIBETHA.

Viverra zibetha, Linn., Syst. Nat. ed. I 2, vol. i. p. 65 ( ( 766); Blanford, Mamm. Brit. India, p. 208 (I S88). 
Viverra undata, Gray, Spic. Zool. p. 9 ( 1830$)$.

Viverra melamurus, Hodgson, Journ. Asiat. Soc. Bengal, vol. x. p. 909 (184I).

Viverra civetoides, Hodgson, loc. cit.

Viverra ashtoni, Swinhoe, Proc. Zool. Soc. I864, p. 379.

Characters.--Size approximately equal to that of the last species, from which the present form may be readily distinguished by the tail being marked with complete dark and light rings throughout its length; general colour dark hoarygrey, often with a brownish or reddish tinge; crest black; sides of the body generally without markings, but sometimes wavy, indistinct, transverse, cloudy stripes present ; front and sides of neck and upper part of chest white, crossed by a broad black gorget, with frequently another dark band in front and a third behind, the latter (when present) meeting a horizontal streak from behind the ear; outer surface of limbs indistinctly barred superiorly, but the whole of the lower portions of the legs and feet uniformly dark brown or black. Length of head and body, about 32 inches; of tail, 8 inches.

Distribution.-Bengal, Assam, Burma, Siam, the south of China, and Hainan. In Sikhim and Nipal it ascends to a considerable elevation in the Himalaya. According to Mr. W. L. Sclater, it is not improbable that the alleged occurrence of this Civet in the Malay Peninsula is due to its having been confounded with an allied species.

Habits.-Usually a solitary creature, this Civet, or Civet-Cat, generally skulks in woods, bushes, or thick grass during the daytime, and only issues out into the open in search of prey after dark. It is unable to climb trees; and probably does not burrow, although it not unfrequently takes possession of holes in the ground. It feeds largely on small Mammals and birds (including domestic ducks and poultry); but it will also consume snakes, frogs, insects, and eggs, as well as fruits and 
certain roots. A good swimmer, it never has any hesitation in taking to the water. The young, in India, are born during the months of May and June; each litter including three or four cubs.

The secretion from the glands placed in front of the scrotum of the male of this and other Civets, and in a corresponding position in the female, escapes by a number of small orifices into a kind of pouch with a long slit-like opening. From this receptacle the Civet of commerce is scraped out periodically by means of a kind of wooden spoon; the natives of many eastern countries keeping these animals in confinement for the sake of this product. Two glands situated more posteriorly yield a secretion with a most noisome and offensive odour.

\section{THE MALABAR CIVET. VIVERRA CIVETTINA.}

Viverra civettina, Blyth, Journ. Asiat. Soc. Bengal, vol. xxxi. p. 332 (1862); Blanford, Mamm. Brit. India, p. 98 (I 888); Sclater, Cat. Mamm. Ind. Mus. pt. ii. p. 236 (I89I).

Characters.-Size nearly as in the last; black rings on tail complete, but the light ones partially interrupted by a broken longitudinal dark stripe on the upper surface; sides of body distinctly marked with dark spots; dorsal crest commencing on the head. First upper molar more quadrangular than in the preceding species. General ground-colour of fur distinctly yellowish.

Distribution.-The Malabar Coast, and the Wynad and Curg districts of Southern India.

IV. THE BURMESE CIVET. VIVERRA MEGASPILA.

Viverra megaspila, Blyth, Journ. Asiat. Soc. Bengal, vol. xxxi. p. 33I (1862); Blanford, Mamm. Brit. India, p. 99 (1888); Sclater, Cat. Mamm. Ind. Mus. pt. ii. p. 227 (1891).

Characters.--Size of the last ; a longitudinal black band down 
the tail continuous, and completely interrupting the light rings on its upper surface; dark rings continuous below, and at first not wider than the light intervening spaces; dorsal crest commencing between the shoulders; sides marked with large, distinct, and somewhat quadrangular dark spots, tending to form transverse bands on the flanks, and longitudinal stripes on the rump. General colour of fur grey, at times with a yellowish or brownish tinge; feet brown. The white front and sides or the neck marked with two or three black gorgets.

Distribution.-Burma, Malay Peninsula, Cochin China, and Sumatra.

V. THE JAVAN CIVET. VIVERRA TANGALUNGA.

Viverra tangalunga, Gray, Proc. Zool. Soc. I832, p. 63 ; id., Cat. Carniv. Mamm. Brit. Mus. p. 47 (I869); Sclater, Cat. Mamm. Ind. Mus. pt. ii. p. 237 (1891).

Characters.-Smaller than the last; longitudinal dark band on upper surface of tail very broad, and the dark rings, except a few near the end, interrupted on the lower surface; sides of body marked by spots of somewhat smaller size than in $V$. megaspila.

Distribution.-Malay Peninsula, Sumatra, Borneo, Celebes, Amboyna, and the Philippine Islands ; the range of this species being more easterly than that of any other member of the genus.

VI. THE RASSE. VIVERRA MALACCENSIS.

Viverra malaccensis, Gmelin, Syst. Nat. vol. i. p. 92 ( (7 788 ).

Viverra leveriana, Shaw, Mus. Leverianum, pt. ii. p. 19 (1796). Viverra indica, Desmarest, Nouv. Dict. Hist. Nat. vol. vii. p. I 70 (I 8 I 7 ).

Viverra rasse, Horsfield, Zool. Researches, plate (I82 I).

Viverra bengalensis, Gray, Ill. Indian Zool. vol. i. pl. iv. $(1832)$. 
Viverra pallida, Gray, Proc. Zool. Soc. 1832, p. 63.

Viverricula indica, Hodgson, Journ. Asiat. Soc. Bengal, vol. $\mathrm{x}$.

p. 909 (I84I).

Viverricula malaccensis, Cantor, Journ. Asiat. Soc. Bengal, vol.

xv. p. I99 (1846); Blanford, Mamm. Brit. India, p. I00 (I888).

Viverra schlegeli, Pollen, Nederl. Tijdschr. Dierkunde, vol. iii. p. 78 (1866); Flower, Cat. Osteol. Mus. Coll. Surg. pt. ii. p. 97 (1884).

Characters.-Size small. Distinguished from all the preceding species by the absence of an erectile crest of elongated hairs down the back, and also the general want of an alisphenoid canal in the skull. The nails are also sharper and curved, and the first toe in each foot shorter and more separated from the others, while the muzzle is more pointed, and the whole build of the animal lighter. On account of these comparatively unimportant points of difference, the species is frequently referred to a distinct genus.

General colour varying from brownish-grey to pale yellowishbrown, usually with several longitudinal black or dark brown stripes down the back, and longitudinally-arranged rows of spots on the sides of the body, but such markings, in some cases, are very indistinct, and the dorsal stripes even wanting. Markings on neck somewhat variable; but generally two dark stripes from behind the ears to the shoulders, and frequently a third in front, crossing the throat; a dusky mark behind the ear, and another in front of the eyes; feet brown or black; tail with complete black and whitish rings, numbering from seven to nine pairs. Length of head and body, from 21 to 23 inches; of tail, inclusive of the hair at the tip, from 15 to ${ } 7$ inches.

Distribation.-Socotra, Comoro Islands, Madagascar, Ceylon, India, Assam, Burma, Malay Peninsula, Java, Southern China, Hainan, and Formosa. With the possible exception of the 
Punjab and Sind, this speces seems to range over the whole of India. It has the widest geographical distribution of any member of the Family; and is also the only one common to Asia and Madagascar; the latter feature in its distribution being a very remarkable one.

Habits.-So far as has been ascertained, while all the other Civets are non-arboreal animals, the Rasse is said to be an expert climber, although it is generally found inhabiting holes in the ground, and does not appear to have been observed in thick forest. Not unfrequently resorting to the neighbourhood of human dwellings, it has been met with hiding in drains and outbuildings; and it is frequently kept in captivity in the East, in which condition it becomes perfectly tame. In addition to preying on such birds and small Mammals as it can contrive to capture, the Rasse, like its congeners, varies its diet with fruit and roots. Four or five young are produced in a litter.

III. TIIE MAIAGASCAR CIVETS. GENUS FOSSA. Fossa, Gray, Proc. Zool. Soc. 1864 , p. $5 \times 8$.

Nearly allied to the Rasse, the single representative of this imperfectly-known genus is distinguished from all the members of the preceding group by the presence of two small bare spots on the under surface of the metatarsus in the hind-limb; while it is believed that there is no scent-pouch. The limbs are remarkable for their slenderness; and the absence of a dark line down the back, and also of a dark gorget, form other distinctive features of the genus. The one species is confined to Madagascar.

\section{DAUBENTON'S CIVET. FOSSA DAUBENTONI.}

Viverra fossa, Schreber, Säugethiere, vol. iii. pl. cxiv. (г 778 ). Fossa daubentonii, Gray, Proc. Zool. Soc. 1864, p. 5 I 8 ; Mivart, Proc. Zool. Soc. 1882, p. 150.

Characters.-General colour of fur greyish, which may be 
marked only with some spots on the flanks, and a few indistinct stripes on the shoulders. Young distinctly striped, the median line of the back being of the general ground-colour bordered by two rows of small irregular spots, externally to which are three dark longitudinal stripes on each side; no throat-gorget; tail spotted, with the spots tending to arrange themselves in rings. Length of head and body, about 16 inches ; of tail, 8 inches.

\section{Distribution.-Madagascar.}

Habits.-Unknown.

IV. THE GENETS. GENUS GENETTA.

Genetta, Cuvier, Règne Animal, vol. i. p. I56 (ISI 7).

Having the same number of teeth, and likewise five toes to each foot, the Genets differ from both the preceding genera by having a naked longitudinal line running up the middle of the under surface of the metatarsus; this bald strip being separated from the pads of the foot by an intervening hairy space. They are further distinguished from Viverra by the want of a scentpouch, and from Fossa by having a dark stripe down the middle of the back. All are comparatively small in size, and they may have a slight crest down the back, but lack a black gorget on the throat. The various species are exceedingly alike to one another, and further comparisons are required before their distinctive characters can be regarded as properly defined. In colour, their fur is brownish, yellowish, or greyish, marked with black or brown spots on the sides of the body and the abovementioned dark line down the back; dark stripes extend tackwards from behind the ears over the shoulders; above each eye is a light-coloured patch, and beneath the same a white spot; the under-parts are light coloured, sparsely spotted with a dark tint; the tail has dark and light rings; and the feet may be either blackish or whitish. In the skull the auditory bulla is less markedly triangular than in Viverra, while 
the last upper molar tooth is relatively larger and more triangular than is generally the case in that genus, and the lower carnassial has a larger heel.

The genus is essentially an African one, although the type species ranges into Southern Europe and Palestine.

\section{THE COMMON GENET. GENETTA VULGARIS.}

Viverra genetta, Linn., Syst. Nat. ed. I 2, vol. i. p. 65 (I 766). Genetta afra, F. Cuvier, Hist. Nat. Mamm. pt. lii. (1825). Genetta vulgaris, Lesson, Man. Mamm. p. I 73 (1827). Genetta bonaparti, Loche, Rev. Mag. Zool. ser. 2, vol. ix. p. $385(1857)$.

Characters.-General colour blackish-grey, marked with black spots and streaks and a black dorsal stripe ; tail relatively long, with the white and black rings of nearly equal length, and the tip whitish; fore-limbs greyish, with black spots; hind-legs black posteriorly in the neighbourhood of the ankle-joint. Length of head and body, about $193 / 4$ inches; of tail, $153 / 4$ inches.

Distribution.-Southern Europe, namely, France, Spain, and Turkey; North Africa; and Palestine. This is one of the very few species of the Family common to Europe and Africa.

Habits.-In general habits the Common Genet (and the other species probably also) appears to be very similar to the Civets, living on the ground, and being found both in wooded and open country, and likewise on bush-covered mountains. Although rare in the south of France, it is stated to be commoner in Spain, but even there is seldom seen. Small Rodents, birds, and their eggs form its chief nutriment; and in pursuit of its prey the Genet is remarkable for the almost Snake-like manner in which it steals among the herbage, with its body elongated and depressed to the greatest possible degree. Its breeding-habits in the wild state are unknown, but in captivity only a single young one is produced at a birth. Genets are 
国

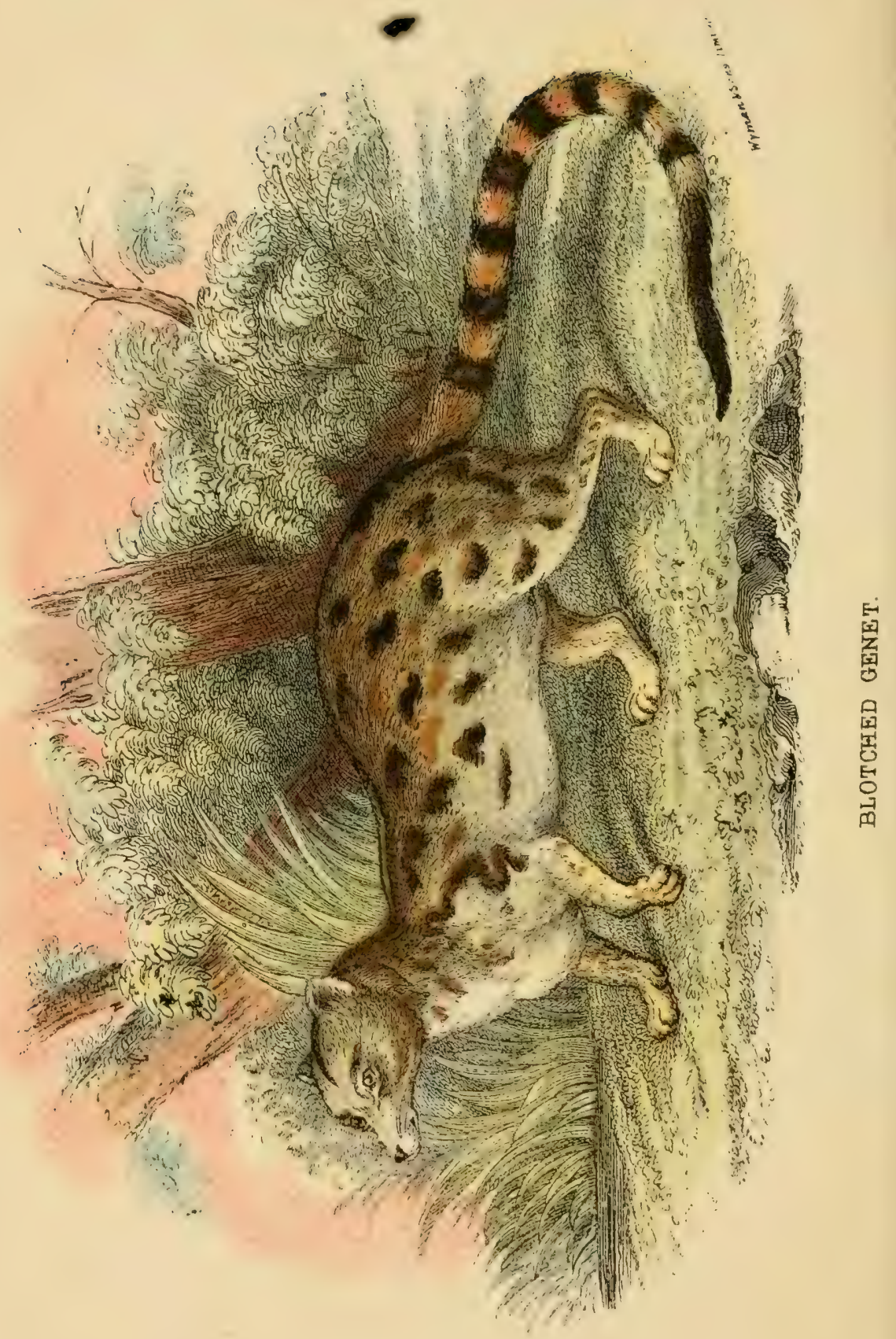


easily tamed, and in some parts of Europe are kept for catching Rats.

II. THE FELINE GENET. GENETTA FELINA.

Viverra felina, Thunberg, K. Svensk. Ak. Handl. vol. xxxii. p. I 66 (I8I I).

Genetta felina, Gray, Proc. Zool. Soc. $18_{32}$, p. 63, and Cat. Carniv. Mamm. Brit. Mus. p. 50 (1869); Bocage, J. Sci. Lisboa, ser. 2, vol. i. p. I 77 (1889).

Characters.-Closely allied to the last, from which, according to Gray, it is chiefly distinguished by the blacker legs and feet, the darker head, and the more distinct black streak on the forehead between the eyes.

Distribution.-South Africa, and, according to Bocage, West Africa (Gaboon).

III. THE SENEGAL GENET. GENETTA SENEGALENSIS.

Viverra senegalensis, Fischer, Synops. Mamm. p. I7o (I829). Genetta senegalensis, Gray, Proc. Zool. Soc. I832; id., Cat. Carniv. Mamm. Brit. Mus. p. 50 (1869).

Genetta aubryana, Pucheran, Rev. Mag. Zool. vol. vii. p. I54 (I 885).

Characters.-General colour pale yellowish-grey, with brown spots and streaks ; dorsal stripe black; the hairs elongated on the loins ; tail long and slender, ringed with black and yellowish, the light rings being the longer, and the tip light; hinder surface of hind-limbs black or blackish.

Distribution.-West, North, and East Africa.

IV. THE BLOTCHED GENET. GENETTA TIGRINA. Viverra tigrina, Schreber, Säugethiere, vol. iii. p. 425 (I 778 ). Genetta abyssinica, Rüppell, N. Wirbelthiere, p. 33 (I835). Genetta tigrina, Gray, List Mamm. Brit. Mus. p. 49 (1843). Viverra abyssinica, Gerrard, Cat. Bones Brit. Mus. p. 7 I (I862). 
Characters.-General col greyish-brown, with large black ish spots or blotches, not unfrequently becoming brownish at the centre; tail long and cylindrical, with the whitish rings shorter than the black ones, and the tip black; hind-feet dark.

Distribution.-South Africa, and northwards on the east coast through Natal and Mozambique to Abyssinia.

\section{v. THE PARDine Genet. GENETTA PARdina.}

Genetta pardina, Geoffroy, Mag. Zool. I832, pl. viii.; Gray, Cat. Carniv. Mamm. Brit. Mus. p. 5 I (I869); Bocage, J. Sci. Lisboa, ser. 2, vol. i. p. I 77 (I889).

Viverra genettoides, Temminck, Esquisses Zool. p. 89 (1853); Matschie, Mittheil. deutsch. Schutzgebieten, vol. vi. art. 3, p. II (I 893); id., Mittheil. Nat. Mus. Lübeck, ser. 2, vol. i. p. I33 (1894).

Genetta servalina, Pucheran, Rev. Mag. Zool, vol. vii. p. I54 (1855).

Genetta feldiana, Du Chaillu, Proc. Boston Soc. vol, vii. p. 302 (I 860).

Genetta angolensis, Bocage, J. Sci. Lisboa, vol. ix. p. 29 (ISS2).

Characters.-Colour typically yellowish- or greyish-brown, with three or four longitudinal rows of black spots more or less brownish at their centres; tail long and short-haired, with elongated reddish or black rings and short light ones, and a black tip; feet and posterior surface of hind-legs brown.

Gray remarks " that specimens vary considerably in the size of the spots; in some they are brown with black edges, in others almost uniformly black; but I can see no characters by which they can be separated." Herr Matschie, who appears to regard the dark form described as Viverra genettoides as a distinct species (with which Genetta servalina is probably idenical), states that specimens from the Cameruns show a long 
black tail-tip, on the under surface of which the last three light rings are indistinctly visible. A variety from Angola ( $G$. angolensis) is described by Bocage as grey, grizzled with black and white, and marked with large black spots and streaks; limbs totally black; tail short, inferior in length to the head and body, black, with grey rings near the base. Length of head and body, about 18 inches; of tail, $16 \mathrm{~T} / 4$ inches.

Distribution.-West Africa (Senegal, Fernando Po, Guinea, Gaboon, the Cameruns, and Angola).

VI. THE RUFOUS GENET. GENETTA RUBIGINOSA. Genetta rubiginosa, Pucheran, Rev. Mag. Zool. vol. vii. p. I54 (I 855); Bocage, J. Sci. Lisboa, ser. 2, vol. i. p. I 77 (I889).

Characters.-This Genet was provisionally identified by Gray with $G$. felina, but black-tailed specimens obtained from Angola by Bocage are regarded as indicating a distinct species, which is probably the one described by Pucheran. These specimens are described as follows :- Ground-colour of the fur greyishwhite with a tinge of rufous; limbs of the same hue, and showing scarcely any trace of dark markings; dorsal stripe and streaks on the body bright rufous, with the exception of those of the last row, which are blackish. The tail, which is of considerable length, generally has four rufous rings near the root, followed by four or five black rings, alternatirg with shorter rings of reddish-white; tip black, formed by the coalescence of the last two or three dark rings. Length of head and body, about 19 inches; of tail, nearly the same.

Distribution.--West Africa (Angola).

V. THE ORIENTAL LINSANGS. GENUS LINSANGA.

Prionodontide, Horsfield, Zool. Researches, plate of Felis gracilis, as a "section" of Felis (1821); volume dated I 824 . Linsang, S. Müller, Verh. Nat. Gesch. p. 28 (1839). 
Having the under surfaco the tarsus and metatarsus completely clothed with hair, as in Viverra, the Oriental Linsangs differ from all the genera mentioned above by having only one (instead of two) pair of molar teeth in the upper jaw. The Linsangs are long-bodied and short-limbed animals, with the claws of the five-toed feet almost as completely retractile as in the Cats, and the fur short, soft, close, and erect. There are no scent-glands corresponding to those which produce civet in Viverra. The ground-colour of the fur is white or greyishwhite, upon which are dark brown or black markings, taking the form either of a small number of large patches extending transversely across the body, or of such patches broken up into quadrangular spots; there are dark longitudinal streaks (sometimes broken into spots) on the neck and shoulders, as well as smaller ones on the head; and the tail is ringed with dark and light. The pupil of the eye is circular when contracted; and the skull is very similar to that of Genetta; but the lower carnassial tooth has its posterior heel smaller than in the latter.

The genus is exclusively Oriental, ranging from North-eastern India to Borneo and Java, although unknown in the Malay Peninsula. It is represented by an allied type in Western Africa.

I. THE BORNEAN LINSANG. LINSANGA GRACILIS. Viverra gracilis, Desmarest, Mammalogie, p. 539 (I820). Felis gracilis, Horsfield, Zool. Researches, plate (I 824). Paradoxurus linsang, Fischer, Synops. Mamm. p. I59 (IS29). Linsang gracilis, Müller, Verh. Nat. Gesch. p. 28 (I839); Gray, Cat. Carniv. Mamm. Brit. Mus. p. 53 (1869). Prionodon gracilis, Gray, Proc. Zool. Soc. 1864, p. 519.

Characters.-Size small; general coloration very similar to that of the next species, but the skull of a different type, being relatively shorter, and with a wider brain-case. Mr. 
Blanford observes that in the present species the pale groundcolour prevails much more than in the next; the upper-parts of the former being marked by irregularly-shaped blackish spots on a pale ground, whereas the upper surface of the latter is dark, with a few white streaks dividing the colour into patches. On the tail of $L$. gracilis the dark rings, especially towards the tip, are shorter than the white ones, and there is a long white tip, whereas in the next species the dark rings are nearly double the length of the white ones, and the white tip is shorter. Length of head and body, about $15 \mathrm{x} / 2$ inches; of tail, $12 \mathrm{~T} / 2$ inches.

Distribution.-Java, Borneo, and perhaps Sumatra.

Nothing has been recorded of the habits of this species.

II. THE BURMESE LINSANG. LINSANGA MACULOSA.

Prionodon maculosus, Blanford, Journ. Asiat. Soc. Bengal, vol. xlvii. p. 152 (1878); id., Mamm. Brit. India, p. I04 (1888). Linsang maculosus, Thomas, Ann. Mus. Genova, ser. 2, vol. x. p. 9 (1892).

Characters.-Size large ; upper-parts covered with large black patches; tail rather shorter than the head and body. Groundcolour of fur grey, marked with about six broad irregular transverse brownish-black bands across the back; the light spaces being thus reduced to narrow stripes. On the sides of the body the dark bands broken up into interrupted longitudinal stripes, one of which passes across the shoulder to the side of the neck, and is continued as a line of spots to the eye. On the upper part of the sides of the neck a broader black stripe passes from a short distance behind the ear across the shoulder, where it merges into the transverse bands. A few spots between the upper stripes on the neck, and likewise on the fore-neck and outer surfaces of the limbs; but the under-parts and feet uniformly pale-coloured. Tail with seven complete black rings, 
alternating with much shorter light ones. Length of head and body, about 19 inches; of tail (exclusive of hair at the tip), I6 inches.

Distribution.-Tenasserim Provinces of Burma. This exceedingly handsome species is only known by two examples, one trapped in Southern Tenasserim, and a second taken near Moulmein.

III. THE NIPALESE LINSANG. LINSANGA PARDICOLOR. Prionodon pardicolor, Hodgson, Calcutta Journ. Nat. Hist. vol. ii. p. 57 ( 1842$)$; Blanford, Mamm. Brit. India, p. Iо3 (1888).

Linsang pardicolor, Gray, List Mamm. Brit. Mus. p. 49 (1843); id., Cat. Carniv. Mamm. Brit. Mus. p. 53 (1869). Viverra pardicolor, Schinz, Synops. Mamm. vol. i. p. 366 (1844).

Characters.-Smaller than the last, from which it is distinguished by the back being marked by broad dark transverse bands broken up into squared spots forming longitudinal rows; tail as long as the neck and body. Ground-colour of fur very pale brown, with large angulated black spots ; under-parts and feet uniform; head also uniform brown, frequently with a black spot behind each ear. Neck marked on each side with a pair of longitudinal stripes; the middle pair continued as rows of large rounded spots down the back, separated by a line of smaller irregular spots; about three rows of squared or rounded spots along the sides of the body, which are also arranged in from six to seven transverse bands. Outer surfaces of upper portion of limbs spotted; tail with from eight to ten complete dark rings, separated by intervening light spaces of approximately the same width. Length of head and body, from I4 to I 5 inches; of tail, I 2 to 13 inches.

Distribntion.-South-eastern Himalaya, extending thence east- 
wards to Yunan. It is stated to be not uncommon in the interior of Sikhim, where it probably lives at moderate elevations.

Habits. - This is the only one of the Linsangs of which we have any information in regard to habits, and even in this case our knowledge is of the scantiest. Hodgson writes that this animal "is equally at home on trees and on the ground. It dwells and breeds in the hollows of decayed trees. It is not gregarious at all, and preys chiefly on small birds, which it is wont to pounce upon from the cover of the grass. 'The times of breeding are said to be February and August, and the litter to consist of two young, there being two litters each year." A tame female in the possession of the same gentleman is stated to have been "wonderfully docile and tractable, very sensitive to cold, and very fond of being petted." It never uttered any sound, and was fed on raw meat. In the wild state Hodgson suggests that the Linsangs may also eat insects.

\section{THE AFRICAN LINSANGS. GENUS POIANA.}

Poiana, Gray, Proc. Zool. Soc. 1864, p. 520.

The members of this genus, which is represented only by a single African species, and perhaps should not be separated from the last, may be defined as Linsangs with a Genet-like metatarsus; there being a bald line on the under surface of that segment of the hind-limb, as in the Genets. In all other respects it agrees with Linsanga; and it may be noted that in L.pardicolor there is a narrow upward prolongation of the main pad of the sole of the hind-foot foreshadowing the naked strip of the present genus.

I. WEST AFRICAN LINSANG. POIANA PÖENSIS. Genetta pöensis, Waterhouse, Proc. Zool. Soc. I838, p. 59. Genetta richardsoni, Thompson, Ann. Mag. Nat. Hist. vol. x. p. 204 ( 1842$)$.

Linsang richardsoni, Gerrard, Cat. Bones Mamm. Brit. Mus. p. 72 (1862). 
Poiana richardsoni, Gray, oc. Zool. Soc. 1S64, p. 520. Poiana pöensis, Mivart, Proc. Zool. Soc. 18S2, p. 159.

Characters.-Professor Mivart writes that the coloration is very similar to that obtaining in Linsanga: "but the spots are smaller and show no tendency to run into transverse bands or stripes, except on the middle of the back of the head, and except a broad mark on each side descending from the back of the head to above the shoulder. The tail is ringed with dark rings, alternately broad and narrow. The muzzle is very pointed. The length of the head and body is about $3^{S}$ inches, that of the tail, $40 \mathrm{~T} / 2$ inches."

Distribution.-West Africa (Sierra Leone and Fernando Po).

This apparently rare animal was originaily described from the flat skin of a young specimen, and nothing has been recorded regarding its habits. It may probably be considered as a rather more specialised furm than its Oriental cousins, from which it may be distinguished at a glance by the peculiar arrangement of the dark rings (about 22 in number) on the unusually long tail, of which the tip is black.

VII. THE HEMIGALES. GENUS HEMIGALE.

Hemigalus, Jourdan, Comptes Rendus, vol. v. p. 442 (1837) Hemigalea, Gray, Proc. Zool. Soc. 186 4, p. 524.

In all the preceding forms, with the exception of Fossa, the tail is marked throughout with distinct rings, whereas in the present genus it is, at most, only so at the base. Moreover, whereas in the whole of the former the auditory bulla of the skull is blunted, in Hemigale it is pointed in front, while the carnassial teeth in the latter are relatively smaller and of a less completely sectorial type than in the other genera. A further most distinctive feature of Hemigale is to be found in the circumstance that, in the hind-foot, the pads in the centre are concentrated, so as to form a bald area on the metatarsus, with 


\section{व \\ 国}

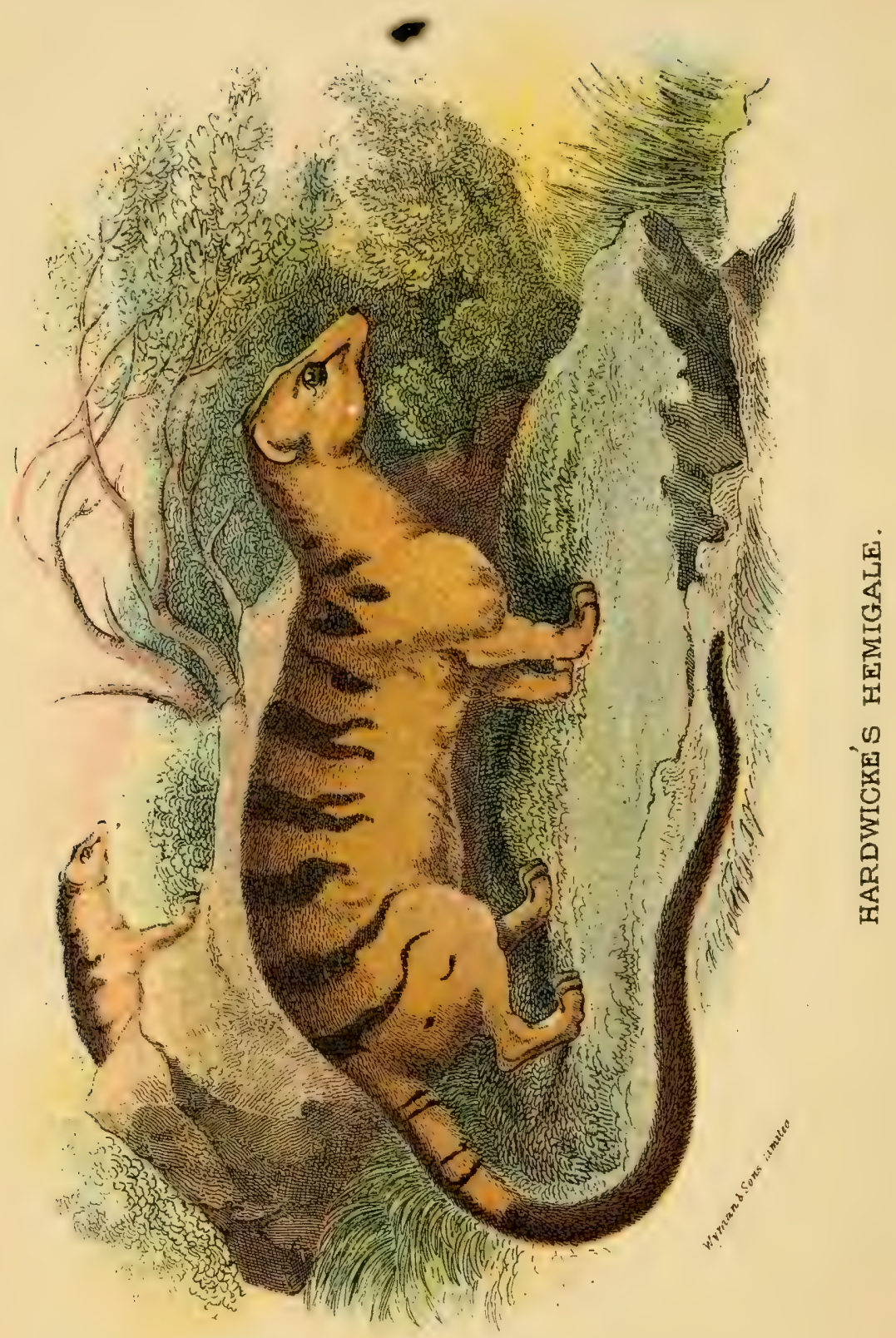


a sharp point directed towards the tarsus, the latter being completely covered with hair. Another peculiarity is that the direction of the hair on the back of the neck is reversed, so as to be inclined forwards. When there are any markings on the back, these are in the form of uninterrupted transverse bands. The five-toed feet have strongly-curved claws; and the nose and upper lip, as in all the foregoing genera, are marked by a median groove. The number of the teeth is the same as in Viverra.

The genus is confined to the countries lying to the eastward of the Bay of Bengal.

I. HARDWICKE'S HEMIGALE. HEMIGALE HARDWICKEI.

Viverra hardzeickii, Gray, Spicil. Zool. p. 9 (I 30 ).

Hemigalus zebra, Jourdan, Comptes Rendus, vol. v. p. $44^{2}$ ( 1837 ).

Paradoxurus derbiamus, Gray, Mag. Nat. Hist. vol. i. p. 579 ( 1837 ).

Paradoxurus zebra, Gray, loc. cit.

Viverra boiei, Müller, Tijdschr. Natuur. Ges. vol.v.p. I 44 (I 863). Hemigalea derbiana, Blyth, Cat. p. $46(1863)$.

Hemigalea hardivickei, Gray, Proc. Zool. Soc. I 864, p. 524;

id., Cat. Carniv. Brit. Mus. p. 57 (1869); Mivart, Proc.

Zool. Soc. I 882, p. 165.

Hemigale harduickei, Thomas, Proc. Zool. Soc. I S86, p. 73. (Plate XXIX.)

Characters.-General colour of fur whitish-yellow, marked on the back with about seven uninterrupted reddish-brown transverse stripes, extending well down on to the flanks; there are also three stripes on the head, and two down the neck, together with some irregular markings on the shoulders, the under parts and feet being uniformly coloured, and the tail ringed at the base, but elsewhere black. Length of head and body, about $15 \mathrm{~T} / 2$ inches; of tail, $161 / 4$ inches. 
Distribution.-Malay Penirula, Sumatra, and Borneo.

Although nothing definite has been recorded, it is probable that the habits of this animal are generally similar to those of the Palm-Civets.

II. HOSE'S HEMIGALE. HEMIGALE HOSII.

Hemigale hosei, Thomas, Ann. Mag. Nat. Hist. ser. 6, vol. ix.

p. 9 (1892); id., Proc. Zool. Soc. I892, p. 222.

Characters.--Size and proportions very similar to those of the last, but the skull more lightly made, and the teeth mo:e delicate. General colour of upper-parts dark smoky-brown or black, with the bases of the body-hairs whitish. Sides of muzzle at the roots of the whiskers white (the corresponding place in $H$. hardwickei being black); cheek below the eye, as well as a patch above and behind the latter, grizzled brownishwhite. Ears thinly haired, pure white internally, their edges forming a marked contrast to the black of the crown of the head. Chin, white ; chest, under-parts, and upper portion of inner surfaces of limbs smoky yellowish-grey; remainder of limbs and whole of tail black.

Its describer remarks "that this species is not a black form of the preceding, is proved by the white patches on the muzzle, the white ears, whitish under side, and also by the differences in the size of the teeth."

Distribution.-Mount Dulit, and not improbably Mount Kina Balu, North Borneo, at an altitude of between 2,000 and 5,000 feet above sea-level. The one known example was discovered by Mr. Charles Hose, after whom the species has received its name.

VIII. TIIE AFRICAN PALM-CIVETS. GENUS NANDINIA. Nandinia, Grav List Mamm. Brit. Mus. p. 54 (1843).

Having a partial!, ' tarsus like Hemigale, the members of this genus are distinguı.. by the imperfect ossification of 
the auditory bulla of the skull. In other respects the genus is very similar to Paradoxurus, the markings taking the form of spots, and the tail being ringed.

The genus is exclusively African, in which region it takes the place of the Oriental Palm-Civets.

I. WEST AFRICAN PALM-CIVET, NANDINIA BINOTATA. Vivcrra binotata, Reinwardt, in Gray's Spicil. Zool. vol. ii. p. 9 (I 830$)$.

Paradoxurus hamiltonii, Gray, Proc. Zool. Soc. I832, p. 67. Paradoxurus binotatus, Gray, op. cit.p. 68.

Nandinia binotata, Gray, List Mamm. Brit. Mus. p. 54 (I 843).

Characters.-Ground-co!our of fur rufous-grey; nape marked with three parallel streaks, one running from the forehead and the other two from the ears; back marked with numerous black spots, rarying in size and number; a yellow spot on each shoulder ; lips, throat, and under-parts rufous-grey; legs grizzled; tail elongated and tapering, marked with numerous black rings, and the tip blackish. Length of head and body, 23 inches; of tail, I9 inches.

Distribution.-West Africa (Fernando Po, Ashanti, and Angola).

II. EAST AFRICAN PALMICIVET. NANDINIA GERRARDI. Nandina gerrardi, Thomas, Ann. Mag. Nat. Hist. ser. 6, vol. xii. p. 205 (1893).

Characters.--Similar to the preceding in size and general colour, but wanting the three distinct black lines found on the upper surface of the neck in that species, while the fur of the body is more sparsely and finely spotted, and the transverse black markings on the tail are narrower, closer together, and more sharply defined. In the single ar..lt specimen known, the tail is also shorter than in $N . r^{\circ} \quad$, but this may be an individual imperfection. The wuwish spots present on the 
withers of the last-named species are also shown in this one, although indistinctly, and the back of the ears is of the same hue as the rest of the fur.

Distribution.-East Africa (Lower Shirè River, Nyasaland). The type specimen, although not described until 1893 , was collected by Sir John Kirk as far back as i86I, and is preserved in the British Museum. When alive, the animal was stated to live on mice and poultry. The skin of an immature specimen was obtained at the same time.

IX. TIIE SMALL-TOOTIIED PALM-CIVETS. GENUS ARCTOGALE.

Arctogale, Gray, Proc. Zool. Soc. 1864, p. 542.

Auditory bulla of skull fully ossified; teeth relatively small; palate very narrow, and its middle portion much produced behind the line of the last molar; no naked glandular tract in front of the scrotum ; tail not ringed; markings in the form of longitudinal stripes or rows of spots on the back. Other characters as in Paradoxurus.

The genus is represented by two species from the eastern part of the Oriental region.

I. THE White-EARED PALM-CIVET. ARCTOGAle LEUCOTIS. Paradoxurus lencotis, Horsfield, Cat. East Ind. Mus. p. 66 ( $185 \mathrm{I})$.

Paradoxurus stigmaticus, Temminck, Esquiss. Zool. p. I20 (1853).

Arctogale stigmatica, Mivart, Proc. Zool. Soc. 1882 , p. 163 . Arctogale leucotis, Blanford, Proc. Zool. Soc. 1885, p. 789 ; id., Mamm. Brit. India, p. I I 5 (I888).

Characters.-Size rather large; fur short and not harsh ; tail about equal in length to head and body. General colour varying from fulvous-grey to dusky-grey, or occasionally brown on the upper-parts; under-parts paler; the back marked by three longitudinal dark bands, which may either be continuous 
or broken up into spots, and in some specimens very indistinct, or even wanting. Head above generally darker, often becoming ashy or black, usually with a narrow white line down the middle of the forehead; feet and terminal portion of the tail brown or black. Burmese examples frequently show some whitish on the tips of the ears. Length of head and body, $26 \mathrm{I} / 2$ inches; of tail, 27 inches.

Distribution.-Sikhim, Arakan, Burma, Nalay Peninsula, Sumatra, and Borneo.

Nothing of importance has been recorded of the habits of this Palm-Civet, which probably do not differ essentially from those of the members of the next genus. If captured young, this species can be easily tamed.

II. THE THREE-STRIPED PALM-CIVET. ARCTOGALE TRIVIRGATA.

Paradoxumus trivirgatus, Gray, Proc. Zool. Soc. 1832, p. 68. Arctogale trivirgata, Blanford, Proc. Zool. Soc. 1885, p. 789.

Characters.-Differs from the preceding species in being slightly smaller, with the three dark lines down the back more distinctly defined, and also in wanting the dark patch at the base of the ears, the skull also being smaller, with the palate less produced backwards.

Distribution.-Java.

$\mathrm{x}$. TIIE PALAI-CIVETS. GENUS PARADOXUtRUS. Paradoxurus, F. Cuvier, Hist. Nat. Mamm. pt. xxiv. (I82 I). Pasuma, Gray, Proc. Zool. Soc. I83 I, p. 95.

Platy'schista, Otto, Nova Acta. Ac. Cæs. Leop.-Car. vol. xvii.

p. $\operatorname{roS}_{9}\left(\mathrm{I} \delta_{35}\right)$.

From the last genus the True Palm-Civets are distinguished by their larger teeth (among which the carnassials are short, with blunted cusps, and the sectorial character but little dc- 
veloped), the less backwar prolongation of the palate, and the presence of a naked glandular area in front of the scrotum of the males, and in a similar position in the females. In common with Arctogale, they have the whole of the metatarsus and the greater portion of the tarsus naked, the hair extending across the hinder portion of the heel in an evenly-curved line. The claws of the five-toed feet are as much curved and as highly retractile as in the Genets, and in the gieater number of cases the long tail is not ringed, while the markings take the form of longitudinal streaks, or more rarely spots, a few species being uniformly coloured. The pupil of the eye is in the form of a vertical slit.

The teeth are numerically the same as in Viverra, but vary considerably in shape in the different species; and only in a few forms does the bony palate extend much tehind the line of the last molar teeth. Although the tail is not endowed with the power of prehension, it can be curled up to a greater or less extent, and in captive specimens this condition is apt to become chronic. In size the majority of the Palm-Civets may be compared to ordinary Cats.

The genus is an exclusively Oriental one, ranging from India as far eastwards as the Philippine Islands, and embracing a large number of species.

On account of their purely nocturnal habits, the PalmCivets are but seldom seen, although on one occasion the present writer was fortunate enough to detect an individual of the Common Indian species moving about in broad daylight among the leaves of a palm-tree in a garden in the suburbs of Calcutta. They are all thoroughly arboreal, and adepts at climbing; and their food comprises fruits as well as the flesh of animals.

Many of the species have an alarmingly long list of synonyms. 


\section{THE COMMON PALM-CIVET. PARADOXURUS}

HERMAPHRODITUS.

Viverra hermaphrodita, Schreber, Säugethiere, vol. iii. p. 426 ( 1778$)$.

Viverra prehensilis, Desmarest, Mammalogie, p. 208 (1820).

Viverra musanga, Raffles, Linn. Trans. vol. xiii. p. 252 (I 820 ). Paradoxurus prehensilis, Gray, Proc. Zool. Soc. I832, p. 66. Paradoxurus musanga, Gray, loc. cit.

Paradoxurus hermaphroditus, Gray, loc. cit.; Blanford, Mamm. Brit. India, p. IoS (I 888); IV. L. Sclater, Cat. Mamm. Ind.

Mus. pt. ii. p. 243 (I89I).

Faradoxurus pallasii, $P$. crossii, and $P$. finlaysonii, Gray, Proc. Zool. Soc. 1832, pp. $67,68$.

Paradoxurus quinquelineatus and P. musangoides, Gray, Mag.

Nat. Hist. vol. i. p. 379 (1837).

Paradoxurus felimus, Wagner, in Schreber, Säugethiere, Suppl. vol. ii. p. 349 (I84r).

Paradoxumus nigrifrons, Gray, List Mamm. Brit. Mus. p. 55 $(\mathrm{I} 8+3)$.

Paradoxurus setosus, Pucheran, in Hombr. et Jacq. Voyage au Pôle Ind. Sud, Zool. vol. iii. p. 25 (1853).

Paradoxurus fasciatus, Gray, Proc. Zool. Soc. I 864, p. 536. Variety $a$.

Paradoxurus strictus, Horsfield, Ann. Mag. Nat. Hist. ser. 2, vol. xvi. p. 105 (1855).

Paradoxurus quadriscriptus, Horsfield, op. cit. p. Io6.

Variety $\beta$.

Viverra niger, Desmarest, Mammalogie, p. 208 (1820).

Viverra bondar, Desmarest, op. cit. p. 2 10.

Paradoxumus typus, F. Cuvier, Hist. Nat. Mamm. pt. xxiv. (I 82 I). Paradoxurus leucopus, Osilby, Zool. Journ. vol. iv. p. 304 (I 828$)$.

Paradoxurus bondar, Gray, Proc. Zool. Soc. is 32 , p. 66. 
Paradoxurus pennanti, Gray, loc. cit.

Platy'schista pallasi, Otto, Nova Acta $\Lambda$ c. Cres. Leop. Car. vol. xvii. p. $1089\left(\mathrm{I}_{35}\right)$.

Putradoxumis hirsutus, Hodigson, Asiat. Researches, vol. xix. p. $72(1836)$.

Praradoxurus niger, Blanford, Proc. Zool. Soc. 1885, p. 792 ; id., Mamm. Brit. India, p. Io6 (1888).

\section{(Plate XXX.)}

Characters.-Bony palate extending less than a quarter of an inch behind the line of the last upper molar teeth; whiskers black, with occasionally a few of the lowest bristles white at the base. Tail nearly or quite as long as the head and body, thickly hai:ed, and only slightly tapering. Fur coarse and frequently long, with some elongated and ragged patches, especially on the back; under-fur short or absent. General colour fulvous, ashy, or black, marked either by streaks, streaks and spots combined, or dusky patches. The slits on the anterior extremity of the bony palate only extending as far back as the canme teeth. Length of head and body varying from 20 to 25 inches; of tail, from 16 to 20 inches. Males are considerably larger than females, and there are also racial variations in point of size.

By Mr. Blanfurd the Indian Palm-Civet (P. Mirer) is regarded as specifically distinct from the Malayan $P$. hermaphroditus. Mr. W. L. Sclater remarks, however, that it seems "more in accordance with the facts to recognise the two forms only as geographical races ; since although the Toddy-Cat of Southern India is fairly distinguishable from that of the Malay Peninsula, the specimens met with in Lower Bengal are intermediate between the two. The typical variety is distinguished by the marked longitudinal stripes down the back; the hill variety (P. strictus) by its darker colour, more distinct spots, and smaller size; the Indian variety $(P$. nigrer $)$ by the absence of definite stripes and spots, which are replaced by dusky patches." 
基

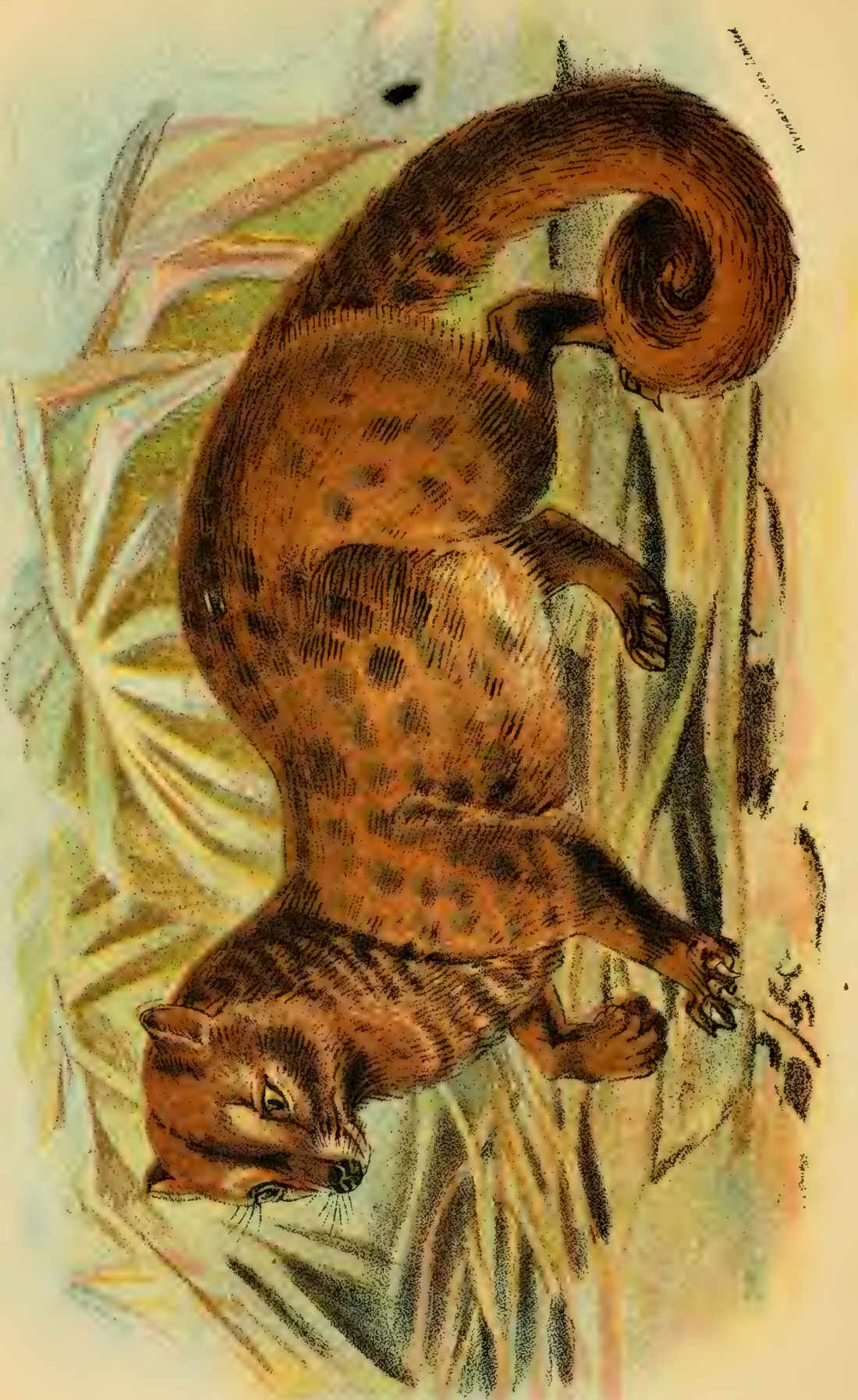


Distribution.-The range of the typical form of this species embraces Burma, Siam, the Malay Peninsula, Sumatra, Borneo, and Java; the variety $P$. strictus is apparently confined to Sikhim and Assam; while the variety $P$. niger is spread over Indix proper and Ceylon, extending to the Himalaya, but becoming rarer in the north-west, and also to the east in Lower Bengal, where it passes almost insensibly into the typical form.

Habits.-The habits of the Common Palm-Civet, cr, as it is often called, Toddy-Cat, may be taken as typical of those of the genus generally. These animals pass the daytime either among the b:anches of trees or in hollows of their trunks, in the neighbourhood of the coast cocoa-nut palms being their favourite resorts, while in more inland districts mangrove-groves are frequently selected. Thatched roofs of houses, as well as outbuildings and drains, are, however, sometimes chosen as dwelling-places, and these animals will occasionally take up their quarters in the heart of cities. From such varied domiciles the Palm-Civet issues forth at dusk in search of food, which comprises the smaller Mammals, birds and their eggs, lizards, insects, fruit, and vegetables, in addition to "toddy" - that is to say, palm-juice-which is eagerly drunk from the vessels suspended from palm-trees to collect it. The young are born in the hollows of trees, and usually number four to five in a litter.

\section{THE PHILIPPINE PALM-CIVET. PARADOXURUS}

PHILIPPINENSIS.

Paradoxurus philippinensis, Jourdan, Comptes Rendus, vol. v. p. 523 ( $18_{37}$ ); Blanford, Proc. Zool. Soc. 1885, p. Soo.

Paradoxurnis zeylanicus, Gray, List Mamm. Brit. Mus. p. 55 (I 843).

Paradoxurus philippensis, F. Cuvier, Ann. Sci. Nat. ser. 2, vol. viii. p. 372 (1837).

Characters.-Very similar to the preceding, but rather smaller, with the fur closer, softer, less ragged, and more even in length, 
and a marked gloss on thairs. Under-fur thicker and more woolly. Upper carnassial tooth with a very large inner tubercle near the middle of its length. General colour dusky-brown on the upper-parts and brownish-grey beneath, with or without indistinct longitudinal rows of spots on the back. Head mostly black or blackish-brown, with a pale band across the forehead and spots beneath the eyes, as in the typical form of the preceding species; feet and tail coloured like the head.

Distribution.-The Philippine Islands and Borneo.* Mr. Blanford remarks that specimens from Borneo appear to connect the Philippine race with the typical P. hermaphroditus.

iIt. LARGE-TOOTHED PALM-CIVET. PARADOXURUS MACRODUS. Parudoxurus macrodus, Gray, Proc. Zool. Soc. 1864, p. 538; Blanford, Proc. Zool. Soc. I 885, p. So ; W. L. Sclater, Cat. Mamm. Ind. Mus. pt. ii. p. 246 (г 8 gr I).

Characters.-Externally very similar to the typical species, but readily distinguished by the much larger size of the teeth.

Distribution.-Malay Peninsula.

IV. JERDON'S PALM-CIVET. PARADOXURUS JERDONI. Paradoxumis jerdoni, Blanford, Proc. Zool. Soc. г885, pp. 6г 3 , 802 ; id., Mamm. Brit. India, p. I I I (1888).

Characters-Distinguished from $P$. hermaphroditus by the greater length of the apertures at the anterior end of the palate. The whiskers are dark brown, and the tip of the tail is black, and not, as figured, white; general colour uniform dark brown.

Distribution.-Southern India; viz., the Madura and Nilgiri Hills.

V. THE RED PALM-CIVET. PARADOXURUS AUREUS.

Paradoxurus aureus, F. Cuvier, Mém. Mus. Paris, vol, ix. p. 48 (1822); Blanford, Proc. Zool. Soc. I885, p. 302 ; id., Mamm. Brit. India, p. I Iо (I 888).

* See Evcrett, Proc. Zool. Soc. I893, p. 495. 
Paradox:mus montanus, Blyth (ex Kelaart), Journ. Asiat. Soc. Bengal, vol. xx. p. I6I (1851).

Paradoxurus zeylanicus, Kelaart, Prodr. Faun. Zeyl. p. 32 (1852; nec Gray).

Characters. - Tail about four-fifths the length of the head and oody; fur moderately soft and thick, of uniform length, and with little woolly under-fur; whiskers rufous; general colour uniform rusty-red or dull chestnut, with occasional traces of longitudinal streaks on the back. Length of head and bodv about I9 inches; of tail, I $51 / 2$ inches.

Distribution.-Ceylon, the specimens from the mountains being darker than those from the plains.

VI. THE HIMALAYAN PALM-CIVET. PARADOXURUS GRAYI.

Paradoxurus grayi, Bennett, Proc. Zool. Soc. I $S_{35}$, p. II 8 ; Blanford, Proc. Zool. Soc. I885, p. 803; id., Mamm. Brit. India, p. I I 2 (I 888).

Paradoxurus nipalensis, Hodgson, Asiat. Researches, vol. xix

p. $76(1836)$.

Paguma grayi, Gray, List Mamm. Brit. Mus. p. 54 (I $8_{43}$ ).

Paradoxumus tytlerii, Tytler, Journ. Asiat. Soc. Bengal, vol. xxxiii. p. I88 (1864).

Characters.-Size larger than in P. hermaphroditus; tail about equal in length to the head and body; fur of uniform, but variable, length, with the woolly under-fur frequently well developed. Bony palate of the skull extending more than a quarter of an inch behind the line of the last molar teeth; whiskers, at least in part, conspicuously white. Colour of upper-parts uniform grey, without markings; under-parts whitish; the tip of the tail frequently dark brown or black. Head brown or blackish, with the exception of the forehead, a broad band beneath the ear, a narrower line down the nose, and a blotch beneath each eye, in all of which places there is a 
larger or smaller admixtu of white hairs. Length of head and body, from 24 to 25 inches; of tail, inclusive of the terminal hairs, about the same.

Distribution.-The Himalaya from Simla to Assam, Arakan, and the Andamans; possibly also some parts of the plains of India.

VII. THE CHINESE PAIM-CIVET. PARADOXURUS LARVATUS.

Gulo larvatus, Griffith, Animal Kingdoni, vol. ii. p. $2 S_{\text {I }}$ ( $1827 ;$ ex Temm. MSS.).

Viverra larrata, Gray, Spicil. Zool. p. 9 (г830).

Paguma larvata, Gray, Proc. Zool. Soc. I83 I, p. 95.

Paradoxurus larvatus, Gray, op. cit. I832, p. 67 ; Blanford, Proc. Zool. Soc. 1885, p. 805.

Characters.-Very similar to the preceding, but smaller. General colour light brownish-grey; the terminal portions of the tail and limbs, parts of the head, and the neck and back between the shoulders black or blackish; a broad white stripe down the middle of the forehead and nose; a white spot beneath the eye and another behind it (which join to form a streak), sharply defined against the blackness of the rest of the face.

Distribution.--Southern China and Formosa.

VIII. WHITE-IVIISKERED PALM-CIVET. PARADOXURUS LEUCOMYSTAX.

Paradoxurus lencomystax, Gray, Proc. Zool. Soc. I 836 , p. 88 ;

Blanford, Proc. Zool. Soc. r 885, p. 805 .

!aradoxurus jourdani, Gray, Mag. Nat. Hist. vol. i. p. 579 $\left(\mathrm{I} \mathrm{S}_{37}\right)$.

Paymlma leucomy'stax, Gray, List Mamm. Brit. Mus. p. 55 ( 1843$)$.

Paradoxurus ogilbyi, Fraser, Zool. Typ. pl. x. (1849). 
Paradoxums rubidus, Blyth, Journ. Asiat. Soc. Bengal, vo!. xxvii. p. $275(1358)$.

Characters.-Size large, only exceeded in $P$. musschenbroecki; tail about three-fourths the length of the head and body. Distinguished from $P$. srayi by the brown or rufous colour of the fur; head-markings generally distinct, brown and whitish; either a broad pale band across the forehead or the whole face whitish. Length of head and body, about 27 inches; of tail, 20 inches.

Distribution.-The Malay Peninsula, Sumatra, Borneo, and probably some of the other Malayan islands, exclusive of Java.

IX. THL CELEBEAN PALM-CIVET. PARADOXURUS MUSSCHENBROECKI.

Faradoxurus musschenbroecki, Schlegel, Notes Leyd. Mus. vol. i. p. 43 (1879); Blanford, Proc. Zool. Soc. I 885 , p. $8 \circ 6$.

Characters.-The largest member of the genus; tail about three-fourths the length of the he.ld and body; fur soft and short. Skull with the bony palate much produced backwards, but otherwise resembling that of $P$. hermaphoroditus; teeth differing from those of all the other species in that the two cheek-series run nearly parallel, in place of being widely diververgent posteriorly. General colour of upper-parts light brownish-chestnut, with numerous light hairs intermixed; underparts varying from fulvous to white; breast rufescent; hinder part of back with a pair of indistinct longitudinal stripes, and some faint spots ; whiskers mixed brown and white. Tail difiering from that of all the other members of the genus, marked with alternating rings of dark and pale brown, which are indistinct on the under surface, and disappear towards the dark tip. Length of head and body, about 35 inches; of tail, 25 inches.

Distribution.-Celebes, 
X. WOOLLY PALM-CIFT. PARADOXURUS LANIGER. Paradoxumus laniger, Hodgson, Asiat. Researches, vol. xix. p 79 ( 1836$)$; Blanford, Proc. Zool. Soc. 1885, p. 807 ; id., Mamm. Brit. India, p. I I 4 (I888). Paguma laniger, Gray, List Mamm. Brit. Mus. p. 55 (1843).

Characters.-An imperfectly known species only provisionally included in the genus. Tail only about half the length of the head and body, very thick at the root, and rapidly tapering; fur very close and woolly. Toe-pads surrounded by hair ; and the claws short. Colour uniform rufescent brown.

Distribution.-? Tibet. Known only by a single badly preserved skin purchased by Hodgson in Nipal.

\section{GENUS ARCTICTIS.}

Arctictis, Temminck, Prospec. Monogr. Mamm. (I 824 ); id., Monogr. Mamm. vol. i. p. xxi. vol. ii. p. 309 (1835). Ictides, Valenciennes, Ann. Sci. Nat. vol. iv. p. 57 (1824).

From the whole of the foregoing genera the present one is distinguished by the completely naked tarsus and metatarsus of the plantigrade hind-fest, by the presence of long pencils of hairs surmounting the short ears, and by the long tail being thoroughly prehensible. The short, compressed, and slightlycurved claws are only partially retractile; the coarse fur is long and shaggy; the pupil of the eye is vertically elongated; and the large glands in front of the scrotum of the male open into a deep fold. There are generally only three pairs of lower pre-mo'ars, but the number of the teeth is otherwise the same as in Viverra, and in some individuals the missing pair of premolars are developed. With the exception of the canines, which are large and curved, with a sharp hinder edge, the teeth are relatively small, both the incisors and molars being separated from one another by gaps. Not unfrequently the last pair of upper molars is wanting. 
The genus is represented solely by the following Oriental species.

I. THE BINTURONG. ARCTICTIS BINTURONG.

Viverra binturong, Raffles, Linn. Trans, vol. xiii. p. 253 (I\&22). Paradoxurnes albifrons, F. Cuvier, Mém. Mus. Paris, vol. ix. p. 48 (1822).

Ictides albifrons, Valenciennes, Ann. Sci. Nat. vol. iv. p. 57 ( 1824$)$.

I. tides ater, F. Cuvier, Hist. Nat. Mamm. pt. xliv. (IS24). Arctictis binturung, Temminck, Monogr. Mamm. vol. ii. p. 308 (I835); Blanford, Mamm. Brit. India, p. I IS (ISSS). Arctictis fenicillatus, Müller, Verhandl. Nat. Gesch. p. 32 $\left({ }_{1} \delta_{39}\right)$.

Characters. - Tail nearly as long as the hcad and body, thick at the root, and clothed with stragsling bristly hairs exceeding in length those on the body; fur as described above. Colour unifo:mly black throughout, although more or less grizzled on the head and outer surface of the fore-limbs, and, in some examples, over the whole body; margins of ears white, but the terminal tufts black. In the young the hairs have long rufous or grey tips. Length of head and body, from 28 to 33 inches; of tail, 26 to 27 inches.

Distribution.-The Himalaya from Simla to Assam, Burma, Siam, the Malay Peninsula, Sumatra, Borneo, ${ }^{*}$ and Java.

Habits.-As might be predicated from its fully prehensile tail (a feature unknown in any other placental Old World Mammal), the Pear-Cat, as this animal is frequently termed, is thoroughly arboreal in its habits, frequenting dense forests, and in consequence of the nature of its haunts and nocturnal mode of life, but seldom seen, at least by Europeans. Somewhat slow in its movements, the Binturong is undoubtedly capable of suspending itsalf by its tail after the fashion of the American Monkeys,

* Everett, Proc. Zool. Soc. 1893, p. 495. 
since this has been demotrated in the case of young individuals kept in captivity. Like the Palm-Civets, this animal is omnivorous in its diet; but as regards its breeding habits, naturalists are still in the dark. It is stated to utter a loud and prolonged cry, which, if verified, will show that in this respect the Binturong differs widely from all other members of the Family. In disposition it is decidedly fierce; but individuals captured when young become tame and gentle without much trouble.

The zoological position of the Binturong was long a matter of controversy, but it may now be regarded as settled that it is a highly specialised form allied to the Palm-Civets.

XiI. THE WEb-Footed Civets. Genus CyNOGale. Cynogale, Gray, Proc. Zool. Soc. 1835, p. 88. Potamophilus, Müller, Tijdsch. Natuur. Gesch. vol. v. p. I40 (1838).

This genus, the last of the Sub-family Viverrine, may be easily recognised by the absence of a vertical groove on the upper lip, the short tail, the partially-webbed feet, and by the under surface of the tarsus and metatarsus being rather less naked than in the Palm-Civets, short hairs clothing the former segment, while the latter is bare. The claws are sharp, rather elongated and retractile; and the first toe on each foot is well. developed.

Like the last, the genus is represented only by a single Oriental species.

I. BENNETT'S CIVET. CYNOGALE BENNETTI.

Cynogale bennetti, Gray, Mag. Nat. Hist. vol. i. p. 578 (1836); id., Cat. Carniv. Mamm. Brit. Mus. p. 78 (г869) ; Mivart. Proc. Zool. Soc. 1882, p. I72; Sanyal, Proc. Zool. Soc. 1894, p. 296.

Viñerra carcharias, Jourdan, Ann. Sci. Nat. ser. 2, vol. viii. p. 281 (I 837 ). 
Fotamophitus barbatus, Müller, Tijdsch. Natuur. Gesch. vol. v. p. I 42 (1838).

Cynogale barbata, Schinz, Synops. Mamm. vol. i. p. 388 (1844).

Characters.-The following description of a living specimen is given by Mr. Sanyal. In form and size this animal resembles partly a Linsang and partly a Prionodon. The head is elongated, and the muzzle broad and depressed, the breadth of the latter appearing more pronounced owing to the exceptional character of the upper lip, which is much thickened in order to support the roots of the abundant and well-developed whiskers. A bunch of whiskers below each ear and close to the outer angle of the eye; also an intermediate set on each side of the nose between the eye and the lip. A tuft of vibrissæ on the chin between the lower lip and the throat. Eyes large and oblique; ears small and rounded; nostrils with distinct lobes adapted for a sub-aquatic life. Tail moderate and thick. Prevailing colour of the fur grey, becoming grizzled white on the back, rump, and outer surface of the limbs*; a dark longitudinal stripe on the crown of the head and nape; eyebrows partially white; a white spot on each side of the head below the ears, corresponding with the place of insertion of the whiskers in this region; lips white. Under-parts blackish; tip of the tail whitish. Length of head and body, about 32 inches; of tail, $9 \frac{1}{2}$ inches.

\section{Distribution.-Malay Peninsula, Sumatra, and Borneo.}

Habits.-Little trustworthy information is obtainable as to the habits of this rare Civet in the native state, although it may be taken as certain that the creature is to a considerable extent

* The colour has been hitherto described as uniformly reddish-brown, save for a narrow dark streak down the head. The difference may, perhaps, be in part accounted for from the fact that one description is taken from the living animal, and the other from dried skins ; and also from the different ages of the specimens examined, old ones being probably more grey than younger examples. 
aquatic, and fecds largely on fish and crustaceans. It is, however, stated also to capture and eat various land animals, and likewise to be capable of ascending trees with facility, so that it may be likened to a climbing Otter. With regard to the habits of the captive specimen mentioned above, which was exhibited in the Calcutta Zoological Gardens, Mr. Sanyal writes as follows: "Except very early in the morning, I have never seen this animal leave its cage during the day; and though it never appears to be particularly savage, it always resents the approach of its keeper, or anyone else, by a sort of low, subdued snarling. The presence of a strong civet-like smell near its cage, especially at night, unmistakably indicates the possession of odoriferous glands. Although said to be omnivorous, it shows greater partiality for an animal than a vegetable diet, and relishes fish more than flesh. I have never observed it indulging in its aquatic habits."

\section{THE MUNGOOSES. GENUS HERPESTES.}

Ichncumon, Lacépède, Mém. Instit. Paris, vol. iii. p. 492 (I SoI ; preoccupied).

Herpestes, Illiger, Prodrom. Meth. Mamm. p. i35 (i $\mathrm{I}_{\text {I }}$ ).

Mangusta, Olivier, in Fischer's Synops. Mamm. p. I62 (IS29). Mungos, Ogilby, Proc. Zool. Soc. I835, p. זо3.

Urva, Hodgson, Journ. Asiat. Soc. Bengal, vol. vi. p. 56 I (1 837$)$. Mesobema, Hodgson, op. cit. vol. x. p. 9 Iо (I $84 \mathrm{I})$.

Osmetictis, Gray, Ann. Mag. Nat. Hist. vol. x. p. 260 (1 842 ). Calogale, p. 560, Calictis, p. 564, Taniogale, p. 569, Onychogale, p. 570, Gray, Proc. Zool. Soc. I864.

With this extensive genus we come to the first representative of the second Sub-family (Herpestina) of the Viverrida, which may be characterised as follows: In the skull the auditory bulla is pear-shaped, and its hinder margin distinctly everted, while the par-occipital process does not project beyond it, but 
is sread orer it, and in the aduit becomes merged in its hinder surface. In the Viamina, nin the other hand, the same process generally projects somewhat beyond the auditory bulla, from which it remains markedly distinct. Instead of being curved and more or less retractile, the claws of the Herpestince are long, exserted, and quite incapable of retraction. The glands so generally present in front of the scrotum of the males of the Viverrince, are invariably absent in the group under consideration. It includes sereral genera, and may be considered mainly characteristic of Africa and Madagascar, since only the typical genus extends into the Oriental region, and even that has more Ethiopian than Asiatic representatives.

As a genus, Herpestes is specially characterised by having five toes to each foot, by the presence of a vertical groove on the nose, and usually of four pairs of pre-molar teeth in each jaw, * the number of molars being, as usual, two. Concerning other features, it may be noted that the muzzle is sharply pointed, the body long and slender, the legs short, and the ears short and rounded. As a rule, the tail is long and tapering, with its investing hair clongated. In the plantigrade feet, the extent to which the sole in the hind pair is naked rariss to a considerable extent with the specics, the bare portion extending in some instances as far back as the heel, while in others the tarsus is invested inferiorly with hair. The fur is coarse, and has a peculiar specked or "pepper-and-salt" appearance, due to the circumstance that the longer hairs are marked wi:h alternating light and dark rings; in no case is the tail ringed. All the cheek-teeth have very sharp cusps, and are thus strikingly unlike those of the Palm-Civets, in which the cusps are more or less blunted. The skull is remarkable for the distinct contraction behind the orbits, and likewise for the fact

* If but three are present in either jaw, thẹre is a gap between the firșt of the series and the canine. 
that the latter are generally completely surrounded by bone, whereas in the Civets an Palm-Civets they are incomplete posteriorly.

The genus has a distribution equivalent to that of the Subfamily, and is the second one in the Family which ranges into the south of Europe, the other being Genetta.

The most convenient arrangement will be found to treat the various species mainly according to their geographical distribution, commencing with the typical Palæearctic form. Two African forms, allied to the members of the next genus, will, however, be considered after the Oriental species.

I. THE EGYPTIAN MUNGOOSE. HERPESTES ICHNEUMON. Viverra ichneumon, Linn., Syst. Nat. ed. I 2, vol. i. p. 63 ( I 766 ). Ichneumon pharaon, Lacépède, Mém. Instit. Paris, vol iii. p. 492 (I 80 I).

Ichneumon agypti, Tiedemann, Zool. vol. i. p. 364 (i So8). Herpestes pharaonis, Geoffroy, Descrip. de l'Egypte, vol. ii. p. I 39 ( I 8 I2).

Herpestes mumidicus, F. Cuvier, Hist. Nat. Mamm. pt. Ixviii. ( 1834 ).

Herpestes widdringtoni, Gray, Ann. Mag. Nat. Hist. vol. ix. p. $50(\mathrm{I} 842)$.

Herpestes dorsalis, Gray, Proc. Zool. Soc. I864, p. 549. Herpestes ichneumon, Thomas, Proc. Zool. Soc. I8S2, p. 64. (Plate $X X X I$.)

Characters.- Size large, form slender; tail about three-quarters the length of the head and bcdy; fur long, more especially on the rump and root of the tail. General colour dark grizzled greyish-brown, the hairs being ringed with dark reddish-brown and creamy-yellow, but the tips of those on the back of a darker yellow; the thick and woolly under-fur bright rufous. Tip of tail shining black, with the hairs elongated into a kind of tassel, which may reach as much as five inches beyond the 


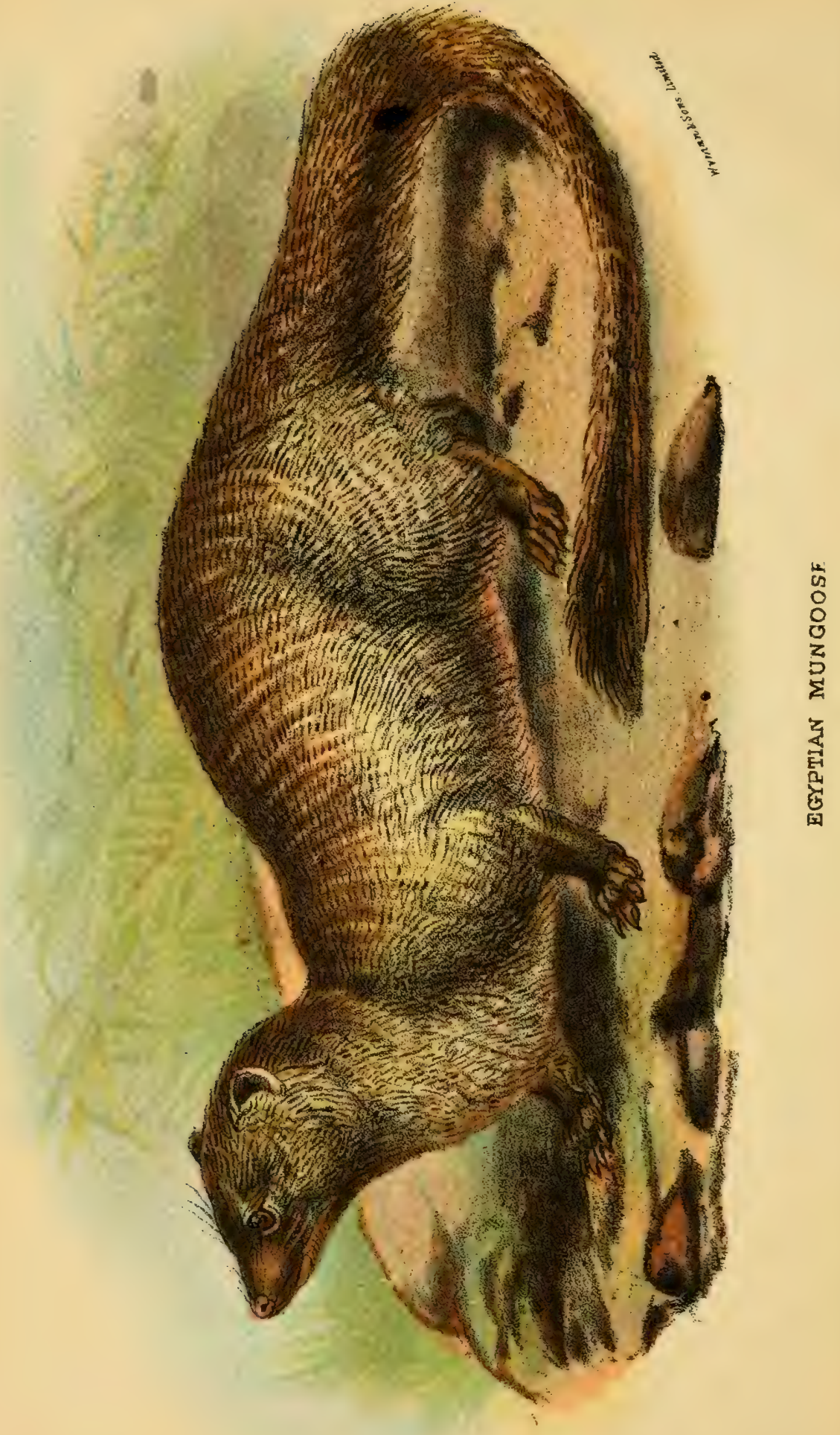


bone. Feet dark brown; the under surface of the metatarsus and tarsus generally quite naked, but the heel itself occasionally hairy. Teeth sharp and slender; the upper carnassial more than double the length of the last molar; and the last lower molar with only two cusps on its outer side. Length of head and body, about 20 inches; of tail, 15 to 17 inches.

Distribution.-Southern Spain, Asia Minor, Palestine, and Africa north of the Sahara.

The habits of this species may be considered in connection with the next. With regard to the occasional presence of hair on the heel, Mr. Thomas remarks "that a partly hairy sole seems to be accompanied by an increased length of the hallux, as though certain individuals or families were accustomed, probably on account of the nature of the soil, to walk in a more digitigrade manner than usual, and the hallux wire in these cases elongated sufficiently to reach the ground. In H. galera I have found the same thing, there being one of our West African specimens of that species with a hairy sole and elongated hallux."

II. THE CAFFRE MUNGOOSE. HERPESTES CAFFER.

Viverra caffra, Gmelin, Syst. Nat. vol. i. p. 85 (1788).

Herpestes madagascariensis, A. Smith, S. African Quart. Journ. vol. ii. p. II 4 (I835).

Herpestes bennettii, Gray, Mag. Nat. Hist. vol. i. p. 578 (1837). Herpestes caffer, Blyth, Cat. p. 52 (1863); Thomas, Proc. Zool. Soc. 1882 , p. 66.

Characters.-Somewhat larger than the last, but similarly coloured, except that the rings on the longer hairs are rather narrower, and are pure black and white in colour, thus communicating a clearer grey tinge to the whole pelage, while the under-fur is dark dull rufous or dark greyish-brown. Under surface of tarsus invariably naked. Skull longer and narrower than in $H$. ichneumon, the width being always less (instead of 


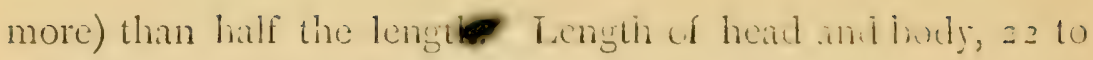
23 inches; of tail, is to 19 inches.

Distribution.-- Africa south of the Sahara. The present species and the closely allied II. iithemmon are readily distinguished from all the other African representatives of the genus by their large size and long black tail-tips. With regard to the propriety of considering them as specifically distinct from one another, Mr. Thomas writes: "I was at first disposed to regard them as only races of one species, as Temminck had done; but I have fumbl such a constancy in their distinguishing characters that, combined with the fact of their ranges being in different zoological regrions, I have been induced to retain them as distinct specics. There is no doubt, however, that they are very closely allicd; but when we remember how very distinct are the fiannas of the southern Palearctic and Ethiopian regions, s.arcely any species being common, it would naturally seem preferable to consider as distinct two forms so fairly wellmarked as are $H$. ichnemm $m$ and $H$. caffer, when the line of demarcition butween them so cra tly corresponds with what is generally recognise 1 as the bondary betwee!n tiro zoological regions."

Habits.- The habits of this species may be taken as characteristic of the genus generally, and may consequently be noticed at some length. None of the Mungooses are arboreal; and they generally dwell in holes in the earth, among bushes, or in hedgerows, being seldom found in thick forest. Their diet includes the smaller Rodent Mammals, Birds and their cggs, as well as Snakes, Lizards, and Frogs; while the Egyptian Mungoose, at least, devours large numbers of Crocodiles' eggs, on which account it has always been held in high estimation by the inhabitants of the Nile Delta. In many parts of Africa the Caffe Mungoose is kept in captivity for the purpose of killing Rate, Nice, and other vurmin; the same being the case in 
India with some of the species inhabiting that country. Not only so. but Mungooses have been introduced into the West Indies for the purpose of killing the Rats that were at one time playing havoc with the sugar-canes; but although the experiment has been successful, it has been very fatal to several kinds of birds. The common Indian Mungoose, which burrows holes for itself, produces from three to four young in a litter; and, like the other species, is commonly found either singly or in pairs. Although these animals are naturally fierce and bloodthirsty, they can be readily tamed, when they form gentle and affectionate little pets, without the ill-odour which renders the Civets so objectionable.

Mungooses are duadly enemies to Snakes, attacking even the most venomous kinds with general impunity, although if severely bitten, they die like other animals. Probably they owe this immunity to their extreme activity, although they are, probably, less susceptible to Snake-venom than other Mammals.

III. TIE ANGOLA MUNGOOSE. HERPESTES ANGOIENSIS. Herpestes angolensis, Bocage, Journ. Sci. Lisb. ser. 2, vol, ii. p. 32 ( 1890$)$.

Characters,--Closely allied to the two preceding. The dark brown pelage, speckled with rufous, approximates this form to II. ichnemonon, but its size is larger, and the tail considerably longer; characters by which it is equally well distinguished from $H$. caffer. The rufous rings on the hairs are decidedly narrower than in $H$. ichneumon. The muzzle, chin, fore-legs, and feet are deep black; the remainder of the pelage speckled with rufous on a blackish-brown ground. The proximal fifth of the tail is covered with long brown hairs ringed with rufous; in the remainder of the tail, except the black tip, the hairs are short and uniformly bright rufous.

Distrịbution, - West Africa (Angola). 
IV. THE SLENDER MUFOOSE. HERPESTES GRACILIS. Herpestes gracilis, Rüppell, Neue Wirbelth. p. 29 ( ${ } S_{35}$ ); Thomas, Proc. Zool. Soc. r8S2, p. 68, IS93, p. 50I ;

Bocage, J. Sci. Lisboa, ser. 2, vol. i. p. I 78 (1889). Herpestes mutgigella, Rüppell, loc. cit. Cynictis melanura, Martin, Proc. Zool. Soc. I 836, p. 56. Herpestes badius, Smith, Illustr. S. African Zool. pl. iv. ( ${ }_{3} S$ ). Ichneumia nigricaudatus, Geoffroy, Mag. Zool, I839, p. IS. Herpestes ochraceus, Gray, Proc. Zool. Soc. I $S_{4} S$, p. I 3 S. Herpestes galinieri, Guerin, Voyage Abyssin. Zool. pl. i. ( $1847-48$ ).

Herpestes lefeborei, I)es Murs. \& Prev. in Lefe'urr. Voyage Abyss. Zool. Atlas, pl. i. (1850); Bocage, op. cit. p. I79. Herpestes ornatus, Peters, Reise Mossambique, Mamm. p. I I 7 (1852).

Herpestes ochromelas, Pucheran, Rev. Mag. Zool. ser. 2, vol. vii. p. 393 ( 1855 ).

Herpestes iodoprymmus, Heuglin, Nova Acta Ac. Cres. Leop.Car. vol. xxix. p. 23 (I86I). Herpestes adailensis, Heuglin, Peterm. Mitth. I86 I, p. I 7 . Calogale granti, p. 561, C. venatica, p. 563, Gray, Proc. Zool. Soc. I 864 .

Galerella ochracea, Gray, op. cit. p. 564 .

Herpestes mutscheltschela, Heuglin, Reise N. O. Afrika, vol. ii. p. 4I (I877).

Herpestes ruficauda, Heuglin, op. cit. p. 43.

Herpestes melanurus, Matschie, Mittheil. deutsch. Schutzgebieten, vol. vi. art. 3, p. I I (1893).

Characters.--This is a very variable species, agreeing with the two preceding ones in the black tip to its tail, but readily distinguished by its markedly inferior size. The form is slender; the tail slightly shorter than the head and body; the fur of medium length, and not elongated either at the root or the tip of the 
tail, while the colour may be either sandy, rufous, or dark greyish-brown. Under-side of tarsus naked. Skull resembling that of $H$. ichneumon in form. Length of head and body, varying from about II to $14 \frac{1}{2}$ inches; of tail, from $10 \mathrm{I} / 2$ to $\mathrm{I} 2$ inches.

Distribution.-Africa, south of the Sahara.

Varieties.-The typical varicty, ranging from Cape Verd across Abyssinia to Natal, is of large size, and has the general colour of the fur dark brownish-grey, with or without black annulations, the tips of the hairs often showing a distinct ruddy tinge. In those specimens without black rings on the hairs the black terminal portion of the tail is not so sharply defined.

In the West African variety, $H$. melanurus, ranging from Liberia to Sierra Leone and the Cameruns, the general colour is dark rufous, with the hairs distinctly ringed with black, the fur being short and crisp.

The South African variety, H. badius, extending from the Cape to Zanzibar, is rather smaller, and distinguished by its bright rufous colour, the hairs being sometimes ringed with black, and the fur rather long and soft.

In the still smaller variety, $H$. ochraceus, typically from Abyssinia, the colour is light sandy-yellow, the hairs in the type specimen being ringed with black. This variety is recorded by Bocage, in the paper cited, from Angola. An allied IVest Coast variety (H. flavescens), from Benguela, according to the same writer, has the fur of a brighter tint, with the hairs on the head and root of the tail tipped with black.

Another variety from Angola (H. punctulatus? = H. muficauda) is of a bright rufous tint, with the hairs tipped with black.

V. THE RED-TAILED MUNGOOSE. HERPESTES SANGUINEUS.

Herpestes sangruineus, Rüppell, Neue Wirbelthiere, 1). 27 (1835); Thomas, Proc. Zcol. Soc. I882, p. 7 I. 
Charactors. - Size and formuch as in the last; fur short and somewhat harsh. General colour vory pale fawn; the hairs ringed with brown and yellowish-white, the latter colour predominating, and the arrangement producing the appearance of cross-bands on the hinder part of the back. Tail with longer hairs, ringed with black and white, although the black is very inconspicuous; its tip yellowish-red, and sharply differentiated from the rumainder. Feet nearly white. Tecth generally similar to those of $I I$. ithmemon. I ength of head and body; about $\mathrm{I} 2$ inches; of tail, either rather more or rather less.

Distribution.-Kordofan.

Habits.-Mr. Thomas writcs that "this species, hitherto only found in Kordofan, is evidently a desert form, having the sandy coloration usually occurring in animals inhabiting sandy plains. Dr. Rüppell seems to have found it numerous, as he brought home five or six specimens. He states that it lives in holes in the ground, among bushes, and that, though fierce when wild, it is yet easily tameable. Baron von Heuglin also found it, though not commonly, in the same region."

VI. NEUMANN'S MUNGOOSE. MERPESTES NEUMANNT. Herpestes neminami, Matschie, S. B. Nat. Fr. Perlin, ISot, p. I 2 т.

Characters.-il small form allied to the two preceding, and closely resembling $H$. sracitis var. chtracelts in general coloration, but distinguished by the absence of annulations on the hairs, and the chestnut-brown colour of the tail-tip. General colour ochre-yellow; the hairs of the middle line of the back with small chestnut-brown tips, giving a reddish-brown speckling to the pelage; the hairs in the last third of the tail darker; feet coloured like the sides and tail.

Distribution.-East Africa (N. Ugogo).

In admitting this form to the rank of a species, it should be noticed that its describer regards the varieties of $H$. gracilis and $H$. albicauda as distinct species. 
TII. THE RUFOUS MUNGOCSE. HERPESTES GAIERA. Mistela salera, Erxleben, Syst. Règn. Animal, p. 453 (I 777 ). Viverra nens, Kerr, Linn. Anim. Kingd. p. I6o ( ( 792 ).

Mustelu afra, Kerr, op. cit. p. I75.

Ichneumon galera, et $I$. afrit, Geoffroy, Descrip. de l'Egypte, vol. ii. p. I 39 (I 8 I 3 ).

Atilax vansire, I. Cuvier, Hist. Nat. Mamm. pt. liv. (1826). Herpestes paludinosus, Cuvier, Règ'le Animal, ed. 2, vol. i.p. I 58 (1 829 ).

Mangusta urinatrix, A. Smith, Zool. Journ. vol. iv. 1) 437 ( 1829$)$.

Herpestes pluto, Temminck, Esquisses Zool. p. 05 ( ( 853 ).

Herpestes loempo, Gray, Proc. Zool. Soc. i 864 , p. 55 I (nec Temminck).

Athylax vansire, et $A$. palualosus, Gray, op. cit. p. 557.

Athylax robustus, Gray, op. cit. p. 558 .

Herpestes palidosis, Blyth, Cat. p. 52 (i $86_{3}$ ).

Herpestes galera, Thomas, Proc. Zool. Soc. ISS2, p. 72.

Characters. - This and the next two species differ from all the preceding in that the tip of the tail is nct darker than the rest; the teeth being generally similar to $H$. iclnemmon, except that the length of the upper carnassial is less than twice that of the last molar.

Size very large; form stout and heavy; length of tail less than that of the body alone. General colour either grizzled reddish-brown and white, or dark blackish-brown without annulations; under-fur greyish-brown. Feet dark brown ; tail coloured like the body, but rather darker, sometimes becoming nearly black near the extremity, but never with a sharply defined black tip. Generally an indistinct whitish mark on the cheek. Tarsus and metatarsus usually quite naked, but occasionally some hair on the hinder part of the former. Skull very stout and heavy, with the teeth relatively small. Length of 
head and body in the typeal variety, about 24 inches; of tail, I 3 inches.

Distribution.-Typically West and South Africa; replaced in East Africa (IVhite Nile) by a larger variety (H. robustus) with a proportionately shorter tail.

Habits.-In South Africa this species is stated to frequent marshy spots and the banks of the smaller rivers, feeding chiefly upon frogs and crustaceans.

VIII. EAST AFRICAN MUNGOOSE. HERPESTES PULVERULENTUS. Herpestes pulverulentus, Wagner, Münch. Gel. Anzeiz. vol. ix. p. 426 (I839); Thomas, Proc. Zool. Soc. 1882, p. 74. Herpestes af iculatus, Gray, Proc. Zool. Soc. IS64, p. 55 I.

Characters.-Size rather small; form somewhat stout; tail about equal in length to the body alone; hinder extremity of tarsus hairy beneath; fur rather long, soft, and shining. General colour uniform grizzled grey, the longer hairs with rings of black and white or yellow, the rings of each colour being of equal length; under-fur brown at the base and grey at the extremity. Hair of tail long; in colour the whole tail like the body; feet slightly darker. I Length of head and body, from 13 to 15 inches; of tail, Io to I I $1 / 2$ inches.

Distribution.-Eastern side of the Cape Colony (Algoa Bay, Natal, \&c.).

With the exception that it has not a black tail-tip, this species presents a considerable resemblance to a very diminutive specimen of $H$. caffer; the nature of the fur being similar in the two species. The geographical distribution is remarkably restricted.

IX. THE SHORT-HAIRED MUNGOOSE. HERPESTES PUNCTATISSIMUS.

Herpestes punctatissimus, Temminck, Esquisses Zool. p. Io8 (I853); Thomas, Proc. Zool. Soc. 1882, p. 74. 
Characters.-Fur short and harsh, the hairs on the back being barely half-an-inch in length. General colour pale grey, the hairs being finely grizzled with black and creamy-white, those on the under-parts having longer pale tips and less black. Tail with the hairs somewhat longer than those on the body, and uniformly ringed with black and white; no trace of a dark tip. Limbs coloured like the body; under surface of tarsus naked. Length of head and body, I3 inches; of tail, Io $1 / 4$ inches.

Distribution.-West and South Africa (Gaboon and Algoa Bay).

This small species is very rare, and presents some resemblance to the Oriental $H$. auropunctatus.

\section{$X$. THE SMall indian MUNGOOSE. HERPESTES} AUROPUNCTATUS.

Viverra auropunctata, Hodgson, Journ. Asiat. Soc. Bengal, vol. v. p. 235 (1836).

Herpestes nipalensis, Gray, Mag. Nat. Hist. vol. i. p. 57 S ( 1837 ). Herpestes auropunctatus, Wagner, in Schreber's Säugethiere, Suppl. vol. ii. p. 3го (г 84 I); Blanford, Mamm. Brit. India, p. I2 r (18SS); Sclater, Cat. Mamm. Ind. Mus. pt. ii. p. 25I (i 89 I).

Herpestes pallipes, Blyth, Journ. Asiat. Soc. Bengal, vol. xiv. p. 346 (1845).

Herpestes javanicus, Blyth, op. cit. vol. xxi. p. 349 (IS52).

Herpestes persicus, Gray, Proc. Zool. Soc. I864, p. 554.

Calogale nepalensis, Gray, Cat. Carniv. Mamm. Brit. Mus. p. I 58 (I869).

\section{Variety.}

Herpestes birmanicus, Blanford (ex Thomas, I886), Mamm. Brit. Ind. p. I 22 (1888).

IVith this species we come to the Oriental representatives of 
the genus, taking the temaining Ethiopian forms later on, since they differ in certain respects from all the others. Like the foregoing species, the Oriental ones have only two cusps on the inner side of the last lower molar tooth.

Belonging to the group in which there are no bands or stripes on the body, and the whole pelage is more or less uniformly coloured, the present species is specially distinguished by its small size, close and compact fur, which is not longer on the rump and the root of the tail than elsewhere, though on the remainder of the tail the hairs are considerably elongated. Tail, exclusive of hair at the tip, about three-fourths the length of the head and body. Tarsus partly haired. In the typical form the colour varies from light grey to dusky-brown, with minute speckles of white or yellow; the under-parts being paler and more uniform, or in some cases white without annulation of the hairs. Under-fur of the back brown basally, then pale brownish-grey or yellow for some distance; the long hairs beyond this blackish-brown, then pale brown or white, and in some cases with dark tips. Hairs of tail with from five to seven alternations of black and white. Some individual differences obtain in the proportions of the black and white rings; dark specimens having the latter reduced to a minimum. Length of head and body, Io to I 2 inches; tail, exclusive of hair, 7 to to inches.

The variety $I I$. birmanicus is of rather larger size, with the general colour dark brown, minutely speckled with grey or yellowish-grey, the under-parts being scarcely paler than the back. Under-fur dark brown at the base, then whitish; on the back the long hairs beyond this at first black, then with a yellowish ring, and finally a black tip. Annulations more numerous on the hairs of the tail. Length of head and body, I 4 or 15 inches; of tail, with hair, 9 or ro inches.

Distribution. - South-west Persia, Sind, Kandahar, and the 
lower ranges of the Himalaya and the neighbouring plains from Kashmir to Sikhim, as well as Lower Bengal. The variety $H$. birmanicus occurs in Assam, Burma, and perhaps the Malay Peninsula.

Mr. W. L. Sclater states that the only grounds for separating the latter are its slightly larger size and darker colour; but the feet of some typical specimens are as large as those of the variety.

XI. THE GREY INDIAN MUNGOOSE. HERPESTES MUNGO. Viverra mungo, Gmelin, Syst. Nat. vol. i. p. 84 (I 788 ). Herpestes griseus, Desmarest, Mammalogie, p. 2 I 2 (I 820 ); Sykes, Proc. Zool. Soc. I83 I, p. I02.

Herpestes frederici, Desmarest, Dict. Sci. Nat. vol. xxix. p. 60 ( 1823 ).

Mangusta malaccensis, Fischer, Synop. Mamm. p. I64 (I829). Mangusta griseus, Fischer, loc. cit.

Herpestes nyula, Hodgson, Journ. Asiat. Soc. Bengal, vol. v. p. $236(1836)$.

Mangusta mungos, Elliot, Madras Journ. vol. x. p. Iо2 (т839). Herpestes pallidus, Wagner, in Schreber's Süugethiere, Suppl. vol. ii. p. 3ix (I $84 \mathrm{I})$.

Herpestes malaccensis, Blyth, Journ. Asiat. Soc. Bengal, vol. xxi. p. $349\left(185^{2}\right)$.

Herpestes fimbriatus, Temminck, Esquisses Zool. p. I I 2 (IS53). Calogale nyula, Gray, Proc. Zool. Soc. I864, p. 560.

Cynictis fimbriatus, Gray, Cat. Carniv. Mamm. Brit. Mus. p. I7 (1869).

Herpestes ferrugineus, Blanford, Proc. Zool. Soc. I874, p. 66I. Herpestes andersoni, Murray, Vertebr. Faun. Sind, p. 34 (I884). Herpestes mungo, Blanford, Proc. Zool. Soc. I887, p. 63I ; id., Mamm. Brit. India, p. I23 (I888).

Characters.-Size large; fur not close and compact; hairs on 
hinder part of back considably elongated ; tail without biack tip ; hairs with the light and dark rings of equal length. Tail a little shorter than the head and body; tarsus completely naked, but the bare portion of the whole sole of the hind-foot rather narrow. General colour greyish-brown, speckled with white or pale grey; not unfrequently a ferruginous tinge on the head, which in one variety extends over the entire body ; under-parts paler. Under-fur light brown, the longer hairs distinct in colour from this, and on the back marked by four or five dark and as many light rings, which are generally of equal length; tips frequently rufous-brown. Claws dark brown. Length of head and body, from 15 to 18 inches; of tail, 14 to 15 inches.

Distribution.-India generally, from Kashmir and the Himalaya southward, and Ceylon. Imported into the Malay Peninsula.

This is the common Mungoose of India, and the one carried about by the itinerant Snake-charmers. The Bengal variety (H. malaccensis) is darker than usual; while a variety found in Sind (H.ferrugineus, or H. andersoni) is characterised by its rich ferruginous tint.

XII. THE RUDDY MUNGOOSE. HERPESTES SMITHI.

Herpestes smithi, Gray, Mag. Nat. Hist. vol. i. p. 578 (г837);

Blanford, Mamm. Brit. India, p. I 26 (I 888).

Herpestes thysanurus, Wagner, Münch. Gel. Anz. vol. ix. p. 439 (1839).

Crossarchus rubiginosus, Wagner, in Schreber's Säugethiere, Suppl. vol. ii. p. 329 (I84I).

Herpestes ellioti, Blyth, Journ. Asiat. Soc. Bengal, vol. xx. p. 162 (1851).

Herpestes rubiginosus, Kelaart, Prodr. Faun. Zeyl. p. 2 I3 (1852). Calictis smithi, Gray, Proc. Zool. Soc. 1864, p. 565. Herpestes jerdoni, Gray, op. cit. p. 550. Herpestes monticolus, Jerdon, Mamm. India, p. I 35 (I $86 \%$ ). 
Characters.-Distinguished from the other uniformiy-coloured Indian forms by the black tail-tip. Fur long, harsh, and somewhat ragged; tail nearly as long as the head and body, or, if the hair be included, longer; heel partially haired. General colour varying from light brownish-grey, speckled with white, to rufous or iron-grey; terminal three or four inches of the tail jet black; behind this the colour ferruginous for a short distance, and then similar to that of the body; underparts sometimes paler than back; feet generally darker, either rufous-brown or blackish. Under-fur grey to greyish-brown; longer hairs, with alternations of some four white, and as many dark brown or black rings, the tips varying from light brown to deep ferruginous-red. Length of head and body, about 20 inches; of tail, 19 inches.

Distribution.-India, from Kashmir southwards, and Ceylon; but everywhere rare, generally frequenting forests.

The variety $H$. jerdoni has the fur very grey.

XiII. THE NILGIRI BROWN MUUNGOOSE. HERPESTES FUSCUS. Herpestes fuscus, Watcrhouse, Proc. Zool. Soc. 1838, p. 55 ; Blanford, Mamm. Brit. India, p. I 27 (I888).

Characters.-No black tip to tail; hairs with three very short light rings, about one-third the length of the dark ones; colour very dark; under-fur dark brown.

Size large; tail rather shorter than head and body, with longer hair; fur long and not very harsh; under-fur long, dense, and woolly; heel hairy beneath. General colour blackish-brown, minutely speckled with yellow or brownish-white; tail rather, and feet much darker. Length of head and body, 18 inches; of tail, with hair, 17 inches.

Distribution.-Travancore, and Nilgiri Hills of Southern India. 
XIV. THE CEYLON MUNGOOSE. HERPESTES FULVESCENS. Herpestes fulvescens, Blyth, Journ. Asiat. Soc. Bengal, vol. xx. p. I62 (I85I); Blanford, Mamm. Brit. India, p. I 27 (I888) ; W. L. Sclater, Cat. Mamm. Ind. Mus. pt. ii. p. 255 (I89I).

Cynictis maccarthice, Gray, Proc. Zool. Soc. I $8_{5}$ I, p. I3I. Onychogale maccarthice, Gray, op. cit. 1864, p. 570.

Herpestes maccarthice, Anderson, Anat.Zool. Research. Exped. Yun-nan, p. I 78 ( 1878 ).

Herpestes ceylanicus, Nevill, Taprohanian, vol. i. p. 62 ( $\mathrm{ISS}_{5}$ ).

Characters.-Distinguished from the last by its general lightyellowish colour, owing to the abundant speckling of the fur with yellow; tail-tip pure yellow; size also less. Length of head and body, about $16 \mathrm{I} / 2$ inches; of tail, $12 \mathrm{I} / 4$ inches.

Distribution.-Ceylon

XV. THE JAVAN MUNGOOSE. HERPESTES JAVANICUS.

Ichnemmon javanicus, Geoffroy, Descript. de l'Egypte, vol. ii. p. I 38 (г 8 I3) ; F. Cuvier, Hist. Nat. Mamm. pt. xxv ( $182 \mathrm{I})$.

Ichneumon ruber, Geoffroy, op. cit. p. I 39.

Herpestes javanicus, Desnarest, Mammalcgie, p. 2 I 2 (IS20);

Anderson, Zool. Anat. Research. Exped. Yun-nan, p. I 85 ( 1878$)$.

Mangusta javanica, Horsfield, Zool. Research. plate (I 824). Mangusta rubra, Fischer, Synops. Mamm. p. I65 (I829). Herpestes exilis, Gervais, Voy. Bonite, p. 32 (I $84 \mathrm{I}$ ). Herpestes rutitus, Gray, Proc. Zool. Soc. I86 I, p. I36. Calogale rutila, Gray, op. cit. I864, p. 56 I ; id., Cat. Carniv. Mamm. Brit. Mus. p. I 59 (1869).

Characters.-Very similar to the last, from which it may be distinguished by its shorter tail, which is only equal to half the length of the head and body. 
Distribation.-Java, Sumatra, Malay Peninsula, Cambedia, and Cochin China.

XVI. THE SHORT-TAILED MUNGOOSE. HERPESTES BRACHYURUS.

Herpestes brachyurus, Gray, Mag. Nat. Hist. vol. i. p. 578 (I836); id., Cat. Carniv. Mamm. Brit. Mus. p. I54 (i869); Anderson, Zool. Anat. Research. Exped. Yunnan, p. 187 (1878).

Characters.-Nearly allied to the last, but with a still shorter tail, which is less than half the length of the head and body. Length of head and body, from $171 / 2$ to I $81 / 2$ inches; of tail, without hair, 7 to 9 inches.

Distribution.-Borneo and Malay Peninsula.

XVII. THE STRIPE-NECKED MUNGOOSE. HERPESTES

VITTICOLLIS.

Herpestes vitticollis, Bennett, Proc. Zool. Soc. 1835, p. 67 ;

Blanford, Mamm. Brit. India, p. I $2 S$ (1888).

Mungos vitticollis, Ogilby, Proc. Zool. Soc. I835, p. Io3. Mangusta vitticollis, Elliot, Madras Journ. vol. x. p. I03 (I839).

Teniogale vitticollis, Gray, Proc. Zool. Soc. I864, p. 569.

Characters.-Its large size, the presence of a black streak on each side of the ear behind the neck, the black tail-tip, and the ruddy rump, serve at once to distinguish this species.

Size large; tail, inclusive of the long hair at the tip, threequarters the length of the head and body; fur long and harsh, longest on the tail; tarsus naked. General colour varying from a grizzled dusky iron-grey to a full ferruginous - or chestnut-red, without speckling, the red being, however, frequently confined to the hinder part of the body and tail, and the hea 1 invariably iron-grey; neck with a black streak running from behind the ear to the shoulder, bordered above and below by 
a paler or more rufous area. Limbs uniformly dark brown or black, and tail with a long black tip. Fur brown at the base; the longer hairs with three or four rings of pale yellowish-grey, alternating with the same number of black ones, or merely one or two rings of each colour near the base, and the remainder of the hairs ferruginous. Length of head and body, 2 I inches; of tail, with hair, I 5 inches, without hair, 13 inches.

Distribution.-Southern India, Malabar Coast, and Ceylon.

XVIII. THE PALE-NECKED MUNGOOSE. HERPESTES SEMITORQUATUS.

Herpestes semitorquatus, Gray, Ann. Mag. Nat. Hist. vol. xviii. p. 2 I I (1846); Anderson, Zool. Anat. Research. Exped Yun-nan, p. igr ( 1878 ).

Characters.-Specially distinguished by the pale area on the neck, and the orange-brown tinge of the fur.

Size rather large; tail about two-thirds the length of the head and body ; tarsus hairy beneath the heel. General colour rich orange-brown, becoming more brightly rufous on the sides of the body, finely speckled with yellow on the back and upper portion of the sides; lower half of the side of the neck, from the muzzle backwards, rufous-yellow, without speckling, this area standing out in marked contrast to the speckled dark brown of the upper part of the neck; fore-legs and lower half of hind-legs dark purplish-brown; upper surface of head less rufous than back; under-parts rich ferruginous-brown, like the sides; tail uniformly coloured, much grizzled, owing to the long pale yellow tips of the hairs. Under-fur pale yellowish-brown at the base, and orange-yellow towards the tips; the longer hairs on the sides of the body rich orange-red, below which there is an indistinct brown band, while the basal portion is pale brown or yellow. On the back the hairs terminate in a short brown tip, preceded 
by a yellow band, which is followed by a long blackish-brown band, extending nearly to the base, which is yellow. Length of head and body, I 7 inches; of tail, without hair, IO $1 / 3$ inches, with hair, II $1 / 2$ inches.

\section{Distribution.-Borneo.}

XIX. THE CRAB-EATING MUNGOOSE. HERPESTES URVA.

? Viverra fusca, Gray, Illustr. Indian Zool. vol. i. pl. v. (1830).

Gulo urva, Hodgson, Journ. Asiat. Soc. Bengal, vol. v. p. 238 (1836).

Uria cancrivora, Hodgson, op. cit. vol. vi. p. 56I (I837). Mesobema cancrivora, Hod son, op. cit. vol. x. p. 91о (I84I). Osmetictis fusca, Gray, Ann. Mag. Nat. Hist. vol.x. p. 260 (I842). Herpestes urva, Anderson, Anat. Zool. Research. Exped. Yunnan, p. 189 (1878); Blanford, Mamm. Brit. India, p. I 29 (I888).

Characters. - A white streak behind the ear; no black tail-tip ; hairs of back tipped with white; under-parts and limbs reddishbrown.

Size large; form very robust; tail about two-thirds the length of the head and body; fur very long, coarse, and ragged; under-fur woolly; naked surface of under part of hindfoot extending about two-thirds the distance to the heel. General colour dusky iron-grey, or blackish with a superficial tinge of grey caused by the long whitish tips of the hairs; a distinct narrow white stripe along the side of the neck from the angle of the mouth to the shoulder; head dark brown, speckled with white; limbs uniformily dark brown, the feet frequently black. Under-fur dark brown at the base, then pale brownish-yellow ; the longer hairs brown at the roots, then light brown or yellowish-brown for a considerab!e distance, after this black, and the tips whitish. Length of head and body, from If $102 \mathrm{I}$ inches; of tail, without the hair, II to 12 inches. 
Distribution.-Himalaya from Nipal to Assam, Arakan, Burma, North Tenasserim, and Southern China.

Habits.-This species is stated to be sub-aquatic in its habits, feeding largely upon Crabs and Frogs.

xx. THE White-TAILED MUNGOOSE. HERPESTES ALBICAUTA. Herpestes albicaudus, Cuvier, Règne Anim. ed. 2, vol. i. p. I 58 (1829).

Herpestes leucuris, Ehrenberg, Sj:nj. Phys. pl. xii. (1330). Ichneumia albesiens, I. Gəofroy, Mig. Zool. vol. vii. p. 394 (I855).

Herpestes loempo, Temminck, Esquisses Zool. p. 93 (I $\left.8_{53}\right)$; Matschie, Mittheil. deutsch. Schutzgebieten, vol. vi. art. 3, p. I I (IS93).

Ichneumia nigricauda, Pucheran, Rev. Mag. Zool. vol. vii. p. 394 ( I $S_{55}$ ).

Ichnemia abu-zendan, Fitzinger and Heuglin, S.B. Ak. Wien, vol. liv. pt. i. p. 56 I ( I866).

Herpestes (Ichneumia) albicanda, Thomas, Proc. Zool. Soc. I882, p. 75 .

Herpestes albicaudatus, Thomas, op. cit. I889, p. 622. Herpestes albicauda, Thomas, op. cit. I894, p. $45^{\circ}$.

With this species we revert to the Ethiopian members of the genus.

Characters.-From all the species noticed abore, the present one is distinguished by having the whole of the lower surface of the tarsus covered with hair, by the upper carnassial tooth being only about one-fourth longer than the last molar, and by the presence of three cusps on the outer side of the last lower tooth. It has been separated as a genus or subgenus, under the name of Ichnemmia, and connects the more typical forms with the under-mentioned Baeogale. 
Size large; form rather slender; tail bushy, and somewhat shorter than the body; under surface of the tarsus and metatarsus thickly haired as far as the base of the first toe ; fur of medium length. General colour blackish-grey, the longer hairs ringed with black and white, except for their terminal third, which is generally black; under-fur woolly, of a uniform dirty grey colour; feet black; hairs on tail very long, in some examples with white bases and long glistening black tips, so that the whole tail appears black ; in others with long white tips beyond the black, thus rendering the entire tail white. In white-tailed specimens the terminal hairs are usually wholly white. Length of head and body, from 23 to 26 inches; of tail, r 5 to $153 / 4$ inches.

Distribution.-Eastern Abyssinia to Natal, West Africa (Guinea, \&c.), and Arabia (Muscat). Regarding the remarkable variation in the colour of the tail of this peculiar species, Mr. Thomas writes: "No one seems to have noticed that the black-tailed $H$. loempo is not even specifically distinct from the typical form, and therefore, of course, possesses all its more important structural characters. $H$. albicauda and $H$. loempo cannot even be separated as varieties; for the only difference between them, namely the colour of the tail, seems to be purely an individual variation. It is true that for the most part specimens from West Africa, representing $H$. loempo, have black tails, and those from East Africa white tails; but I have seen too many exceptions to this rule to feel justified in regarding the two forms as varietally distinct. Thus there is in the Berlin Museum a specimen from Accra, on the Gold Coast, which has a regular white tail, just as the typical $H$. albicauda; and, on the other hand, black-tailed specimens from East Africa are by no means rare. Moreover, in the British Museum we have two specimens from the Bogos country, Abyssinia, received together, the skulls of which are quite identical, one 
having a black loempo-like tail, and the other a tail with quite as much white on it as in average albicanda. We thus see that the presence or absence of a white tip to the tail-hairs is a character upon which no specific distinction can be founded; and, in fact, it would rather seem that the white tail is the result of a desert life, specimens from sandy districts having, as a rule, white, and those from forest-regions black tails."

XXI. LARGE-TOOTHED MUNGOOSE. HERPESTES GRANDIS.

Herpestes grandis, Thomas, Proc. Zool. Soc. I889, p. 622.

Characters.-Known only by the skeleton, which indicates an animal of larger size than the average of the preceding species (to which it is closely allied), and with relatively much longer limbs. The teeth generally larger and heavier than in $H$. albicauda, this being especially the case with the canines and the last lower molar, the latter having not only a more comp.ex crown, but being likewise proportionately large as compared with the first lower molar (carnassial).

Distribution.-South Africa (probably from the Limpopo or Zululand).

XIV. SIX-MOLARED MUNGOOSES. GENUS IIELOGALE. Helogale, Gray, Proc. Zool. Soc. 186r, p. 308.

The single representative of this genus is distinguished from the majority of the species of Herpestes by having only three pairs of pre-molar teeth in each jaw ; the first of these being approximated to the canine, and thus serving to distinguish the genus from the few forms of Herpestes with only three premolars, in all of which there is a gap between the first of that series and the canine. The skull is also shorter and broader, with the walls of the brain-case thinner, and the ridges for muscular attachment less developed. The sole of the hind foot is naked. The last lower molar has but two cusps on its outer side. The writer is inclined to agree with Professor Mivart (Proc, 
Zool. Soc. I882, p. I78), as to the doubtful validity of the genus.

I. The small mungoose. helogale parvula. Herpestes parvulus, Sundevall, Oef. K. Vet. Ak. Förhandl. Stockh. I846, p. I 2 I.

Helogale parvula, Gray, Proc. Zool. Soc. I 86r, p. 308; Thomas, Proc. Zool. Soc. I882, p. 79 ; Jentink, Notes Leyd. Mus. vol. xi. p. 3 r (I888); Bocage, J. Sci. Lisboa, ser. 2, vol. i. p. 180 (I889).

Herpestes undulatus, Peters, Reise Mossambique, Säug. p. I I 4 ( 1852$)$.

Helogale undulata, Thomas, op. cit. p. 80 ; Jentink, loc. cit.

Characters.-Size small, form slender; tail rather shorter than the body. Typically the general colour dark finely-grizzled greyish-brown throughout, the hairs being ringed with black or brown and yellowish-white, and the feet and tail rather darker than the body. In the variety, H. undulata, the general colour is grizzled rufous on the upper-parts; neck, under-parts, and legs rich rufous, with less black grizzling; size rather larger than in typical form. Length of head and body, from $8 \mathrm{~T} / 4$ to ro inches; of tail, from $4 \frac{1}{2}$ to $63 / 4$ inches.

Distribution,-East Africa (Natal to Mozambique); West Africa (Angola).

The typical form is from Natal, and the rufous variety from Mozambique. These were regarded by Mr. Thomas as specifically distinct, but Dr. Jentink subsequently came to the conclusion that they were probably only varieties. The latter view is also taken by Prof. Bocage, who first recorded the species from West Africa, where both the grey and the red phase is met with, although the two appear to be locally separated.

Frabits.-Anchieta, as quoted by Bocage, states that the "Bimuires," as these animals are called in Angola, inhabit alike 
cultivated and wild districts; and that they live in small parties, which frequently combine to attack Snakes. Holes in trees, and burrows dug by their own strong claws in the ground, serve for their habitation; while they not unfrequently take possession of the deserted mounds of White Ants or Termites. In Mozambique, according to Peters, the Small Mungoose is extremely partial to hens' eggs, which it breaks in a peculiar fashion, throwing them with its fore-paws between its hind-legs against a wall or stone.

XV. the Four-toed mungooses. GEnUS bdeogale.

Bdeogale, Peters, Reise Mossambique, p. II9 (1852).

In this East and West African genus the teeth agree in number and general characters with those of Herpestes albicanda, but there are only four toes to each foot. The sole of the hind-foot is hairy.

I. THE thick-TAILED MUNGOOSE. DDEOgale CRASSiCAUdA. Bdeogale crassicauda, Peters, Reise Mossambique, p. Izo (I852); Thomas, Proc. Zool. Soc. I882, p. 8I.

Characters.-Distinguished from the next species by the relatively longer tail, in which the long hairs are white in their basal, and black in their terminal half, instead of being uniformly blackish-brown. 'The last lower molar seems also proportionately longer.

Distribution.-Mozambique.

II. THE PUISA MUNGUOSE. DDEOgale PUISA. Bdeigale puisa, Peters, Reise Mossambique, p. I24 ( $185^{2}$ ); Thomas, Proc. Zool. Soc. I882, p. 8 I.

Characters.-Size rather large; form slender; tail less than half the length of the head and body; under surface of tarsus and metatarsus thickly haired to the base of the toes. General colour dark brownish, with or without rings on the hairs; long and soft under-fur tawny-yellow ; limbs nearly black ; head grey 
1sh ; tail bushy, uniformly blackish-brown. Length of head and body, from 15 to $20 \mathrm{I} / 2$ inches; of tail, from 7 to 9 inches.

Distribution.-Mozambique and Zanzibar.

All the species of the genus appear to be very rare animals; and nothing is known of their habits.

III. BLACK-FOOTED MUNGOOSE. BDEOGALE NIGRIPES.

Bdeograle nigripes, Puche:an, Rev. Mag. Zool. vol. vii. p. I I I (1855); Thomas, Proc. Zool. Soc. I882, p. 82.

IJerpestes, sp., Bocage, J. Sci. Lisboa, ser. 2, vol. i. p. Iio (1889).

Characters.-This imperfectly known form was originally named from a skin from the Gaboon, which Mr. Thomas (op. cit. p. 77) thought might belong to an individual of Herpestes albicauda, which had, through some accident, lost the first toe on each foot. Bocage writes, however, that two Mungooses from Angola resemble in appearance, and also in the conformation of their skulls and teeth, Herpestes albicauda; but they differ in their system of coloration, and the absence of the first toe in both the fore- and hind-feet. The fur, composed of shorter hairs ringed with black and white, and without any admixture of the longer ones so abundant in $H$. albicauda, presents a uniform coloration of white speckles upon a blackish ground. The blackness of the limus is less marked than in the latter.

If these specimens do not indicate that $B d$. nigripes is a good species, they would seem to show that the number of digits in $H$. albicauda is not constant, and therefore that the genus $B$ deogale has no exis!ence.

Distribution.-West Africa (Gaboon and Angola).

XVI. GENUS CYNICTIS.

Cynictis, Ogilby, Proc. Zool. Soc. I833, p. 48.

In this South African genus there are five toes on the fore. fect and four on the hird-feet; the teeth agree in number and 
general characters with those of Herpestes ichneumon, the last lower molar having only two external cusps, and the soles of the hind-feet being hairy. Like all the foregoing genera of the Sub-family, the nose is medianly grooved. Mr. Thomas remarks that "this genus is a very distinct and well-marked one, not only on account of its different number of digits, but also from the fact that its skull is very differently shaped to that of Herpestes, more resembling Suricata than any of the genera of this section." The auditory bulla has a large hole near the middle.

I. THE PENCILLED MUNGOOSE. CYNICTIS PENICILlata. Herpestes penicillatus, Cuvier, Règne Anim. ed. 2, vol. i. p. I $5^{S}$ ( 1829 ).

Mangusta levaillantii, A. Smith, Zool. Journ. vol. iv. p. 437 ( 1829 ).

Cynictis steedmanni, Ogilby, Proc. Zool. Soc. IS33, p. 49.

Cynictis typicus, Smith, S. African Quart. Journ. vol. ii. p. I I6 ( 1835 ).

Cynictis ogilbyi, Smith, op. cit. p. I I 7 .

Ichneumia albescens, I. Geoffroy, Mag. Zool. I839. pl. xii.

Cynictis leptura, Smith, Illustr. Zool. S. Africa, pl. xvii. (i 849). Cynictis penicillata, Thomas, Proc. Zool. Soc. I 882, p. 83.

Characters.-Size medium; form slender, and head relatively small; tail bushy, about equal in length to the body. General colour ranging from dark yellow to light yellowish-grey, the longer hairs light yellow for the basal half, then with a black ring, and the tip white; the individual variation in the general colour being due to differences in the length of these white tips. Under-fur rich yellow; chin white; under-parts and limbs somewhat paler than back; hairs of bushy tail frequently exceeding a couple of inches in length, their colour generally similar to those of the back, but the terminal hairs white throughout. Length of head and body, $5_{5}$ to $15 \mathrm{~T} / 2$ inches; of tail, 9 to $9 \mathrm{I} / 4$ inches. 
Distribution.-Cape Colony and Orange Free State.

Habits.-This Mungoose is an inhabitant of dry sandy districts, in which it burrows holes where it reposes during the night, while in the daytime it is abroad, engaged either in hunting for the mice and birds on which it feeds or merely in basking in the sunshine.

\section{THE SMOOTH-NOSED MUNGOOSES. GENUS RHYNCHOGALE.}

Rhinngale, Gray, Proc. Zool. Soc. I 864, p. 375 ; nec Gloger. Rhynchogale, Thomas, Proc. Zool. Soc. I894, p. I39.

The absence of a groove from the nose to the upper lip serves to distinguish this genus not only from all the foregoing members of the Herpestince, but likewise from all the Viverrince with the exception of Cynogale. There are five toes to each foot, and four pairs of pre-molar teeth in each jaw, while the palate of the skull is concave, and the under surface of the tarsus and metatarsus hairy. The teeth have blunted cusps suited apparently for grinding rather than cutting ; and the last molar in both jaws is relatively very large.

The genus appears to be confined to East Africa.

I. MELLER'S MUNGOOSE. RHYNCHOGALE MELLERI.

Rhinogale melleri, Gray, Proc. Zool. Soc. 1864, p. 375 ; Thomas, Proc. Zool. Soc. I882, p. 85 .

Rhynchogale melleri, Thomas, Proc. Zool. Soc. 1894, p. I39.

Characters.-Size and form very nearly as in Herpestes ichneumon; tail about as long as the body; under surface of tarsus and metatarsus hairy as far as the bases of the toes. General colour uniform pale brown, the longer hairs with one or two rings of brown and white, which pass so gradually into one another as to give little appearance of grizzling to the pelage; head and under-parts paler, in the former the white of the hairs showing more conspicuously; feet darker : under-fur grey at 
the roots and pale brown at tips. Tail with long hairs, and gradually darkening from its root to the tip, the hairs of the basal third being uniformly brown, those of the middle third white at the basal and black at the terminal half, and those ot the terminal third entirely black. Length of head and body in type specimen, 22 inches; of tail, 15 inches.

\section{Distribution.-Nyasaland.}

For upwards of thirty years the gュnus was known only by a single specimen, which, curiously enough, presents the abnormality of having five pairs of pre-molar teeth in the upper jaw.

Habits.-According to Mr. A. Whyte, the re-discoverer of the species, wild fruits are always found in the stomach of this Mungoose. Commenting on this, Mr. Thomas writes that "Mr. Whyte's observation on the food of R. melleri is of great interest, as its fruit-eating habits may perhaps account for the peculiar structure and wear of its molars. In all the three specimens before me the posterior molars appear to be more worn than the anterior, as though an unusual amount of chewing had fallen to their share; but it must be admitted that this appearance may be deceptive, and the explanation may be that the second upper molar is naturally so much flatter than usual that it appears to be worn flat almost at once."

xViII. TIIE CUSIMANSES. GENUS CROSSARCiUUS.

Crossarchus, F. Cuvier, Hist. Nat. Mamm. pl. xlvii. (IS25). Ariela, Gray, Proc. Zool. Soc. I 864, p. 565 .

Agreeing with Rhynchogale in the smooth upper lip, the present genus is distinguished by having only three pairs of pre-molar teeth in each jaw, by the flat bony palate of the skull, and the naked soles of the hinder part of the hind-feet. The last lower molar is similar to that of Bdeorale, having three external cusps. The genus is represented by four species locally scattered over Africa. 
I. THE CUSIMANSE. CROSSARCHUS OPSCURUS.

Crossarchus obscurus, F. Cuvier, Hist. Nat. Mamm. pt. xlvii. (1825); Thomas, Proc. Zool. Soc. I882, p. 87.

Characters.-The distinctive feature of this species is the grizzled dull brown colour of the fur of the back, in which the tips of the hairs are yellow, and there is no trace of crossbarring.

Size medium; form rather stout; muzzle elongated; tail about half the length of the head and body. General colour dull grizzled brown; the longer hairs dark brown for fourfifths of their length, with yellow tips; under-fur brown at the roots and grey above; head more finely grizzled than the back, with a rufous tinge; at the extremity of the tail the yellow tips of the hairs changing to red; feet nearly black. Length of head and body, from $12 \mathrm{I} / 2$ to 15 inches; of tail, $6 \mathrm{~T} / 2$ to $7 \mathrm{~T} / 2$ inches.

Distribution.-West Africa (Cameruns and Congo).

Habits.-This species is stated to probe in soft ground for insects with its muzzle, the elongated form of which would appear well suited for such a purpose.

II. THE gambian CUSIMANSE. CROSSaRchus gambianus. Herpestes gambianus, Ogilby, Proc. Zool. Soc. 1835, p. Iо2. Mungos gambianus, Gray, Proc. Zool. Soc. I864, p. 575. Crossarchus gambianus, Thomas, Proc. Zool. Soc. I882, p. 88.

Characters.-Differs from the last in the general colour being grey, and likewise in the annulated hairs, which are, however, not so arranged as to produce cross-bands on the hinder part of the body. The latter region accordingly differs from the shoulders only in being more rufous. Neck and chest white; a distinct black streak on the side of the neck, as in Herpestes vitticollis. Length of head and body, 15 inches.

Distribution.-West Africa (Gambia). 
This species, which, we lieve, is still known only by an imperfect adult specimen and a second immature example, has a marked general resemblance to the under-mentioned $C$. fasciatus; and $\mathrm{Mr}$. Thomas remarks that it "is very interesting as showing what a comparatively unimportant character is the presence of cross-bands on the back. Its coloration is extremely similar to that of $C$. fasciatus; yet by a simple disarrangement of the hairs of the back all the broad distinct cross-bands vanish, and the back only presents a coarse grizzled rufous-grey colour."

\section{NARROW-BANDED CUSIMANSE. CROSSARCHUS ZERRA.}

Herpestes zebra, Rüppell, Neue Wirbelth. Abyss. p. 30 (1835). Herpestes gothneh, Fitzinger and Heuglin, S.B. Ak. Wien, vol.

liv. pt. i. p. 560 (1866).

Herpestes leucostethicus, Fitzinger and Heuglin, op. cit. p. $56 \mathrm{r}$. Crossarchus zebra, Thomas, Proc. Zool. Soc. I882, p. 89.

Characters.-Size rather smaller and form more slender than in the last; tail half as long as the head and body. General colour grizzled grey, with dark narrow cross bands on the hinder half of the back, five or more dark and light bands going to an inch. Longer hairs marked with very short black, and pale yellow or white, rings; under-fur dirty yellowish-grey; chin, chest, and under-parts more or less bright rufous, a welldefined line along the side of the neck demarcating this tint from the grey above. Generally a white line of variable width down the middie of the under surface of the body. Fect and tail darkening towards their extremities, the tip of the latter being frequently black. Length of head and body, I 3 to $13 \mathrm{I} / 2$ inches; of tail, $6 \mathrm{x} / 2$ to 7 inches.

Distribution.-Abyssinia.

Habits. - In common with the other members of the genus, this Mungoose is a burrowing animal, and is frequently seen 


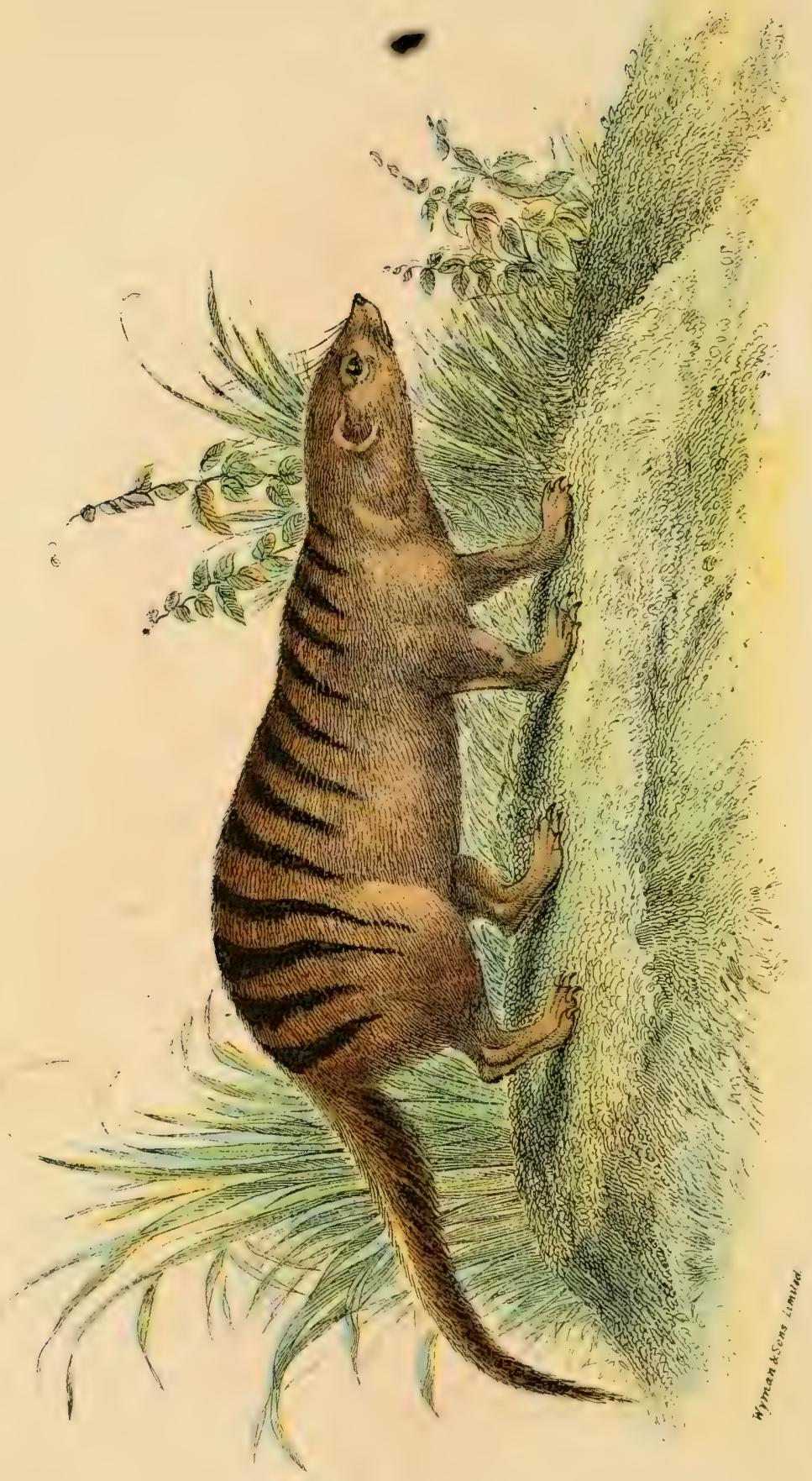

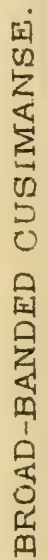


abroad during the daytime. Its food appears to be partly animal and partly vegetable.

IV. RROAD-B.1NDED CUSIMANSE. CROSSARchus fasciatus. IIerpestes fasciatus, Desmarest, Dict. Sci. Nat. vol. xxix. p. 58 (I 823 ).

Ichneumon tenionotus, Smith, S. African Q cart. Journ. vol. ii. p. II4 (I835).

Ariela tenionota, Gray, Proc. Zcol. Soc. I864, p. 565 . Crossarchus fasciatus, Thomas, Proc. Zool. Soc. I882, p. $90^{\circ}$ Bocage, J. Sci. Lisboa, ser. 2, vol. i. p. ISo (1889).

(Plate $X X X I 1$.

Characters.-Readily distinguished from the last by the broad bands on the back and the grey under surface. Size medium; form stout; tail rather more than half the length of the head and body. Geileral colour grizzled grey; the hinder part of the back marked with broad dark and light cross-bands, of which about three and a half go to an inch. Longer hairs annulated with long black and light rings, the base of the latter being always rufous, but the tip either rufous or yellow. Under-fur greyish-brown; neck, chest, and under-parts of the same grizzled grey as the shoulders; feet and tail becoming more or less completely black at their extremities. Length of: head and body, I 2 to I 3 inches; of tail, 7 to 8 inches.

Distribution.-South-east Africa (Caffraria to Mozambique and Nyasaland); West Africa (Angola).

The stripes in this species are generally twelve to thirtecn in number; and from the description of this and the preceding form, it will be seen that the width of the stripes is dependent on the length of the rings on the hairs.

v. DybowsKi's CUSIMANSE. CROSSARChUS DYBOWSKII. Crossarchus dybozeskii, Pousargues, Archiv. Mus. Paris, ser. 3 , vol. vi. p. I 2 I (1894). 
Characters.-A uniformly coloured species, distinguished from all the other four by its greatly inferior dimensions. The chest and throat lack the black and white markings characteristic of $C$. gambianus, while the colour of the pelage is quite unlike that of $C$. obscurus.

Distribution.-Oubangui region, Upper Congo.

xix. THE MEERKats. GeNUS SURICATA.

Suricata, Desmarest, Tabl. Méth. Mamm., in Nouv. Dict.

Hist. Nat. vol. xxiv. (I 804 ).

Rhyzana, Illiger, Prodr. Syst. Mamm. p. I34 (I8rr).

From the other Smooth-nosed Mungooses the single South African representative of this genus is distinguished by having only four (instead of five) toes on each of the fore- and hind-feet; while it is further characterised by having three pairs of pre-molar teeth in the upper, and four in the lower jaw ; and likewise by the naked under surface of the whole of the tarsus and metatarsus. The muzzle is produced; the front claws are elongated and nearly double the length of those on the hind-feet; the profile of the face is convex; and the teeth are of the general type of those of the preceding genus.

I. THE MEERKAT. SURICATA TETRADACTYIAA:

Viverra suricatia, Erxleben, Syst. Règn. Anim. p. 4SS (I777).

Viverra tetradactyla, Schreber, Süugethiere, vol. iii. p. 434 ( 1778 ).

ITus zenik, Scopoli, Delic. Faun. Flor. vol. ii. p. 84 ( ( 786 ).

Viverra zenik, et $V$. tetradactyla, Gmelin, Syst. Nat. vol. i. p. 85 ( 1789$)$.

Surricuta capensis, Desmarest, Tabl. Méth. Mamm. in Nouv. Dict. Hist. Nat. vol. xxiv. ( 1804 ).

Rhyzana tetradactyla, Illiger, Prodr. Syst. Mamm. p. I34 (I8I I). Suricata viverrina, Desmarest, Nouv. Dict. Hist. Nat. 2nd ed. vol. xxxii. p. 297 (18 I9). 
Rhyzana typicus, Smith, S. African Quart. Journ. vol. ii. p. I 7 (I 835$)$.

Suricata tetradactyla, Thomas, Proc. Zool. Soc. 1882, p. 92.

Characters.-Size small; form slender; tail about half the length of the head and body; fur long and soft. General colour light grizzled grey, with black cross-bands on the hinder part of the back, these dark and light bands being formed by the regular arrangement of the hairs, which are ringed with black and white, the latter colour predominating. Under-fur dark rufous. Head nearly white, with the exception of a distinct oblong black mark round the eyes; ears black; tail yellowish, with a distinct black tip; feet coloured like the body. Length of head and body, 14 to 15 inches; of tail, 7 to 8 inches.

Distribution.-Cape Colony, ranging to Algoa Bay.

Habits.-Meerkats are sociable little animals, found both in the plains and on the mountains of the Cape Colony. In the latter situation they dwell in caves and the crevices of the rocks; but in the former dig burrows for themselves wherever the soil is sandy, the long curved black claws of the fore-feet being specially adapted for such work. Unlike the typical Mungooses, they are essentially diurnal animals, not making their appearance above ground till well after sunrise, and loving to bask in the full solar rays. When abroad they frequently sit up on their hind-legs after the manner of Marmots, when they will ailow themselves to be approached within a short distance before disappearing suddenly into their holes. When approached by a Dog, they utter a series of little short barks. Easily tamed, these little animals form bright and amusing pets. Their food is stated to consist largely of bulbous roots. XX. THE STRIPED MUNGOOSES. GENUS GALIDICTIS. Galidictis, Geoffroy, Comptes Rendus, vol. v. p. 578 (1837).

The whole of the remaining members of the Family Viverride are confined to the island of Madagascar, and while the 
present and two following are allied to the Herpestina, the fourth is so markedly distinct as to constitute a Sub-family by itself. Whether the first three genera should be regarded as constituting another Sub-family (the Galidictince), or should be included in the Herpestina, may be open to doubt; Pro fessor Mivart taking the former view, while several other zoologists are inclined to adopt the latter.

In the present genus there are only three pairs of pre-molar teeth in each jaw, of which the first is placed close to the canine. The canines themselves are characterised by their very large relative size, this feature being especially marked in those of the lower jaw, where they are long, strong, and curved, with a basal projection on the hinder side. The feet are furnished with five toes, of which the long claws are more curved than in the typical Herpestince; while the tarsus is more or less completely naked. The muzzle has a median groove inferiorly; and the hairs of the tail are long. From the whole of the other members of the Family the members of this genus may be distinguished by the light and dark longitudinal stripes on the fur of the upper-parts.

Together with the next two genera, Galidictis differs from the typical Herpestinee by the absence of an alisphenoid canal in the skull; while the three are distinguished from all other Viverride in wanting a foramen on the outer side of the lower end of the humerus.

I. THE BROAD-STRIPED MUNGOOSE. GALIDICTIS STRIATA. Putorius striatus, Cuvier, Règne Anim. ed. 2, vol. i. p. I44(1835). Galidictis striata, Geoffroy, Comptes Rendus, vol. v. p. 578 (1837); Mivart, Proc. Zool. Soc. I882, p. I86. Mustela striata, Geoffroy, Cat. Mus. Paris, p. 98 (I85I).

Characters.-Size small ; length of tail rather less than that of head and body; muzzle somewhat blunted. General colour whitish-brown, with seven or nine broad longitudinal blackish 
stripes down the upper-parts, of which the middle pair do not extend so far back as the rest; head brown; limbs like groundcolour of body; tail whitish. Length of head and body, about I4 inches; of tail, I 3 inches.

\section{Distribution.-Madagascar.}

II. THE NARROI-STRIPED MUNGOOSE. GALIDICTIS VITTATA. Galidictis vittata, Gray, Proc. Zool. Soc. I848, p. 21 ; Mivart, Proc. Zool. Soc. I882, p. I86.

Characters. - General colour grizzled grey; the back and sides with eight nearly equal-sized and rather narrow longitudinal blackish-brown stripes; chin and under-parts pale brown; hind-feet and outer surface of fore-legs reddish-brown; tail grizzled black and grey, becoming white towards and at the tip ; the longer hairs brownish-white, with two, or occasionally three, broad black rings. Size approximately as in the last.

Distribution.-Madagascar.

Nothing appears to have been recorded with regard to the habits of either of the species of this genus.

XXI. THE RING-TAILED MUNGOOSES. GENUS GALIDIA.

Galidia, Geoffroy, Comptes Rendus, vol.v. p. 580 (1837).

Distinguished from the preceding genus by the smaller size of the lower canine tooth, and by the under surface of the tarsus and metatarsus being more or less covered with short sparse hairs. As regards coloration, the body is uniform, while the tail is ringed. The skull is very similar to that of Galidictis, but has the muzzle and palate relatively narrower, and the hinder portion of the latter flat, instead of concave.

\section{ELEGANT MUNGOOSE. GALIDIA ELEGANS.}

Galidia elegans, Geoffroy, Compies Rendus, vol. v. p. 580 (1837); Mivart, Proc. Zool. Soc. I882, p. I8.

Characters.-Size small; tail rather more than three-quarters the length of head and body. General colour dark chestnut- 
brown, with the hairs uniformly coloured; tail ringed with black. Length of head and body, about I 5 inches; of tail, I 2 inches.

\section{Distribution.-Madagascar.}

XXII. THE BROWN-TAILED MUNGOOSES. GENUS HEMIGALIDIA.

Hemigalidia, Mivart, Proc. Zool. Soc. I882, p. I88.

Distinguished from the last by the presence of four pairs of pre-molars, and the larger size of the second upper molar (which is very small in Galidia), as well as by the uniformly coloured tail, the more pointed muzzle, and the less curved claws.

I. THE UNIFORM MUNGOOSE. HEMIGALIDIA UNICOLOR. Galidia unicolor, Geoffroy, Comptes Rendus, vol. v. p. 58 I (I837).

Galidia concolor, Geofiroy, Mag. Zool. 1839, p. 30 ; Gray, Cat.

Carniv. Mamm. Brit. Mus. p. 56 (r869).

Hemigalidia concolor, Mivart, Proc. Zool. Soc. I882, p. i 88.

Characters.-Ears broad and short; tail little more than half the length of the head and body. General colour reddishbrown, speckled with black.

Distribution.-Madagascar.

II. THE olivaceous MUNGOGSE. Hemigalidia olivaceA. Galidia olivacea, Geoffroy, Mag. Zool. I839, p. 36 ; Gray, Cat.

Carniv. Mamm. Brit. Mus. p. 56 (I 869).

Hemigalidia olivacea, Mivart, Proc. Zool. Soc. I882, p. 188.

Characters.-General colour olive-brown, speckled with yellow. Hinder cheek-teeth relatively broader than in the last.

Distribution.-Madagascar.

XXIII. TIIE SMALL-TOOTHED MUNGOOSES. GENUS EUPLERES.

Eupleres, Doyere, Ann. Sci. Nat. ser. 2, vol. iv. p. 280 (I 855 ). This genus, which, as already mentioned, is generally re- 
garded as indicating a distinct Sub-family, is distinguished from the typical Herpestina, as well as from Galidictis and its allies, by the non-eversion of the hinder border of the auditory bulla of the skull, and from all the other members of the Family by its peculiar dentition. The canine teeth are of very small size, and scarcely distinguishable from the first three pre-molars, which are widely separated from one another in both jaws; in addition to which the molars are very similar to the pre-molars. So like, indeed, is the whole dentition to that of many of the Insectivora, that the genus was long regarded as pertaining to that Order. The head and skull are very small in proportion to the body; and the muzzle is long, slender, and sharply pointed. The nose and upper lip are medianly grooved; the five-toed feet are very slender; and the under surface of the tarsus and metatarsus is covered with short hair; the claws are long.

I. THE SMALL-TOOTHED MUNGOOSE. EUPLERES GOUdOTI. Eupleres goudotii, Doyere, Ann. Sci. Nat. ser. 2, vol. iv. p. 28 I (1835); Gray, Cat. Carniv. Mamm. Brit. Mus. p. I 77 (1869); Mivart, Proc. Zool. Soc. I882, p. I89.

Characters.-Size small; taii bushy and rather short; ears large; fur woolly. General colour uniform olive-grey, minutely speckled with yellow, becoming paler on the under-parts. Dark bands across the shoulders in the young. Length of head and body, about $\mathrm{r} 2$ inches; of tail, 7 inches.

Distribution.-Madagascar.

Habits.-Beyond the bare statement that it burrows in the ground, nothing definite seems to have been recorded regarding the mode of life of this singular and aberrant member of the Viverride. From its weak jaws, and peculiarly modified teeth, it would, however, seem to be highly probable that its nutriment consists chiefly, if not entirely, of insects or worms. 


\section{EXTINCT CATS AND CIVETS.}

\section{FAMILY FELID $Æ$ (suprà, p. I).}

I. GENUS FELIS (suprd, p. 26).

Reference having already been made to such existing specics as have been discovered in a fossil state, it will suffice here to allude to some of the more important extinct representatives of the genus. The earliest known True Cats appear to be the small Felis media and F. pysmaa, from the Middle Miocene strata of Sansan, in the Department of Gers, France, with which F. turnauensis, from the corresponding strata of Styria, may prove to be identical. From the Lower Pliocene beds of Darmstadt, Attica, and Persia, species have been described under the names of $F$. antediluviana, F. prisca, F. liodon, and $F$. attica; the latter being known by an entire skull, much resembling that of the Wild Cat, but with more powerful teeth. The Upper Pliocene strata of the Auvergne and the Val d'Arno have likewise yielded remains of several species, such as $F$.arvernensis, F. brevirostris, F. issiodorensis, and $F$.pardinensis; while in the Pliocene of Montpellier we have $F$. christoli, resembling a Lynx in size. In the Pliocene strata of the Siwalik Hills of Northern India the great $F$. cristata, which was fully as large as a Tiger, appears to show characters intermediate between that species and the Jaguar; while the same deposits have also yielded remains of a small species apparently allied to the living $F$. bengalensis. In the Pliocene of the United States there occur remains of two species of the size of the Lion known as $F$. atrox and $F$. augusta ; while from the Pleistocene of Argentina certain Cats more or less nearly allied to the Jaguar and other existing South American species have been named.

\section{GENUS CYNALLURUS (suprà, p. 20I).}

The only fossil species referred to the same genus as the Hunting-Leopard is one from the Siwalik Hills described as C. brachygnathus. Unfortunately this is known only by the 
lower jaws, and the generic determination cannot be regarded as altogether free from doubt until the upper carnassial tooth be discovered.

\section{GENUS MACHERODUS}

Machairodus, Kaup, Oss. Foss. Darrnstadt, pt. 2, p. 24 (1 833 ). Agnotherium, Kaup, op. cit. p. 28.

Steneodon, Croizet, Rev. Encyclop. vol. lix. p. 76 (1833).

Cultridens, Croizet, in Huot's Nouv. Cours. Elém. Géol. vol. i.

p. 265 ( 1837 ).

Smilodon, Lund, K. Danske, Vid. Selsk. Skr. vol. ix.p. 293(1842). Meganthereon, Pomel, Cat. Méthod. p. 58 (i 853 ).

Drepanodon, Bronn, Lethæa Geognost, vol. iii. p. I I 5 (I85356).

Trucifelis, Leidy, Proc. Acad. Philad. I862, p. I75.

The Sabre-toothed Tigers, as the members of this genus are commonly called, are easily distinguished from the True Cats by the enormous development of the upper canine teeth, which frequently have serrated cutting edges, and were protected by a downward flange-like expansion of the front of the lower jaw, against which they rested when the mouth was closed. These animals were common to both the Old and New Worlds, and some of the Pleistocene species attained very large dimensions; the exposed portion of the highly compressed canines of a South American species measuring upwards of seven inches in length. That these Cats were the most specialised of the entire Family, may be considered certain ; but there is great difficulty in understanding how they made use of their tusks, since when the mouth was open these would extend right across the opening, and it is almost impossible to believe that they could have been used with the jaws closed. The oldest representative of the genus is $M$. insignis from the Upper Eocene (Oligocene) Phosphorites of Central France. In the Middle Miocene of France and Styria we have M. palmidens and $M$. jourdani; and in the Lower Pliocene of Darmstadt, 
France, Attica, Samos, Hungary, and Persia, M. aphanistus ( $=$ M.leoninus) and M.ogygia (=M.orientalis and M. schlosseri). Farther eastwards we meet with $M$. sivalensis and the larger M. palaindicus in the Pliocene of the Indian Siwalik Hills. In the Upper Pliocene of the Auvergne and Tuscany there occurs the great $M$. cultridens, the female of which has been described as $M$. meganthereon; while in the Pliocene of the Val d'Arno the genus was represented by two other species, distinguished by the structure of their upper tusks, known as $M$. crenatidens and $M$. nestianus, the former probably also occurring in the forest-bed of the Norfolk Coast. The latest European form is $M$. latidens, of which the great serrated upper tusks have been found in the caverns of England, France, and Liguria.

Turning to the New World, we find the genus represented in the Pliocene strata of Pennsylvania and Texas by $M$. gracilis and $M$. fatalis, while a rock-cleft in Florida has yielded remains of a species (M. floridamus) only second in size to the great South American form mentioned below. In the caves or Brazil and the Pleistocene Pampas formation of the Argentine, the gigantic $M$. neogreus was the largest and most specialised of the whole genus; its range also extended to Ecuador. This splendid animal is known by several complete skulls and skeletons, one of the latter having been described as a distinct species under the name of $M$. necator, on account of the absence of a perforation on the outer side of the lower end of the humerus. This, however, is probably only an individual abnormality. Both $M$. latidens and $M$. neogreus lived in the human period; and the cause of their extinction (and likewise that of the genus itself) has yet to be satisfactorily explained.

It should be mentioned that although in the later representatives of the genus, the skull resembles that of the True Cats in the absence of an alisphenoid canal, yet this perforation is present in the earlier $M$. palmidens. 
IV. GENUS EUSMILUS.

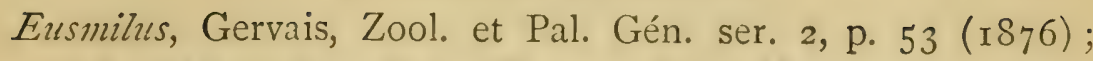
Lydekker, Cat. Foss. Mamm. Brit. Mus. pt. v. p. 310 ( 1887 ).

This genus agrees with the preceding in the general structure of the lower jaw and the large size of the upper canine teeth ; but differs in the excessive depth of the descending flange-like expansion at the front of the lower jaw, and also in having only two pairs of lower incisor teeth. It is further characterised by the small size of the front lobe of the blade of the upper carnassial tooth, as well as in the presence of a small posterior krel to the corresponding lower tooth, the latter feature affiliating it to the more generalised members of the Family. The genus is known only by $E$. bidentatus from the Upper Eocene (Oligocene) Phosphorites of Central France.

\section{GENUS ÆLURICTIS.}

Alurogale, Filhol, Ann. Sci. Géol. vol. iii. art. 7, p. r4 (I872) nec Fitzinger.

Ailurictis, Trouessart, Bull. Soc. Angers. vol. xv. Cat. Mamm. p. 92 (I885).

With this genus we come to the first of several genera of Cat-like Mammals agreeing with Machcerodus in the possession of elongated and compressed upper canine teeth protected by a flange-like expansion of the lower jaw, and likewise by the angulated front surface of the latter; but differing in several important structural features indicative of more generalised affinities. In the first place, the upper carnassial tooth has only two (instead of three) lobes to its cutting blade, while the corresponding lower tooth has always a well-developed posterior heel. Further, the upper molar is placed more or less posteriorly to the carnassial, instead of on its inner side, and a small second lower molar is generally retained behind the lower carnassial tooth. There are likewise usually three, instead of two, lower pre-molar teeth. Differences also obtain in 
the structure of the base of the skull by which these primitive Cats differ from their modern allies, one of these being the presence of an alisphenoid canal. There is also a difference in the structure of the astragalus bone of the ankle, while many of these extinct Cats have a third trochanter to the femur, or thigh-bone.

On account of these structural distinctions, these primitive Cats have been referred to a distinct Family, the Nimravida; but in the structure of the lower carnassial tooth, as well as in some other features, they are clearly connected by means of Eusmilus and Macharodus palmidens with the more typical representatives of the latter genus, and it is thus evident that the whole assemblage forms but a single family group.

The genus Elurictis, as represented by AE. intermedia and two other species from the Upper Eocene of France and Württemberg, has large upper canines, a small two-rooted anterior upper pre-molar, a small rounded upper molar inserted by two roots, a very small and single-rooted anterior lower pre-molar, and the lower molar (which may be wanting) also small and implanted in the jaw by a single root. Only fragments of the skull, which in the case of the type species indicate an animal nearly as large as a Leopard, are known.

\section{GENUS DINICTIS.}

Dinictis, Leidy, Proc. Acad. Philad. I854, p. I27; Scott, Proc. Amer. Phil. Soc. I889, p. 2 I I.

Datiophilus, Cope, Rep. U.S. Geol. Survey for 1873 , p. 508 (I874).

In this genus the skull is characterised by its short, vaulted, and generally Cat-like form, the first upper pre-molar being very minute and single-rooted, and the last molar transversely elongated, and inserted by three roots. In the lower jaw the first pre-molar is minute; and the carnassial differs from that of Eluricitis in having a cusp on the inner side of the blade, 
ihe last molar being small and oval. In the limbs the femur has a third trochanter; the five-toed hind-feet were probably plantigrade, and present considerable resemblances to those of the primitive Civets and Dogs, while the claws were retractile. The genus is exclusively North American, and is represented by some three species from the Miocene strata of Nebraska, Colorado, and Oregon, its typical member being Dinictis felina, which appears to have been an animal of the approximate dimensions of a Lynx.

Of $D$. cyclops Professor Cope remarks that "although of an inferior position in the system of Carnivora, its powers of destruction must have excelled those of the Catamount [Lynx]. While the skull is generally less robust, its sectorial teeth are not smaller nor less eff ctive than those of that animal, and the canines far excel those of the living species, as instruments for cutting their prey."

VII. GENUS NIMRAVUS.

Nimravus, Cope, Proc. Acad. Philad. r879, p. I69; id., Amer. Naturalist, vol. xiv. p. 842 (1880).

Nearly allied to the last, this genus, which is likewise North American, forms an exception to the present group in that there are only two pairs of pre-molar teeth in the lower jaw. In the upper jaw the first pre-molar is minute, and the molar transversely elongated; while in the lower jaw the carnassial tooth is devoid of an inner cusp, and the second molar very small. The femur has no third trochanter. While the preceding genus is most common in the Lower Miocene White River beds, the present one is confined to the overlying Upper Miocene John Day beds of Oregon, where it is represented by $N$. gomphodus and $N$. confertus, both of which may be compared in size to a Leopard. In all the points in which the genus differs from Dinictis, it approximates to the modern Cats: precisely as might have been expected from the higher geological horizon in which its remains occur. 


\section{GENUS POGONODON.}

Pogonodon, Cope, Amer. Naturalist, vol. xiv. p. 843 (I880).

This genus is characterise $\mathbb{A}$ by the great depth of the flangelike expansion of the lower jaw, and its remarkably broad anterior surface, coupled with the presence of three pairs of lower pre-molars, and the absence of the small last molar. The two known species, $P$. platycopis and $P$. brachyops, come from the Upper Miocene strata of the John Day River, Oregon. As they were both of large size, and furnished with long tusks, they would appear to have been the most powerful beasts of prey that flourished in their epoch.

IX. GENUS ARCIIALURUS.

Archclums, Cope, Amer. Naturalist, vol.xiii. p. 79s, a (1879); vol. xiv. p. $8+1$ (1880).

Characterised by the remarkably short muzzle of the skull, which descends abruptly from the forehead, this North American genus differs from all the Cats hitherto noticed in possessing four pairs of pre-molar teeth in the upper jaw, there being also a small second lower molar. The lower carnassial tooth has no inner cusp, and only a very small posterior heel. It is represented only in the Upper Miocene of the John Day River by $A$. debilis, a species of the approximate dimensions of a Leopard.

$\mathrm{X}$. GENUS HOPLOPHONEUS.

Hoplophonens, Cope, Rep. U.S. Geol. Surv. for I873, p. 509, (1874) ; id., Amer. Naturalist, vol. xiv. p. 849 (1880).

Although the skull is very similar to that of Nimravus, this genus differs from all the preceding members of the group in the reduction in the number of the teeth, which are numerically the same as in Eusmilus and the True Cats; that is to say, there is no second molar in the lower jaw behind the carnassial tooth, while there are only two pairs of pre-molars in the same jaw, and either two or three pairs of upper pre-molar teeth. In this respect, therefore, the genus forms a connect- 
ing link between the preceding one and Eusmilus. The forefoot is remarkable for the small size of the first toe, and the scapho-lunar bone of the carpus, or wrist, still retains traces of its dual origin which are totally lost in all existing Cats. The femur has a third trochanter, the hind-foot resembles that of Dinictis, and the tail is of unusual length. The genus is represented by five species, two of which occur in the White River beds of Nebraska and Colorado, and the other two in the overlying strata of the John Day River in Oregon. All are about the size of a Lynx.

\section{GENUS PSEUD瓜URUS.}

Pseudcelurus, Gervais, Zool. et. Pal. Franç. vol. i. p. I 27 (I848-50).

The present is the first of two genera from the Midd'e Tertiary deposits differing so remarkably from all the forms yet noticed, that it is a question whether they have any right to a place in the present family at all, and whether their affinities are not rather with the Viverrine Cryptoprocta. If, as some writers consider to be the case, they are the direct ancestors of the typical Felide, there will be no question that the latter Family is clcsely connected with the Viverrida, and has not been independently derived from the primitive Creodont Carnivora (see p. 22). In these genera there are three or four pairs of pre-molar teeth in each jaw, while in the upper jaw there is one pair, and in the lower two pairs of molars, the lower carnassial tooth having a cutting posterior heel. The slender lower jaw differs from that of the preceding group in that its lower border is highly convex instead of straight, and the front surface rounded in place of being squared. The limbs are relatively long, and the five-toed feet partially digitigrade. The dentition is more Cat-like than in all living Viverride, in spite of the presence of four pre-molars in both jaws, and of a second lower molar. The skeleton, however, presents so many primitive 
features that it is comparablewith that of the Viverrida rather than that of the Filide, the osteology of Procelurus presenting a marked resemblance to Cryptoprocta; indeed, Dr. H. Filhol is of opinion that the Tertiary genus is the direct ancestor of the existing form. In Pseudclurus the feline characters of the dentition are more marked.

In the genus under consideration there are only three pairs of pre-molar teeth, and the lower carnassial tooth has no distinct inner cusp, the upper tusk being large, with a sharp posterior edge. The first lobe of the blade of the upper carnassial tooth is reduced to a small cusp; while the hinder lobe of the same is formed by two small cusps. The typical species ( $P$. quadridentatus) occurs in the Middle Miocene beds of France and Styria; and may be compared in size to a Lynx. A lower jaw of a more slender type, from the Pliocene LoupFork beds of Nebraska, has been assigned to a second species, with the name of P. intrepidus.

\section{GENUS PROELURUS.}

Proailurus, Filhol, Ann. Sci. Géol. vol. x. art. 3, p. I 92 (1879).

In this genus there are four pairs of pre-molar teeth in each jaw ; the lower carnassial has a large inner cusp as well as a posterior heel ; and in the upper carnassial the anterior lobe of the blade of the True Cats is represented only by a rudimentary cusp, while the inner tubercle is large and placed close to the front edge. In the base of the skull the alisphenoid bone is perforated by a canal; while in the presence and position of certain foramina in this region the base of the skull agrees with the primitive Civets and Dogs. The limbs were relatively long and slender; the femur retained a third trochanter; and the tail was extremely elongated. The genus is represented in the Lower Miocene and Upper Eocene (Oligocene) of France by the two species $P$. lemantensis and $P$. juliemi. which may be compared in point of size to a șmall Civet. 


\section{FAMILY VIVERRID $\approx$ (suprà, p. 206).}

I. GENUS VIVERRA (suprà, p. 210).

Palcomephitis, Jäger, Foss. Säugeth. Württ. p. 78 ( $\left.\mathrm{I}_{35}\right)$; Fraas, Fauna Steinheim, p. 9 (1870).

In the Pleistocene cavern-deposits of Madras, this genus is represented by $V$. karmuliensis, a species about the size of the existing $V$. zibetha, but distinguished by the more elongated form of the pre-molar teeth, in which respect it agrees with the following species, and approximates to the under-mentioned Ictitherium. $\quad V$. bakeri and $V$. durandi are considerably larger species from the Pliocene rocks of the Siwalik Hills in Northwestern India. The Pliocene of Perpignan, in France, has yielded remains of another species known as $V$. pepraxti, while in the Middle Miocene of France and Styria we have respectively $V$. sansaniensis and $V$. steinheimensis; and in the Lower Miocene of the former country $V$. leptorhyncha. Civets likewise occur in the Upper Eocene (Oligocene) deposits of France and Hampshire; and have been described as $V$. minima, $V$. angustidens, $V$. simplicidens, and $V$. hastingsiee. The latter, which was of the approximate size of the large Indian Civet, appears to be common to England and France, and is characterised by the crowns of the teeth being much taller than in the existing representatives of the genus.

\section{GENUS AMPHICTIS.}

Amphictis, Pomel, Cat. Méthod., p. 63 (1853).

This genus, as represented by $A$. antiqua and $A$. leptorhyncha, from the Lower Miocene and Upper Eocene of France, is nearly allied to the last, from which it may be distinguished by the more elongated form of the last lower molar, which is implanted in the jaw by two distinct roots, and has relatively taller cusps, and a larger posterior heel. 


\section{GENUS HERETES (suprd, p. 244).}

Remains of Carnivores which have been referred to this genus occur in the Miocene and Upper Eocene (Oligocene) strata of Europe; but many of these present characters intermediate between the existing members of the genus and Viverra, so that it is frequently impossible to say to which of the two they should be assigned. For instance, the above-mentioned Viverra minima has been referred by one writer to Herpestes, while some specimens referable to $H$. lemanensis have been described as Viverra. It would thus appear that the two genera had a common origin; and it may be added that through an extinct Miocene and Upper Eocene genus known as $C$ ynodictis they both seem intimately connected with the ancestors of the modern Dogs and Foxes (Canide).

One of the best known species is the large Herpestes lemanensis from the Lower Miocene deposits of the south of France, with which the so-called Viverra antiqua, and perhaps $H$. priscus, as well as a German form, appear to be identical. The skull is stated to approximate to Viverra in possessing an alisphenoid canal. A second Lower Miocene species (H. primavus) is distinguished by the great relative length of the last lower pre-molar tooth, while in the Middle Miocene beds of GriveSt.-Alban, France, the genus is represented by yet another species known as Herpestes crassus.

\section{GENUS PROGENETTA.}

Progenetta, Depéret, Archiv. Mus. Lyon, vol. v. p. 34 ( 1892$)$.

This genus is represented only by a single species $(P$. in certa) of the size of a small Leopard from the Middle Miocene dep sits of France, and is chiefly distinguished by details in the structure of the teeth, into the consideration of which it would be quite out of place to enter in a work of the present nature. 


\section{GENUS ICTITHERIUM.}

Ictitherium, Wagner, Abh. bäyer. Acad. vol.v.pt. 2, p. 335 (I 848 ). Galeotherinm, Wagner, op. cit. vol. iii. pl. i. (I840), nec Jäger. Thallasictis, Gervais (ex Nordmann), Zool. et. Pal. Franç. vol.

i. p. $\mathrm{I} 20$ (1848-50).

Palhy'ena, Gervais, op. cit. 2 nd ed. p. 242 (1858).

Lepthycena, Lydekker, Pal. Ind. (Mem. Geol. Surv. Ind.), ser. ro, vol. ii. p. 31 2 (1884).

Having the same number of teeth as in the Civets, this European and Asiatic genus of the Lower Pliocene differs from all the other members of the Family in that the upper carnassial tooth has a three-lobed blade, as in the modern Cats and Hyænas, one of the species having been regarded as a connecting link between the Viverride and Hycrida. The skull is elongated and narrow, with a strong and upwardly-curved postorbital process behind the socket of the eye, the hind-foot is furnished with five toes, and the tail is very long.

The three species, namely, I. robustum, I. orbignyi, and I. hipparionum, occurring in the Lower Pliocene deposits of France, Attica, Samos, Hungary, Bessarabia, and Persia, vary in size from that of a Civet to that of a Jackal. The third and largest is the one making the nearest approximation to the Hyænas, its upper carnassial tooth being greatly elongated, and the molars in the same jaw very small. In the Siwalik rocks of India the genus is represented by the imperfectly known $I$. siz'alense.

\section{GENUS PALÆOPRIONODON.}

Palcopronodon, Filhol, Comptes Rendus, vol. xc. p. I579 (I880); id., Bull. Soc. Philom. ser. 8, vol. i. p. I I 5 (1889).

This and the following genus appear to form a connecting link between the Civets (Viverrida) and the Weasels (Mustelide), and are thus placed by some palæontologists in the 
first Family, and by others in the second. It may be observed that the Mustelida, together with the Ursida (Bears), differ from the Felide and Vizerrida, in the absence of a partition in the auditory bulla of the skull, as well as in certain other structural features of the same region. In consequence of these essential differences, the Felide and Viverrida, together with the allied Families of the Hycenidee and Proteleida, have been brigaded together in one primary group with the designation of Aluroidea; while the Mustelide and Ursida have been linked as the Arctoidea. The intimate connection shown to exist by fossil forms between the Civets and Weasels on the one hand, and betwixt Dogs and Bears on the other, indicates, however, that such associations are altogether erroneous, and that the absence of the partition in the auditory bullæ of the Weasels and Bears is in all probability an acquired character which has arisen independently in the two groups.

Whether the two genera now under consideration should be placed in the Viverride or in the Mustelide is a matter of but comparatively little moment, seeing that when we come to primitive annectant types classification, as adopted in the case of recent animals, becomes a practical impossibility. Since, however, in the second of the two genera there is, at least, a trace of the partition in the auditory bulla, the writer considers it preferable that they should be placed here.

Palcoprionodon is characterised by usually having but a single pair of upper molar teeth, although there are two pairs in the lower jaw, and its dentition corresponds, therefore, numerically with that of the Linsangs in the present Family, as well as with the majority of Weasels. In the general characters of the base of the skull, and especially in the presence of an alisphenoid canal, the genus resembles the more typical Vizerridce, although the position of the so-called condylar foramen at the hinder part of the base of the skull, as well as the pres- 
ence of a glenoid cavity near the socket for the articulation of the lower jaw, affiliate it to the Mustelide, with which, as we have seen, it agrees in the number of its teeth. The teeth themselves have a marked resemblance to those of the Linsangs, the upper molar lacking the expansion of its inner half so characteristic of the Mustelide. It does not appear to have been ascertained whether there is a partition in the auditory bulla of the skull.

The genus is represented by two species, $P$. mutabilis and $P$, simplex, from the Upper Eocene (Oligocene) Phosphorites of France, both of which may be compared in size to the smaller Icnneumons.

VII. GENUS STENOPLESICTIS.

Stenoplesictis, Filhol, Comptes Rendus, vol. xci. p. 346 (I880).

In this genus, which is also represented by two species (S. cayluxi and S. minor) from the French Phosphorites, the second upper molar is present, and of larger size than in those specimens of Palceprionodon, in which it is developed at all, while in the lower carnassial tooth the inner cusp is larger than in the latter. The auditory bulla is stated to possess a complete partition.

By means of certain other forms from the French Phosphor: ites, for which the names Haplogale and Stenogale have been proposed, Palcoprionodon and Stenoplesictis are so intimately connected with undoubted Weasels like the Tertiary Plesictis, that it is quite impossible to determine where the Viverride really end and the Mustelide commence.

In conclusion, it may be mentioned that the Lawer Tertiaries of North America have yielded remains of certain genera of primitive Carnivora known as Miacis and Didymictis, which appear not only to connect the Viverride very closely with the Canida, but likewise to indicate a transition from both to the still more primitive Creodont Carnivora. 


\section{ALPHABETICAL INDEX.}

Aard-Wolf, Ir.

abu-wudan, Ichneumia. 254.

abyssinica, Genetta. 2 I9.

Viverra. 219.

adailensis, Herpestes. 250.

xgypti, Ichneumon. 246 .

AElurictis. 285, 286.

intermedia. 286 .

Elurogale. 285.

affinis, Felis. I82.

afra, Genetta. 218.

Ichneumon. 253.

Mustela. 253.

africanus, Leo. 27.

Agnotherium. 283.

Ailinura. I2I.

planiceps. I2I.

Ailurictis. 285 .

Ailurogale planiceps. I2I.

albescens, Felis. 140.

Ichneumia. 264, 270.

albicauda, Herpestes. 252, 264, $265,268,269$.

Ichneumia. 264. albicaudatus, Herpestes. 264. albifrons, Ictides. 24 I.

Paradoxurus. 24I.

Amphictis. 291.

antiqua. 291.

leptorhyncha. 291.

andersoni, Herpestes. 257, 25 S.

Angola Mungoose. 249.

angolensis, Genetta. 220.

Herpestes, 249.

Angora Cat. 162.

angustidens, Viverra. 291. Ant-eater, Banded Marsupial. 39. antediluviana, Felis. 2 S2. Antelopes. I, 2. antiqua, Amphictis. 29I.

Viverra. 292. aphanistus, Machærodus. $28_{3}$. apiculatus, Herpestes. 254.

Archælurus. 288.

debilis. 288.

Arctic Fox. 20.

Arctictis. 240.

binturong. $24 \mathrm{I}$.

penicillatus. 24I.

Arctogale. 230.

leucotis. 230.

stigmaticus. 230.

trivirgata. 23I.

Ariela. 272.

tænionota. 275.

Arimau-Dahan. II 5 .

arvernensis, Felis, $2 S 2$.

ashtoni, Viverra. 222.

Asiatic Leopard. 78.

asiaticus, Leo. 27.

Athylax. 253.

paludosus. 253 .

robustus. 253 .

vansire. 253.

Atilax. 253 .

vansire. 253 .

atrox, Felis. 282,

attica, Felis. 282.

aubryana, Genetta. 2 50.

augusta, Felis. 282.

aurata, Felis. I2 I, I38.

auratus, Leopardus. 121

aureus, Lynx. 197.

Paradoxurus. 236 . 
auropunctata, Viverra. 235.

auropunctatus, Herpestes. 255.

badia, Felis. I22.

badius, Felis. I8.

Herpestes, 250, $25 \mathrm{I}$.

baileyi, Felis. 200.

Lynx. 200.

bakeri, Viverra. 29 I.

Banded Marsupial Ant-eater. I9.

barbarus, Leo. 27.

barbata, Cynogale. 243.

barbatus, Potamophilus. 243.

Bay Cat. I8.

Bornean. I22.

Bdeogale. 264, 268.

crassicauda. 268.

nigripes. $264,269$.

puisa. 268.

Bears. 293.

Polar. 20.

bengalensis, Felis, I26, I29, I30, 282 .

Viverra. 214.

bennetti, Cynogale. 242.

bennettii, Herpestes. 247.

Viverriceps. I24.

Bennett s Civet. 242.

berberorum, Caracal. I 89.

bidentatus, Eusmilus. 285 .

binotata, Nandinia. 229.

Viverra. 229.

binotatus, Paradoxurus. 229.

Binturong. 24I.

binturong, Arctictis. $24 \mathrm{I}$.

birmanicus, Herpestes. 255, 256, 257.

Black-footed Mungoose. 269.

Bogotà Tiger-Cat, I 50.

bonapartii, Genetta. 218.

bondar, Paradoxurus. 233.

Viverra. 233.

Booted Lynx. I84.

borealis, Felis. 192.

Lyncus. I92, 195.

Bornean Bay Cat. I22.

braccata, Felis. I52, I 53.

brachygnathus, Cynælurus. 232.

brachyop;, Pogonodon. 288.

brachyura, Felis. II 4 . brachyurus, Herpestes. $26 \mathrm{r}$.

Leopardus. II 4 , II 5 .

Neofelis. II4.

brevirostris, Felis. 282.

Broad-banded Cusimanse. 275.

Broad-striped Mungoose. 279.

Brown-tailed Mungoose. 279.

Bushy-tailed Red-spotted Cat. I32.

caffer, Chaus. I 55.

Herpestes. $\quad 247,248,249,254$.

caffra, Felis. I8, I 55, I84.

Viverra. 247.

Caffre Cat. I8, I55, 156, I57.

African. I 57 .

Caffre Mungoose. 247 .

Calictis smithi. 258.

caligata, Felis. I55, I84.

Calogale. 244.

granti. 250.

nipalensis. 255 .

nyula. 257.

rutila. 260.

calomitli, Felis. $15 \mathrm{I}$.

caluxi, Stenoplesictis. 295.

canadensis, Felis. 195.

Lyncus. 195.

Canadian Lynx. 21.

cancrivora, Mesobema. 263.

Urva. 263.

canescens, Felis. I 39.

Canidæ. II, 292, 295.

capensis, Felis. I35.

Suricata. 276.

Caracal. 21, 23, I88, I90.

berberorum. ISS.

melanotis. I88.

caracal, Felis. $\quad$ I 88.

Lynx. I88.

carcharias, Viverra. 242.

Carnivora, I.

Carnivorous Animals. I.

carolinensis, Felis. 197.

Carthusian Cat. I62.

Cat, Angora. 162.

Bay. I8.

Bushy-tailed, 132.

Caffre. I8, 155, 156, I 57.

Carthusian. 162. 
Cat, Chinese. I62.

Desert. I57, I79, I 8 I.

Domestic. 4, 5, I56, I62, I63, I64, i78, I8r.

Fire, I22.

Fishing. I22, 123.

Flat-headed. I8, I2 I.

Fontanier's. I20.

Geoffroy's. I 49, I 50.

Grass. I75.

Grey. I6I.

Grey Tiger. I38, 139.

Jungle. 21 , I80, 182,185 .

Leopard. I26, 127, 157 .

Long-tailed. - I45.

Malay. I62.

Manx. I63.

Marbled. I7, I9, II7, II3.

Mombasa. 163 .

Nipal. 130.

Paja. I75.

Pale. 186.

Pallas's. I74.

Pampas. I75, I78, I79.

Persian. 162.

Red Tiger. I37.

Reed. I84.

Rusty-spotted. I27, I33, I 3 1, I 57.

Servaline. I35, 136 .

Sháw's. 180, 182.

Small-footed. I 52 .

Steppe. I80, 187.

Tibetan. II9.

Tiger. $4, \mathrm{I} 7, \mathrm{I} 44, \mathrm{I} 45, \mathrm{I} 46$.

Waved. I82.

Wild. I8, I55, I57, I7c。

catenata, Felis. I39, I4I。

Catolynx charltoni. II 8 .

marmoratus: iI 8 .

catolynx, Felis, I82.

Cats, Extinct. 282.

catus, Felis. I8, I70.

caudata, Felis. IS7.

caudatus, Chaus. 187.

Felis, 187 .

cayluxi, Stenoplesictis. 295.

celidogaster, Felis. I23, I38.

ceylanicus, Herpestes. 260.

Ceylon Mungoose. 260.

Chained Ocelot. I4I. chạltoni, Catolynx. II 8.

Felis. 117.

Uncia. II 7.

chati, Felis. I44.

Chaus caffer. 155.

caudatus. I 87 .

jacquemonti. I83.

libycus. 182 .

ornatus. 179.

pulchellus. I79.

servalinus, I26, I79.

chaus, Felis. 158, 180, 182, 197 . Lynx. 182.

chinensis, Felis. I26, I 28.

Leopardus. $71,81,126,123$.

Chinese Cats. I62.

Chita. 73, 203.

Woolly. 203.

christoli, Felis. 282.

chrysothrix, Felis. 137.

Civet, Bennett's. . 242.

civetoides, Vivérra. 212.

Civets. 4, II $, 22,243,246,28$ I, $293,294$.

African. 211.

Bennett's, 242.

Burmese. 213.

Daubenton's. 216.

Indian. 2 II.

Javan. 214.

Malabar. 213 .

Palm. 245, 246.

True. 2 Io.

Web-footed. 242.

civetta, Viverra. 2 I I.

civettina, Viverra. $2 \mathrm{I} 3$.

Clouded Leopard. 17, I9, II3.

Colocolo. I6, I77.

colocolo, Felis. I6, I76, I77.

concolor, Felis. IOI.

Galidia. 280.

Hemigalidia. 280

Leopardus. 102.

Uncia. I02.

confertus, Nimravus. 287 .

Cougar. III.

couguar, Felis. ror.

Crab-eating Mungoose. 263.

crassicauda, Bdeogale. 268.

crassus, Herpestes. 292. 
crenatidens, Machærodus. 284 . cristata, Felis. .282,

Crossarchus. 272.

dybowskii. 275 .

fasciatus. 274,275 .

gambianus.' 273,276 .

obscurus. $273,276$.

rubiginosus. 258 .

zebra. 274 .

crossii, Paradoxurus, 233.

Cryptoprocta. 4, 22, 208, 289, 290. ferox. 208. typicus. 209.

Cubs and Tiger. 49.

Cultridens." 283 . Machærodus. ' 283.

Cusimanse. $272,273$. Broad-banded. 275. Dybowski's. 275. Gambian. 273. Narrow-banded. 274. cyclops, Dinictis. 287. Cynælurus. $5,23,282$. brachygnathus, 282 . jubatus. I7, 74 .

Cynictis. 269.

fimbriatus. 257 .

leptura. 270.

maccarthiæ. 260.

melanura. 250.

ogilbyi. 270 .

penicillata. 270 .

steedmanni. $27 \mathrm{c}$.

typicus. 270.

cynocephalus, Thylacinus. Ig.

Cynodictis. 292.

Cynofelis. 202.

guttata. 202.

jubata. 202.

Cynogale. 242, $27 \mathrm{r}$.

barbata. 243.

bennetti. 242.

Dahan, Arimau-. II 5.

Daptophilus. 286.

darwinii, Felis. I5 1 .

debilis, Archrelurus: 288 .

derbiana, Hemigalea. 227.

derbianus, Paradoxurus. 227.

Eesert-Cat. I57, I79, I8I.
Desert-Cat, Indian. I8, 19. diardi, Felis: I14, II7.

Didymictis. 295.

Dinictis. $286,287,289$. cyclops, 287. felina. 287 .

Dogs. II.

Domestic Cats. 4, 5, I56, I62. I63, I64, I78, I8r.

domestica, Felis. 156, 158 .

dorsalis, Herpestes. 246. dorsul, Leopardus. II 7 .

Drepanodon: 283.

durandi, Viverra. 29r.

dybowskii, Crossarchus. 275

Dybowski's Cusimanse. 275 .

Fast African Mungoose: 254.

Egyptian Mungoose. 246.

elegans, Galielia. “279.

Elegant Mungoose. 279.

etlioti, Herpestes. 258:

Leopardus. I26.

Viverriceps. i26.

erythrotis, Felis. 182 .

Eupleres. 280.

goudoti. $28 \mathrm{I}$.

euptilura, Felis. ' 132.

Eusmilus. $\quad 285,286,288,289$

bidentatus. 285 .

exilis, Herpestes. 260 .

Extinct Cats. 282 .

Eyra. I8, 153.

eyra, Felis. 18, 153 .

fasciatus, Crossarchus. 274, 275.

Herpestes. 275.

Lynx. 275 .

Myrmecobius. ' 9.

Paradoxurus. 233.

fatalis, Machærodus, 284 .

feldiana, Genetta. 220 .

Felidx. I, 15, 18, 19, 67, 282, 2S9, $290,294$.

felina, Dinictis. 287.

Genettà. 219.

Viverra. 219.

felinus, Paradoxurus. 233.

Felis. $8,22,26,282$.

affinis. 102: 
Felis albescens. I 40 . antediluviana. 282. arvernensis. $2 \mathrm{Sz}_{2}$ atrox. 282.

attica. 282.

augusta. 282 .

aurata. I2I, 133 .

badia. I 22.

badius. 18 .

baileyi. 200.

bengalensis. I25, I29, I30, 232 .

borealis. 192 .

braccata. 152, 153 .

brachyura. II4.

brevirostris. 282 .

caffra. I8, I 55, IS4.

caligata. 155,184 .

calomitli. I5I.

canescens. I39.

capensis. I35.

caracal. 188.

catenata. I39, I4I.

catolynx. 182.

catus. 18, 170.

caudata. 187.

caudatus. 187.

celidogaster. 123, I33.

charltoni. II7.

chati. I44.

chaus. I58, $180,182,137$.

chinensis. I26, 123.

christoli. 282.

chrysothrix. I 37 .

colocolo. I6, I76, 177 .

concolor. IOI.

coltguar. IOI.

cristata. 282.

darwinii. I5I.

diardi. II 4 , II7.

domestica. $156,158$.

erythrotis. I82.

euptilura. 132.

eyra. $18,153$.

fontanieri. $7 \mathrm{I}, 80,8 \mathrm{I}$.

herschelli. I 26.

himalayana. 123, 124.

huttoni. 156 .

galeopardus. I35.

geoffroyi, I49, I50, I77.

grisea. I40, I4I.
Felis guigna. $149,150,176,177$. guttata. 145.

inconspicua. 155, IS2.

irbis. 92.

issiodorensis. 282 .

jacquemonti. I 88 .

jaguarondi. I5I, I52, 153 .

japanensis. 80.

javanensis. I26, 128, I29, I30.

jerdoni. I26, 128, 130, I3I.

jubata. 202.

kutas. I82.

lanea. 202.

leo. $18,27$.

leo goojratensis. 27 .

leopardus. $7 \mathrm{I}$.

liodon. 282 .

longicaudatus. II 7 .

libycus. 183.

lupulina. 192.

lybica. 155 .

macrocelis. II4.

macroceloides. II4.

macrura. I44, I 45 .

maniculata. 155 .

manul. I74.

margarita. 155 .

margay. 145.

marmorata. I7, II7.

media. 282.

megaballa. 202.

megalotis. 156 .

melanura. 140.

melas. $7 \mathrm{I}$.

mexicana. I5I.

microtis. I32, I33.

minuta. I26, I2S, I3I.

mitis. I44, I 45 .

moormensis. I20.

nebulosa. I7, II3, I2 I.

neglecta. I38.

nigrescens. $12 \mathrm{I}$.

nigripectus. 174 .

nigripes. I 55 .

nipalensis. 126,130 .

obscura. 155 .

ocelot. I39.

ogilbyi. II 7 .

onca. I 7, 95 .

ornata, 18, I57, 179, 180, 18r. 
Felis pajeros. I75. pallida. I86, I 87 . panthera. 71. pardalis. I7, 139. pardina. 201. pardinensis. 282 . pardinoides. I49, I5 0. pardochroa. I30. pardochrous. $\quad$ I 26. pardoides. I40, I4I. pardus, I7, 7I, 74, SI. passerum. I75. picta. I40. planiceps. I8, I2I. prisca. 282. pulchella. I55. puma. I8.

pygmæa. 282. rubiginosa. $127, \mathrm{I} 28, \mathrm{I} 29, \mathrm{I} 3 \mathrm{O}, \mathrm{I} 33$. rufa. 197. rutila. I38, I39. scripta. II9. senegalensis. I35. serval. 17. servalina. I26, I35, 179. shawiana. I80, I8I, IS2. spelra. 20,27 . strigilata. 177 . sumatrana, I 26. sylvestris. I7O. temmincki. 120. tenasserimensis. 126.

tigrina. 17, 144. tigris. 18,48 . togoënsis. I 37 . torquata. 156,158 , I 2 . tristis. $\quad$ I2O. tulliana. $7 \mathrm{r}$. turnauensis. 282 . uncia. $17,92$. uncioides. 93. unicolor. IO2, I5I, 153. virgata. 192. viverriceps. 123 . viverrina. 16, 123 . vulpinus. 192. wagati. I26, I 28. yagouarondi. I5I. ferrugineus, Herpestes Field-Rat. I8I.

$357,258$. fimbriatus, Cynictis. 257. Herpestes. 257.

finlaysonii, Paradoxurus. 232. Fire-Cat. 122.

Fishing Cat. I6, I22, I23.

Flat-headed Cat. I8, I2I. flavescens, Herpestes. $25 \mathrm{I}$. floridanus, Lynx. 197.

Machærodus. 284 . fontanieri, Felis. 7r, 80, 8I. Fontanier's Cat. I2O. Leopard. 8o.

Fossa. 4, 208, 216. daubentoni. 216. fossa, $\mathrm{v}$. viverra. 216. fossa, Fossa, v. Four-toed Mungooses. 263. Fox, Arctic. 20. frederici, Herpestes. 257. fulvescens, Herpestes. 260. fusca, Osmetictis. 263. Viverra. 263. fuscus, Herpestes. 259.

galeopardus, Felis. 135 .

Galeotherium. 293.

galera, Herpestes. 247, 253 . Ichneumon. 253. Mustela. 253.

Galerella ochracea. 250.

Galidia. 279, 280. concolor. 280. elegans. 279. olivacea. 280. unicolor. 280.

Galidictinæ. 278.

Galidictis. $277,273,279,2 S$ I striata. 278. vittata. 279.

galinieri, Herpestes. 250. Gambian Cusimanse. 273. gambianus, Crossarchus. 273. Herpestes. 273. Mungos, 273.

Gato pajero. 175,176 .

Gazelles. I.

Genetta. 246. afra. 218. 
Genetta angolensis. 220. aubryana. 219.

bonapartii. 218.

feldiana. 220.

felina. 219.

genetta, v.

poënsis. 225 .

richardsoni. 225 .

rubiginosa. $22 \mathrm{I}$.

senegalensis. 219.

servalina. 220.

tigrina. 220.

viverra. $2 \mathrm{I} 8$.

genetta, Genetta, v.

genettoides, Viverra. 220.

Genets. 217.

Blotched. 219.

Common. 218.

Feline. 219.

Pardine. 220.

Rufous. 221.

Senegal. 219.

geoffroyi, Felis. I49, I50, I77.

Geoffroy's Cat. I49, I 50.

Gerbillus hurrianæ. I8I.

gerrardi, Nandinia. 229.

Golden or Bay Cat. I2O.

gomphodus, Nimravus. 287.

goojratensis, Felis leo. 27.

gothneh, Herpestes. 274.

goudoti, Eupleres. $28 \mathrm{I}$.

goudotii, Eupleres. $28 \mathrm{I}$.

gracilis, Felis. 222.

Herpestes. 252.

Linsanga. 222.

Machærodus. 284.

Prionodon. 222.

Viverra. 222.

grandis, Herpestes. 266.

granti, Calogale. 250.

Grass Cat. I75.

Grey Cats. I6I.

Grey Indian Mungoose. 257.

Grey Tiger-Cat. I38, I39.

grisea, Felis. I4O, I4I.

griseus, Herpestes. 257.

Leopardus. I39.

Mangusta. 257.

guigna, Felis. I49, I 50, I76, I77.

Gulo urva. 263.

guttata, Cynofelis. 232.

Felis. I45.

hamiltoni, Paradoxurus. 229.

Haplogale. 295.

hardwickei, Hemigale. 227. Viverra. 227.

hastingsiæ, Viverra. 29I.

Helogale. 266.

parvula. 267.

undulata. 267.

Hemigale. 227.

derbiana. 227.

hardwickei. 227.

hosei. 228.

Hemigalidia. 280.

concolor. 280.

olivacea. 280.

unicolor. 280.

Hemigalus zebra. 227.

hermaphroditus, Paradoxurus. 233.

Viverra. 233.

hernandesii, Leopardus. $95,96$.

Herpestes. 244, 245, 266, 269, $270,292$.

adailensis. 250.

albicauda. $252,264,265,268,269$.

albicaudus. 264 .

andersoni. 257, 258 .

angolensis. 249.

apiculatus. 254 .

auropunctatus, 255 .

badius. 250, $25 \mathrm{I}$.

bennettii. 247 .

birmanicus, $255,256,257$.

brachyurus. $26 \mathrm{I}$.

caffer. $247,248,249,254$.

ceylanicus. 260 .

crassus. 292.

dorsalis. 246.

ellioti. 258 .

exilis. 260.

fasciatus. 275.

ferrugineus, 257,258 .

fimbriatus. 257 .

flavescens, $25 \mathrm{I}$.

frederici. 257.

fulvescens. 260 .

fuscus. 259 .

galera. 247,253 . 
IIerpestes galinieri. 250. gambianus. 273 . gothneh. 274.

gracilis. 250, 252.

grandis. 266.

griseus. 257.

ichneumon. $246,248,249,25$ I, $252,253,270, .27 \mathrm{I}$.

iodoprymnus. $25 \mathrm{c}$.

javanicus. $255,260$.

jerdoni. 258.

lefebvrei. 250.

lemanensis. 292.

leucurus. 264 .

loempo. $253,264,265$.

maccarthix. 260.

madagascariensis. 247.

malaccensis. $257,253^{\circ}$.

melanurus. 250, 251 .

monticolus. 258 .

mungo. 257.

mutgigella. 250 .

mutscheltschela. 250 .

neumanni, 252.

nipalensis. 255 .

numidicus. 246 .

nyula. 257.

ochraceus. 250, 25I , 252.

ochromelas. 250.

ornatus. 250.

pallidus. 257.

pallipes. 255.

paludinosus. 253.

paludosus. 253.

parvulus. 267.

penicillatus. 270.

persicus. 255 .

pharaonis. 246.

pluto. 253.

primzerus. 292.

priscus. 292.

pulverulentus. 254 .

punctatissimus. 254.

punctulatus. 251 .

robustus. 254 .

rubiginosus. 258 .

ruficauda. $250,25 \mathrm{I}$.

rutilus. 260 .

sanguineus. 251 .

semitorquatus. 262.
IIerpestes smithi. 258 .

thysanurus. 258 .

undulatus. 267.

urva. 263 .

vitticollis. $26 \mathrm{I}, 273$.

widdringtoni. 246 .

zebra. 274.

Herpestinx. $245,271,278,281$.

herschelli, Felis. I 26.

himalayana, Felis. I23, I24.

hipparionum, Ictitherium. 293.

Ilippopotamus. I7 I.

hirsutus, Paradoxurus. 234 .

Hoplophoneus. 288.

horsfieldi, Leopardus. 126.

hosei, Hemigale. 228.

Hunting-Leopard. 5, I7, 74.

hurrianie, Gerbillus. I8I.

huttoni, Felis. I56.

Hyæenas. II.

IIyzenidæ. II, 293, 294.

Hybrids, Lion-Tiger. 45.

Hydrochærus. 97.

Ichneumia. 264.

abu-wudan. 264.

albescens. 264 .

albicauda. 264 .

nigricauda. 264.

nigricaudatus. 250 .

Ichneumon. 244.

ægypti. 246.

afra. 253.

galera. 253.

javanicus. 260.

pharaonis. 246.

ruber. 260.

trnionotus. 275.

ichneumon, Herpestes. 246, 248, $249,25 \mathrm{I}, 252,253,27 \mathrm{I}$.

Viverra. 246.

Ictides. 240.

albifrons: $24 \mathrm{I}$.

ater. $24 \mathrm{I}$.

Ictitherium. 29I, 293.

hipparionum. 293.

orbignyi. 293.

robustum. 293.

sivalense. 293.

incerta, Progenetta. 292. 
inconspicua, Felis. I55, IS2.

inconspicuus, Leopartus. I55.

Inclian Desert-Cat. I8, 19.

indica, Viverra. $2 \mathrm{I} 4$.

Viverricula. 215.

insignis, Machærodus. 283.

intermedia, Alurictis. 286.

intrepidus, Psendælurus. 290.

iodoprymnus, Herpestes. 250.

irbis, Felis. 92.

Uncia. 93.

isabellina, Felis. 192.

isabellinus, Lynx. 192.

issiodorensis, Felis. 282.

jacquemonti, Chaus. 183 .

Felis. 183 .

Jaguar, 13, I7, 21, 95.

jaguarondi, Felis. 15I, I 52, 153 .

japanensis, Felis. 80.

Lecpardus. $7 \mathrm{I}$.

javanensis, Felis. I 26, I28, I 29, I 30.

Leopardus. I26, I2S.

javanica, Mangusta. 260.

iavanicus, Herpestes. 255, 260.

Ichneumon. 260.

Javan Mungoose. 260.

jerdoni, Felis. I26, I28, I29, I30, I3I.

Herpestes. $25^{8}$.

Paradoxurus. 236.

jourdani, Machærodus. 283 .

jubata, Cynofelis. 202.

Felis, 202.

jubatus, Cynæelurus. 17,74 .

julieni, Proælurus. 290

Jungle Cat. 21, ISo, I82, I85.

karnuliensis, Viverra. 291.

kutas, Felis. I82.

lanea, Felis. 202.

laneus, Cynælurus. 202.

laniger, Paguma. 240.

Paradoxurus. 240.

Large-toothed Mungoose. 266.

larvata, Paguma. 238 .

Viverra. 238.

larvatus, Gulo. 238.

Paradoxurus. 238.
Lagomys. I75.

latidens, Machærodus. 284 .

lefebvrei, Herpestes. 250.

lemanensis, Herpestes. 292.

Proælurus. 290.

Leo africanus. 27.

asiaticus. 27.

barbarus. 27.

nobilis. 27.

leo, Felis. I8, 27.

leoninus, Machærodus. 283 .

Leopard. 4, I7, 21, 74 .

Asiatic. 78.

Clouded. I7, I9, II3.

Fontanier's. So.

Hunting. 5, 17, 74 .

Snow. 93.

Leopard-Cat. 127, I 57.

leopardus, Felis, 7 I.

Leopardus auratus. I2I.

brachyurus. II 4 , II 5 .

chinensis. 7I, 8I, 126, I2S.

concolor. IO2.

dorsul. II7.

ellioti. I26.

fontanieri. $7 \mathrm{I}$.

griseus. 139 .

hernandesii. 95, 96 .

horsfieldi. 126.

inconspicuus. I 55 .

japanensis. 7 I, 126, I28, 129.

javanensis. I 26.

marmoratus. II7.

moormensis. I20.

onca. 95.

pardalis. 139.

pardus. $7 \mathrm{I}, 74$.

pictus. I39, 14 I.

reevesi. I 26 .

serval, I35.

sumatranus. I26.

tigrinoides. 145 .

uncia. 92.

varius. $7 \mathrm{I}$.

viverrinus: 123.

yagouarondi. I5I.

Lepthyæna. 293.

leptorhyncha, Amphictis. $20 \mathrm{I}$.

Viverra. 29I.

leptura, Cynictis. 270. 
leucomystax, Paguma. 238. Paradoxurus. 238.

leucopus, Paradoxurus. 233.

leucostethicus, Herpestes. 274.

leucurus, Herpestes. 264.

levaillantii, Mangusta. 270.

libycus, Chaus. 182. Felis, 183.

Linsanga. 223. gracilis. 222.

maculosus. 223.

pardicolor. 224.

richardsoni. 225.

linsang, Paradoxurus. 222.

Linsangs. 221, 225.

African. 225.

Bornean. 222.

Burmese. 223.

Nipalese. 224.

Oriental. $22 I$.

liodon, Felis, 282.

Licn. 4, 9, 12, 18, $21,27$.

Lion-Tiger hybrids, 45 ,

loempo, Herpestes. 253, 264, 265, 298.

longicaudatus, Felis. II 7 .

Long-tailed Cat. 145.

lybica, Felis. 155.

Lyncus. 23, 192.

borealis. 192, 195 .

canadensis. 195.

isabellinus. I93.

lynx. 192.

pardinus. 200.

rufus. 197.

vulgaris. 192.

Lynx, Booted. I84.

Canadian. 21 .

Pardine. 21 .

Lynx. I82.

aureus. 197.

baileyi. 200.

caracal. 188.

chaus. I82.

fasciatus. 197 .

floridanus. 197.

montanus. 197.

rufus. 197.

lynx, Felis. I9I.

Lyncus. 192. lynx, Red. 197.

Lynxes. 4, 2 I.

maccarthix, Cynictis. 260.

Herpestes. 260.

Onychogale. 260.

Machærodus. 22, 283, 285 .

aphanistus. 284 .

crenatidens. 284 .

cultridens. 284 .

fatalis. 284 .

floridanus. 284

gracilis. 284 .

insignis. 283.

jourdani. 283 .

latidens. 284.

leoninus. 284 .

meganthereon. 284 .

necator. 284 .

neogæus. 284.

nestianus. 284.

palrindicus. 284 .

palmidens. $283,284,286$.

ogygia. 284.

orientalis. 284.

schlosseri. 284 .

sivalensis. 284.

Machairodus. 283.

macrocelis, Felis. II4.

Neofelis. II4.

Uncia. II 4.

macroceloides, Felis. II 4 .

Uncia. II4.

macrodus, Paradoxurus. 236.

macrura, Felis. I44, 145.

maculosus, Linsanga. 223.

madagascariensis, Herpestes. 247.

malaccensis, Herpestes. 257, 258.

Mangusta. 257.

Viverra. 214.

Viverricula. 215 .

Malay Cat. I62.

Mangusta. 244.

griseus. 257.

javanica, 260.

levaillantii. 270.

malaccensis. 257.

mungos. 257.

rubra. 260.

urinatrix. 253. 
Mangusta vitticollis. 26I. maniculata, Felis. $\quad 155$. manul, Felis. I74.

Manx Cats. I63.

Marbled Cat. I7, I9, I17, I I8. margarita, Felis. I 55 . margay, Felis. 145 . marmorata, Felis. 17, I17.

Uncia. II7. marmoratus, Catolynx. II 8 .

Leopardus. II 7 . media, Felis. $28 \mathrm{I}$.

Meerkat. 276. megaballa, Felis. 202.

Meganthereon. 283. meganthereon, Machærodus، $2 S_{3}$. megaspila, Viverra. 213. megalotis, Felis. $\quad 156$. melanura, Cynictis. 250.

Felis. I40. melanurus, Herpestes. 250, $25 \mathrm{I}$.

Viverra. 212. melas, Felis. $7 \mathrm{I}$.

melleri, Rhinogale. 271, 272. Rhynchogale. $27 \mathrm{I}$.

Meller's Mungoose. $27 \mathrm{I}$.

Mesobema. 244.

cancrivora. 263. mexicana, Felis. I5I. Miacis. 295. microtis, Felis. I32, I33. minima, Viverra. 291 . minor, Stenoplesictis. 295. minuta, Felis. I26, I28, I3 1 . mitis, Felis. I44, I45.

Mombasa Cat. 163. montanus, Lynx. 197.

Paradoxurus. 237. monticolus, Herpestes. $25^{8}$. moormensis, Leopardus. $\quad$ I2O.

Felis, I20. mungo, Herpestes. 257. mungo, Viverra. 257. Mungoose. 244.

Angola. 249.

Black-footed. 269.

Broad-striped. 278.

Brown-tailed. $28 \mathrm{~S}$.

Caffre. 247.

Ceylon. 260.
Mungoose, Crab-eating. 263.

East African. 254.

Egyptian. 246.

Elegant. 279.

Four-toed. 268.

Gambian. 273.

Grey Indian. 257.

Javan. 260.

Large-toothed. 266.

Meller's. 27 I.

Narrow-banded. 274.

Narrow-striped. 279.

Neumann's. 252.

Nilgiri Brown. 259.

Olivaceous. 280.

Pale-necked. 262.

Pencilled. 270.

Puisa. 268.

Red. 268.

Red-tailed. 251.

Ring-tailed. 279.

Ruddy. 258.

Rufous. 253.

Short-haired. $25 \%$.

Short-tailed. 260.

Six-molared. 266.

Slender. 250.

Sinall. 267.

Small Indian. 255.

Small-nosed. $27 \mathrm{I}$.

Small-toothed. 280, 28I.

Striped. 277.

Stripe-necked. 26 r.

Thick-tailed. 268.

Uniform. 280.

White-tailed. 264.

Mungos. 244.

gambianus. 273.

vitticollis. $26 \mathrm{I}$.

mungos, Mangusta. 257.

musanga, Paradoxurus. 233.

Viverra. 233.

musangoides, Paradoxurus. 233.

musschenbroecki, Paradoxurus.

239.

Mustela afra. 253.

galera. 253.

striata. 278.

Mustelidæ. I6, 293, 294, 295.

Mus zenik. 276. 
mutabilis, Palæoprionodon. 295. mutgigella, Herpestes. 250. mutscheltschela, Herpestes. 250. Myrmecobius fasciatus. 19.

Nandinia, 228. binotata. 229. gerrardi. 229.

Narrow-banded Cusimanse. 274. Narrow-striped Mungoose. 279. nebulosa, Felis, I7, II3, I2 I. necator, Machærodus. 284. neglecta, Felis. I38. nems, Viverra. 253.

Neofelis brachyurus. II4. macrocelis. II 4 .

neogæus, Machærodus. 284. nepalensis, Calogale. 255. nestianus, Machærodus. 284. neumanni, Herpestes. 252. Neumann's Mungoose. 252. niger, Paradoxurus. 234. Viverra. 223. nigrescens, Felis. I2I.

nigricauda, Ichneumia. 264.

nigricaudatus, Ichneumia. 250. nigrifrons, Paradoxurus. 233 . nigripectus, Felis. I74. nigripes, Bdeogale. 264, 269. Felis. I55.

Nimravidæ. 286 .

Nimravus. 287. confertus. 287 . gomphodus. $28 \%$.

Nipal Cat. I 30. nipalensis, Felis. I26, 130 . 1 ierpestes. 255. Paradoxurus. 237. nobilis, Leo. 27. numidicus, Herpestes. 246. nyula, Calogale. 257. Herpestes. 257.

obscura, Felis. I55. cibscurus, Crossarchus. 273. Ocelot. I7, I39. Chained. I4: ocelot, Felis. I39. ochracea, Galerella. 250. ochraceus, Herpestes. 250, 25I, 252. ochromelas, Herpestes. 250. ogilbyi, Cynictis. 270.

Felis. 117.

Paradoxurus. 238. ogygia, Machærodus. 283. olivacea, Galidia. 280 .

Hemigalidia. 280.

Olivaceous Mungoose. 280. onca, Felis. 17, 95.

Leopardus. 95.

Uncia. 95.

Onychogale maccarthire, 260. orbignyi, Ictitherium. 293. orientalis, Machrerodus. 283.

Viverra. 2II.

ornata, Felis. 18, 157, 179, I80, I8I.

ornatus, Chaus. $\quad$ I79.

Herpestes, 250.

Osmetictis. 244 .

fusca. 263.

Otters. 4.

Sea. 4.

Ounce. I7, 20, 92 .

Paguma. 23r.

grayi. 237.

laniger. 240.

larvata. 238.

Paja-Cat. I75.

Pajeros pampanus. $\quad$ I75.

palæindicus, Machærodus. 283.

Palromephitis. 29I.

Palieoprionodon. 293, 294, 295

mutabilis. 295 .

simplex, 295.

Pale Cat. 186.

Pale-necked Mungoose. 262.

Palhyæna. 293.

Pallas's Cat. I74.

pallida, Felis. I86, I87.

Viverra. 215.

pallidus, Herpestes. 257.

pallipes, Herpestes. 255.

Palm-Civets。 228, 230, 231, 245, 246.

Africar. 228.

Celebean. 239.

Chinese. 238.

Common. 233. 
Palm-Civets, East African. 229.

Himalayan, 237.

Jerdon's. 236.

I arge-toothed. 236.

Philippine. 235.

Red. 236.

Small-toothed. 230.

Three-striped. 23 I.

West African. 229.

White-whiskered. 238.

Woolly. 240.

palmidens, Machærodus. 283,284 , 286.

paludinosus, Herpestes. 253.

paludosus, Herpestes. 253.

pampanus, Pajeros. 175.

Pampas Cat. I75, I78, I79.

Panther. 7I, 74 .

panthera, Felis. 7 I.

Paradoxurus. 23r.

albifrons. 24I.

aureus. 235 .

binotatus. 229.

bondar. 233 .

crossii. 233 .

derbianus. 227.

fasciatus. 233.

felinus. 233.

finlaysonii. 233.

grayi. 237.

hamiltoni. 229.

hermaphroditus. 233.

hirsutus. 234.

jerdoni. 238 .

laniger. 240.

larvatus. 238.

leucomystax. 238 .

leucopus. 233.

leucotis. 230.

linsang. 222.

macrodus. 236.

montanus. 237.

musanga. 233.

musangoides. 233.

musschenbroecki. 239.

niger. 234.

nigrifrons. 233.

nipalensis. 237.

ogilbyi. 238 .

pallasii. 233.
Paradoxurus pennanti. 234 .

philippensis. 235 .

philippinensis. 235 .

prehensilis. 233.

quadriscriptus. 233.

quinquelineatus. 233.

rubidus. 239.

strictus. 233.

trivirgatus. 231 .

typus, 233.

tytlerii. 237 .

zebra. 227.

zeylanicus. 235,237 .

Pardalina warwicki. I24, I 49.

pardalis, Felis. I7, I39.

Leopardus. I39.

pardicolor, Linsanga. 224 •

Prionodon, 224.

Viverra. 224.

l'ar line Lynx. $2 \mathrm{I}$.

pardinensis, Felis, 282.

pardinoides, Felis. I49, I 50.

pardochrous, Felis. 126, 130.

pardoides, Felis. 140, I4I.

pardus, Felis. $17,7 \mathrm{I}, 74,8 \mathrm{I}$.

pardus, Leopardus. 7I, 74 .

parvula, Helogale. 267.

parvulus, Herpestes. 267.

passerum, Felis. I75.

Pencilled Mungoose. 270.

penicillata, Cynictis. 270.

penicillatus, Herpestes. 270.

pennanti, Paradoxurus. 234.

pepraxti, Viverra. $29 \mathrm{I}$.

Persian Cat. I62.

persicus, Herpestes. 255.

pharaonis, Ichneumon. 246.

Herpestes. 246.

philippensis, Paradoxurus. 235.

pbilippinensis, Paradoxurus, 235.

Pizas. 175 .

picta, Felis. I40.

pictus, Leopardus. I39, I4I. planiceps, Ailinura. $12 \mathrm{I}$.

Ailurogale. I2I.

Felis. I8, I2I.

Viverriceps. I2I.

platycopis, Pogonodon. $2 S S$.

Platyschista. 23I.

pallasi. 234. 
Plesictis. 295.

pluto, Herpestes. 253.

pöensis, Genetta. 225.

Prionodon. 225, 226.

Pogonodon. 288. brachyops. 288. platycopis. 288.

Poiana. 225. pöensis. 225, 226. richardsoni. 226.

Polar Bear. 20.

poortmanni, Viverra.

Potamophilus, 242.

barbatus. 243 .

prehensilis, Paradoxurus. 233. Viverra, 233.

primævus, Herpestes. 232.

Prionodon. 243.

gracilis. 222.

maculosus. 223.

pardicolor. 224.

prisca, Felis. 282.

priscus, Herpestes. 292.

Proæelurus. 290.

julieni. 290.

lemanensis. 290.

Proailurus. 290.

Progenetta. 292. incerta. 292.

Proteleidre. II, 294.

Pseudælurus. 289, 290. intrepidus. 290. quadridentatus, 290. puisa, Bdeogale. 268. Puisa Mungoose. 268. pulchella, Felis. I55. pulchellus, Chaus. I79. pulverulentus, Herpestes. 254. Puma. 4, 18, 21, IOI. puma, Felis. I8.

punctatissimus, Herpestes. 254.

punctulatus, Herpestes. $25 \mathrm{I}$.

Putorius striatus. 278.

pygmæa, Felis. $28 \mathrm{I}$.

quadridentatus, Pseudælurus. 290. quadriscriptus, Paradoxurus. 233. quinquelineatus, Paradoxurus. 233.

\section{Rasse. 214.}

rasse, Viverra. 214.

Rat, Field. I8r.

Red-spotted Cat, Bushy-tailed. I32.

Red-tailed Mungoose. $25 \mathrm{I}$.

Red Tiger-Cat: 137.

Reed Cat. I84.

reevesi, Leopardus. I 26.

regalis, Tigris. 48.

Retractile-clawed Cats. 26.

Rhinoceroses. I 7 I.

Rhinogale. $27 \mathrm{I}$.

melleri. 27I, 272.

Rhynchogale. 271, 272. melleri. 27I.

Rhyzæna 276.

tetradactyla. 277 .

typicus. 277.

richardsoni, Genetta. 225.

Linsang. 225.

Poiana. 225.

Ring-tailed Mungonses. 279.

robustum, Ictitherium. 293.

robustus, Athylax. 253.

Herpestes. 254.

ruber, Ichneumon。 260 .

rubidus, Paradoxurus. 239.

rubiginosa, Felis, 127, 128, I29, I3O, 133 .

Genetta. 22 I.

Viverriceps. 133.

rubiginosus, Crossarchus, 258.

Herpestes. 258.

rubra, Mangusta. 260.

Ruddy Mungoose. 258.

rufa, Felis. 197.

ruficauda, Herpestes. 250, $25 \mathrm{I}$.

Rufous Mungoose. 253.

rufus, Lyncus. I97.

Lynx. 197.

Rusty-spotted Cat. I27, 133, 134, I 57.

rutila, Calogale. 260.

Felis. I38, 139 .

rutilus, Herpestes. 260.

Sabre-toothed Tigers. 22.

sanguineus, Herpestes. 25 I. sansaniensis, Viverra. 291. schlegeli, Viverra. 215. 
schlosseri, Machærodus. 283. scripta, Felis. II 9.

Sea-Otters. 4 . semitorquatus, Herpestes. 262. senegalensis, Felis. I35.

Genetta. 219.

Viverra. 219.

Serval. I7, I35.

togoënsis. I37.

serval, Felis. $\quad$ I7, I35.

Leopardus. I35.

servalina, Felis. I26, I79.

Genetta. 220.

Servaline Cat. I35, I36.

servalinus, Chaus. I26, I79.

shawiana, Felis. I8o, I81, I82.

Shaw's Cat. I80, I82.

Short-haired Mungoose. 254 .

Short-tailed Mungoose. 260. simplex, Palæoprionodon. 295. simplicidens, Viverra. 291. sivalense, Ictitherium. 293. sivalensis, Machærodus. 283. Six-molared Mungooses. 266. Slender Mungoose. 250.

Small-footed Cat. 152 .

Small Indian Mungoose. 255.

Small Mungoose. 267.

Small-nosed Mungooses. $27 \mathrm{r}$.

Small-toothed Mungoose. 280, $28 \mathrm{r}$.

Smilodon. 283.

smithi, Calictis. 258.

Herpestes. 258 .

Snow-Leopard. 93.

spelæa, Felis. 20, 27.

Spotted Tiger-Cat. $\quad$ I 49.

steedmanni, Cynictis. 270.

steinheimensis, Viverra. 291.

Steneodon. 283.

Stenogale. 295.

Stenoplesictis. 295.

cayluxi. 295.

minor. 295.

Steppe Cat. I80, 187.

striata, Galidictis. 27 S.

Mustela. 278.

striatus, Putorius. 278.

strictus, Paradoxurus. 233.

strigilata, Felis. 177 .
Striped Mungooses. 277.

Striped-necked Mungoose. 261 . sumatrana, Felis. I26.

sumatranus, Leopardus. 126.

Suricata. $270,276$.

capensis, 276.

suricatta, v.

tetradactyla. 277 .

suricata, Viverra. 276.

suricatta, Suricata, v.

sylvestris, Felis. I70.

Tæniogale vitticollis. 26I.

trenionota, Ariela. 275 .

trenionotus, Ichneumon. 275.

Tail-less Cats. 162.

Tail-less Hares. 175 .

'Tegree Cat. I 37 .

temmincki, Felis. I20.

tenasserimensis, Felis. I 26.

tetradactyla, Rhyzena. 276.

Suricata. 276, 277.

Viverra. 276.

Thallasictis. 293.

Thick-tailed Mungoose. 268.

Thylacine. I9.

Thylacinus cynocephalus. I9.

thysanurus, Herpestes. 258.

Tibetan Tiger-Cat. II9.

Tiger. 4, I8, 48 .

Sabre-Toothed. 22.

Tiger-Cat. 4, I7, I44, I45, 146.

Bogotà. 150.

Grey, 138.

Red. I37.

Spotted. I 149.

Tibetan. Irg.

tigrina, Felis. I7, I44.

Genetta. 219.

Viverra. 219.

tigrinoides, Leopardus. $\quad$ I45.

tigris, Felis. I8, 48 .

Tigris regalis. 48 .

Togo Serval.. I 37.

togoënsis, Felis. 137 .

Serval. I37.

torquata, Felis. $156,158,182$.

tristis, Felis. I2O.

trivirgata, Arctogale. 23I.

trivirgatus, Paradoxurus. 23 I. 
Trucifelis. 283 .

tulliana, Felis. 7 I.

turnauensis, Felis. $28 \mathrm{r}$.

typicus, Cryptoprocta. 209.

Cynictis. 270.

Rhyzæna. 277.

typus, Paradoxurus. 233.

tytleri, Paradoxurus. 237.

Uncia charltoni. II7.

concolor. IO2.

irbis. 93 .

macrocelis. II 4 .

macroceloides, iI 4 .

marmorata. II 7 .

onca. 95.

uncia, Felis. 17, 92.

Leopardus. 92.

uncinicles, Felis. 93.

undata, Viverra. 2 I2.

undulata, Helogale. 267.

undulatus, Herpestes. 267.

unicolor, Felis. 102, I51, 152.

Galidia. 280.

Hemigalidia. 280.

Uniform Mungoose. 280.

urinatrix, Mangusta. 253.

Ursidee. 294.

Urva. 244.

cancrivora. 263.

urva, Gulo. 263.

Herpestes. 263.

vansire, Athylax. 253.

Atilax. 253.

varius, Leopardus. 7 I.

virgata, Felis. 192.

vittata, Galidictis. 279.

vitticollis, Herpestes. 261, 273.

Mangusta. 26I.

Mungos. 26r.

Trniogale. $26 \mathrm{r}$.

Viverra. 29I, 292.

abyssinica. 219.

angustidens. $29 \mathrm{r}$.

antiqua. 292.

ashtoni. 222.

auropunctata. 255 .

bakeri. 29r.

bengalensis. 214 .
Viverra binotata. 229.

binturong. $24 \mathrm{I}$.

boiei. 227.

bondar. 233 .

caffra. 247.

carcharias. 242.

civetoides. 2 I 2 .

civetta. 2II.

civettina. 213.

durandi. 29I.

felina. 219.

fossa. 216 .

fusca. 263.

genetta. 218 .

genettoides. 220.

gracilis. 222.

hardwickii. 227.

hastingsiæ. $29 \mathrm{I}$.

hermaphroditus. 233.

ichneumon. 246.

indica. 214.

karnuliensis. 29r.

leptorhyncha. $29 \mathrm{I}$.

leveriana. $2 \mathrm{I} 4$.

malaccensis. $2 \mathrm{I} 4$.

megaspila. 213 .

melanurus, 212.

minima. 291, 292.

mungo. 257.

musanga. 233.

nems. 253 .

niger. 233.

orientalis. $2 \mathrm{II}$.

pallida. 215.

pardicolor. 225.

pepraxti. $29 \mathrm{I}$.

poortmanni. $2 \mathrm{II}$.

prehensilis. 233 .

rasse. 214.

sansaniensis. 291.

schlegeli. 215.

senegalensis. 219.

simplicidens. 291.

steinheimensis. $29 \mathrm{r}$.

suricata. 276.

tetradactyla. 276 .

tigrina. 219.

undata. 212 .

zenik. 276.

zibetha. 2II, $29 \mathrm{r}$. 
Viverriceps bennettii. I24. ellioti. 126. planiceps. 121 . rubiginosa I 33

viverriceps, Felis. I23.

Viverricula. 215. indica. 215. malaccensis. 215 .

Viverridx. 4, II, 22, 277, 278, 281, 289, 290, 29I, 293, 294, 295.

viverrina, Felis. $16,123$.

Suricata. 276.

Viverrinæ. 245.

viverrinus, Leopardus. $\quad 123$.

vulgaris, Lyncus. 192.

vulpinus, Felis. 192.

wagati, Felis. I26, I2S.

warwicki, Pardalina. I24, I49.

Waved Cat. IS2.
Weasels. I6, 293,"294.

Web-footed Civets. 242.

White Cats. I6r.

White-tailed Mungoose. 264. widdringtoni, IIerpes!es. 246.

WVild Cat. I8, I55, I57, I70.

Wolf, Aard. II.

yagouarondi, Felis. I 5 I. Leopardus. I5I.

Yaguarondi. I5I, I52.

zebra, Crossarchus. 274.

Hemigalus. 227.

Heıpestes. 274.

Paradoxurus. 227.

zenik, Mus. 276.

Viverra. 276.

zeylanicus, Paradoxurus. 235, 237

zibetha, Viverra. 2II, 29 I. 


8 

SMITHSONIAN INSTITUTION LIBRARIES

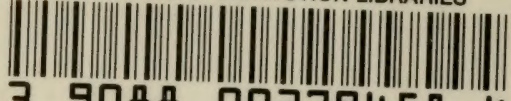

39088 00279458 4

nhmamm QL737.C2L98

A handbook to the carnivora 